\title{
Nondestructive testing of concrete bridge decks using ground- penetrating radar and the chain drag method
}

Jerry J. Scheff

West Virginia University

Follow this and additional works at: https://researchrepository.wvu.edu/etd

\section{Recommended Citation}

Scheff, Jerry J., "Nondestructive testing of concrete bridge decks using ground-penetrating radar and the chain drag method" (1998). Graduate Theses, Dissertations, and Problem Reports. 935.

https://researchrepository.wvu.edu/etd/935

This Thesis is protected by copyright and/or related rights. It has been brought to you by the The Research Repository @ WVU with permission from the rights-holder(s). You are free to use this Thesis in any way that is permitted by the copyright and related rights legislation that applies to your use. For other uses you must obtain permission from the rights-holder(s) directly, unless additional rights are indicated by a Creative Commons license in the record and/ or on the work itself. This Thesis has been accepted for inclusion in WVU Graduate Theses, Dissertations, and Problem Reports collection by an authorized administrator of The Research Repository @ WVU. For more information, please contact researchrepository@mail.wvu.edu. 


\title{
Nondestructive Testing of Concrete Bridge Decks Using Ground Penetrating Radar and the Chain Drag Method
}

\author{
A Thesis \\ Submitted to the Advisory and Examining Committee \\ College of Engineering and Mineral Resources \\ West Virginia University \\ In Partial Fulfillment of the Requirements \\ for the Degree of: \\ Master of Science \\ in \\ Civil Engineering
}

by:

Jerry J. Scheff

West Virginia University

Morgantown, West Virginia

1998 


\section{This thesis}

is dedicated to

\section{my mother and father.}




\section{ACKNOWLEDGMENTS}

I would like to thank my research advisor and committee chairman, Dr. Roger H.L. Chen, for providing guidance and motivation throughout the course of this project. Appreciation is also extended to the other members of my committee, Dr. Udaya B. Halabe and Dr. Hota V.S. GangaRao, for reviewing this work and providing helpful suggestions.

I must also express my sincere gratitude to Dr. Tom Chung from Penetradar Corporation for all of the help that he provided me with the radar software and for putting up with the many phone calls that I made to him. I would like to recognize Don Lipscomb, Mohammad Shaffei, and Mark White from the West Virginia Department of Transportation for their help in collecting the radar data that was used in this project.

Finally, I would like to thank my family and friends back home for motivating me to work hard towards completing this work so that I could return home in a timely manner.

I wish to acknowledge the Department of Civil and Environmental Engineering at West Virginia University, the Constructed Facilities Center at West Virginia University, and the West Virginia Division of Highways for providing financial assistance which allowed me the opportunity to conduct this research. 


\begin{abstract}
The structural integrity of our nation's highway bridges has become a legitimate concern. As of July of 1996 , about $30 \%$ of the nearly 582,000 bridges in the United States were considered deficient. In West Virginia the statistic is worse, where over $45 \%$ of the bridges are substandard. Since the cost of fully replacing the deficient bridges would run into the billions of dollars, the most efficient means of determining which bridges need to be replaced versus which bridges need rehabilitation should be determined.

This thesis presents the findings of two different nondestructive techniques that are used for bridge deck analysis: the chain drag method and ground penetrating radar (GPR). The chain drag testing was performed in the laboratory with 23 simulated concrete bridge deck specimens. The specimens contained varying internal conditions such as with/without steel reinforcement and with air and water filled cracks. The tests were to determine if the chains could uncover the different characteristics of each specimen, and to see if the varying sizes of the three chains had any influence on the outcome of the results.
\end{abstract}

The GPR testing was performed in the field on three highway bridge decks. The purpose of this testing was to determine if the GPR technique could accurately assess the depths to the different deck interfaces (overlay/concrete, 1st layer rebar, deck bottom, etc.), and to examine whether the radar software could find bridge deterioration.

The chain drag study found that some trends were observed for specimens with similar characteristics. However, some discrepancies did exist which could be attributed 
to the nonhomogeneous nature of concrete. It was also concluded that heavier chains uncovered the specimen characteristics much easier than the lighter chains.

The GPR study concluded that color intensity plots were quite accurate in determining the depth to the deck interfaces. The results from the postprocessing software used in the research were not as accurate in the depth analysis. Also, the confidence in the deterioration maps generated in the postprocessing software was low due to the great variation when minor parameters were slightly adjusted.

Future research regarding the laboratory chain drag testing should concentrate on determining ways to minimize the unwanted noise signals from the electrical systems and from other outside sources. Future research for GPR scanning is recommended to include the use of color intensity plots to directly determine interface depth measurements, the purchase and study of an updated version of the postprocessing software, and the comparison of bridge deterioration maps from both chain drag testing and GPR testing on the same bridge deck in the field. 


\section{TABLE OF CONTENTS}

ACKNOWLEDGMENTS

ABSTRACT

TABLE OF CONTENTS vi

LIST OF FIGURES IX ix

LIST OF TABLES Xiv

CHAPTER 1 INTRODUCTION .............................................................

1.1 Problem Statement 1

1.2 Research Objectives 2

1.3 Scope 3

1.4 Organization 3

CHAPTER 2 GENERAL INFORMATION, THEORY, AND

LITERATURE REVIEW ..........................................................5

2.1 General Information 5

2.1.1 Factors Contributing to Bridge Difficulties 5

2.1.2 Bridge Rating 6

2.1.2.1 Sufficiency Rating 7

2.1.2.2 Step-By-Step Procedure for Rating Analysis $\quad 8$

2.2 Bridge Deck Analysis $\quad 8$

2.2.1 Focus of Report 8

2.2.2 Chain Drag Method 9

2.2.2.1 Field Apparatus 9

2.2.2.2 Summary of Procedure $\quad 9$

2.2.3 Inspection With GPR 10

2.3 Theory 11

2.3.1 Theory of Chain Drag 11

2.3.1.1 Waves Traveling Through Solid 11

2.3.1.2 Waves Traveling Through Air 14

2.3.2 Theory of GPR 15

$\begin{array}{lll}2.4 & \text { Literature Review } & 17\end{array}$

2.4.1 Literature on GPR 17

2.4.2 Literature on Impact-Echo 22 
3.1 Laboratory Specimens 27

3.2 Apparatus 27

3.2.1 Chain Drag 27

3.2.2 Sound Measuring Equipment 28

3.2.3 Concrete Specimens 30

$\begin{array}{lll}3.3 & \text { Purpose of Testing } & 30\end{array}$

3.4 Procedure 30

CHAPTER 4 RESULTS OF THE LABORATORY EXPERIMENTS

USING CHAIN DRAG............................................... 42

4.1 Introduction $\quad 42$

4.2 Noise 43

4.3 Results 44

4.3.1 Batch $1 \quad 44$

4.3.2 Batch $2 \quad 46$

$\begin{array}{lll}4.3 .3 & \text { Batch } 3 & 47\end{array}$

4.3.4 Batch $4 \quad 48$

4.3.5 Batch $5 \quad 49$

4.4 Discussion of Experiment 50

CHAPTER 5 GPR SYSTEM AND BRIDGE INFORMATION.............................69

$\begin{array}{lll}5.1 & \text { Introduction } & 69\end{array}$

5.2 GPR System 69

$\begin{array}{lll}5.3 \text { GPR Equipment } & 70\end{array}$

5.3.1 Radar Antenna $\quad 70$

5.3.2 Master Control Console $\quad 71$

5.3.3 ACPRO Data Acquisition and Processing System 71

5.3.4 Computer Interface/Display Control Unit 71

5.4 Functions of GPR Software 71

$\begin{array}{ll}\text { 5.4.1 Radar Data Acquisition } & 72\end{array}$

5.4.2 Radar Data Processing 73

5.4.3 Post-Processing 75

5.4.3.1 Attenuation $\quad 76$

5.4.3.2 AC Echo Characteristics $\quad 76$

5.4.3.3 Change Detector $\quad 76$

5.4.3.4 Bottom Echo Characteristics 77

5.5 Pertinent Bridge Information 77

$\begin{array}{lll}\text { 5.5.1 Bridge } 1 & 77\end{array}$

$\begin{array}{lll}5.5 .2 & \text { Bridge } 2 & 78\end{array}$

$\begin{array}{lll}5.5 .3 & \text { Bridge } 3 & 78\end{array}$ 


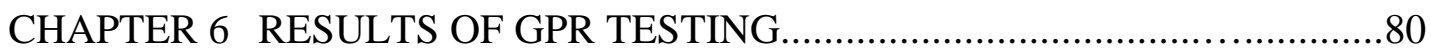

$\begin{array}{ll}6.1 & \text { Introduction } \\ 6.2 & \text { Results }\end{array}$

$\begin{array}{llr}6.2 \text { Results } & 80\end{array}$

$\begin{array}{lll}\text { 6.2.1 Bridge } 1 & 81\end{array}$

$\begin{array}{lll}6.2 .2 & \text { Bridge } 2 & 84\end{array}$

$\begin{array}{lll}6.2 .3 & \text { Bridge } 3 & 87\end{array}$

$\begin{array}{lll}6.3 & \text { Summary of GPR Testing } & 91\end{array}$

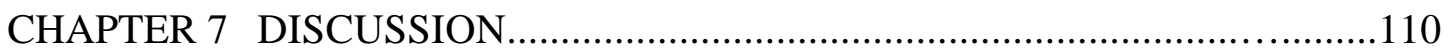

$\begin{array}{lll}7.1 & \text { Introduction } & 110\end{array}$

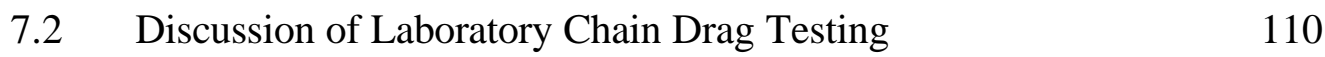

$\begin{array}{ll}7.3 & \text { Discussion of In-Situ GPR Scanning } \\ \end{array}$

CHAPTER 8 CONCLUSIONS AND RECOMMENDATIONS............................117

$\begin{array}{lll}8.1 & \text { Introduction } & 117\end{array}$

$\begin{array}{lll}8.2 & \text { Conclusions } & 117\end{array}$

$\begin{array}{lll}8.3 \text { Recommendations } & 120\end{array}$

$\begin{array}{ll}\text { REFERENCES } & 122\end{array}$

$\begin{array}{lr}\text { APPENDIX A } & 125\end{array}$

$\begin{array}{ll}\text { APPENDIX B } & 126\end{array}$

$\begin{array}{ll}\text { APPENDIX C } & 138\end{array}$

APPROVAL OF EXAMINING COMMITTEE 144 


\section{LIST OF FIGURES}

2.1 Summary of Sufficiency Rating Factors (FHWA, 1995) 24

2.2 WVDOT Employee Conducting Chain Drag Test 25

2.3 Van and Antenna Used in Project 25

2.4 Transmission and Reflection of Radar Waves at Different Interfaces 26

3.1 Details of Specimens in Batch 1

3.2 Details of Specimens in Batch 2

3.3 Details of Specimens in Batch $3 \quad 36$

3.4 Details of Specimens in Batch 4

3.5 Details of Specimens in Batch 5 38

3.6 Frequency Response Curve for Microphone Used in Testing 39

3.7 Pick-Up Pattern for Microphone Used in Testing 39

3.8 Schematic of Laboratory Test Set-Up 40

3.9 Experiment Set-Up with Microphone, Microphone Stand, Oscilloscope, Amplifier, and Specimen

3.10 Chains 1, 2, and 3 Used in Testing (Left to Right) 41

4.1 Specimens with Corresponding High Amplitude Frequency Ranges 52

4.2 Sample Voltage vs. Time Graph from Oscilloscope 53

4.3 Sample Power Spectral Density (PSD) Graph 53

4.4 Extracted Noise PSD Graph 53

4.5 Specimen B12 with Chains 1, 2, and $3 \quad 54$

4.6 Specimen B13 with Chains 1, 2, and 3

4.7 Specimen B14 with Chains 1, 2, and 3 55 
4.8 Specimen B15 with Chains 1, 2, and 3

4.9 Comparison of Batch 1 with Chain $1 \quad 56$

4.10 Comparison of Batch 1 with Chain $2 \quad 56$

4.11 Comparison of Batch 1 with Chain $3 \quad 56$

4.12 Specimen B21 with Chains 1, 2, and 3 57

4.13 Specimen B22 with Chains 1, 2, and 3 57

4.14 Specimen B23 with Chains 1, 2, and 3 57

4.15 Specimen B24 with Chains 1, 2, and $3 \quad 58$

4.16 Specimen B25 with Chains 1, 2, and $3 \quad 58$

4.17 Comparison of Batch 2 with Chain $1 \quad 59$

4.18 Comparison of Batch 2 with Chain $2 \quad 59$

4.19 Comparison of Batch 2 with Chain $3 \quad 59$

4.20 Specimen B31 with Chains 1, 2, and 3 60

4.21 Specimen B33 with Chains 1, 2, and 3 60

4.22 Specimen B34 with Chains 1, 2, and 3 61

4.23 Specimen B35 with Chains 1, 2, and $3 \quad 61$

4.24 Comparison of Batch 3 with Chain $1 \quad 62$

4.25 Comparison of Batch 3 with Chain $2 \quad 62$

4.26 Comparison of Batch 3 with Chain $3 \quad 62$

4.27 Specimen B41 with Chains 1, 2, and 3 63

4.28 Specimen B42 with Chains 1, 2, and 3

4.29 Specimen B43 with Chains 1, 2, and 3

4.30 Specimen B44 with Chains 1, 2, and 3 64 
4.31 Specimen B45 with Chains 1, 2, and $3 \quad 64$

4.32 Comparison of Batch 4 with Chain 1

4.33 Comparison of Batch 4 with Chain $2 \quad 65$

4.34 Comparison of Batch 4 with Chain $3 \quad 65$

4.35 Specimen B51 with Chains 1, 2, and 3

4.36 Specimen B52 with Chains 1, 2, and 3

4.37 Specimen B53 with Chains 1, 2, and 3

4.38 Specimen B54 with Chains 1, 2, and 3 67

4.39 Specimen B55 with Chains 1, 2, and $3 \quad 67$

4.40 Comparison of Batch 5 with Chain $1 \quad 68$

4.41 Comparison of Batch 5 with Chain $2 \quad 68$

4.42 Comparison of Batch 5 with Chain $3 \quad 68$

5.1 Photograph of Bridge \#2666, I-79 North 79

5.2 Photograph of Bridge \#2667, I-79 North 79

5.3 Photograph of Bridge \#2667, I-79 South 79

6.1 Color Intensity Plot of Bridge 1, Pass 1

6.2 Color Intensity Plot of Bridge 1, Pass 2

6.3 Color Intensity Plot of Bridge 1, Pass $3 \quad 93$

6.4 Color Intensity Plot of Bridge 1, Pass 4

6.5 Color Intensity Plot of Bridge 1, Pass 5

6.6 Color Intensity Plot of Bridge 2, Pass 1

6.7 Color Intensity Plot of Bridge 2, Pass 2

6.8 Color Intensity Plot of Bridge 2, Pass $3 \quad 95$ 
6.9 Color Intensity Plot of Bridge 2, Pass $4 \quad 96$

6.10 Color Intensity Plot of Bridge 2, Pass $5 \quad 96$

6.11 Color Intensity Plot of Bridge 2, Pass $6 \quad 97$

6.12 Color Intensity Plot of Bridge 3, Pass 1

6.13 Color Intensity Plot of Bridge 3, Pass $2 \quad 98$

6.14 Color Intensity Plot of Bridge 3, Pass $3 \quad 98$

6.15 Color Intensity Plot of Bridge 3, Pass $4 \quad 99$

6.16 Time vs. Deck Length for Bridge 1 100

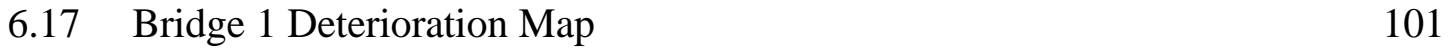

6.18 Time vs. Deck Length for Bridge 2 102

$\begin{array}{lll}\text { 6.19a } & 103\end{array}$

6.19b Bridge 2 Deterioration Map, Continued 104

6.20 Time vs. Deck Length for Bridge 3 105

6.21a Bridge 3 Deterioration Map 106

6.21b Bridge 3 Deterioration Map, Continued 107

6.22a Knollwood Bridge, I-79 South Delamination Survey from 1993

$\begin{array}{ll}\text { Chain Drag Testing (WVDOT) } & 108\end{array}$

6.22b Knollwood Bridge, I-79 South Delamination Survey from 1993

$\begin{array}{ll}\text { Chain Drag Testing, Continued (WVDOT) } & 109\end{array}$

$\begin{array}{lll}7.1 & \text { Photograph of Greenbrier Bridge } & 115\end{array}$

7.2 Color Intensity Plot of Greenbrier Bridge 115

$\begin{array}{ll}\text { 7.3 Waterfall Plot of Greenbrier Bridge } & 116\end{array}$

$\begin{array}{lll}7.4 & \text { Waterfall Plot of Normal Bridge } & 116\end{array}$ 
B-1 FILEUTIL Main Menu Screen 132

B-2 Radar Data File Conversion Screen 132

B-3 Changing DMI Constant Menu Screen 133

B-4 Bridge Processing Main Menu Screen 133

B-5 Processing Settings Menu Screen 134

B-6 Number of Data Files Menu Screen 134

B-7 Flat Metal Plate Filename Menu Screen 135

B-8 Flat Plate Response Menu Screen 135

B-9 Free Space Calibration Filename Menu Screen 136

B-10 Waterfall Plot Display Screen 136

$\begin{array}{lll}\text { B-11 Scope Display Screen } & 137\end{array}$

B-12 Bridge Processing Output Screen 137

C-1 Bridge Definition Dialog Box 141

$\begin{array}{lll}\text { C-2 File Select Dialog Box } & 141\end{array}$

C-3 Check Selection Dialog Box 142

C-4 User Defined Threshold Coefficient Dialog Box 142

$\begin{array}{lll}\text { C-5 Postprocessing Selection Dialog Box } & 143\end{array}$

C-6 Graphs Displaying Postprocessed Data and Filtering 143 


\section{LIST OF TABLES}

3.1 Specimen Configurations for Batches 1, 2, and 3

3.2 Specimen Configurations for Batches 4, and 5

3.3 Size of Chains Used in Laboratory Testing vs. Size of Common Chain 33

4.1 Specimens with Corresponding High Amplitude Frequency Ranges 52

6.1 Calculated vs. Actual Interface Depths for Bridge \#2666

-Assumed Dielecric Constant of Overlay Same as Concrete

(From Color Intensity Plots)

6.2 Calculated vs. Actual Depths Measured from Overlay/Concrete

Interface for Bridge \#2666 (From Color Intensity Plots)

6.3 Calculated vs. Actual Interface Depths for Bridge \#2666

-Assumed Dielectric Constant of Overlay Same as Concrete

(From Postprocessing)

6.4 Calculated vs. Actual Interface Depths Measured from

Overlay/Concrete Interface for Bridge \#2666 (From Postprocessing) 83

6.5 Percentage of Deck Deteriorated for Bridge \#2666 84

6.6 Calculated vs. Actual Interface Depths for Knollwood Bridge, I-79 North-Assumed Dielectric Constant of Overlay

Same as Concrete (From Color Intensity Plots)

6.7 Calculated vs. Actual Interface Depths Measured from

Overlay/Concrete Interface for Knollwood Bridge, I-79 North

(From Color Intensity Plots) 
6.8 Calculated vs. Actual Interface Depths for Knollwood Bridge, I-79 North-Assumed Dielectric Constant of Overlay

Same as Concrete (From Postprocessing) 86

6.9 Calculated vs. Actual Interface Depths Measured from Overlay/Concrete Interface for Knollwood Bridge, I-79 North (From Postprocessing) 86

6.10 Percentage of Deck Deteriorated for Knollwood Bridge, I-79 North 87

6.11 Calculated vs. Actual Interface Depths for Knollwood Bridge, I-79 South-Assumed Dielectric Constant of Overlay Same as Concrete (From Color Intensity Plots) 88

6.12 Calculated vs. Actual Depths Measured from Overlay/Concrete Interface for Knollwood Bridge, I-79 South (From Color Intensity Plots) 88

6.13 Calculated vs. Actual Interface Depths for Knollwood Bridge, I-79 South-Assumed Dielectric Constant of Overlay Same as Concrete (From Postprocessing)

6.14 Calculated vs. Actual Interface Depths Measured from Overlay/Concrete Interface for Knollwood Bridge, I-79 South (From Postprocessing) 89

6.15 Percentage of Deck Deteriorated for Knollwood Bridge, I-79 South 90 


\section{CHAPTER 1}

\section{INTRODUCTION}

\subsection{Problem Statement}

The structural integrity of our nation's bridges has become a legitimate concern. According to computer analysis performed by the Associated Press on Federal Highway Administration (FHWA) data, approximately $31.4 \%$ of the nation's 582,000 highway bridges were rated deficient as of June 30, 1996. The percentage is worse in West Virginia, where $45.4 \%$ of the bridges are substandard. A major contributor of the problems encountered by the bridges is the deterioration of the bridge deck.

According to the FHWA, it would cost approximately 90 billion dollars to fully rehabilitate or reconstruct all of the dilapidated highway bridges across the United States, therefore it would be economically impossible to do so. Consequently, it is of the interest of the bridge inspector to locate problem areas early in order to slow the deterioration rate. Contemporary methods of bridge deck inspection, such as chain drag and impact echo, are slow, laborious, and restrict the flow of traffic due to lane closures. These methods are also subjected to outside influences, such as noise and weather, which reduce the reliability of the overall inspection. Another method of bridge deck inspection, known as core sampling, yields relatively accurate results; however, it causes local damage to the deck and slows traffic as well.

Another technique used in determining subsurface characteristics of concrete bridge decks, which is relatively new, is known as ground penetrating radar (GPR). This 
method of inspection takes much less time to conduct and is much less sensitive to ambient conditions compared to the other techniques. GPR is a non-contact procedure which can be performed on a moving van at speeds ranging from 5 to 30 miles per hour, thus keeping traffic flow rates higher than when using other techniques.

The disadvantage of using GPR is that the data generated from scanning a bridge deck are difficult to interpret. Research is being performed on the usage of GPR to better understand its capabilities and to quantify the accuracy of using such a system.

\subsection{Research Objectives}

The objectives of this study are:

- to scan three actual bridge decks with the West Virginia Department of Transportation (WVDOT) GPR system;

- $\quad$ to study the characteristics of signal patterns from the three different bridge decks;

- $\quad$ to determine concrete bridge deck thickness, and where steel reinforcement and delaminations exist;

- $\quad$ to compare the findings from the GPR analysis with that from the bridge deck inspection reports generated by the WVDOT using the chain drag method;

- $\quad$ to use the chain drag method on laboratory specimens to determine different frequency characteristics under controlled conditions such as:

specimens with air filled cracks

specimens with water filled cracks

specimens with steel reinforcement. 
- to compare the findings from the chain drag method to the GPR results from Phases I and II on the same laboratory specimens.

\subsection{Scope}

This study tests the capabilities of GPR by scanning three actual bridge decks and verifying the findings with bridge inspection reports performed by the WVDOT, and also by conducting controlled laboratory experiments. Depending on the accuracy of the GPR results, new methods of bridge deck inspections can be invoked which could speed the inspection process and allow less chance for human error.

\subsection{Organization}

This thesis is organized into eight chapters with an Appendix. Chapter 2 consists of some general information about bridge inspection, theory about the chain drag method and GPR, and a comprehensive literature review. Chapter 3 tells about the laboratory testing of concrete bridge deck specimens with the chain drag method, including a detailed discussion of the equipment and the procedure of the experiment. Chapter 4 provides the results of the laboratory testing discussed in Chapter 3. The GPR system is discussed in Chapter 5, along with the three bridges that were scanned by the system. Chapter 6 provides the results of the radar scanning on the three bridge decks. A discussion about the situations encountered throughout the project is included in Chapter 7. Finally, conclusions and recommendations for future research are provided in Chapter 8. Appendix A provides a checklist that is recommended to be reviewed before scanning a

bridge deck. Appendices B and C provide the step-by-step procedures of how to process 
the bridge deck information and then perform post-processing tasks from start to finish.

Each individual chapter starts with text which refers to figures and tables. The figures can be found at the end of each chapter. 


\section{CHAPTER 2}

\section{GENERAL INFORMATION, THEORY, AND LITERATURE REVIEW}

\subsection{General Information}

\subsubsection{Factors Contributing to Bridge Difficulties}

As was mentioned previously, many of our nation's bridges are structurally deficient and/or functionally obsolete. The functional obsolescence has to do with the geometry of the bridge. For example, some bridges may not have a proper clearance to suit some of the trucks of today, or perhaps a bridge may lack sufficient lane widths to accommodate for a driver's sense of feeling safe. Bridges that are functionally obsolete are posed with a serviceability issue, whereas a structurally deficient bridge is a safety issue. The structural deficiency of a bridge may have resulted from a number of factors (Taly, 1998). These factors include, but are not limited to:

- $\quad$ Designs for lighter loads as opposed to much heavier loads of today;

- Designs according to codes, specifications, or stress levels that are no longer applicable;

- $\quad$ Reduction of the live-load capacity as a result of aging, deterioration, or damage to structural members.

A great many of the existing bridges were built before the second World War. Back then the bridges were designed for only an H-10 (10 tons) truck loading (GangaRao, 1998). Today, because of the economic demand of the hauling industry, truckers are being required to carry heavier loads, such as HS-25 (three axle truck weighing 45 tons) and HS-30 (three axle truck weighing 54 tons). When these heavier trucks are driven over 
joints or deck surface cracks, the resulting impact loading becomes an important issue as well.

For some bridges, an increase in dead load may be a reason for its loss of structural integrity. The increase may be due to replacing an old deck by a thicker new deck, or from the addition of a new wearing surface without removing the older wearing surface. With the increase of dead load comes the increase of dead-load moment, which consequently decreases the live-load carrying capacity of a bridge, leading to very many structural safety issues (Taly, 1998).

Even another reason for the structural deficiency of bridges across the United States is that bridges that were designed in the Pre-World War II era used much weaker material than what is used today. For instance, the steel that was utilized then only had a yield value of approximately $7 \mathrm{ksi}$ (GangaRao, 1998). Today, steel is being used routinely with a yield value of 50ksi. For some old bridges the only reason they have not failed as of yet is because of their factor of safety.

\subsubsection{Bridge Rating}

The Bridge Maintenance Engineer must make the decision to either rehabilitate a deficient bridge extensively or sparsely, or to replace the bridge altogether. Sometimes the cost of rehabilitating a bridge outweighs the cost to replace the structure, therefore the judgment of the engineer in this matter is very important. To aid in the decision making process of the Maintenance Engineer, different types of bridge ratings were introduced. 
One such rating procedure will be discussed here in detail, known as the sufficiency rating.

\subsubsection{Sufficiency Rating}

The sufficiency rating provides an overall report of the condition of a bridge to establish the possibilities of replacement versus extensive rehabilitation, or replacement versus sparse rehabilitation. This type of rating is based on a 100 point scale, with 100 points being associated with a bridge that is brand new, to 0 points indicating a bridge with no structural integrity whatsoever. A bridge with a sufficiency rating between 80 and 100 points would normally lead to some type of rehabilitation ranging from minor to extensive, while a rating between 55 and 80 would usually invoke extensive rehabilitation or perhaps replacement. Any rating less than 55 ordinarily results in bridge replacement (GangaRao, 1998).

The point scoring system in the sufficiency rating process is derived from the following four factors (see Figure 2.1):

1. Structural safety (approximately 55 points) which includes...

- $\quad$ Deck

- $\quad$ Superstructure

- $\quad$ Guard rail system

- $\quad$ Substructure;

2. Serviceability and functional obsolescence (approximately 30 points);

3. Essentiality for public use (approximately 15 points); and,

4. Special reductions including detour length and other traffic safety features (FHWA, 1995). 


\subsubsection{Step-By-Step Procedure for Rating Analysis}

The following is a step-by-step procedure for the analysis of the sufficiency rating developed by the National Cooperative Highway Research Program (NCHRP) in 1987:

1. Analyze the bridge completely for service loads, which means finding moments and forces from applied loads such as an HS-25 truck load;

2. Find member stresses as required from dead load;

3. Find load carrying capacity based on actual cross-sectional properties and allowable stresses;

4. Find member capacity available to carry live load by subtracting the value obtained in step 2 from the value obtained from step 3; and ,

5. Find the rating factor by dividing the allowable capacity for live load plus impact by the capacity required for live load plus impact.

\subsection{Bridge Deck Analysis}

\subsubsection{Focus of Report}

The previous sections of this chapter have dealt with the inspection of the bridge as a whole; however, the focus of this research project is to analyze the inspection process of only the concrete bridge deck. The two main categories of bridge deck inspection that will be compared throughout this report are the chain drag method and GPR. 


\subsubsection{Chain Drag Method}

The chain drag method is the principle way in which delamination surveys are conducted in the state of West Virginia. Although the process may seem to be quite empirical, according to employees at the WVDOT the method yields accurate results. This practice is not recommended to be employed on bridge decks that have been overlaid with asphalt. However, bridge decks that have been overlaid with Portland cement concrete mixtures may use this method (ASTM D4580-86, 1986).

\subsubsection{Field Apparatus}

The field apparatus consists of chains, copper tubing, measuring tape, markers, and stringline. The measuring tape, markers, and stringline are used to develop a grid system on the bridge deck, while the chains and copper tubing are used in conducting the test. A common chain drag set-up includes four or five segments of $25.4 \mathrm{~mm}$ (1") link chain of 6.4mm (1/4") diameter steel approximately 457.2mm (18”) long, attached to a $609.6 \mathrm{~mm}$ (24") long piece of copper tubing. That copper tubing is attached at the midpoint by another piece of copper tubing, which in turn is attached to its midpoint by yet another piece of copper tubing so that all tubing resembles the letter I.

\subsubsection{Summary of Procedure}

The first step in the procedure of the chain drag method, according to the American Society for Testing Materials (ASTM), is to remove any accumulation of debris that may be found on the bridge deck. Next, a grid system should be constructed on the deck with a lumber crayon so that delaminated areas can be plotted easily. Usually there 
are two people conducting the test: one to drag the chain and one to do the marking. The next step is to drag the chains over the entire body of the deck surface. Nondelaminated areas produce a clear ringing sound, as opposed to a dull or hollow noise encountered on delaminated concrete. Any perceived delaminated areas are to be marked with a lumber crayon or with spray paint (ASTM D4580-86, 1986). A photograph of a WVDOT employee conducting a chain drag test can be seen in Figure 2.2.

To plot what was found during the testing procedure, a scaled map of the bridge deck should be constructed first. By noting the marked areas on the bridge deck with respect to the grid lines, the delaminated areas are to then be plotted. The next step is to determine the total amount of area encompassed by the delaminated areas. Then, to obtain the percent of deck area delaminated, divide the total delaminated area by the total bridge deck area and multiply that answer by 100 (ASTM D4580-86, 1986).

According to the ASTM, the precision and bias of the chain drag method were unknown as of 1992.

\subsubsection{Inspection With GPR}

The inspection of bridge decks using GPR is a relatively new procedure. There is much research taking place on the subject of using radar for inspection purposes to test its validity. GPR can be used on any bridge deck surface; whether it be exposed concrete or overlaid with asphalt. Outside acoustical noise does not affect the outcome of the GPR data and weather conditions can be taken into account when processing the information.

The GPR testing is performed from a van which has anywhere from one to five antennas mounted on either the front or the rear of the vehicle. The van and antenna used 
in this particular project can be seen in Figure 2.3. Each antenna scans a space of approximately one square foot of deck below, depending on the distance between the antenna and the bridge deck surface. A line of scanning underneath an antenna is known as a pass. The way in which GPR operates is the antenna sends radar waves into the deck. At different interfaces within the body of the bridge deck the radar waves are either reflected or transmitted. Bridge deck interfaces include deck surface, asphalt/concrete interface, top layer rebar, bottom of deck, etc. One can determine what lies beneath the surface and at what depth by how long and at what voltage the radar waves return to the antenna. Figure 2.4 shows a sketch of how the antenna sends and receives signals from different interfaces.

\subsection{Theory}

\subsubsection{Theory of Chain Drag}

The chain drag method is essentially a sounding technique. When the chains come into contact with the concrete surface, waves are generated on the deck. These waves travel through the solid material of the deck and excite the surrounding air. Compression waves are formed in the excited air that travel toward your ears and vibrate your eardrums, causing a person to experience sound. Therefore, two theoretical systems are involved in the chain drag method: waves traveling through the solid material of the bridge deck, and waves traveling through the air.

\subsubsection{Waves Traveling Through Solid}

The waves that travel through a solid material, namely the concrete bridge deck in 
this case, are generated in much the same fashion as when the impact echo technique is used. The principle of the impact echo technique is simple and involves striking the concrete surface with a steel ball of specific diameter and thereby creating a transient stress wave which propagates into the concrete (Shaw and $\mathrm{Xu}, 1997)$. This compression wave is reflected from the back-side of the concrete or from any internal anomalies or other objects, such as rebar, which can cause a fluctuation in material density along the path of the pulse (Shaw and $\mathrm{Xu}, 1997)$. Aside from compression waves, there are also shear waves generated from the impact.

Compression waves and shear waves are known as P-waves and S-waves, respectively. P-waves move along the path of the wave propagation, alternating between tension and compression. S-waves induce shear deformations by moving in a direction perpendicular to the wave propagation path. The "P" or Primary wave designation comes from the fact that they are the most rapid and are the first to arrive at any given point. The "S" or Secondary wave refers to the fact that these shear stress waves are slower than the P-waves and therefore arrive after the P-wave at any given point (Clough and Penzien, 1993).

In order to perform a thickness calculation of concrete from an impact echo test, the $\mathrm{P}$-wave speed, $\mathrm{C}_{\mathrm{p}}$, must be determined. In many instances, $\mathrm{C}_{\mathrm{p}}$ is found by performing an impact echo test on an area of known thickness. However, when the thickness of the concrete is the unknown, an independent means of determining the wave speed must be employed (Lin and Sansalone, 1997).

In semi-infinite elastic solids, $\mathrm{C}_{\mathrm{p}}$ can be determined from the following relation (Lin and Sansalone, 1997): 


$$
C_{p}=\sqrt{\frac{E(1-v)}{(1+v)(1-2 v) \rho}}
$$

where, $\quad E=$ Modulus of elasticity

$$
\begin{aligned}
& \rho=\text { mass density } \\
& v=\text { Poisson's ratio }
\end{aligned}
$$

R-waves propagate at a velocity, $C_{R}$, which can be related to $C_{p}$ by the following approximate relation (Lin and Sansalone, 1997):

$$
C_{p}=\frac{1+\mathrm{v}}{0.87+1.12 v} \sqrt{\frac{2(1-\mathrm{v})}{(1-2 v)}} C_{R}
$$

For a typical value of Poisson's ratio in normal strength concretes of 0.18 , the previous relation can be reduced to:

$$
C_{p}=1.76 C_{R}
$$

The depth, T, to an internal void or crack or to an external boundary can now be calculated as:

$$
T=\frac{C_{p}}{2 f}
$$


where, $\quad f=$ the frequency of the P-wave reflections from the internal interface or external boundary (Lin and Sansalone, 1997).

\subsubsection{Waves Traveling Through Air}

As was previously mentioned, waves that travel along the surface of the concrete deck during a chain drag test excite the surrounding air and the compression waves that are formed by this excitation reach the human ear in the form of sound. It is this sound that is the basis of the decision of whether there is or is not a delamination at a given point on the deck to a person conducting a chain drag test.

The propagation of a small-amplitude acoustic signal can be described by the following equation (Ziomek, 1995):

$$
\nabla^{2} \psi(t, r)-\frac{1}{c^{2}} \frac{\partial^{2}}{\partial t^{2}} \psi(t, r)=x_{M}(t, r)
$$

where, $\quad \Psi(\mathrm{t}, \mathrm{r})=$ velocity potential at time $\mathrm{t}$ and position $\mathrm{r}=(\mathrm{x}, \mathrm{y}, \mathrm{z})$ in $\mathrm{m}^{2} / \mathrm{s}$

$\mathrm{x}_{\mathrm{M}}(\mathrm{t}, \mathrm{r})=$ input acoustic signal to the fluid medium

$\mathrm{c}=$ the constant speed of sound in $\mathrm{m} / \mathrm{s}$

The fluid medium mentioned in the description of $\mathrm{x}_{\mathrm{M}}(\mathrm{t}, \mathrm{r})$ is the air in this case and the input acoustic signal would be the surface waves of the concrete bridge deck. There are a few assumptions that the previous linear, three-dimensional, lossless wave equation is based upon. The first is that the fluid media is ideal, or nonviscous. That means that the fluid does not possess a resistivity to fluid flow. The second assumption is that the fluid is 
homogeneous. Although air is a mixture of several gases, it is often considered to be a homogeneous substance because of its uniform chemical composition (Cengal and Boles, 1994).

\subsubsection{Theory of GPR}

The equations in this section discuss the theoretical behavior of radar signals in concrete. The velocity of an electromagnetic wave in concrete, $\mathrm{v}$, is as follows (Chen et al., 1994):

$$
\mathrm{v}=\frac{c}{\sqrt{\varepsilon_{r}}}
$$

where, $\quad c=$ the velocity of an electromagnetic wave in a vacuum or air

$$
(0.3 \mathrm{~m} / \mathrm{ns})
$$

$\varepsilon_{\mathrm{r}}=$ the relative dielectric constant of concrete $(\cong 8)$.

The distance between certain interfaces can be determined once the electromagnetic wave velocity is determined from equation 2.6 and the two-way wave travel time is known. The equation for that distance is given next:

$$
d=\frac{(\mathrm{v} \times \Delta t)}{2}
$$

where, $\quad \Delta \mathrm{t}=$ two-way wave travel time between interfaces. 
As an electromagnetic wave travels through concrete, its energy dissipates. This dissipation is also known as attenuation. The attenuation, $A$ in $\mathrm{dB} / \mathrm{m}$, can be calculated from the following equation (Chen et al., 1994):

$$
A=12.863 \times 10^{-8} f \sqrt{\varepsilon_{r}}\left(\sqrt{1+\tan ^{2} \delta}-1\right)^{\frac{1}{2}}
$$

where, $\quad \mathrm{f}=$ the wave frequency in $\mathrm{Hz}$

$$
\tan \delta=\text { the loss tangent or dissipation factor. }
$$

The loss tangent can be obtained from the following relation (Chen et al., 1994):

$$
\tan \delta=1.8 \times 10^{10} \frac{\sigma}{f \varepsilon_{r}}
$$

where, $\quad \sigma=$ the electrical conductivity of the material in $\mathrm{mho} / \mathrm{m}$.

The ratio of the reflected wave amplitude to the incident wave amplitude at an interface is known as the amplitude reflection coefficient, $\mathrm{R}_{1,2}$. It can be determined by (Chen et al., 1994):

$$
R_{1,2}=\frac{\sqrt{\varepsilon_{r 1}}-\sqrt{\varepsilon_{r 2}}}{\sqrt{\varepsilon_{r 1}}+\sqrt{\varepsilon_{r 2}}}
$$

where the subscripts 1 and 2 denote the different media at an interface. 
The ratio of the transmitted wave amplitude to the incident wave amplitude is known as the amplitude transmission coefficient and it can be found using equation 2.11 (Chen et al., 1994).

$$
T_{1,2}=\frac{2 \sqrt{\varepsilon_{r 1}}}{\sqrt{\varepsilon_{r 1}}+\sqrt{\varepsilon_{r 2}}}
$$

The electromagnetic properties of concrete can be found from Halabe et al. (1993), who provides an in depth discussion on the subject.

\subsection{Literature Review}

There has recently been much research on the subject of GPR for the use of nondestructively evaluating a concrete bridge deck; however, it is very difficult to obtain literature on the topic of the chain drag test. For that matter, recent research on the impact-echo test has been searched for and will be presented in this section, since both the chain drag method and the impact echo method are sounding techniques.

\subsubsection{Literature on GPR}

In Phase I of this particular project, Chen et al. (1994) from West Virginia University used 15 concrete bridge deck specimens to test the usage of GPR for nondestructive evaluation purposes. The 15 specimens were cast in three batches and had varying internal conditions such as with/without reinforcement and with air and waterfilled cracks. The researchers enhanced the existing radar system provided by the WVDOH by adding a data acquisition system, software, and computer. Color intensity 
plots and individual radar waveforms from the specimens were compared to determine if the radar system could locate the different specimen characteristics. Also, the researchers developed a computer program with a graphical user interface for theoretical synthesis of the radar waveforms generated from the concrete bridge deck specimens. The program was developed with an inversion subroutine to predict internal conditions from the radar waveforms, such as porosity, chloride content, and top rebar cover. Based on the laboratory tests, it was concluded that the GPR technique could be used effectively for the in-situ evaluation of concrete bridge decks. However, the researchers felt that the effect of asphalt overlays on the detectability of defects had to be researched in the future.

Phase II of this project was then initiated by Halabe et al. (1996) at West Virginia University to further investigate GPR as a tool to inspect concrete bridge decks and pavements. In addition to the 15 concrete bridge deck specimens from Phase I, 10 concrete pavement specimens were cast with varying internal characteristics similar to the conditions in Phase I. Asphalt layers with varying thickness were poured on 20 of the specimens (14 bridge deck and 6 pavement) and tested using the GPR system. The color intensity plots and individual radar waveforms were compared to determine if the radar system could locate the internal anomalies. The study concluded that the GPR technique was a reliable method for condition assessment of bridge decks and pavements with and without asphalt overlay. The researchers found that asphalt overlay of 25.4-76.2mm (13") thickness had a negligible effect on the sensitivity for detecting the subsurface defects. They also determined that the debonding at the asphalt/concrete interface was found more easily than finding the internal cracks within the underlying concrete layer.

Millard et al. (1997), at the University of Liverpool in England, used an oil and 
water emulsion to simulate concrete in their radar tests. The oil and water emulsion was used in order to save time on the large number of concrete specimens that would have been needed to be cast and cured. They studied the effects of reinforcing bars and voids of different sizes, shapes, and placements on the limitations of their identification by radar and their influence on detecting other items of interest. They also developed a coaxial transmission line that successfully measured the electrical properties of concrete within the frequency range of $1 \mathrm{MHz}$ to $1 \mathrm{GHz}$. The researchers found difficulty in estimating the depth and determining the size of rebars and voids especially when they were spaced closely together or near the top surface, because of the overlapping of the reflected radar signals.

SlatonBarker and Wallace (1997), with the cooperation of the New York State Department of Transportation, used dual frequency radar to assess concrete slabs of known characteristics in the lab and actual bridge decks in the field. They used two different frequency antennas to reduce the amount of false readings encountered when using only one antenna and to more accurately assess the amount of damage that has occurred once the anomaly has been detected. The findings from the laboratory experiments were used to interpret the radar signals from the different bridges in the field. The $300 \mathrm{MHz}$ antenna was more suited to detect defects on the bottom portion of the specimens, while the $1 \mathrm{GHz}$ antenna was found to work better for defects near the top surface. The correlation between the $300 \mathrm{MHz}$ and the $1 \mathrm{GHz}$ antennas was found to average nearly $50 \%$, which means that the antennas detected some of the same defects, but also found some that were invisible to the other antenna. The probability that both antennas would falsely find a defect is less than if only one antenna found a defect, thus 
increasing the reliability of the radar data. When both antennas found defects on the bridge decks in the field, $98 \%$ of the areas were verified by visual inspection.

Reel et al. (1997) tested 10 different bridge decks in Ontario, Canada using deck assessment by radar technology (DART). They discovered processing strategies such as the use of waterfall plots, thresholding, and strata plots used to determine layer thicknesses and where voids and reinforcing bars existed. They correlated their findings on the bridge decks with core sampling and the use of a covermeter and discovered their predictions with DART were within $\pm 9 \%$ of the actual values. Concrete cover at one core location was found to be within $3 \mathrm{~mm}$ of what dart predicted.

Chung et al. (1994), from the Ministry of Transportation, Ontario (MTO) and the Communications Research Laboratory (CRL) at McMaster University, performed a series of experiments to better interpret the radar waveforms reflected from sample blocks, including exposed concrete with and without reinforcement, asphalt, and waterproofing membrane. A rigorous theoretical analysis was developed and proved to be in agreement with the radar signatures. For the exposed concrete, the researchers found difficulty in determining the depth of the cover over the reinforcement because of the strong surface reflection. To overcome this problem, they subtracted the estimated surface reflection of the known transmitted signal from the composite signal to come up with a residue waveform, which clearly displayed the reflections from the rebars alone. The tests with the asphalt and with the waterproofing membrane proved that the thickness of each sample block was easily discernible. The results from the asphalt testing showed that the values of the relative dielectric constant of asphalt were all within $\pm 7.8 \%$.

Shaw and $\mathrm{Xu}$ (1997) used different pulse-echo methods to inspect concrete 
structures. The methods used were ultrasonic pulse velocity (UPV), impact-echo, and GPR. They found that the UPV technique was a useful investigative tool, but due to the lack of experimental reference data and not being able to systematically document what was found, much of the evaluation was speculative. They also found that the UPV and impact-echo techniques complement each other when used together. The researchers discovered that GPR is a quick and accurate way to inspect concrete, but thought that since concrete is a material whose properties change with time, the accuracy and penetration ability of the GPR would be affected.

Molyneaux et al. (1995), at the University of Liverpool in England, conducted a series of studies to apply the use of radar with neural networks to determine if reinforcing bars could be accurately located at different depths inside concrete. The network analysis software used in the study for developing the neural network was called Aspirin/MIGRAINES. The researchers used an oil and water emulsion to simulate concrete without the need to cast and cure a multitude of specimens. A total of 132 trials were used: 101 with rebars and 31 without. The results showed that the system was successful 94 times out of $101(93 \%)$ in locating the rebars and determining at what depths they were found when they were present. However, of the 31 trials without rebars present, the system inaccurately located rebars 13 times which corresponded to a $42 \%$ failure rate. The system also had trouble determining the bar diameter throughout the study. The researchers noted that care should be taken when using their system on real concrete because aggregate particles were not present in the oil and water emulsion tank and could cause additional radar scatter when used in the field.

Saarenketo and Soderqvist (1994) used GPR to evaluate three different bridge 
decks in Finland. They used air-coupled and ground-coupled antennas of different frequencies ranging from $1.0 \mathrm{GHz}$ to $2.5 \mathrm{GHz}$. They found that the $1.0 \mathrm{GHz}$ antenna gave the best radar images without any data manipulation. The researchers had acceptable accuracy in determining asphalt thicknesses on the bridge decks. However, they had some problems differentiating between the protective concrete layer and the slab when the waterproofing membrane was thin between the two layers.

Rhim et al. (1994), from the Massachusetts Institute of Technology, tested the use of radar at frequency ranges of $9-11 \mathrm{GHz}$ remotely on two concrete slabs in the laboratory at distances of $20 \mathrm{~m}$ (65.6ft). The two slabs had the dimensions of 24in x 24in x 3in. One was a plain concrete specimen and the other had one reinforcing bar that had a $13 \mathrm{~mm}$ (0.5in) diameter. Coarse aggregates were not used in the concrete mix to reduce the amount of radar scattering. The results showed that the rebar was best detected when the scanning was performed in the direction parallel to the axis of the rebar.

\subsubsection{Literature on Impact-Echo}

Lin and Sansalone (1997), from Cornell University, developed a method to independently determine the P-wave speed in concrete by using a Rayleigh-wave, also known as R-wave, speed measurement between two points on the surface of the concrete. By placing two transducers on the surface of the concrete at strategic locations and measuring the arrival time differences between the transducers, the R-wave speed could be found which directly corresponded to the P-wave speed. Once the P-wave speed is known, items of interest such as concrete thickness can be easily determined. They discussed the errors in using this method. For example, when the arrival time difference of 
the R-wave at each transducer is greater than $80 \mu \mathrm{s}$, the error in determining the R-wave speed was $2.6 \%$ when the maximum deviation was $2 \mu \mathrm{s}$. Also, this method of finding the P-wave speed based on the R-wave speed requires the assumption that the Poisson's ratio for concrete is 0.18 . The error in that assumption varied from $2.1 \%$ to $-2.5 \%$ for Poisson's ratios ranging from 0.15 to 0.21 . Numerical analysis using Finite Element Modeling was used at the onset of the testing. To verify the results from the numerical studies, two concrete blocks were constructed and tested in the lab. The relative errors for determining the concrete thicknesses for slabs 1 and 2 were $1.4 \%$ and $4.2 \%$, respectively.

Sansalone, Lin, and Streett (1997), from Cornell University, developed a procedure for determining pavement thicknesses using a direct P-wave speed measurement and the impact-echo method. They also summarized the systematic errors associated with the testing procedure and data acquisition. The results from the tests in the laboratory and in the field show the accuracy of this method. The estimations of the thickness of a $0.2 \mathrm{~m}$ thick concrete specimen were within $\pm 3 \mathrm{~mm}$ of the actual thickness.

Poston and Sansalone (1997) used the impact-echo method to detect cracks in beams and columns of a post-tensioned parking garage structure. They were successful in identifying the cracks and prioritizing the beams and columns for the type of rehabilitation needed. The impact-echo results were verified when certain structural members were removed during the rehabilitation and cracks were exposed. 


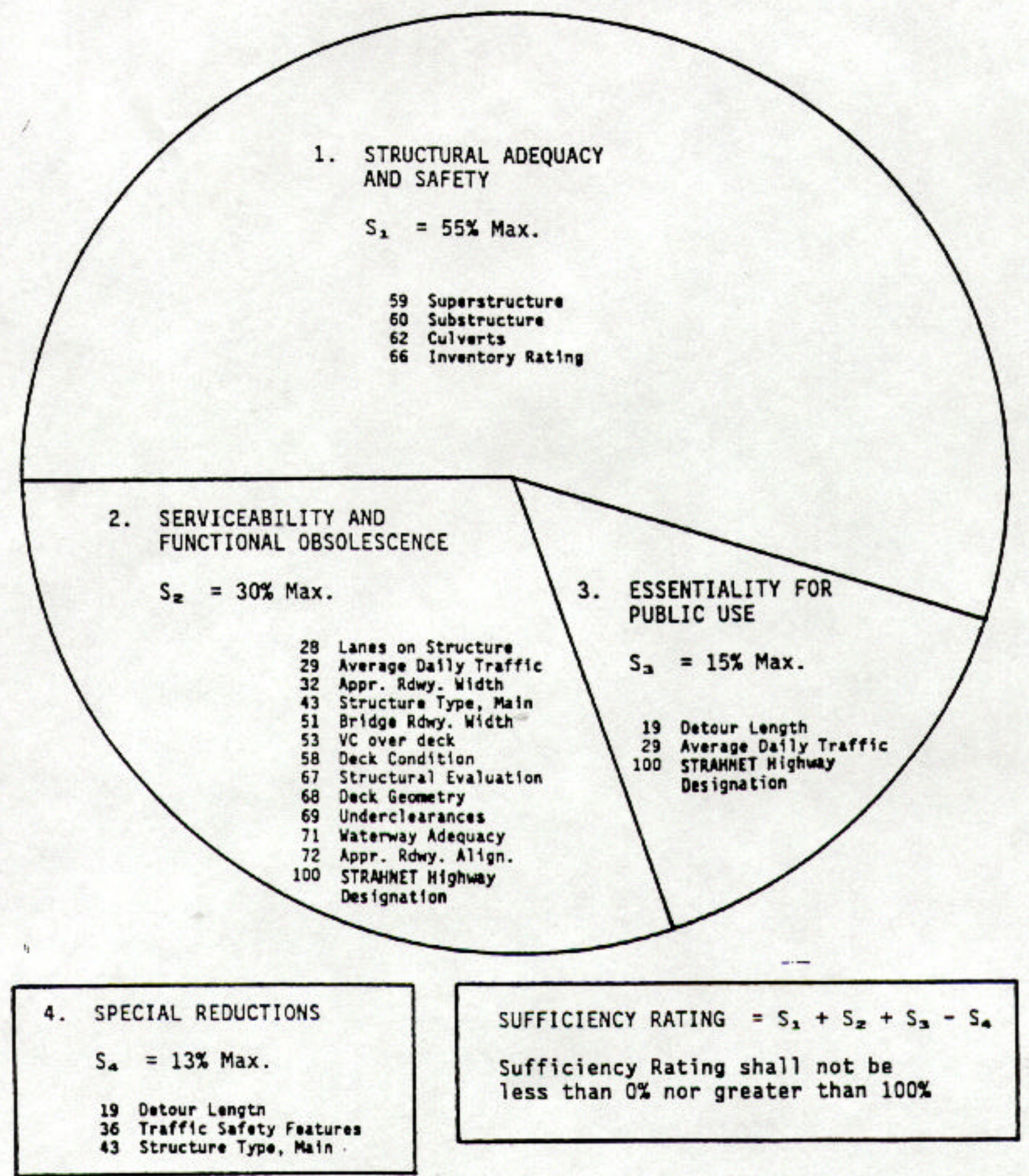

Figure 2.1: Summary of Sufficiency Rating Factors (FHWA, 1995) 


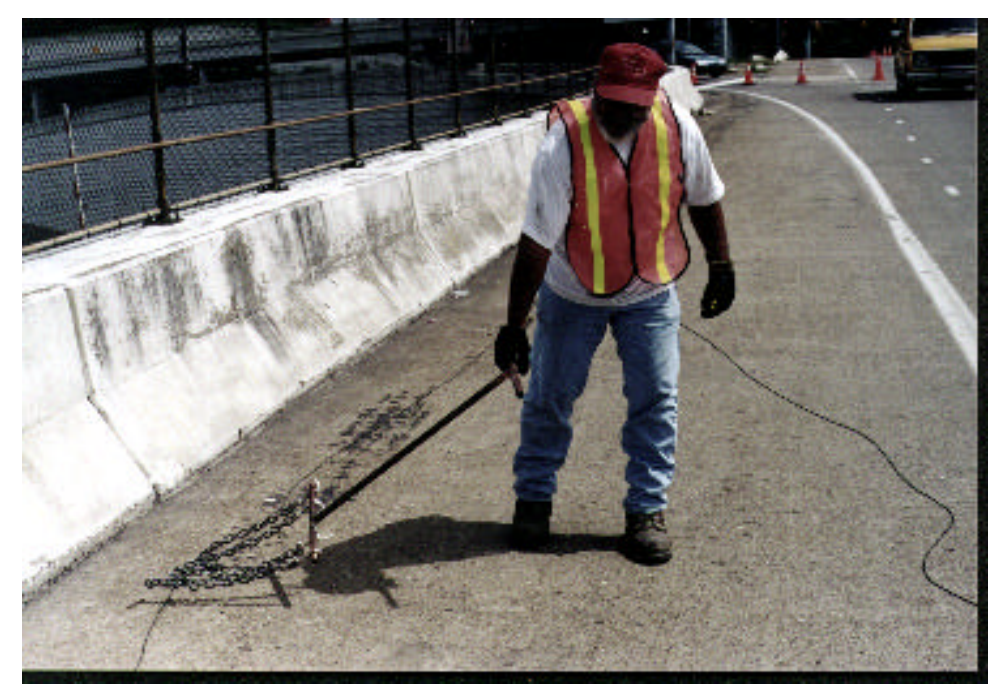

Figure 2.2: WVDOT Employee Conducting Chain Drag Test

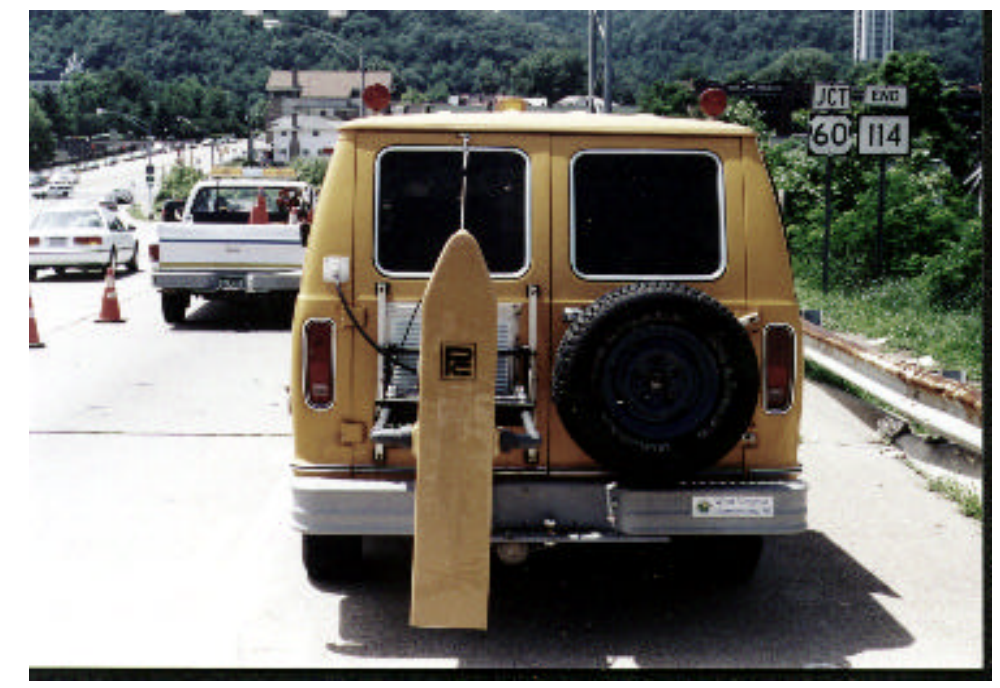

Figure 2.3: Van and Antenna Used in Project 


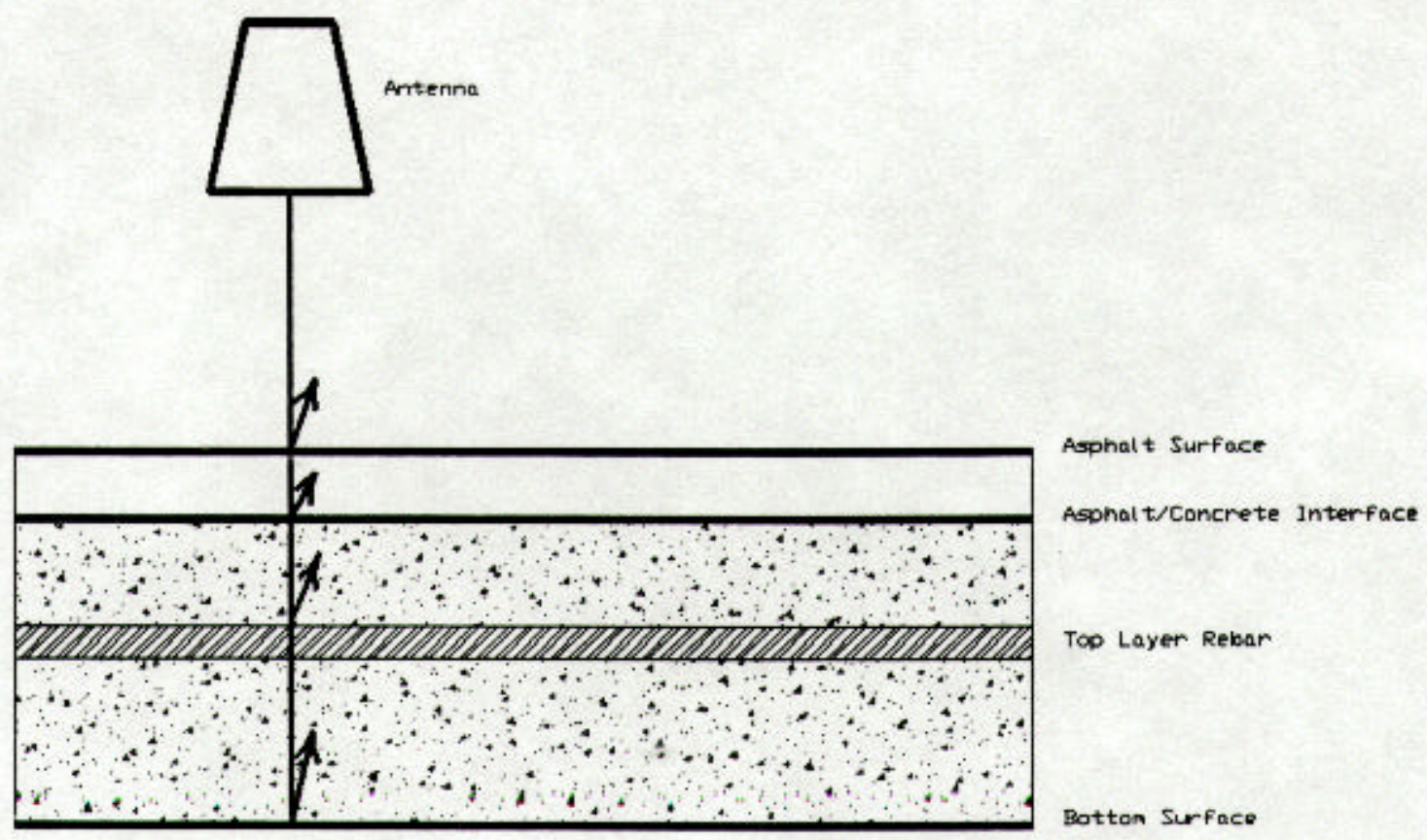

Figure 2.4: Transmission and Reflection of Radar Waves at Different Interfaces 


\section{CHAPTER 3}

\section{CHAIN DRAG TESTING OF LABORATORY SPECIMENS}

\subsection{Laboratory Specimens}

Twenty-three concrete bridge specimens from the previous two phases of this project were used for the laboratory testing of the third phase. The purpose of using these concrete blocks were to simulate bridge decks. The footprint of each specimen was $609.6 \mathrm{~mm} \times 609.6 \mathrm{~mm}$ (24" x 24") with their depths varying from $152.4 \mathrm{~mm}$ to $304.8 \mathrm{~mm}$ (6" to 12"). Within the body of each specimen existed differing internal conditions such as air-filled and water-filled cracks, with and without steel reinforcement. The concrete was designed with a compressive strength of $4300 \mathrm{psi}$, a water/cement ratio of 0.5 , and a ratio of cement:sand:aggregates of 1:2:3. The specimens are shown in Figures 3.1 through 3.5. A summary of the characteristics of each specimen is given in Tables 3.1 and 3.2.

\subsection{Apparatus}

\subsubsection{Chain Drag}

The chain drag configuration used in the testing of the concrete specimens was obtained from the WVDOT. It consisted of three steel chains attached to the bottom of copper tubing configured in the shape of the letter I. The three chains, named Chains 1,2 , and 3, varied in size from one another. For instance, Chain 1 was 736.6mm (29”) long of $12.7 \mathrm{~mm}(0.5 ")$ link chain, approximately $3.2 \mathrm{~mm}(0.125 ")$ in diameter. Chain 2 was $622.3 \mathrm{~mm}(24.5 ")$ long of $25.4 \mathrm{~mm}$ (1") link chain, $6.4 \mathrm{~mm}(0.25$ ") in diameter. Finally, Chain 3 was $647.7 \mathrm{~mm}$ (25.5”) long of $28.6 \mathrm{~mm}$ (1.125") link chain, $6.4 \mathrm{~mm}(1 / 4 ")$ in 
diameter. Table3.3 shows the dimensions of the three chains in a more succinct manner and the photograph of Figure 2.2 contains a common chain drag configuration. According to ASTM Designation: D 4580-86: Standard Practice for Measuring Delaminations in Concrete Bridge Decks by Sounding, a common chain drag configuration consists of four or five segments of $25.4 \mathrm{~mm}(1 ")$ link chain of $6.4 \mathrm{~mm}(0.25$ ") diameter steel approximately 457.2mm (18") long.

\subsubsection{Sound Measuring Equipment}

The equipment used in measuring and recording the sound generated during the laboratory testing consisted of a microphone, a microphone stand with a microphone boom adapter, an amplifier, and an oscilloscope.

The Cardioid Dynamic Microphone was purchased from Radio Shack. The microphone was used to simulate the human ear so that the sound of the steel chains dragging against the concrete blocks could be quantified. It had a unidirectional pickup pattern which reduced the background noise and the feedback. The microphone had a mesh windscreen to reduce wind effects and a $3.96 \mathrm{~m}$ (13ft) long cable with a $6.4 \mathrm{~mm}$ $(0.25$ ") diameter phone plug. Its impedance was 600 Ohms and the sensitivity associated with it was -76 decibels. The frequency response was between 50-15000 Hz. The frequency response curve and the pickup pattern can be seen in Figures 3.6 and 3.7, respectively.

The microphone stand and microphone boom adapter were both purchased from Radio Shack, as well. The stand was adjustable from 838.2mm-1549.4mm (33"- 61") with a positive-locking clutch and a heavy-duty cast base. It also had protective rubber 
feet and standard $15.9 \mathrm{~mm}(0.625$ ")-27 thread. The boom adapter had a $787.4 \mathrm{~mm}$ (31") chrome tube and attached to the free end of the microphone stand. Like the stand, the boom adapter also had $15.9 \mathrm{~mm}(5 / 8$ ")-27 threads and positive locking action. The usefulness of the boom adapter was for angling the microphone down towards the concrete bridge specimens.

The Optimus SA-155 Stereo Mini Amplifier was also purchased from Radio Shack. The purpose of the amplifier was to increase the signal strength because the signal was originally too small to be picked up by the oscilloscope on the lowest voltage settings. The gain of the amplifier is unknown; however, it is not needed since all tests were conducted with exactly the same conditions.

The Nicolet-310 Digital Oscilloscope was used to record the sound received by the microphone on a voltage versus time graph. The built-in disk drives on the top of the oscilloscope allowed for easy signal saving. Thus, transferring the data from the oscilloscope to the personal computer was a simple task.

A schematic of the equipment set-up can be seen in Figure 3.7. The boom adapter was connected to the microphone stand at an angle that was approximately 45 degrees. The height of the microphone stand was adjusted occasionally so that the microphone was always about $76.2 \mathrm{~mm}$ (3") from the concrete blocks which varied in height. The microphone was positioned at the end of the boom adapter and plugged into the amplifier. The volume knob on the amplifier, which influenced the magnification of the signal, was set at mid-strength for each test performed. The amplifier was then plugged into the oscilloscope. The volts full scale and the time per point switches on the oscilloscope were 
set at 1 volt and 1 millisecond, respectively. Photographs of all of the equipment used in the testing can be seen in Figures 3.9 and 3.10.

\section{$\underline{\text { 3.2.3 Concrete Specimens }}$}

The concrete specimens were positioned directly beneath the microphone and was placed upon two $50.8 \mathrm{~mm} \times 101.6 \mathrm{~mm}$ (2"x4") strips of wood. The wood was on both ends of the blocks and were used to simulate bridge abutments. Not only do the size and characteristic of each block influence the outcome of the experiment; the size, shape, and location of the defect plays an important role as well.

\subsection{Purpose of Testing}

There were two main reasons for conducting the chain drag tests. The first goal was to determine if the chains could uncover the differences between the concrete bridge specimens in the lab. From Phases I and II of this project it was already concluded that the radar equipment could distinguish between the differing characteristics of each concrete block. In Phase III, the research will determine if the chain drag method can measure up to the radar in the lab. The second reason for performing the laboratory tests was to compare the signals of each individual chain. This was to determine if the different chain sizes had any influence on the signals that were generated.

\subsection{Procedure}

Once all of the equipment was set up in the correct manner the testing took place. The first step in the experimental procedure was to reduce the amount of outside noise as 
much as possible. This included making sure there were no people in the lab and only experimenting when there were no noises coming from the vents in the laboratory walls while the testing occurred. The next step was to adjust the triggering knob on the oscilloscope so that it was ready to receive a signal. Chain 1 was then ready to be dragged across the concrete bridge specimen. Upon impact of the steel and the concrete, the oscilloscope started receiving signals. The chain was dragged from one corner of the block to the other in a sweeping motion, raising the chain off the concrete surface briefly between strokes. The amount of time for each triggering allowed for approximately four strokes per signal. Five different signals for each chain on each block was collected for consistency purposes. Chain 2 was used after Chain 1 had generated five signals, followed by Chain 3. Once all three chains were used on a particular specimen another block was positioned so that the process could be repeated. This procedure carried on until all 23 concrete blocks had been tested. 


\begin{tabular}{|c|c|c|c|}
\hline Specimen & Specimen Type & $\begin{array}{c}\text { Dimensions of Crack } \\
\text { and/or Defect in the } \\
\text { Specimen }\end{array}$ & Position \\
\hline B12 & Plain Concrete & $\overline{---}$ & -- \\
\hline B13 & Air Crack (Cardboard) & $6^{\prime \prime}$ dia. $\times 0.03^{\prime \prime}$ thick & 3" from top \\
\hline B14 & Air Crack & $24^{\prime \prime} \times 0.03^{\prime \prime}$ thick & $3^{\prime \prime}$ from top \\
\hline B15 & Steel Plate & $24^{\prime \prime} \times 0.03^{\prime \prime}$ thick & $3^{\prime \prime}$ from top \\
\hline B21 & Plain Concrete & -- & -- \\
\hline B22 & Air Crack (Plexiglass) & $8 "$ dia. $\times 0.11$ thick & $3^{\prime \prime}$ from top \\
\hline B23 & Air Crack (Plexiglass) & $8 "$ dia. $\times 0.22$ thick & $3^{\prime \prime}$ from top \\
\hline B24 & $\begin{array}{c}\text { One Layer Steel } \\
\text { Reinforcement (at top) }\end{array}$ & $\begin{array}{l}\# 4 \text { bars } 8 " c-c \\
\# 6 \text { bars } 6 " c-c\end{array}$ & 1" from top \\
\hline$B 25$ & $\begin{array}{l}\text { Two Layer Steel } \\
\text { Reinforcement }\end{array}$ & $\begin{array}{l}\# 4 \text { bars } 8 " c-c \\
\# 6 \text { bars 6" c-c } \\
\end{array}$ & $\begin{array}{c}1.5^{\prime \prime} \text { from top } \\
1 \text { " bottom clear cover }\end{array}$ \\
\hline B31 & Plain Water-Filled Crack & $7^{\prime \prime} \times 7^{\prime \prime} \times 0.12^{\prime \prime}$ & $3^{\prime \prime}$ from top \\
\hline B33 & $\begin{array}{c}\text { One Layer Steel } \\
\text { Reinforcement (at top) }\end{array}$ & $\begin{array}{l}\text { \#4 bars 8" c-c } \\
\text { \#6 bars 6" c-c }\end{array}$ & $1.5^{\prime \prime}$ top clear cover \\
\hline \multirow[t]{2}{*}{ B34 } & \multirow{2}{*}{$\begin{array}{c}\text { One Layer Steel } \\
\text { Reinforcement (top) } \\
+ \\
\text { Air Crack (Plexiglass) }\end{array}$} & $\begin{array}{l}\# 4 \text { bars } 8 " \mathrm{c}-\mathrm{c} \\
\# 6 \text { bars 6" c-c }\end{array}$ & $1.5^{\prime \prime}$ top clear cover \\
\hline & & $8 "$ dia. $\times 0.11 "$ thick & $\begin{array}{l}\text { Just above top steel } \\
\text { reinforcement }\end{array}$ \\
\hline \multirow[t]{2}{*}{ B35 } & \multirow{2}{*}{$\begin{array}{c}\text { One Layer Steel } \\
\text { Reinforcement (top) } \\
+ \\
8 \% \text { Saline Water-Filled Crack }\end{array}$} & $\begin{array}{l}\# 4 \text { bars } 8 " c-c \\
\# 6 \text { bars 6" c-c }\end{array}$ & $1.5^{\prime \prime}$ top clear cover \\
\hline & & $7^{\prime \prime} \times 7 " \times 0.12^{\prime \prime}$ & $\begin{array}{l}\text { Just above top steel } \\
\text { reinforcement }\end{array}$ \\
\hline
\end{tabular}

Table 3.1: Specimen Configurations for Batches 1, 2, and 3 (Chen et al., 1994) 


\begin{tabular}{|c|c|c|c|c|}
\hline Specimen & Specimen Type & $\begin{array}{c}\text { Specimen } \\
\text { Dimensions }\end{array}$ & $\begin{array}{c}\text { Dimensions of Crack } \\
\text { and/or Defect in the } \\
\text { Specimen }\end{array}$ & Position \\
\hline B41 & Plain Concrete & $24^{\prime \prime} \times 24^{\prime \prime} \times 12^{\prime \prime}$ & -- & -- \\
\hline B42 & Plain Concrete & $24^{\prime \prime} \times 24^{\prime \prime} \times 10^{\prime \prime}$ & -- & -- \\
\hline B43 & Plain Water Crack & $24^{\prime \prime} \times 24^{\prime \prime} \times 10^{\prime \prime}$ & $7^{\prime \prime} \times 7^{\prime \prime} \times 0.2^{\prime \prime}$ & $5^{\prime \prime}$ from top \\
\hline B44 & $8 \%$ Saline Water Crack & $24^{\prime \prime} \times 24^{\prime \prime} \times 10^{\prime \prime}$ & $7^{\prime \prime} \times 7^{\prime \prime} \times 0.2^{\prime \prime}$ & $5^{\prime \prime}$ from top \\
\hline B45 & Air Crack & $24^{\prime \prime} \times 24^{\prime \prime} \times 10^{\prime \prime}$ & $24^{\prime \prime} \times 6^{\prime \prime} \times 0.12^{\prime \prime}$ & $5^{\prime \prime}$ from top \\
\hline \hline B51 & $\begin{array}{c}\text { Plexiglass and } \\
\text { Plain Water Crack }\end{array}$ & $24^{\prime \prime} \times 24^{\prime \prime} \times 12^{\prime \prime}$ & $7^{\prime \prime} \times 7^{\prime \prime} \times 0.2^{\prime \prime}$ & $5^{\prime \prime}$ from top \\
\cline { 3 - 5 } & & $7^{\prime \prime} \times 7^{\prime \prime} \times 0.2^{\prime \prime}$ & $10^{\prime \prime}$ from top \\
\hline B52 & Plain Concrete & $24^{\prime \prime} \times 24^{\prime \prime} \times 10^{\prime \prime}$ & -- & - \\
\hline B53 & Plain Water Crack & $24^{\prime \prime} \times 24^{\prime \prime} \times 10^{\prime \prime}$ & $7^{\prime \prime} \times 7^{\prime \prime} \times 0.2^{\prime \prime}$ & $5^{\prime \prime}$ from top \\
\hline B54 & $8 \%$ Saline Water Crack & $24^{\prime \prime} \times 24^{\prime \prime} \times 10^{\prime \prime}$ & $7^{\prime \prime} \times 7^{\prime \prime} \times 0.2^{\prime \prime}$ & $5^{\prime \prime}$ from top \\
\hline B55 & Air Crack (Plexiglass) & $24^{\prime \prime} \times 24^{\prime \prime} \times 10^{\prime \prime}$ & $10^{\prime \prime} \times 7^{\prime \prime} \times 0.2^{\prime \prime}$ & $5^{\prime \prime}$ from top \\
\hline \hline
\end{tabular}

Table 3.2: Specimen Configurations for Batches 4 and 5 (Halabe et al., 1996)

\begin{tabular}{|c|c|c|c|}
\hline Chain & Length $(\mathbf{m m})$ & Link size $(\mathbf{m m})$ & Diameter $(\mathbf{m m})$ \\
\hline 1 & 736.6 & 12.7 & 3.2 \\
\hline 2 & 622.3 & 25.4 & 6.4 \\
\hline 3 & 647.7 & 28.6 & 6.4 \\
\hline Common & 457.2 & 25.4 & 6.4 \\
\hline
\end{tabular}

Table 3.3: Size of Chains Used in Laboratory Testing vs. Size of Common Chain 


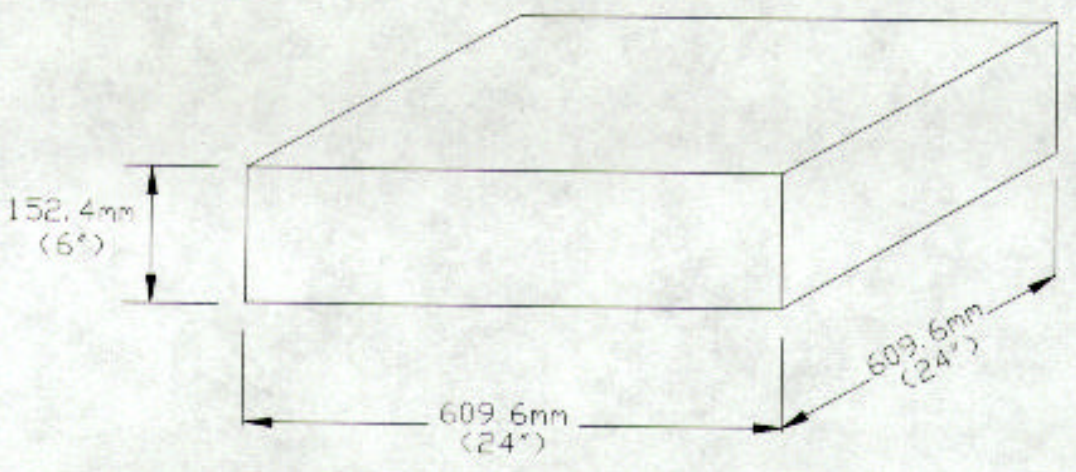

Flan Specmen

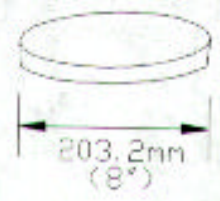

Cordooard

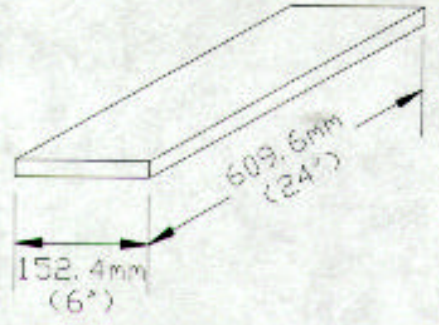

Air Crack

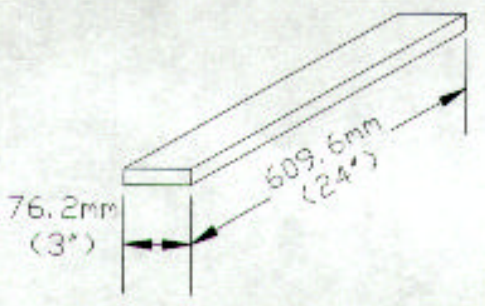

Steel Plate

Embedied Crack Shope and Sizes

(Thickness $=0.76 \mathrm{~mm}$ )

Figure 3.1: Detals of Specimens in Batch 1 (Chen et al, 1994) 


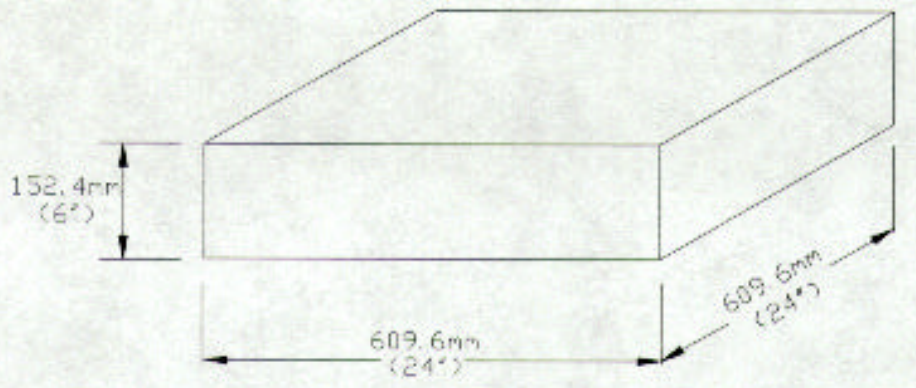

Floin Specimen
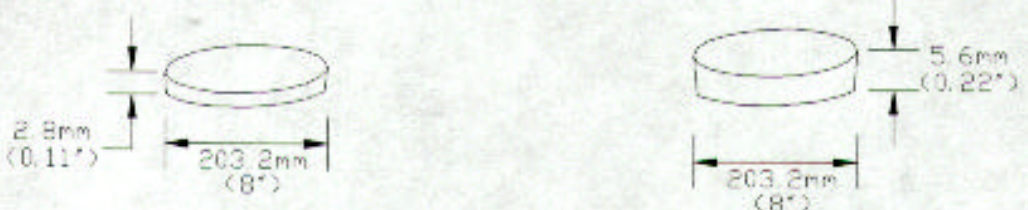

Erkedsed Lrack Shape and Sizes

$$
\text { (Pexglass) }
$$

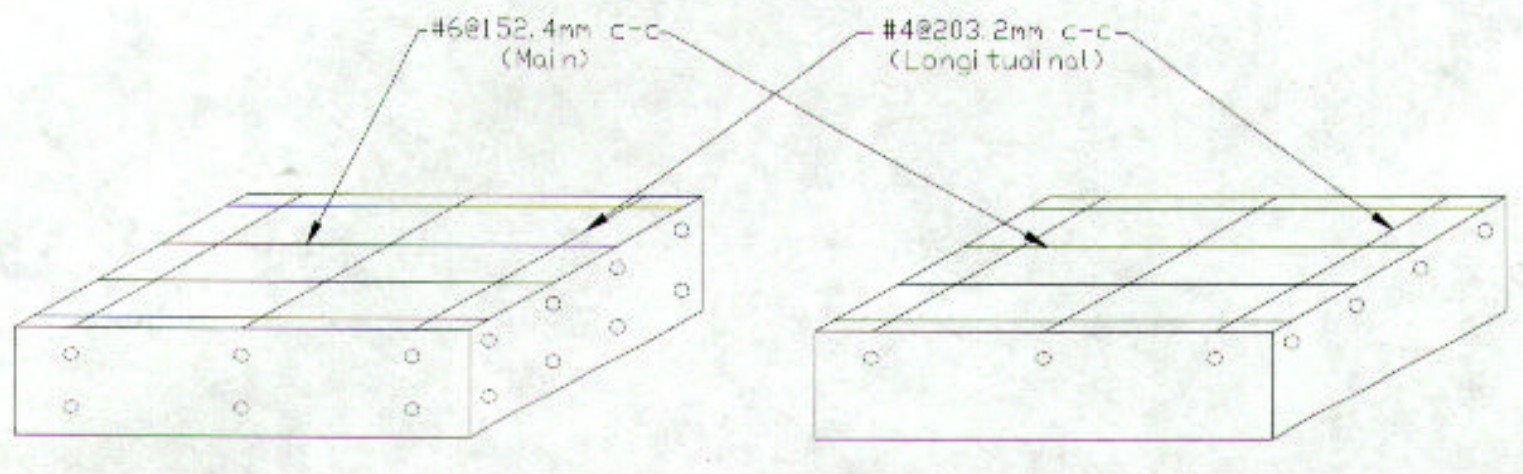

$\begin{array}{ll}\text { Clear cover of long tudinal rekars } & 57.2 \mathrm{~mm} \text { top, } 44.5 \mathrm{~mm} \text { bottom } \\ \text { Cean cover of main rebarsi } & 381 \mathrm{~mm} \text { top, } 25.4 \mathrm{~mm} \text { bottom }\end{array}$

Figure 3 2: Details of Specmens in Batch? (Chen et al., 1994) 


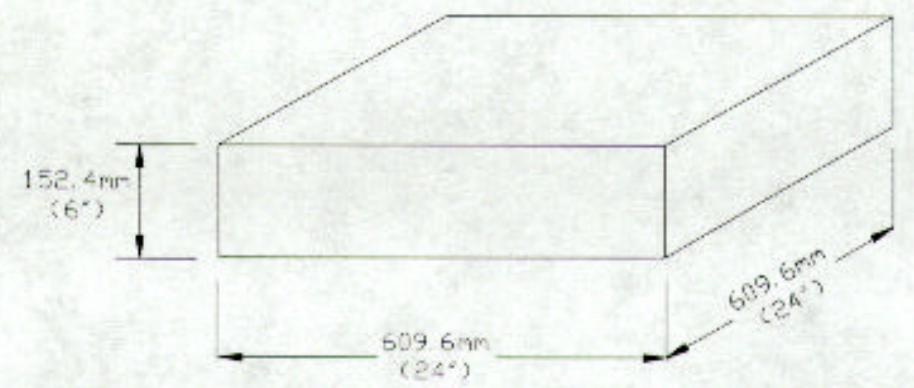

Specimen Shape and Sizes

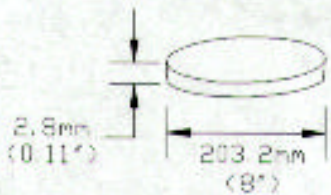

Plexiglass

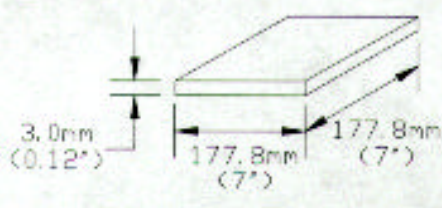

P.ain-water crack

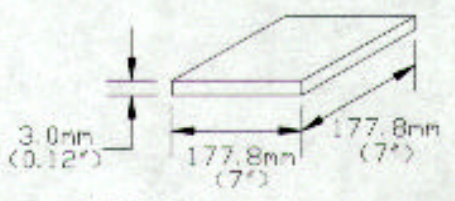

8\% Soline-woter srack

Crack Shapes ano Sizes

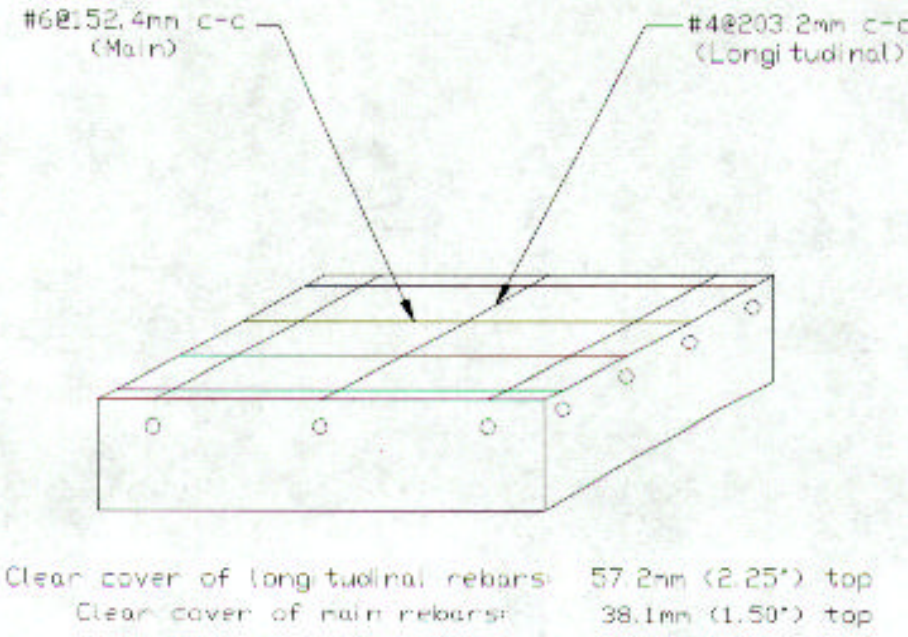

Figure 3, 3: Details of Specimens in Batch 3 (Chen et a., 1994) 

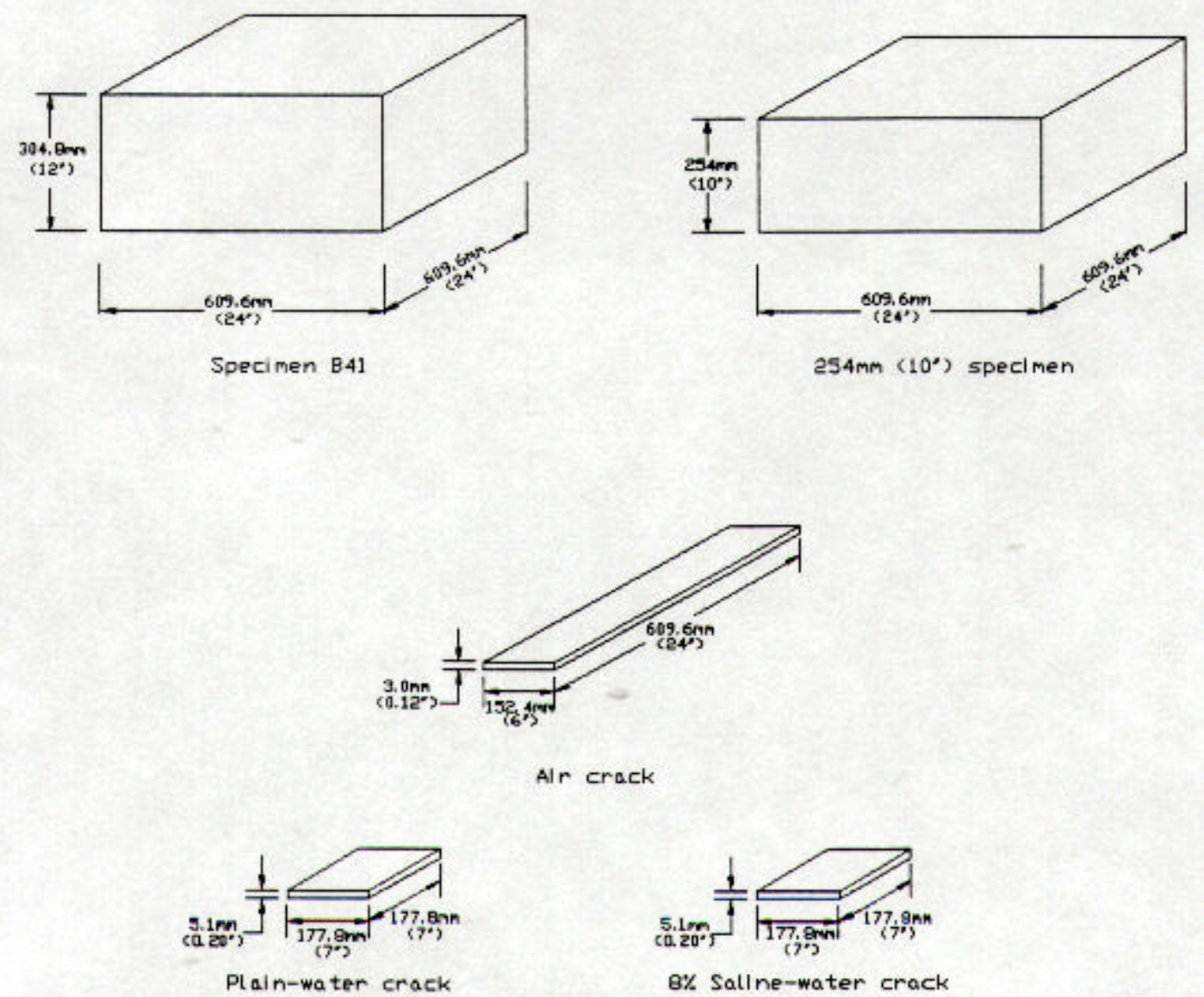

Crack Shapes and SIzes

Figure 3.4: Details of Specimens in Batch 4 (Halabe et al., 1996) 


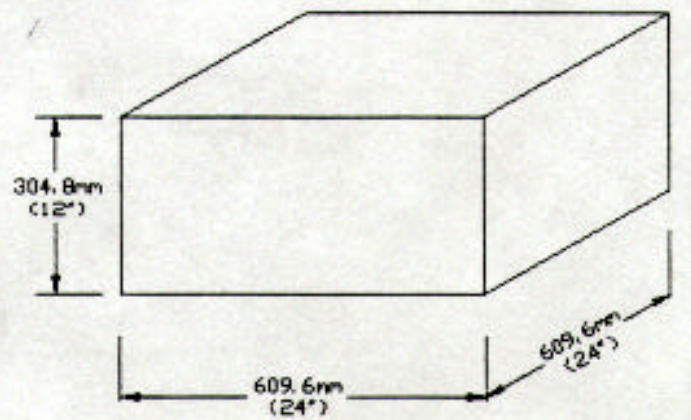

Specimen B5:

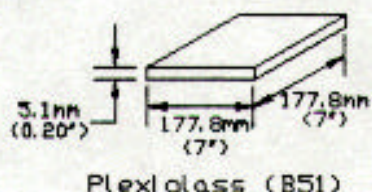

Plexlglass (B51)

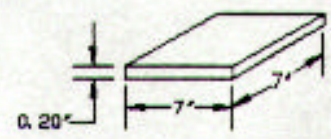

Plain-water crack

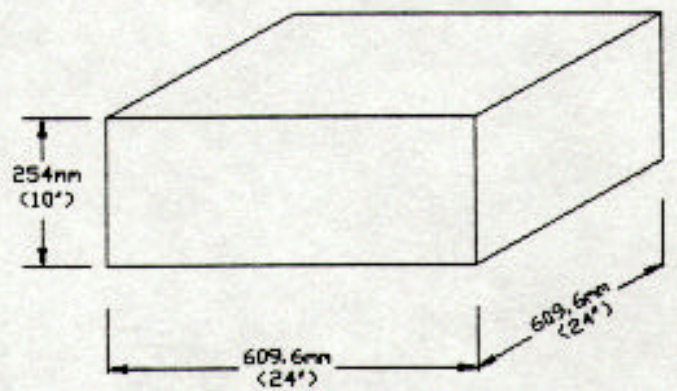

$254 \mathrm{~mm}\left(10^{\circ}\right)$ specimen

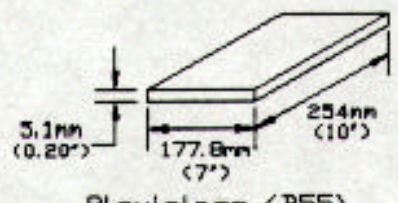

Plexiglass (B55)

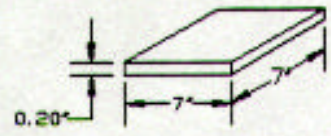

8\% Sallne-water crack

Crack Shapes and Sizes

Figure 3.5: Details of Specimens in Batch 5 (Halabe et al., 1996) 


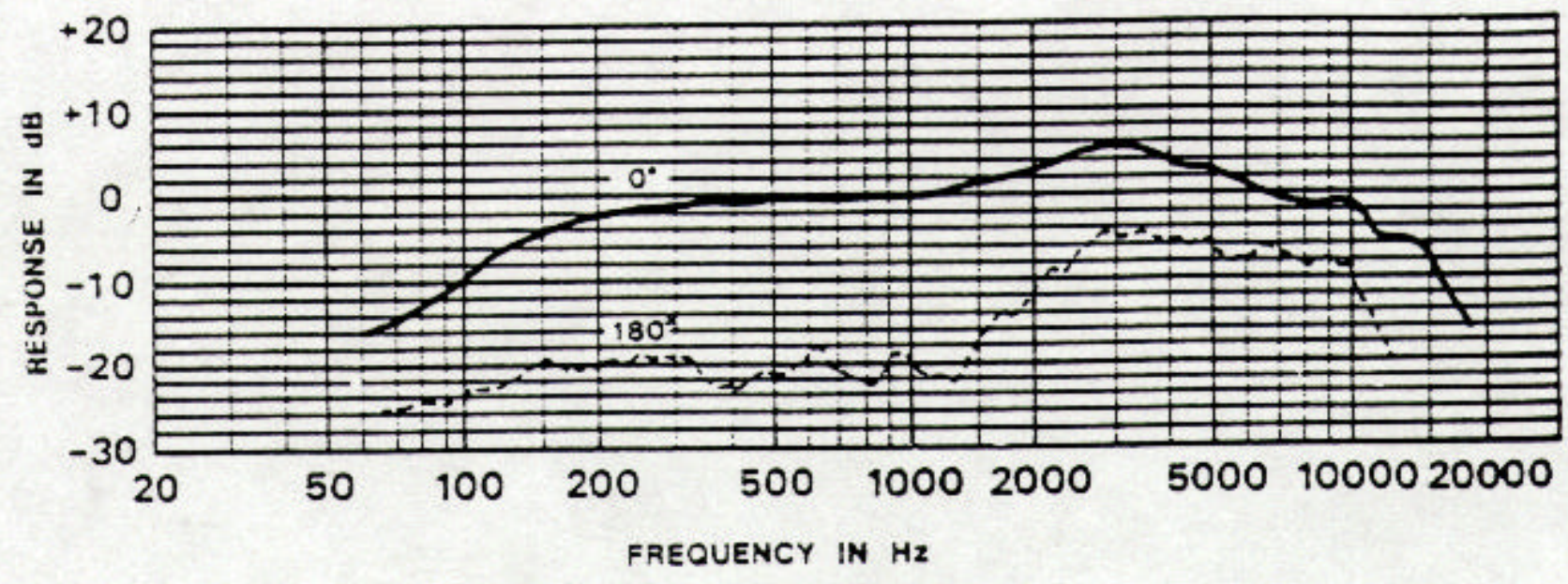

Figure 3.6: Frequency Response Curve for Microphone Used in Testing
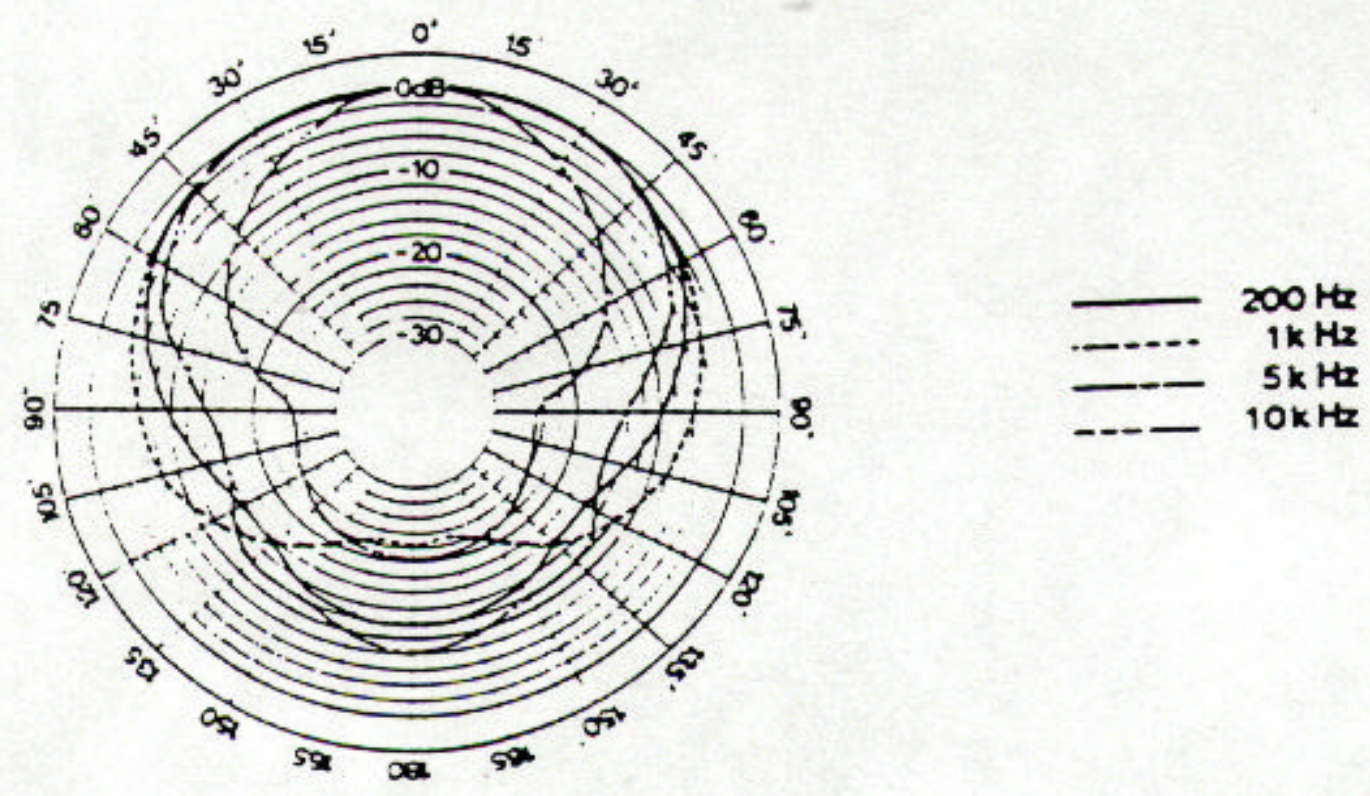

Figure 3.7: Pick-Up Pattern for Microphone Used in Testing 


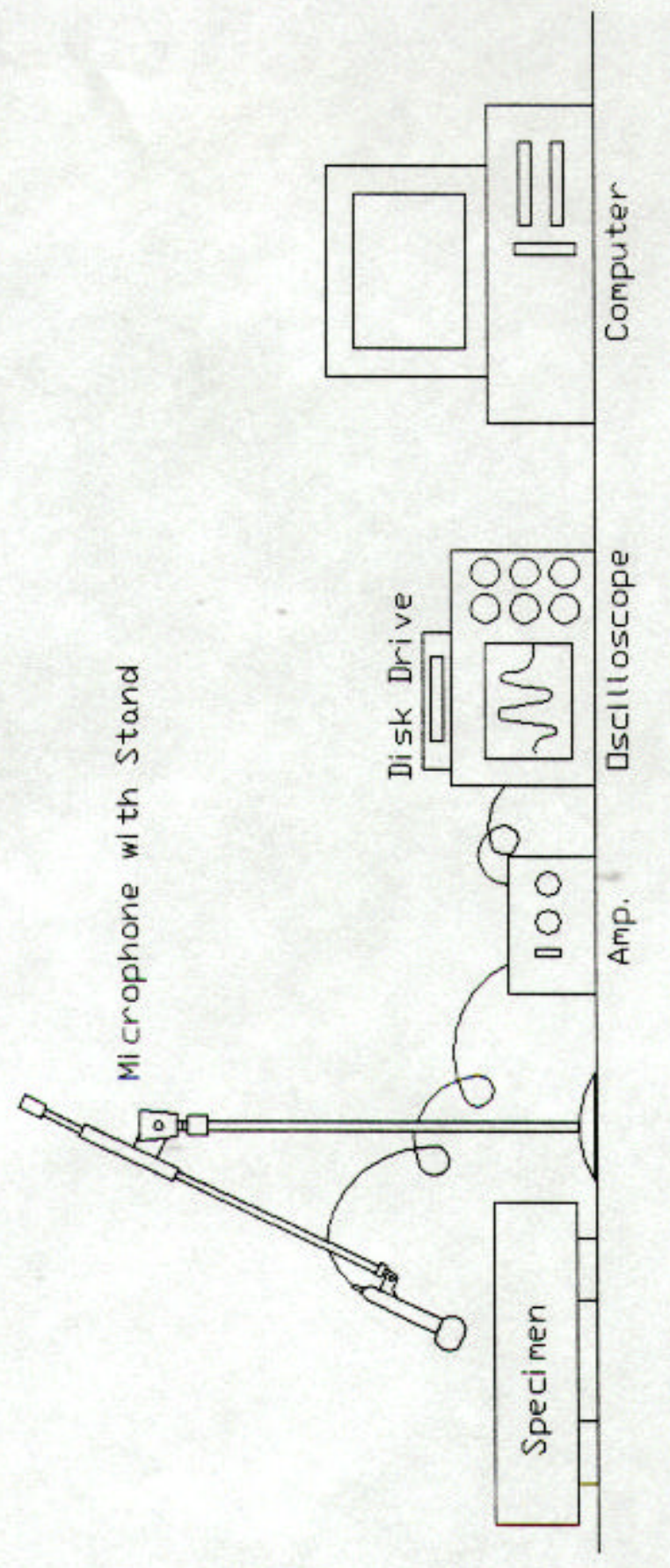

$\stackrel{0}{7}$
+
0
$\sim$

in

0

\begin{tabular}{l}
7 \\
1 \\
+ \\
0 \\
1 \\
0 \\
0 \\
0 \\
\hline
\end{tabular}

$\stackrel{4}{0}$

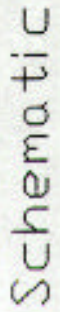

$\ddot{\infty}$

लं

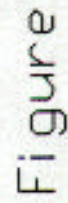



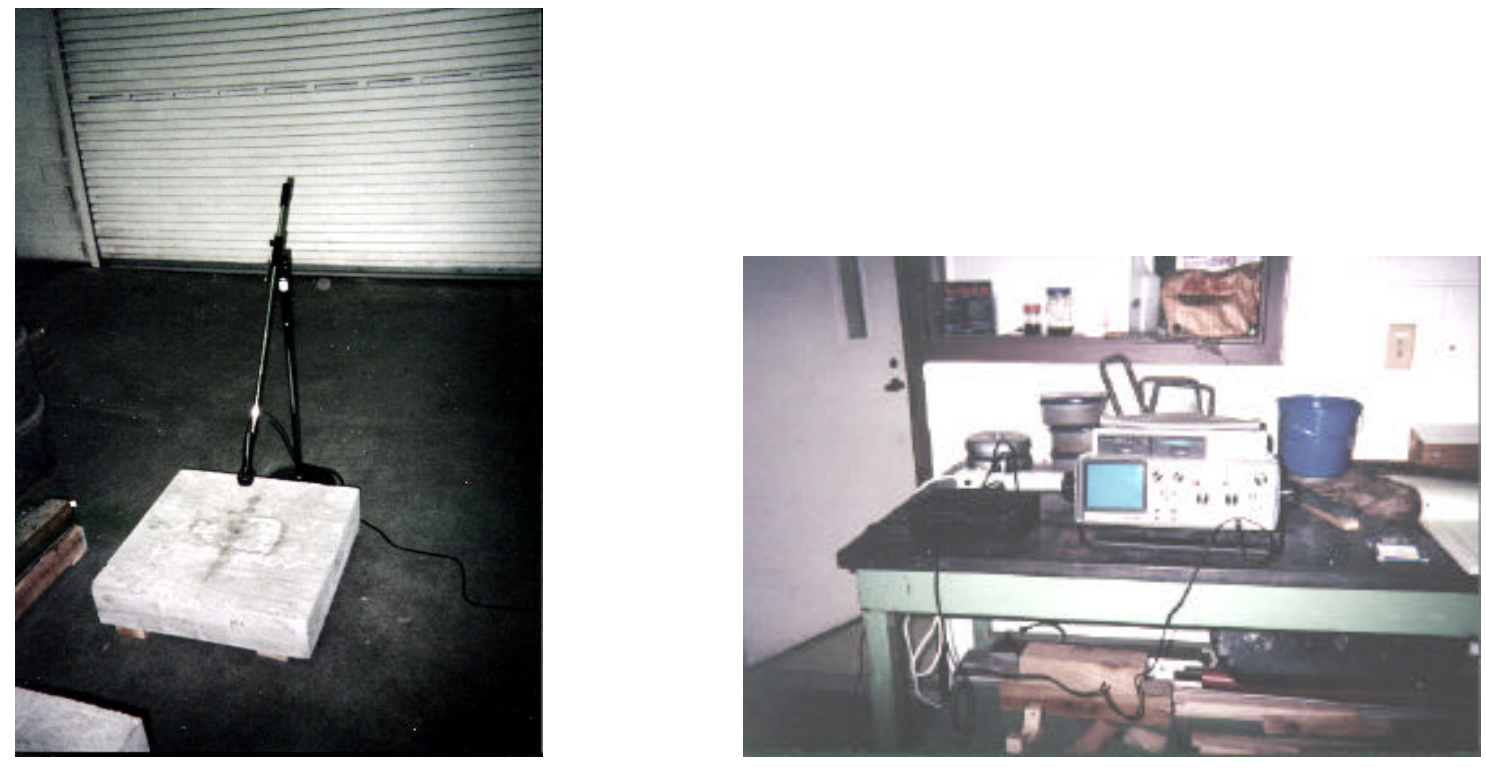

Figure 3.9: Experiment Set-Up with Microphone, Microphone Stand, Oscilloscope, Amplifier, and Specimen

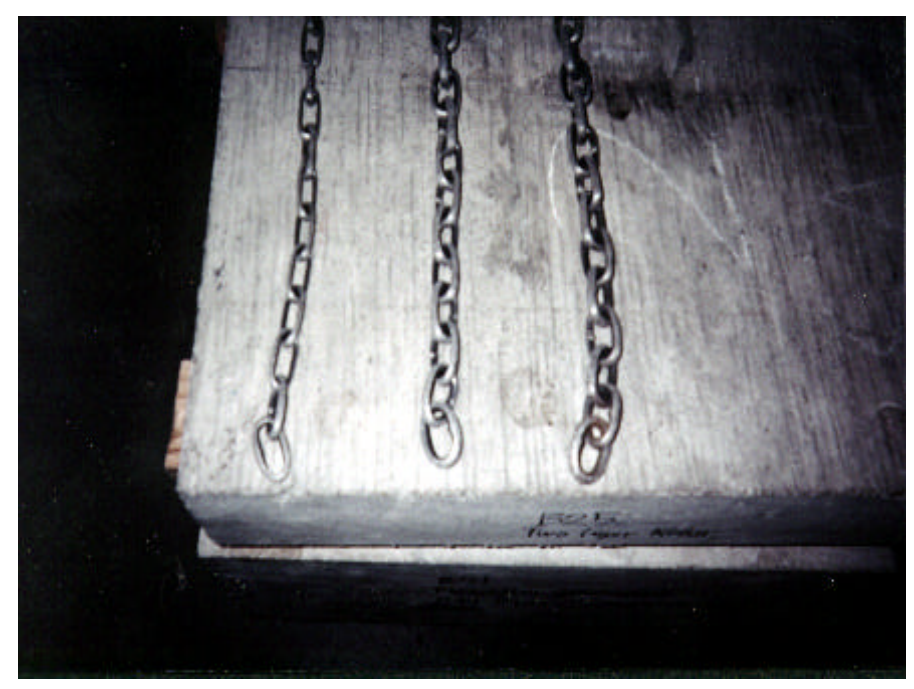

Figure 3.10: Chains 1, 2, and 3 Used in Testing (Left to Right) 


\section{CHAPTER 4}

\section{RESULTS OF THE LABORATORY EXPERIMENTS USING CHAIN DRAG}

\subsection{Introduction}

Now that the laboratory testing has been discussed in a preliminary sense, it is time to discuss the results of the experiment. But before that takes place, it is important to mention a few items first.

The signals that were captured on the oscilloscope during the simulated chain drag testing in the lab were shown with time as the independent variable (see Figure 4.2 for an example graph). In order to better interpret the signals, a transformation of that graph into the frequency domain needed to be performed. Possible methods of transformation include the Discrete Fourier Transform (DFT), the Fast Fourier Transform (FFT), and the Power Spectral Density (PSD).

The PSD was chosen as the method of transformation because it reduces the overall relative contribution of unwanted noise in comparison to the wanted signal from the chain dragging against the concrete. This is because the PSD basically magnifies the signal in the frequency domain by the power of two. The component of the overall signal comprised of noise is already small when compared to the wanted signal (see Figure 4.2). When both components are squared the noise element becomes even less of a factor. Although the contribution of noise may be small, it must be noted that the appearance of noise in the PSD figures is unavoidable due to the fact that the noise is consistent throughout the time history of the original voltage versus time signal. See Figure 4.3 for an example of a PSD graph. 
In addition to the transformation of the independent variable in the time versus voltage graph obtained from the oscilloscope, the dependent variable also needed a minor modification. This is because the testing was performed by a human being and not a machine. For instance, a machine can produce consistent input signals, whereas a person cannot. It is impossible to drag the chain in the same fashion for all specimens. If no modification is made, then there is no basis for a comparison. To alleviate this situation, the amplitudes were normalized with respect to the peak amplitude. After the normalization process was completed, the five highest peaks were chosen to make another plot of frequency versus normalized amplitude. This plot was then compared and contrasted from specimen to specimen, chain to chain, in the form of a scatter plot.

\subsection{Noise}

It will become apparent that all specimens yielded high amplitudes at frequencies of $42.75 \mathrm{~Hz}$ and $58 \mathrm{~Hz}$. These two frequencies signify unwanted noise signals. The noise at $58 \mathrm{~Hz}$ most likely is due to the $60 \mathrm{~Hz} \mathrm{AC}$ current that is present in the electrical system of the laboratory. Thus, the $58 \mathrm{~Hz}$ is due to electrical noise.

The $42.75 \mathrm{~Hz}$ could have resulted from a number of noise sources. One type of noise source could have been triboelectric currents, which results from friction between a conductor and an insulator inside of wires. Humidity and salts from human touch on the electrical equipment also may have caused the unwanted noise. Another source of noise could have been an unknown electromagnetic field in the laboratory testing area.

Figure 4.2 showed an example of a time history of a chain dragging against a concrete block. It is simple to notice the noise in this figure: it lies between the high 
amplitude components. Of course the noise is present throughout the figure; however, it is easily distinguishable between the high amplitude areas since there is no interference from the true signal. In order to see the frequency associated with the noise, it is necessary to extract a portion of the time history that is comprised solely of noise, and then to apply a PSD to it. The PSD of the extracted noise component of Figure 4.2 can be seen in Figure 4.4. That figure clearly shows that the frequency associated with the noise is predominantly at $42.75 \mathrm{~Hz}$ and $58 \mathrm{~Hz}$.

\subsection{Results}

Sufficient information has now been given for the discussion of the results of the laboratory experiments. All high amplitude frequency components outside of the range of 42-45 Hz and 58-60 Hz tell a story of the individual specimen and/or chain.

\subsubsection{Batch 1}

All of the concrete blocks in Batch 1 were $152.4 \mathrm{~mm}$ (6") in depth. The first specimen was plain concrete without any cracks or reinforcing bars (B12). Chains 1 and 3 yielded no significant frequencies outside of the noise range of $42-45 \mathrm{~Hz}$ and $58-60 \mathrm{~Hz}$, as evidenced by Figure 4.5. Chain 2 was similar to the other chains; however, it also produced a high amplitude frequency at $76 \mathrm{~Hz}$. The second specimen in the batch (B13) was composed of a $0.76 \mathrm{~mm}(0.03$ ") thick piece of cardboard, located at mid-depth, with a 152.4mm (6") diameter. The cardboard was used to simulate an air crack. In addition to the trivial noise frequencies, Chains 2 and 3 yielded frequencies between 25 and $28 \mathrm{~Hz}$. The most likely reason for the absence of this low frequency from the first chain is the fact 
that Chain 1 is much lighter in comparison to the other two chains. Heavier chains produce a more definitive sound when dragged along concrete. The plot associated with this specimen can be seen in Figure 4.6.

Specimen B14 also had an embedded air crack, however the size of the crack within this block was of a different size. The crack was $0.76 \mathrm{~mm}(0.03$ ") thick, located at mid-depth, but it ran throughout the length of the specimen. All three chains produced high amplitude frequencies within the range of 52 to $56 \mathrm{~Hz}$, as seen in Figure 4.7. It is clear from specimens B13 and B14 that the shape and size of the anomaly does matter in this experiment, because both blocks have simulated air cracks that are of different dimensions and yield different results.

The last specimen in this batch (B15) was composed of a steel plate with the same location and dimensions as the air crack of B14. Figure 4.8 clearly indicates the high amplitude frequencies produced by all three chains lie within the range of 62 to $72 \mathrm{~Hz}$. From specimens B14 and B15, it is apparent that an embedded characteristic with the same size and shape, but with different densities, will produce different frequencies. The more dense the anomaly, the higher the frequency. This is true because it is more difficult for the compression waves to travel within the body of the block through a more dense object, thus it returns to the surface at a much higher rate.

Figure 4.9 shows a comparison of all four specimens in Batch 1 when tested with Chain 1. This plot shows clearly that the air crack of B14 lies within the frequency range of 52 to $56 \mathrm{~Hz}$ and the steel plate of B15 yields a high amplitude frequency around $67 \mathrm{~Hz}$. All other specimens when tested with Chain 1 do not produce any frequencies outside of the trivial noise range due to the lightness of the chain. Figures 4.10 and 4.11 show a 
comparison of Batch 1 with Chains 2 and 3, respectively. It is clear from these two graphs that the heaviness of the latter two chains bring out more frequency characteristics from the concrete blocks.

\subsubsection{Batch 2}

The specimens that were cast in Batch 2 were all of the same dimension and were 152.4mm (6") in depth. The first specimen (B21) was a plain concrete specimen, much like B12 of Batch 1. However, unlike B12, B21 yielded high amplitude frequencies within the frequency range of 50 to $53 \mathrm{~Hz}$ (Figure 4.12). The reason for this difference, as pointed out by Bhandarkar in an earlier thesis dealing with the casting of the concrete in this project, is most likely the higher water content of the second batch in comparison to the first batch.

The second and third specimens in this batch were both comprised of air cracks simulated by pieces of plexiglass. The difference between the two blocks was the thickness of the plexiglass. The simulated air cracks of B22 and B23 were $2.8 \mathrm{~mm}(0.11$ ”) and 5.6mm (0.22") thick, respectively. They were both $203.2 \mathrm{~mm}\left(8^{\prime \prime}\right)$ in diameter and located in the middle of each specimen. All three chains yielded frequencies within the range of 50 to $53 \mathrm{~Hz}$ for B22. However, the thicker plexiglass of specimen B23 yielded high amplitudes within the frequency range of 65 to $70 \mathrm{~Hz}$. Again, size plays an important role in this experiment. The last two specimens in this batch consisted of concrete blocks embedded with one and two layers of steel reinforcing bars (B24 and B25). B24 showed no significant frequencies outside of the trivial noise range. However, B25 produced high amplitude frequencies within the range of 67 to $69 \mathrm{~Hz}$ and 75 to $78 \mathrm{~Hz}$. 


\section{$\underline{4.3 .3 \text { Batch } 3}$}

The four specimens of Batch 3 were also $152.4 \mathrm{~mm}$ (6") in depth and the plots associated with these blocks can be seen in all Figures 4.20 through 4.26. B31 consisted of a $177.8 \mathrm{~mm} \times 177.8 \mathrm{~mm} \times 3.0 \mathrm{~mm}$ (7”x7”x0.12") crack fully saturated with tap-water. The high amplitude frequencies associated with this specimen all lied within 65 and $68 \mathrm{~Hz}$ and were only apparent when tested with the heavier Chains 2 and 3. Chain 1 only produced strong signals within the range of noise.

The second specimen in this batch (B33) consisted of one layer of steel reinforcement much like the specimen B24. The frequencies associated with both similar specimens yielded exactly the same results: nothing outside of the trivial noise range.

B34 had one layer of steel reinforcement embedded also, but it included an air crack simulated by a $2.8 \mathrm{~mm}(0.11$ ") piece of plexiglass as well. For this specimen, Chains 2 and 3 produced strong signals within 67 to $70 \mathrm{~Hz}$. The lighter Chain 1 did not show any significant results.

B35 was similar to B34 with respect to the one layer of steel reinforcement, but instead of an air crack, this specimen had a $177.8 \mathrm{~mm}$ x 177.8mm x 3.0mm (7"x7"x0.12") crack fully saturated with salt-water. All three chains produced high amplitudes within the frequency range of 67 to $74 \mathrm{~Hz}$.

\subsubsection{Batch 4}

The specimens of Batch 4 were all 254mm (10") thick, except for B41 which was 304.8mm (12") in depth. The plots in this batch can be seen in Figures 4.27 through 4.34. 
The first two specimens (B41 and B42) were plain concrete blocks which differed only in their thickness. Chains 2 and 3 produced strong signals at frequencies which ranged between 110 and $120 \mathrm{~Hz}$. The reason for such a high amplitude is most likely due to the thickness of the block.

The strong signals from the $254 \mathrm{~mm}(10$ ") thick concrete specimen (B42) were within the frequency range of 50 to $53 \mathrm{~Hz}$. These frequencies are most likely due to the 254mm (10") thickness.

B43 was a concrete block with a $177.8 \mathrm{~mm}$ x $177.8 \mathrm{~mm}$ x $5.1 \mathrm{~mm}$ (7'x7'x0.2”) crack fully saturated with tap-water, located at mid-depth. Both Chains 1 and 2 produced no significant voltages outside of the trivial range; however, Chain 3 yielded strong signals at $50 \mathrm{~Hz}$ and between 85 and $88 \mathrm{~Hz}$.

The fourth specimen (B44) was similar in characteristic to B43 except that instead of tap-water, the crack in this block was fully saturated with salt-water. No conclusions were able to be drawn from this block because all strong signals lied within the frequency range of 42 to $45 \mathrm{~Hz}$ and 58 to $60 \mathrm{~Hz}$.

The $609.6 \mathrm{~mm} \times 152.4 \mathrm{~mm} \times$ 3.0mm (24"x6"x0.12”) air crack of specimen B45 was also located at mid-depth. This specimen yielded frequencies within 75 and $80 \mathrm{~Hz}$ when subjected to Chains 2 and 3, further validating the fact that the heavier chains produce more definitive sounds.

\section{$\underline{4.3 .5 \text { Batch } 5}$}

The specimens in Batch 5 were all 254mm (10") in thickness except for B51, which was $304.8 \mathrm{~mm}$ (12") thick. Figures 4.35 through 4.42 illustrate the results of this 
batch in graphical form.

The 304.8mm (12”) thick specimen (B51) contained an air crack simulated by $5.1 \mathrm{~mm}(0.2$ ") plexiglass and a plain water-filled crack. The plexiglass and the water-filled crack were located $127 \mathrm{~mm}-254 \mathrm{~mm}(5 "-10 ")$ from the top surface, respectively. Chains 2 and 3 produced high amplitude frequencies between 72 and $75 \mathrm{~Hz}$. Chain 1 showed no significant results.

The second specimen of Batch 5 (B52) was a plain concrete specimen $254 \mathrm{~mm}$ (10") thick, exactly like B42. However, the frequencies outside of the noise range for B52 lied between 67 and $70 \mathrm{~Hz}$, instead of 50 to $53 \mathrm{~Hz}$ as was the case with B42. The reason for the drastic change could be from the fact that the two specimens came from different batches which were cast at different times. The nonhomogeneous nature of concrete may have caused a large difference between the aggregate size and/or water content for the two specimens.

B53 and B54 were both water-filled cracks with the dimensions of $177.8 \mathrm{~mm} \mathrm{x}$ 177.8mm x 5.1mm (7"x7"x0.2") located at mid-depth. The only difference between the two blocks was the crack from B53 was saturated with tap-water, while the crack from B54 was filled with salt-water. B53 produced strong signals within 75 to $78 \mathrm{~Hz}$ and B54 produced high amplitudes between 70 to $74 \mathrm{~Hz}$. Therefore, both specimens yielded rather similar results.

The last specimen (B55) contained plexiglass with the dimensions of $254 \mathrm{~mm} x$ 177.8mm x 5.1mm (10"x7”x0.2") located at mid-depth. Significant voltages were produced at frequencies between 52 and $55 \mathrm{~Hz}$, similar to the previous specimens with simulated air cracks. 


\subsection{Discussion of Experiment}

A summary of the laboratory testing can be seen in tabular form in Table 4.1. From that table one can formulate some of the trends and discrepancies that were uncovered from the experiment. For example, specimens that had embedded rebars had high amplitude frequencies in the range of $60-80 \mathrm{~Hz}$. Also, many of the specimens with simulated air cracks contained frequencies in the range of $50-55 \mathrm{~Hz}$. In addition, the specimens with water-filled cracks displayed a frequency range of 60-80 Hz. Without fail, the unwanted noise signals from the specimens were found between 40-45 Hz and 55-60 $\mathrm{Hz}$.

Some of the discrepancies that were encountered in the testing can be best exemplified by some of the plain concrete specimens. For example, both blocks B12 and B21 were $152.4 \mathrm{~mm}(6 ")$ in thickness, yet their high amplitude frequencies were between $70-80 \mathrm{~Hz}$ and $50-55 \mathrm{~Hz}$, respectively. Also, the 254mm (10”) plain concrete specimens, B42 and B52, contained frequency components from $50-55 \mathrm{~Hz}$ and $60-70 \mathrm{~Hz}$, respectively. The differences can be attributed to the nonhomogeneous nature of concrete and the fact that specimens from different batches were cast and cured at different times, affecting the material properties of the concrete.

One of the conclusive statements that can be made from this experiment is that chain size does matter when performing a chain drag test on a concrete bridge deck. There were many instances throughout the testing where the heavier Chains 2 and 3 uncovered frequencies that the lighter Chain 1 could not produce. Because of the differences in size, shape, and location of the anomalies found within the body of the deck, it is difficult to interpret the exact meaning of all the frequencies encountered. 
In the future a broader frequency band should be utilized in conducting similar laboratory chain drag tests. The testing in this project studied frequencies within the range of $0-1000 \mathrm{~Hz}$. Perhaps including frequencies up to $2000-3000 \mathrm{~Hz}$ may uncover more characteristics of the concrete specimens.

The phenomena of the chain drag test is empirical; no equations are available to explain the testing. Chain dragging in the field could not be employed for finding specific characteristics under the surface of a bridge deck. The procedure is beneficial when the intention is to discover properties that are uncommon from concrete in good condition, such as when encountering delaminated concrete after dragging on sound concrete. However, the results from this study shows that chain dragging cannot uncover specific bridge deck characteristics such as concrete thickness and where delaminations and rebars exist. The laboratory experiment encompassed within this report is a small step in truly understanding the science of the chain drag test on concrete bridge deck surfaces. 


\begin{tabular}{|c|c|c|c|c|c|c|c|c|c|c|}
\hline 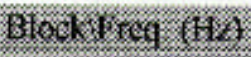 & $20-30$ & 30.18 & Noise & $15-26$ & $50-55$ & Notse & $60-70$ & 79.8 & $80-90$ & -90 \\
\hline 1812 & & & $x$ & & & $x$ & & $x$ & & \\
\hline $\mathrm{B}+3$ & $X$ & & $x$ & & & $x$ & & & & \\
\hline 1314 & & & $\mathrm{X}$ & & $x$ & $x$ & & & & \\
\hline B15 & & & x & & & $x$ & $\mathrm{X}$ & $x$ & & \\
\hline $\mathrm{B21}$ & & & $x$ & & $x$ & $x$ & & 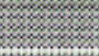 & & \\
\hline 1822 & & & X & & X & x & $2 x$ & 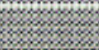 & & \\
\hline 1323 & & & $\mathrm{x}$ & & & x & $\mathrm{X}$ & & & \\
\hline 824 & & & $x$ & & & $x$ & & & & \\
\hline 1225 & & & $x$ & & & X & $\mathrm{x}$ & $x$ & & \\
\hline 831 & & & X & & & X & X & & & \\
\hline Bis & & & $\mathrm{X}$ & & & $x$ & & & & \\
\hline $\mathrm{Bat}$ & & & $x$ & & & x & $x$ & & & \\
\hline 835 & & & $x$ & & & x. & $x$ & x. & & \\
\hline 941 & & & X & & & $x$ & & & & t. \\
\hline 184 & & & $x$ & & $x$ & x & & & & \\
\hline 84s. & & & $\mathrm{x}$ & & & $x$ & & & $\mathrm{x}$ & \\
\hline $\mathrm{B} 4 \mathrm{H}$ & & & $\mathrm{X}$ & & & $x$ & & 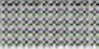 & & \\
\hline 845 & & & $\mathrm{X}$ & & & $x$ & & $x$ & & \\
\hline B51 & & & $x$ & & & $x$ & & $x$ & & \\
\hline $\mathrm{B} 52$ & & & $x$ & & & $x$ & $\mathrm{X}$ & & & \\
\hline B. 3 & & & $\mathrm{X}$ & & & $x$ & & $x$ & & \\
\hline B 4 : & & & $\mathrm{X}$ & & & $x$ & & $x$ & & \\
\hline BS5 & & & $\mathrm{X}$ & & $\mathrm{X}$ & 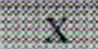 & & & & \\
\hline
\end{tabular}

Table 4.1: Specimens with Corresponding High Amplitude Frequency Ranges

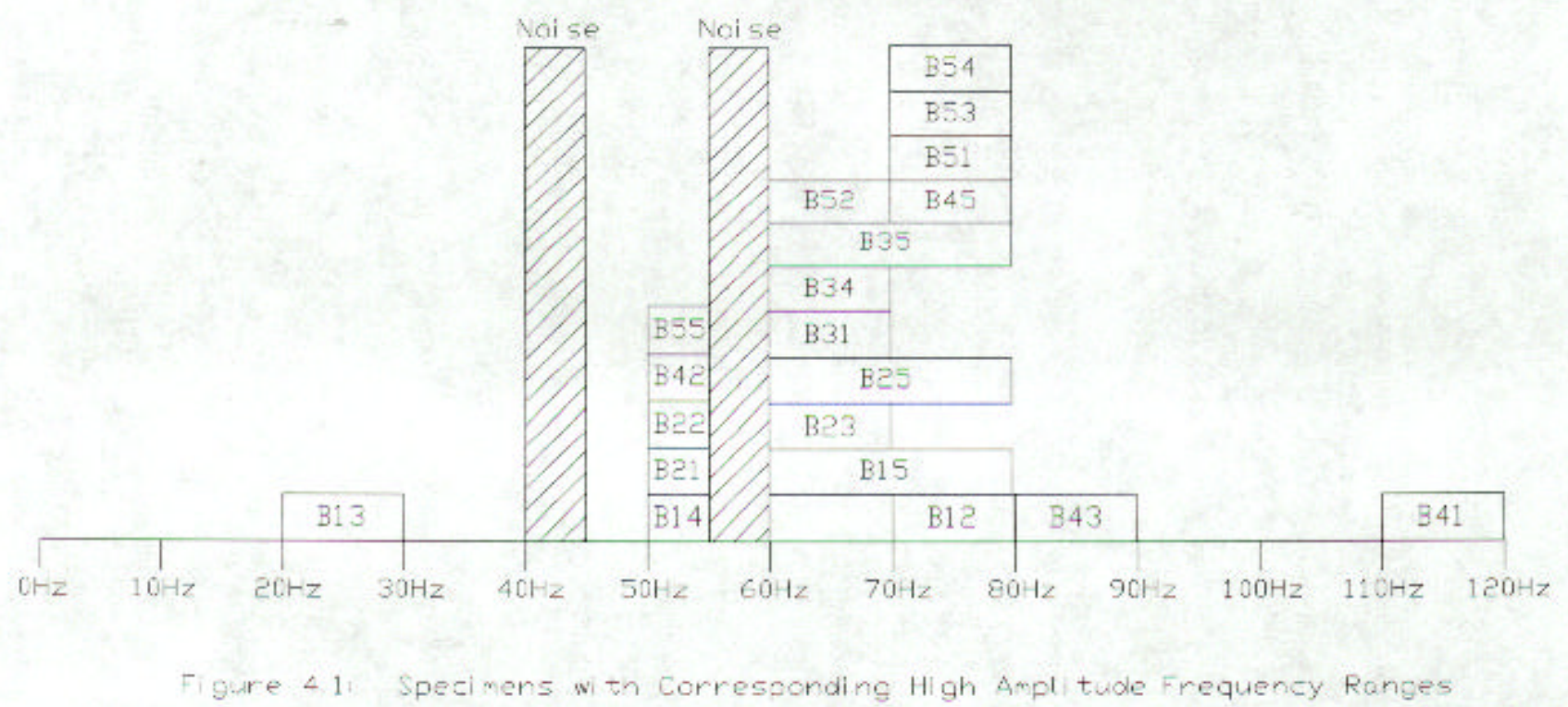




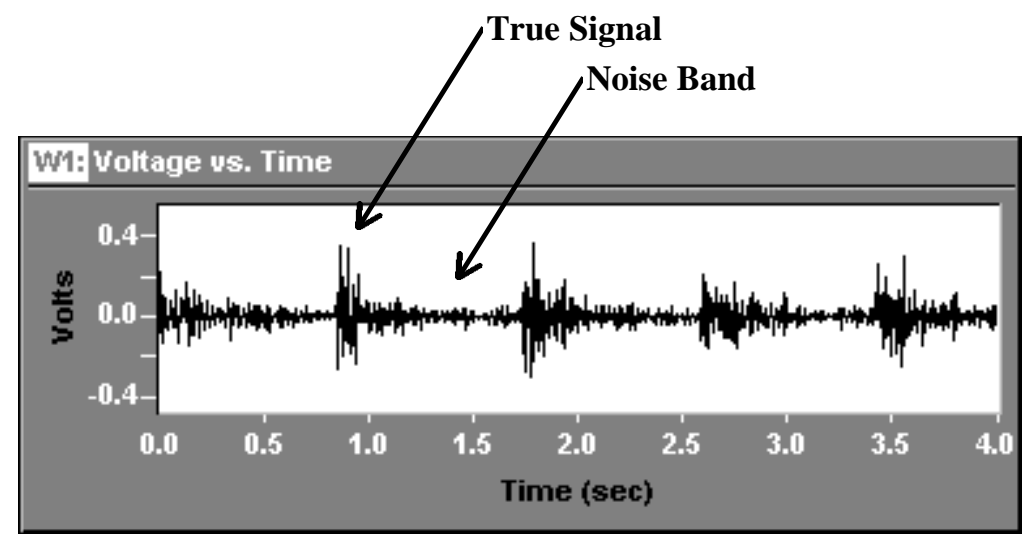

Figure 4.2: Sample Voltage vs. Time Graph from Oscilloscope

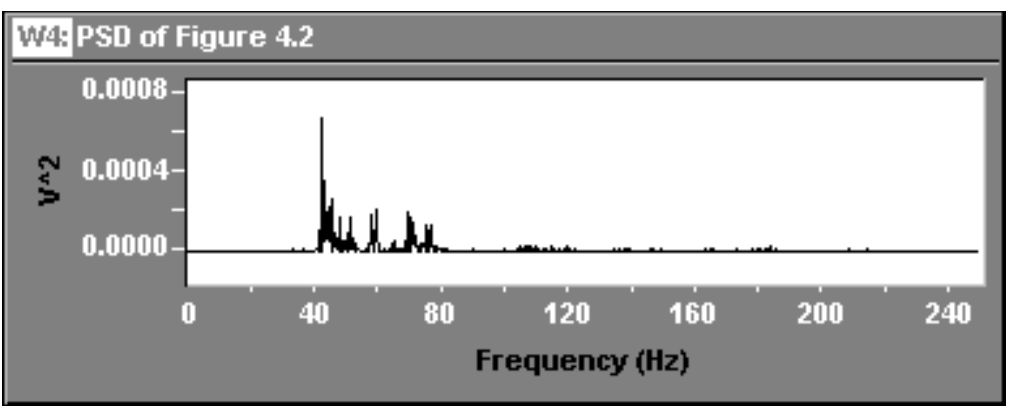

Figure 4.3: Sample Power Spectral Density (PSD) Graph

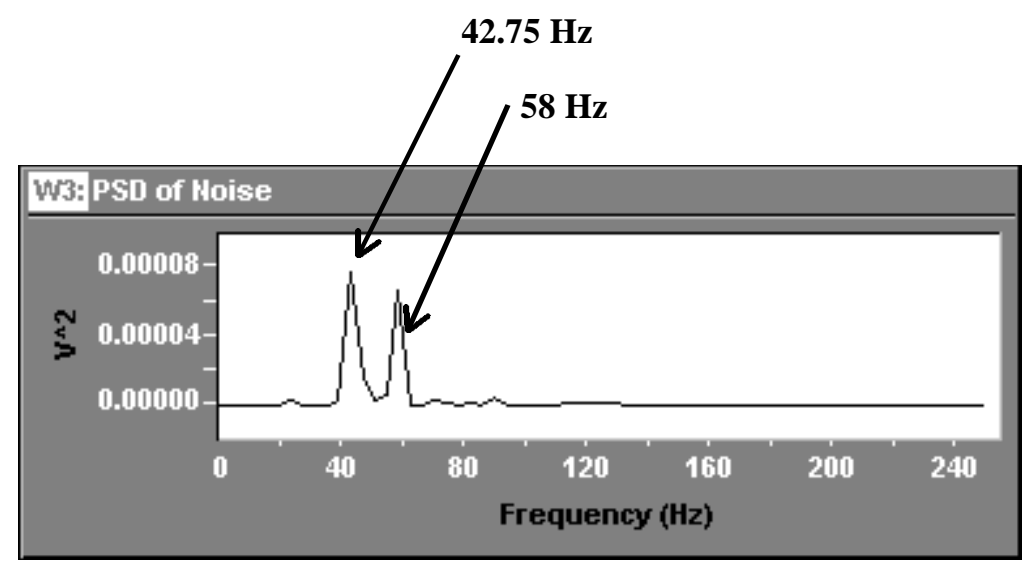

Figure 4.4: Extracted Noise PSD Graph 


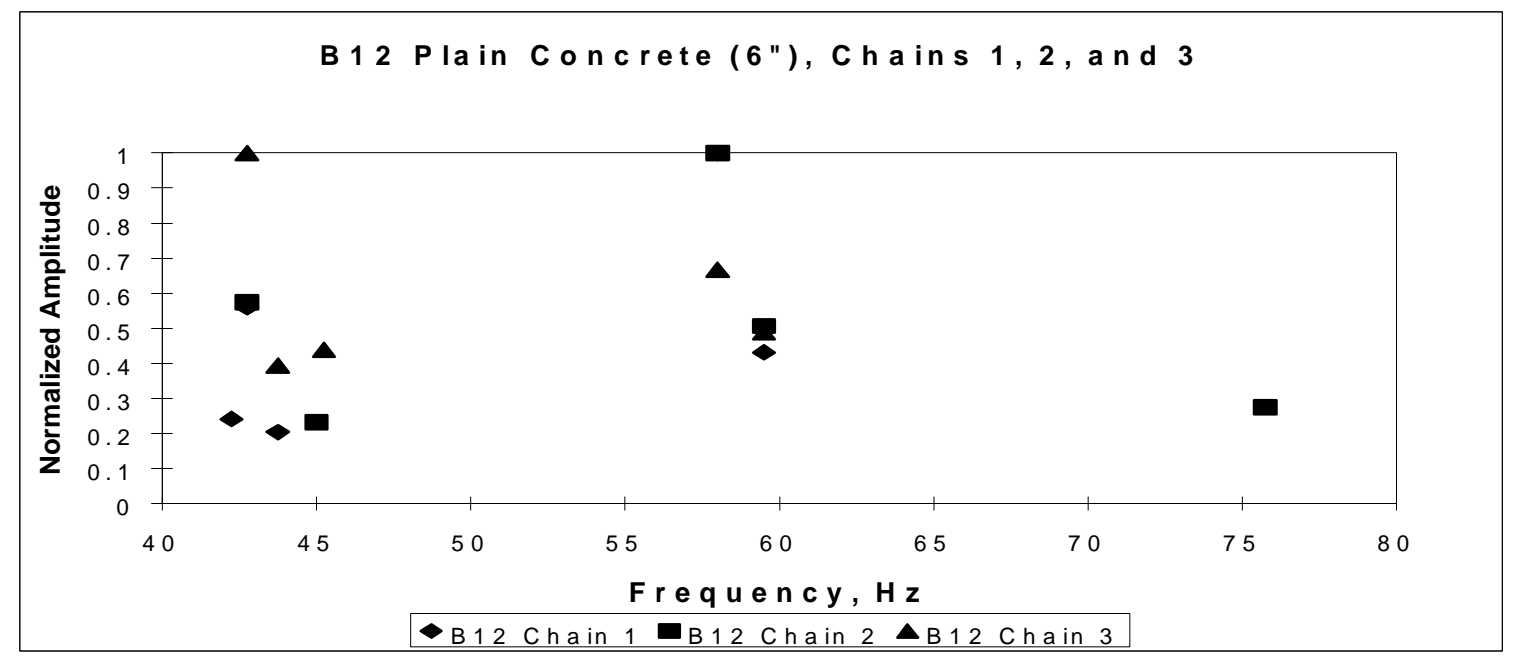

Figure 4.5: Specimen B12 with Chains 1, 2, and 3

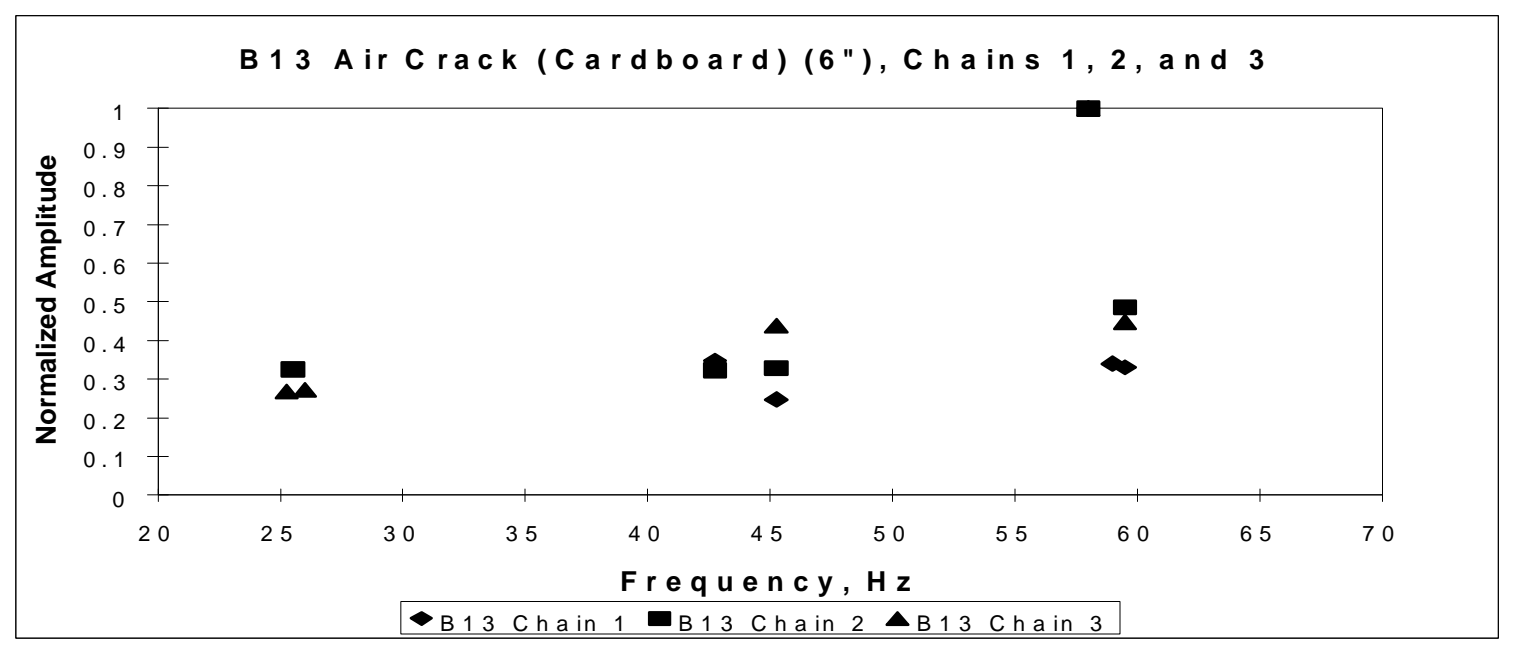

Figure 4.6: Specimen B13 with Chains 1, 2, and 3 


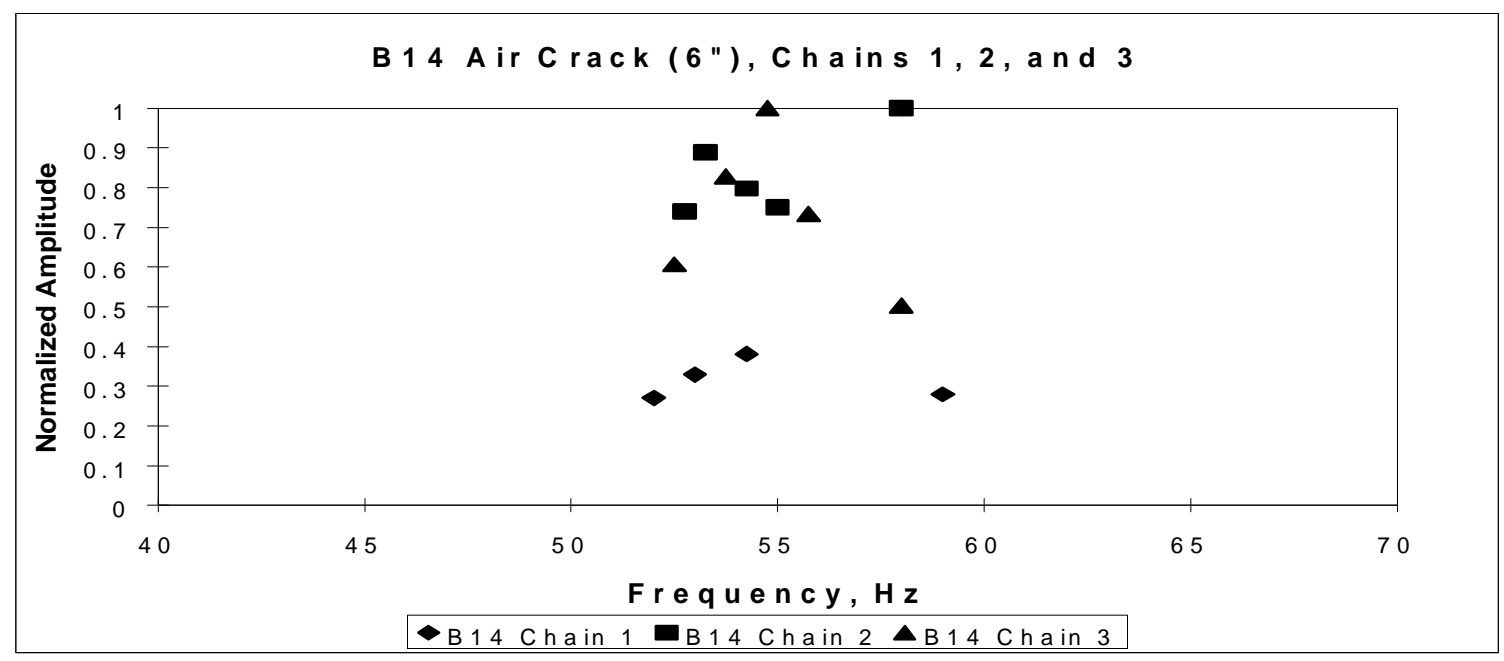

Figure 4.7: Specimen B14 with Chains 1, 2, and 3

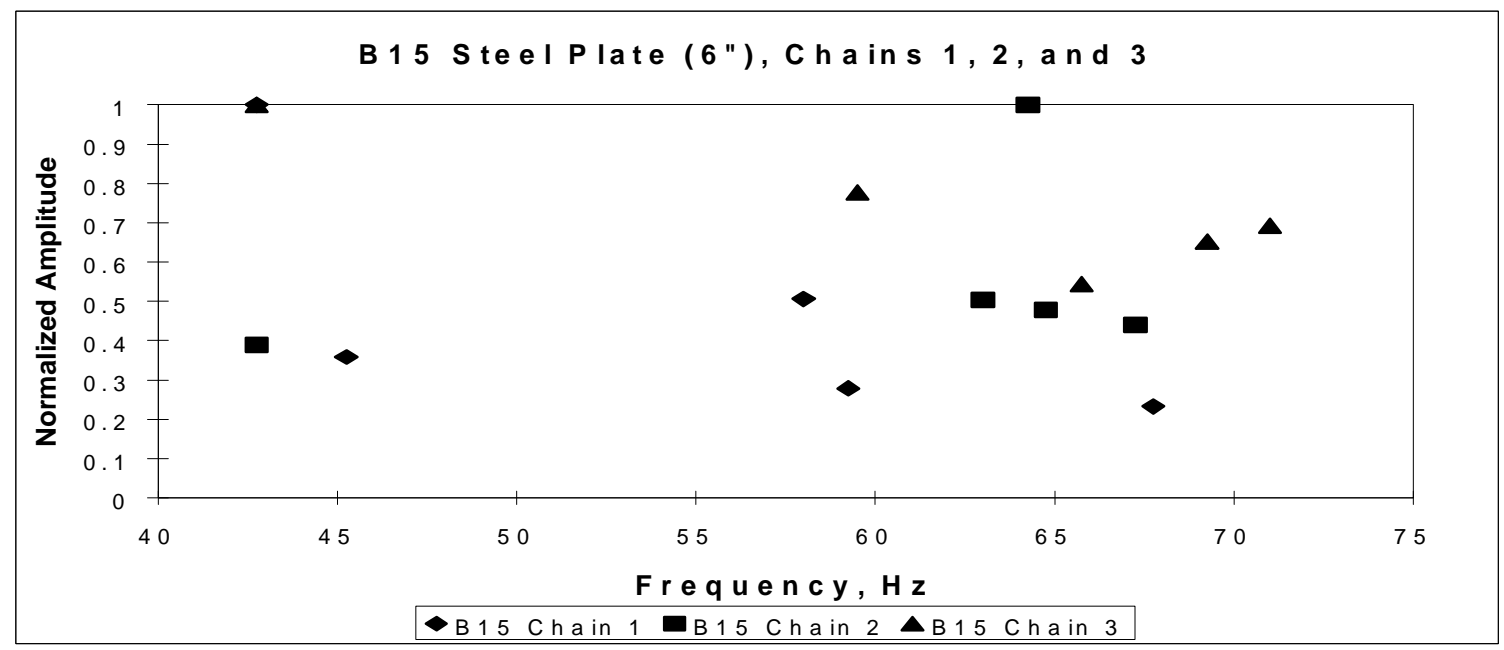

Figure 4.8: Specimen B15 with Chains 1, 2, and 3 


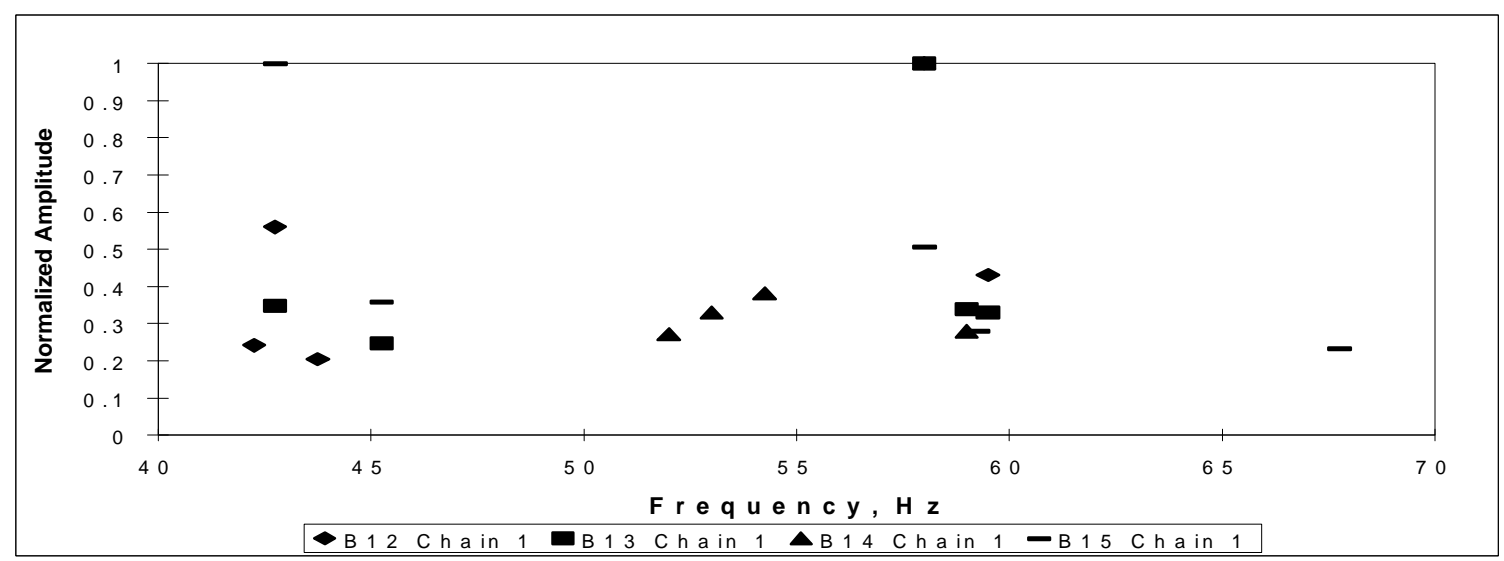

Figure 4.9: Comparison of Batch 1 with Chain 1

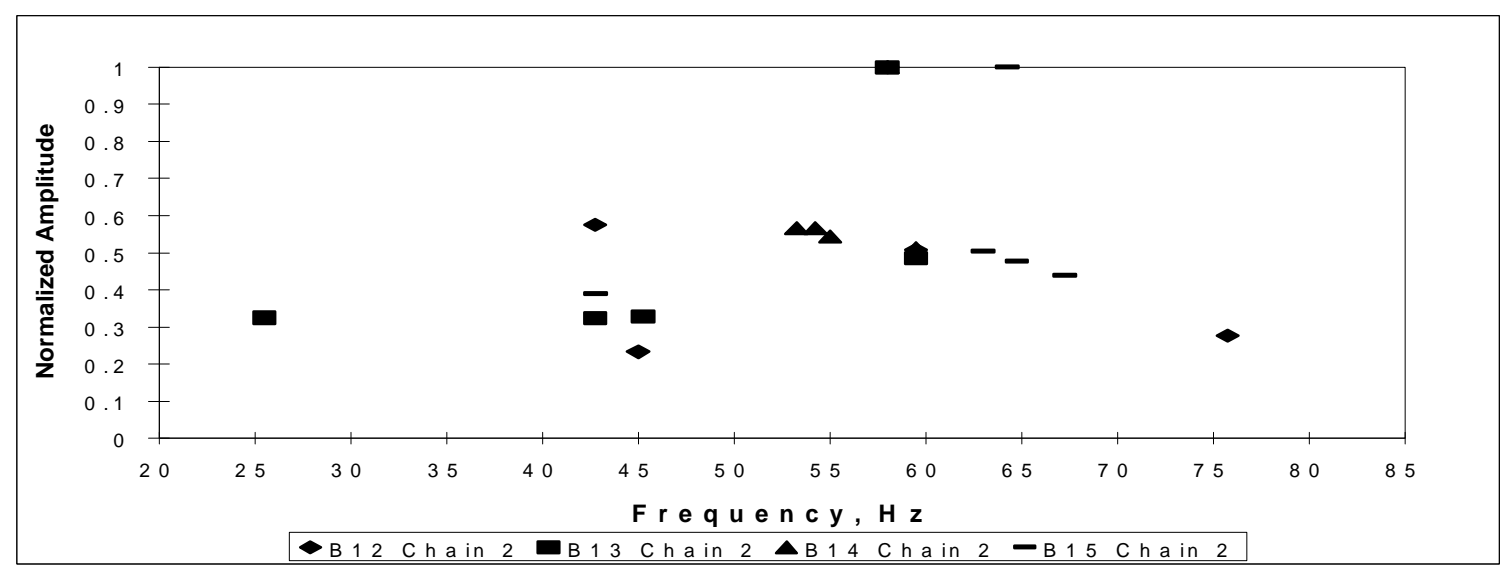

Figure 4.10: Comparison of Batch 1 with Chain 2

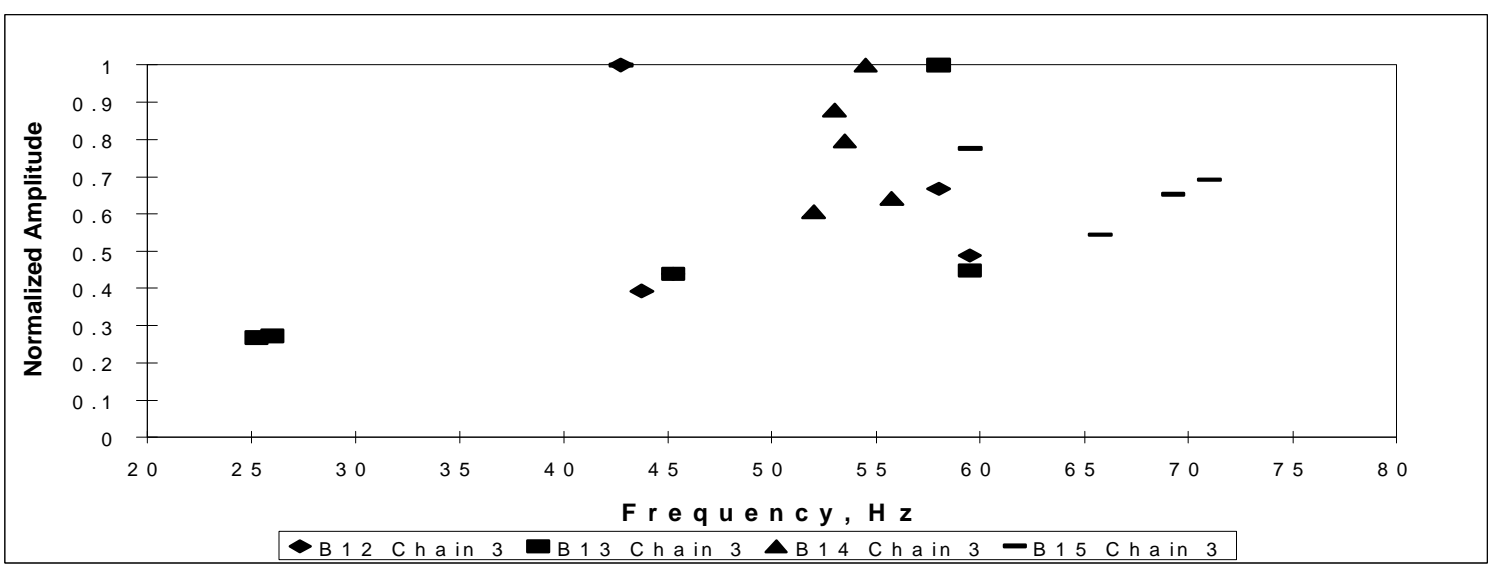

Figure 4.11: Comparison of Batch 1 with Chain 3 


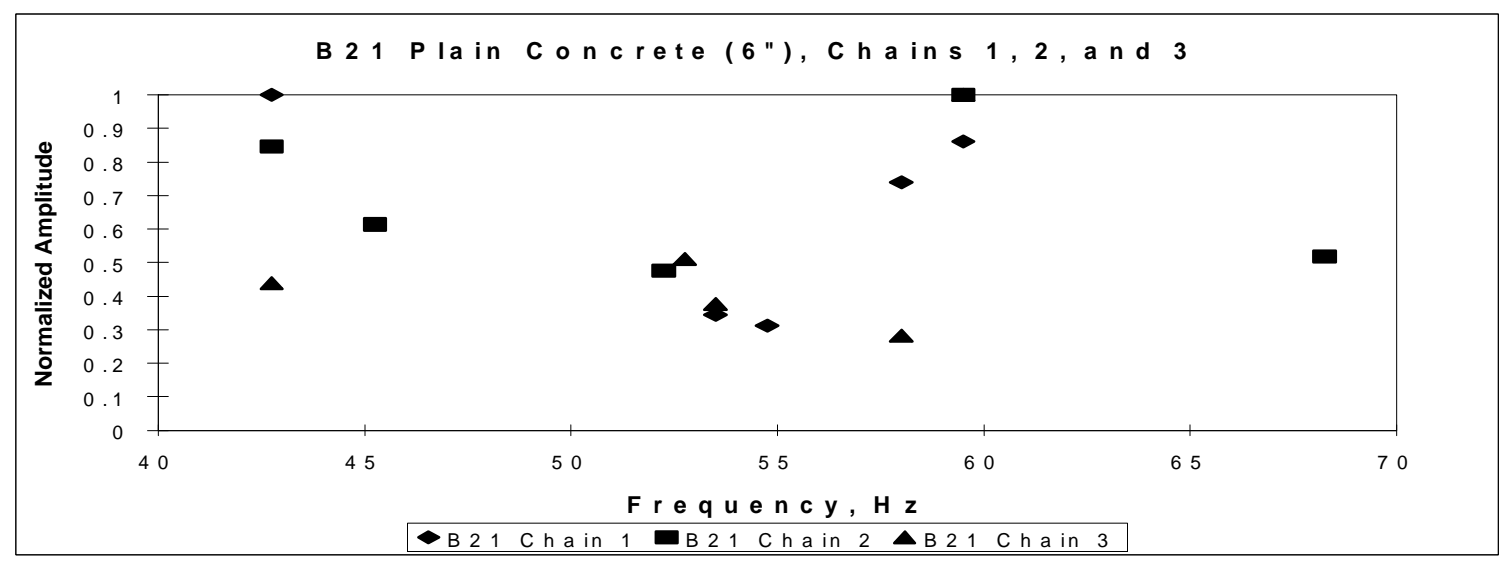

Figure 4.12: Specimen B21 with Chains 1, 2, and 3

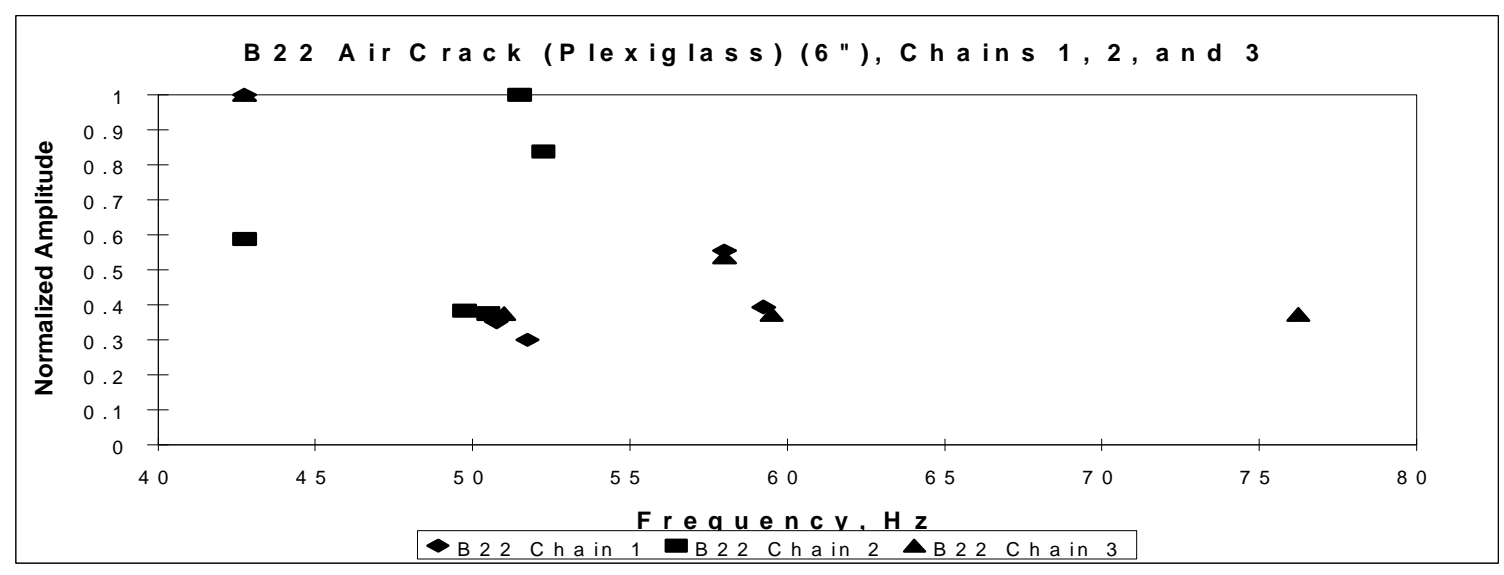

Figure 4.13: Specimen B22 with Chains 1, 2, and 3

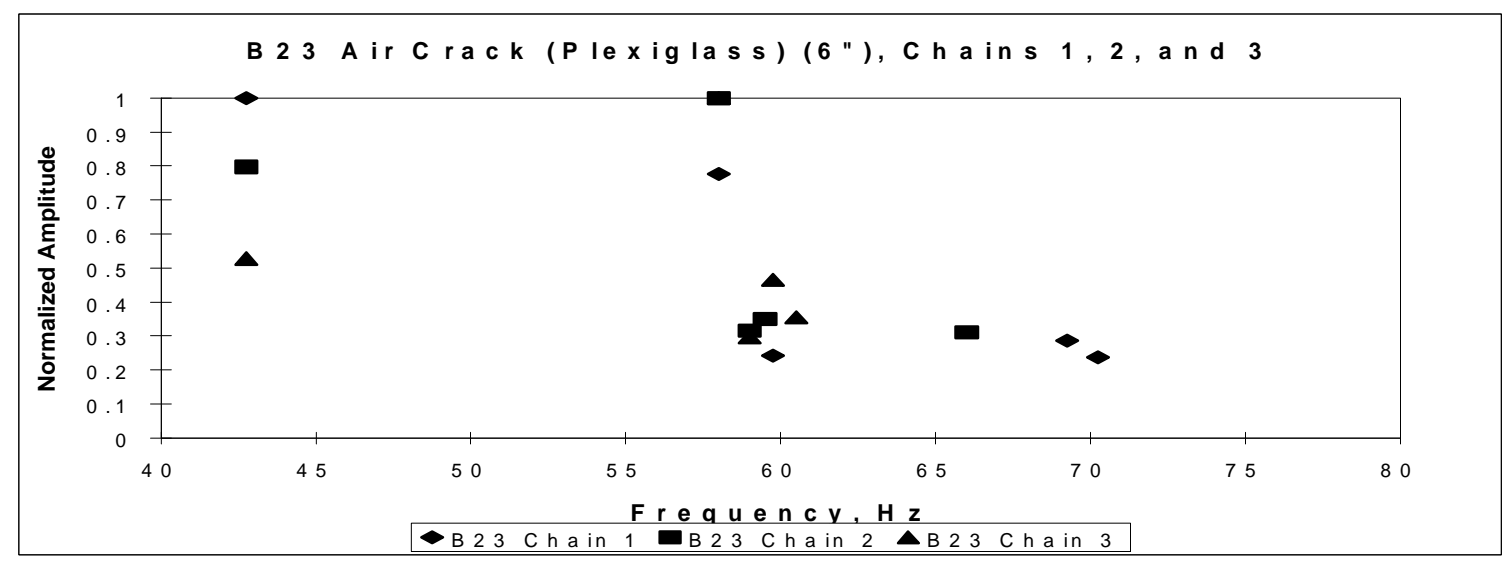

Figure 4.14: Specimen B23 with Chains 1, 2, and 3 


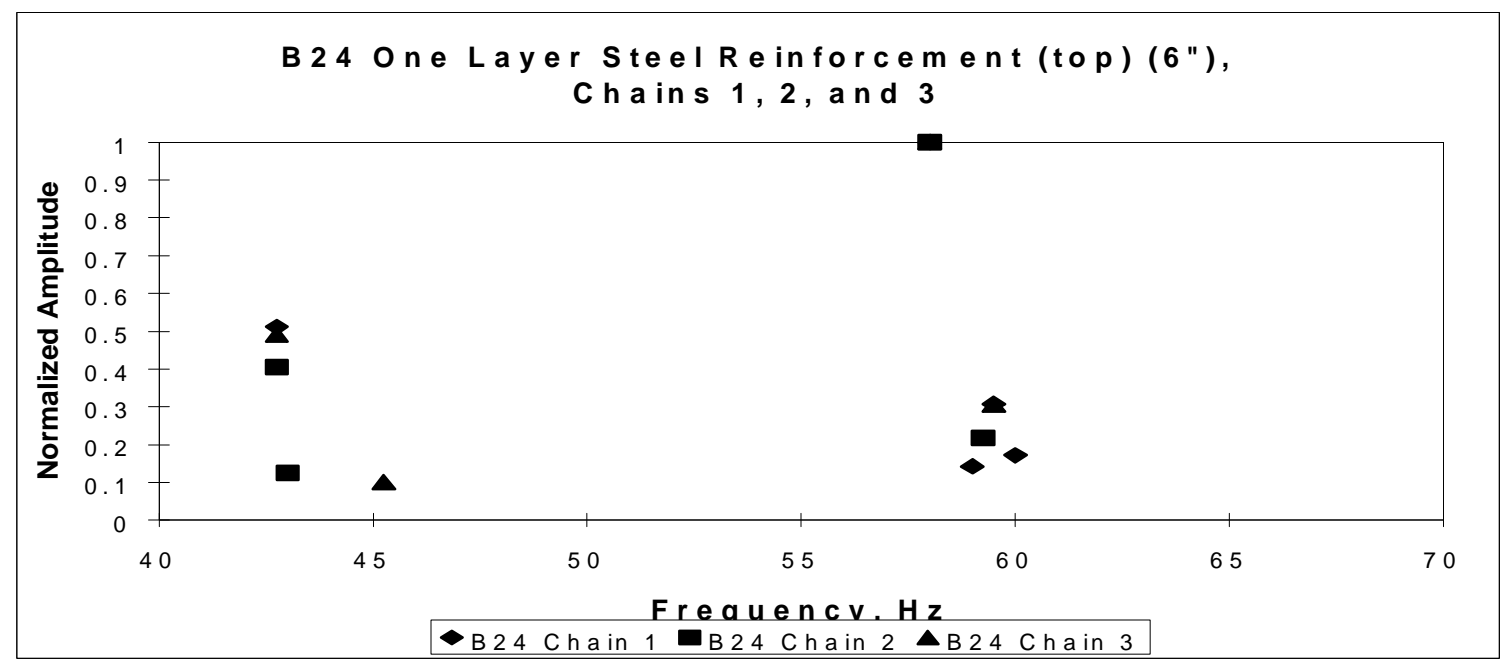

Figure 4.15: Specimen B24 with Chains 1, 2, and 3

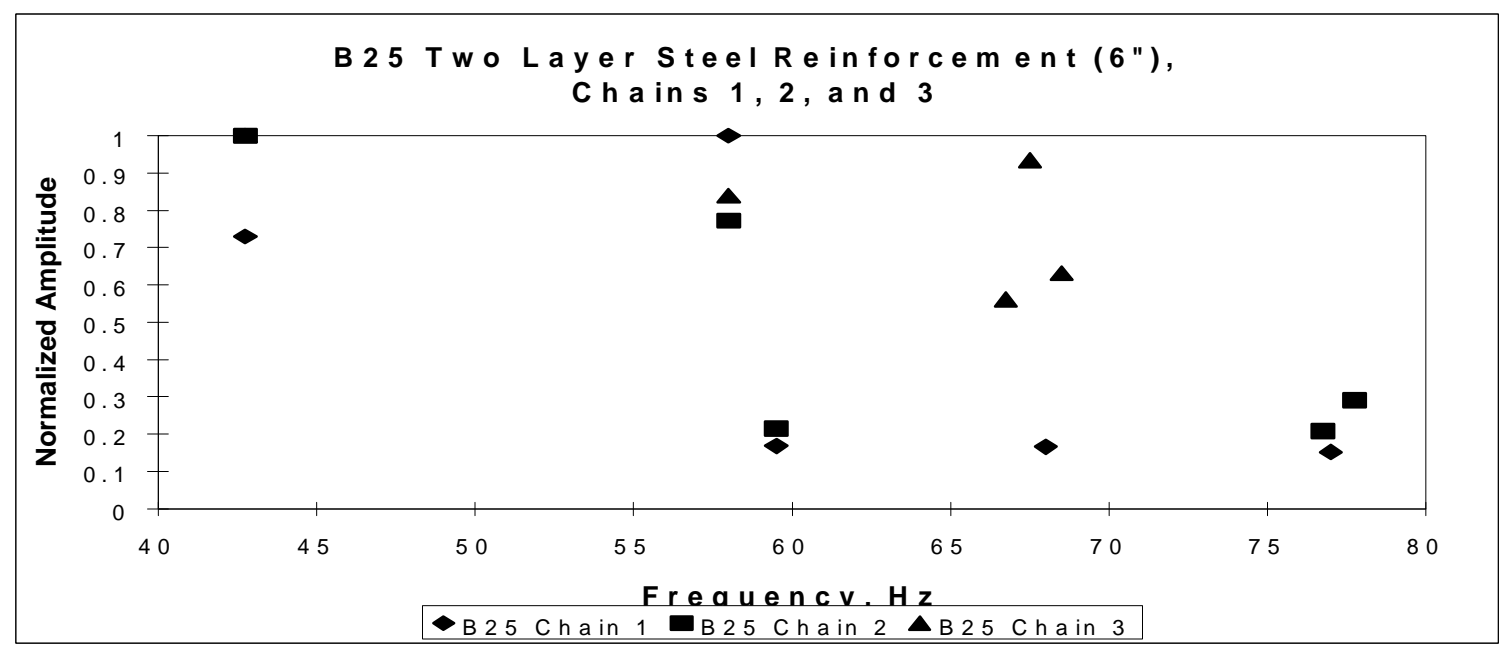

Figure 4.16: Specimen $B 25$ with Chains 1, 2, and 3 


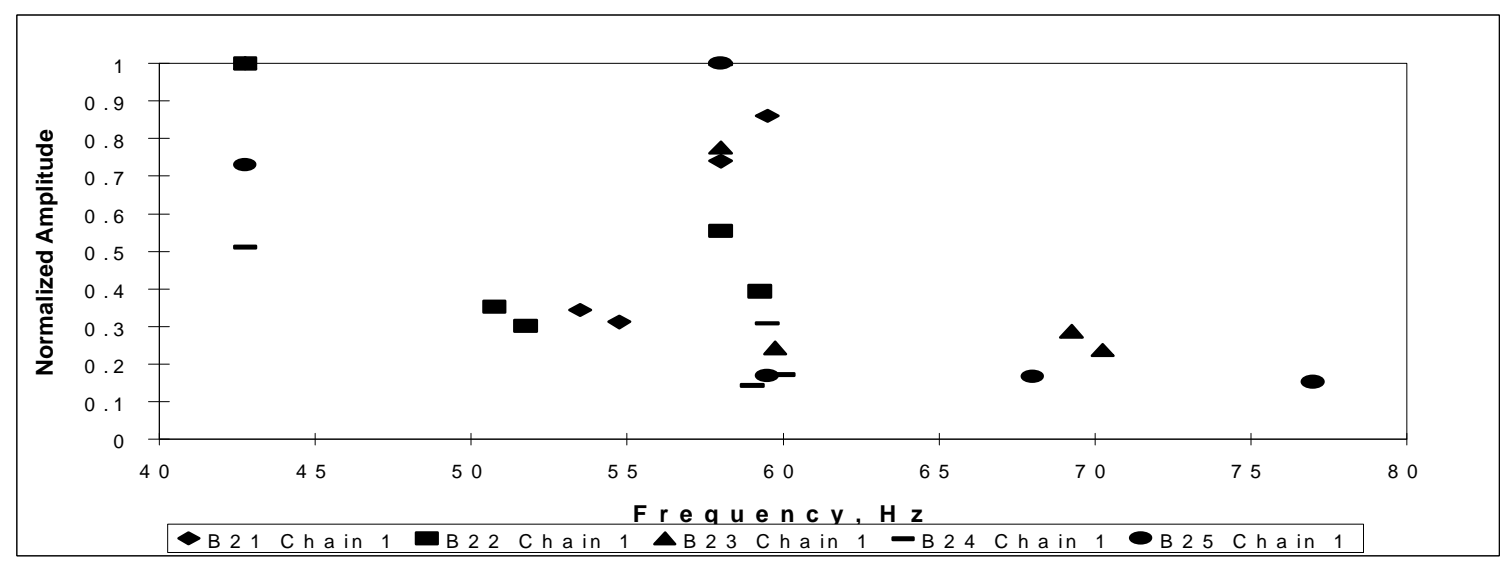

Figure 4.17: Comparison of Batch 2 with Chain 1

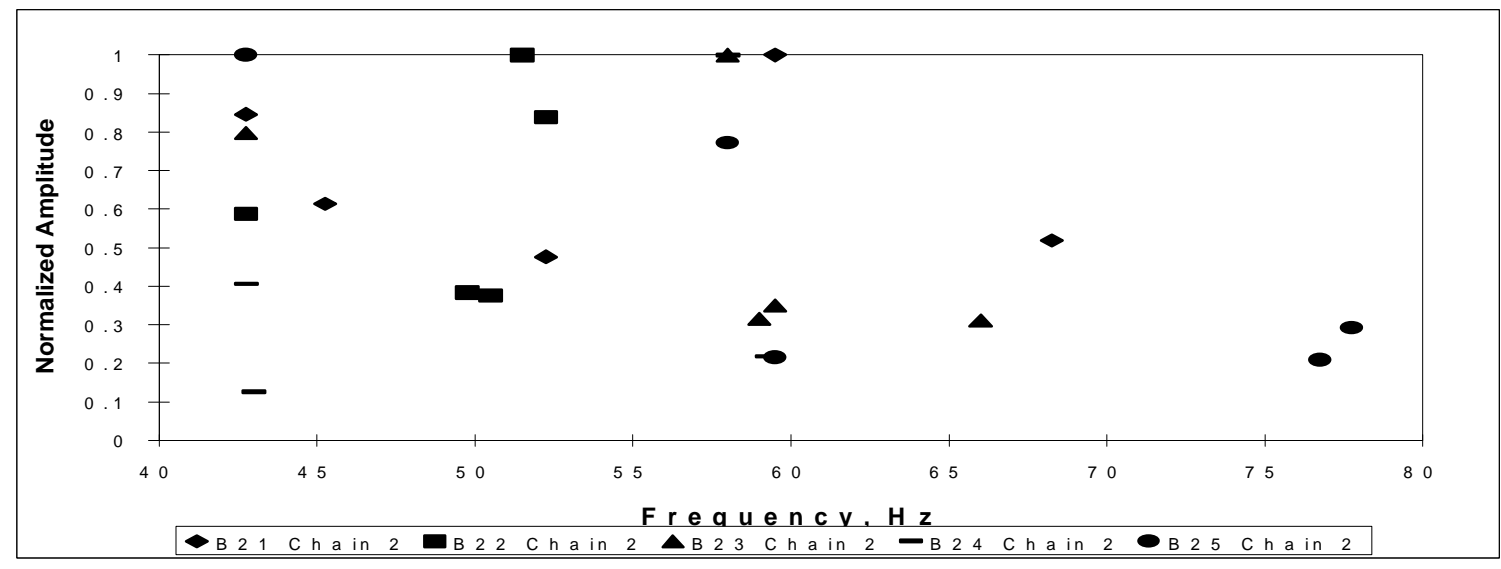

Figure 4.18: Comparison of Batch 2 with Chain 2

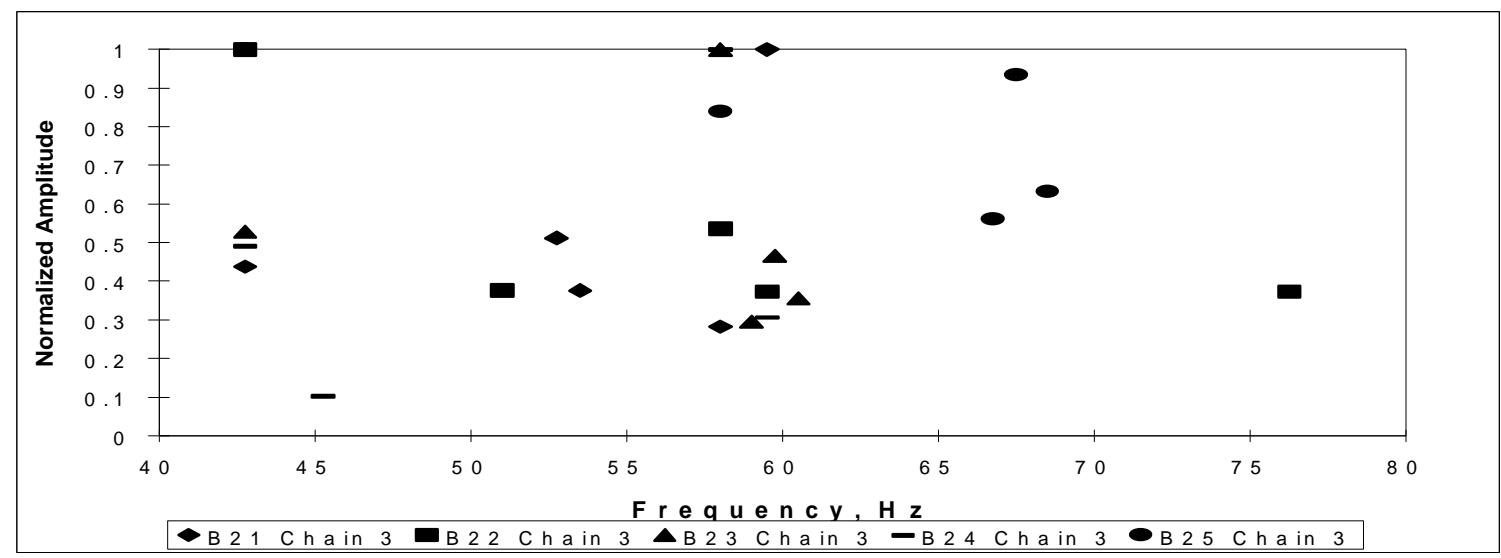

Figure 4.19: Comparison of Batch 2 with Chain 3 


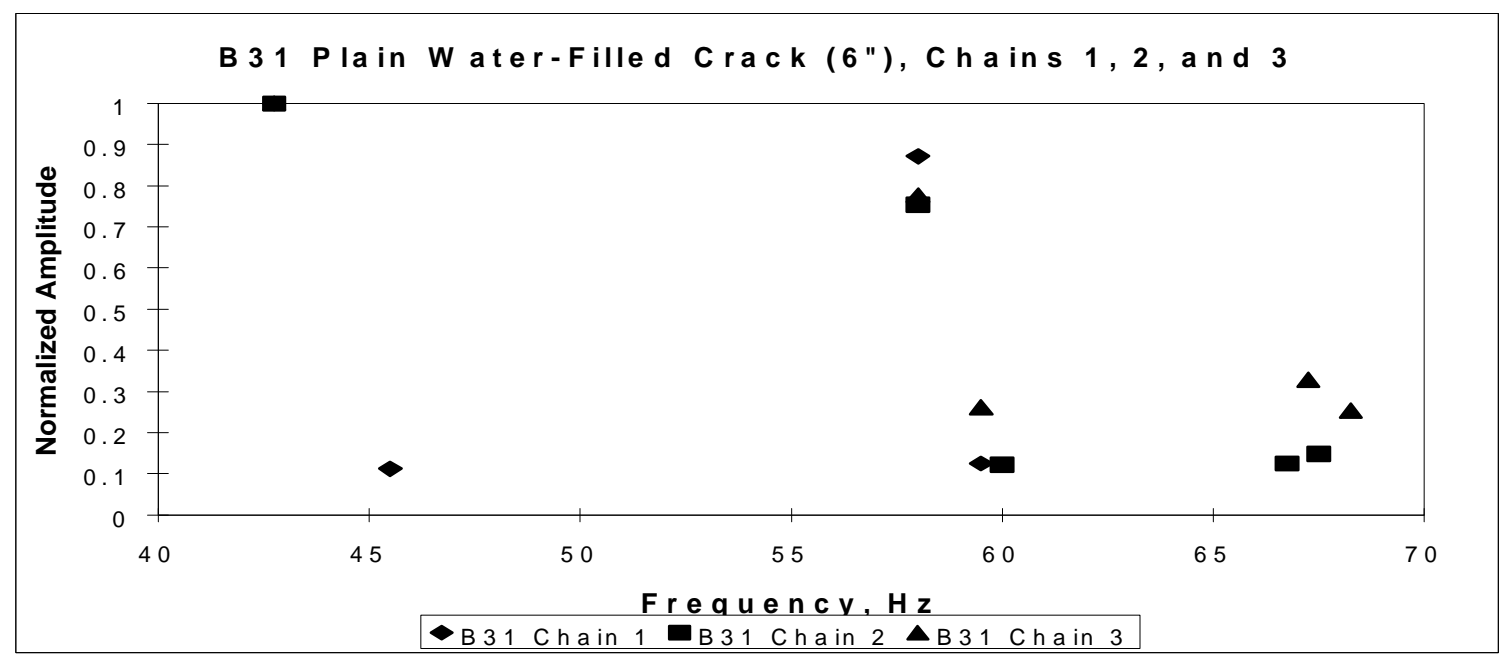

Figure 4.20: Specimen B31 with Chains 1, 2, and 3

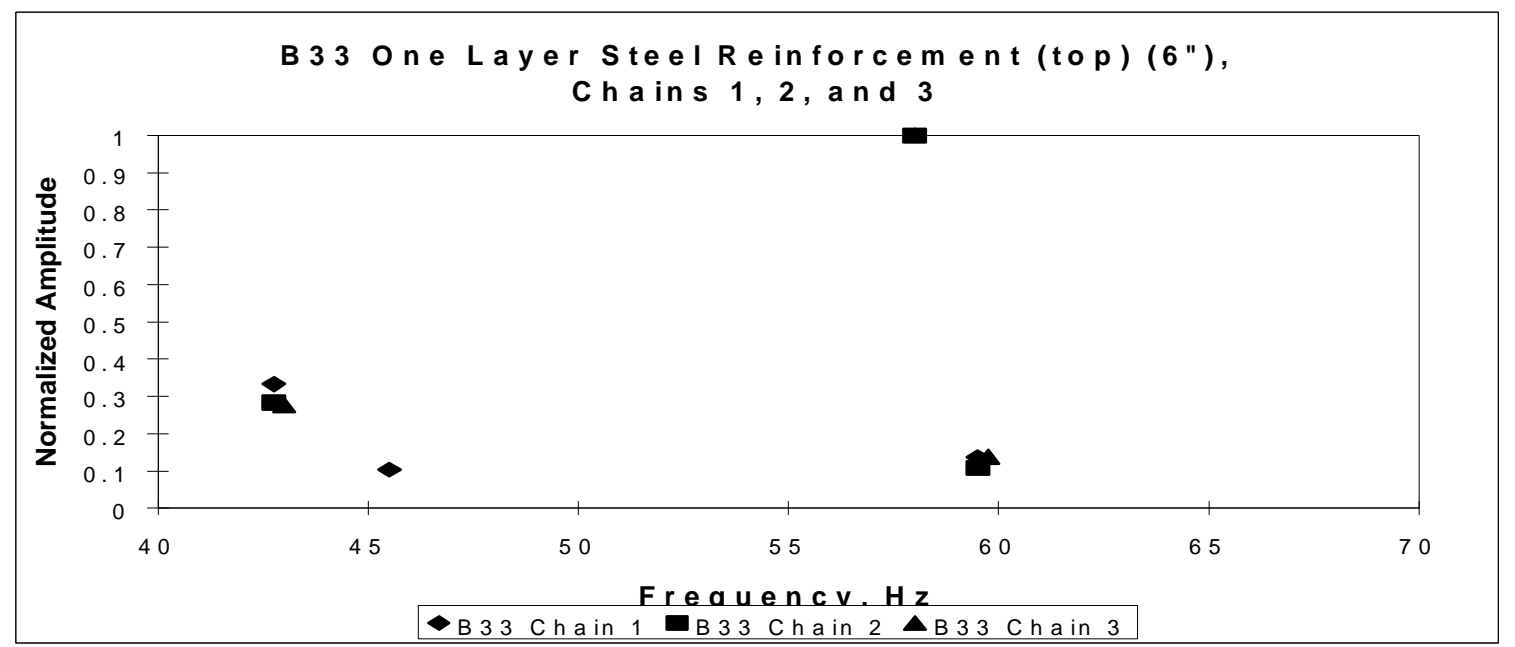

Figure 4.21: Specimen B33 with Chains 1, 2, and 3 


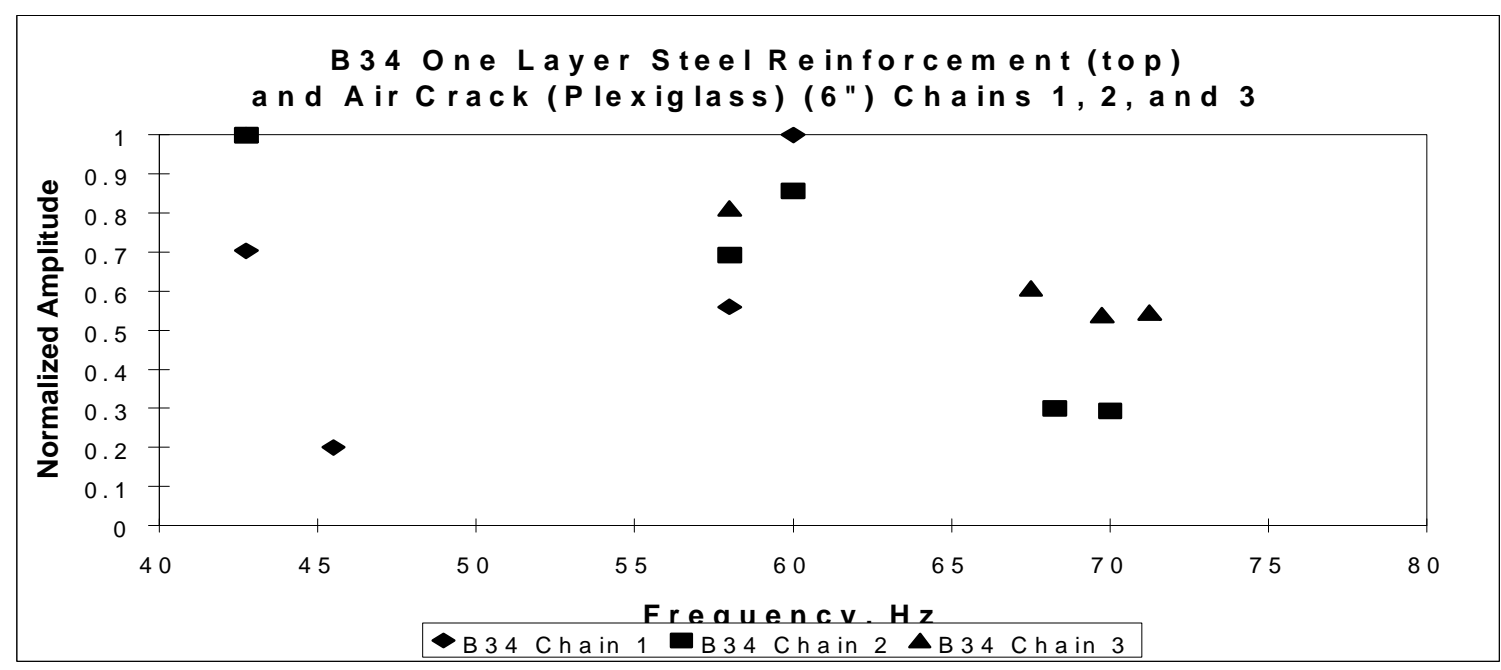

Figure 4.22: Specimen B34 with Chains 1, 2, and 3

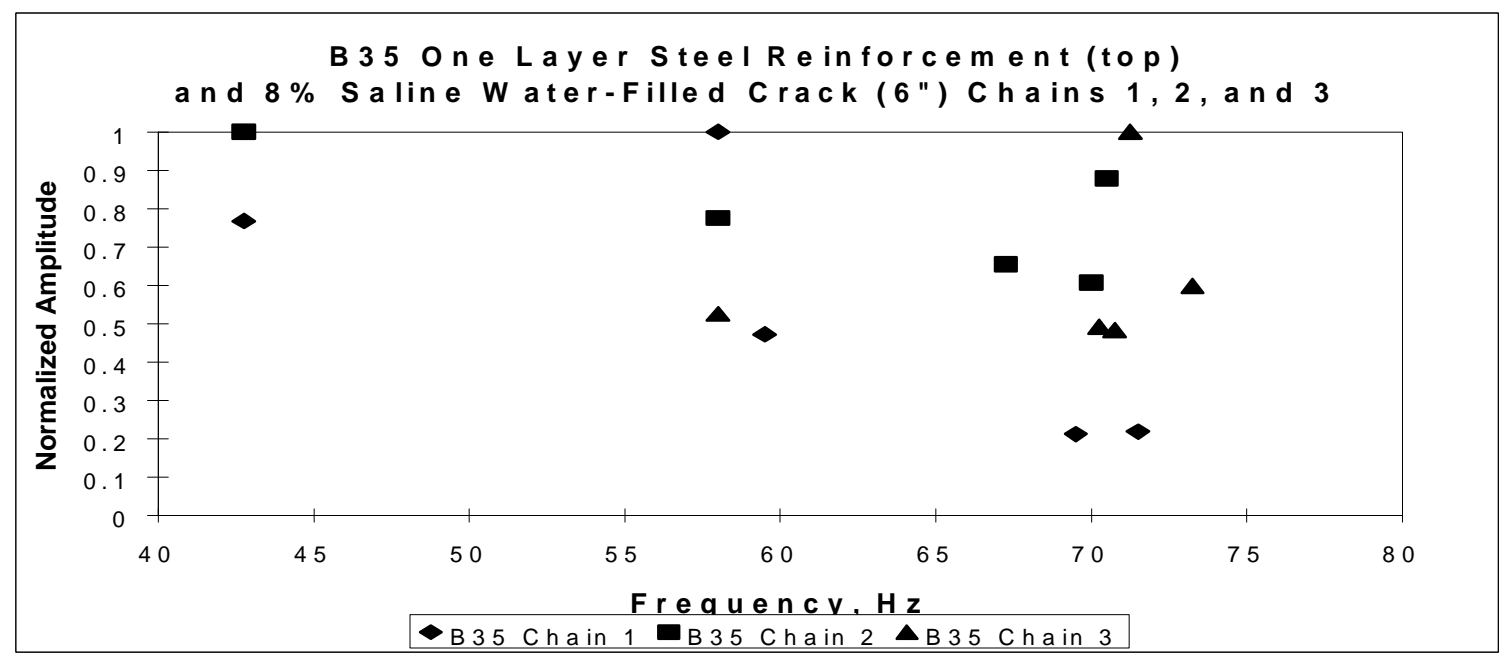

Figure 4.23: Specimen $B 35$ with Chains 1, 2, and 3 


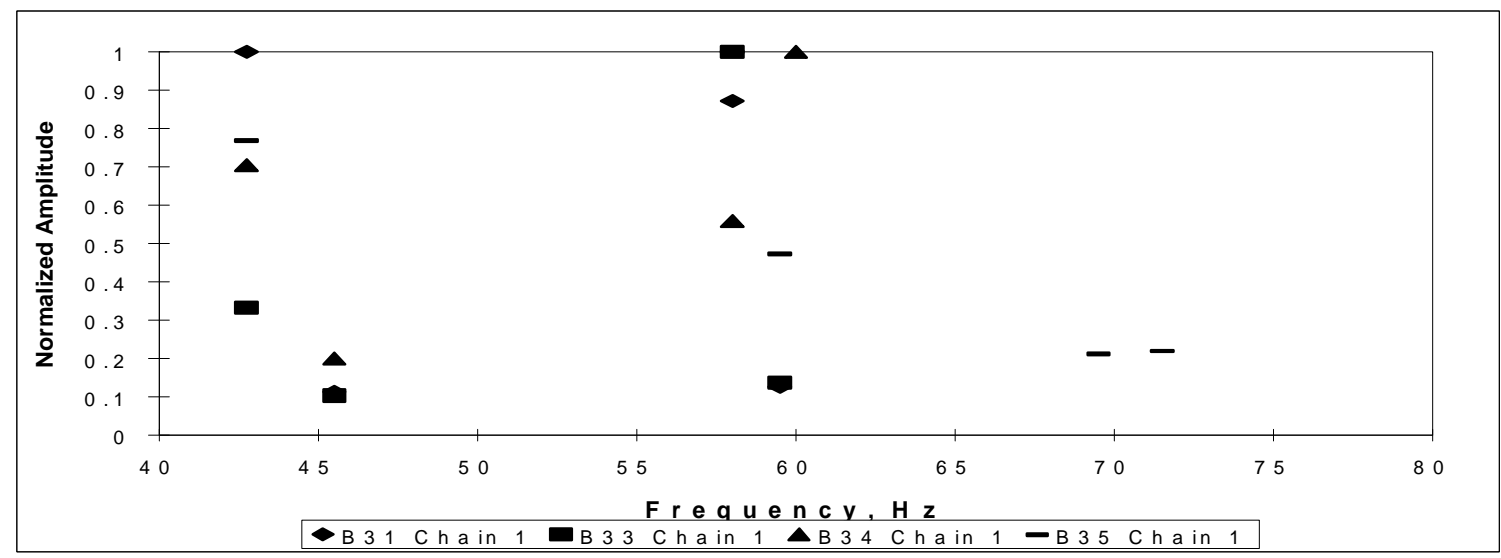

Figure 4.24: Comparison of Batch 3 with Chain 1

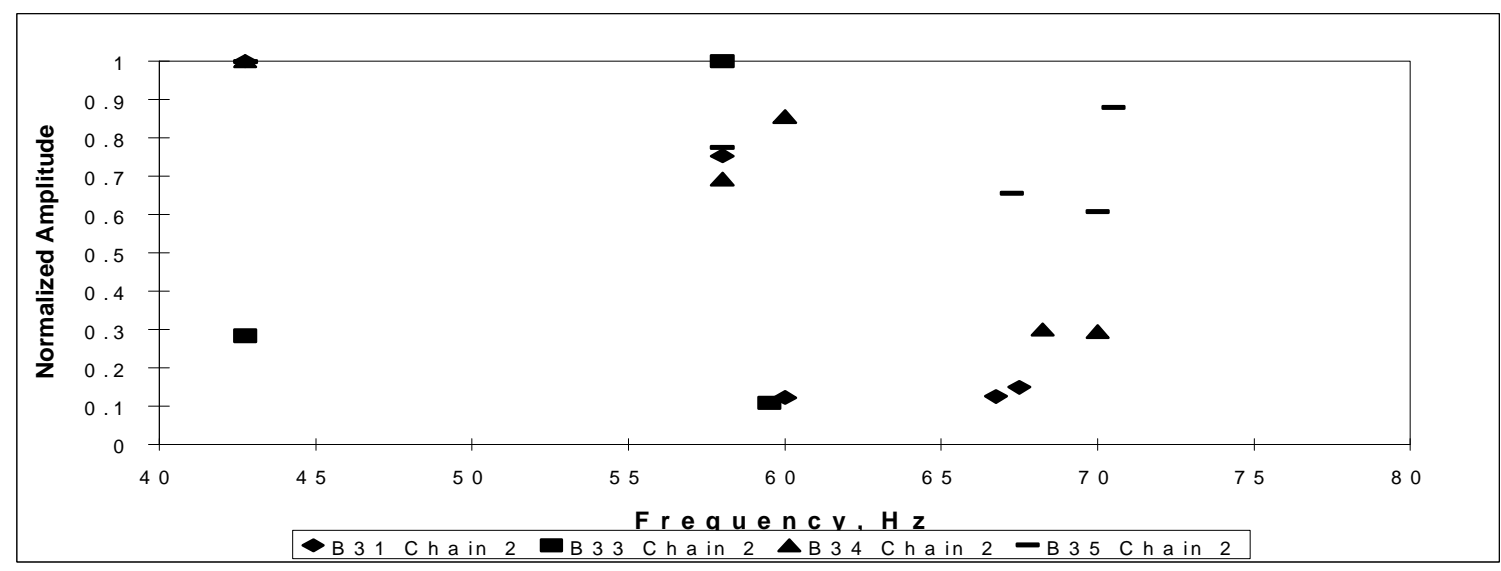

Figure 4.25: Comparison of Batch 3 with Chain 2

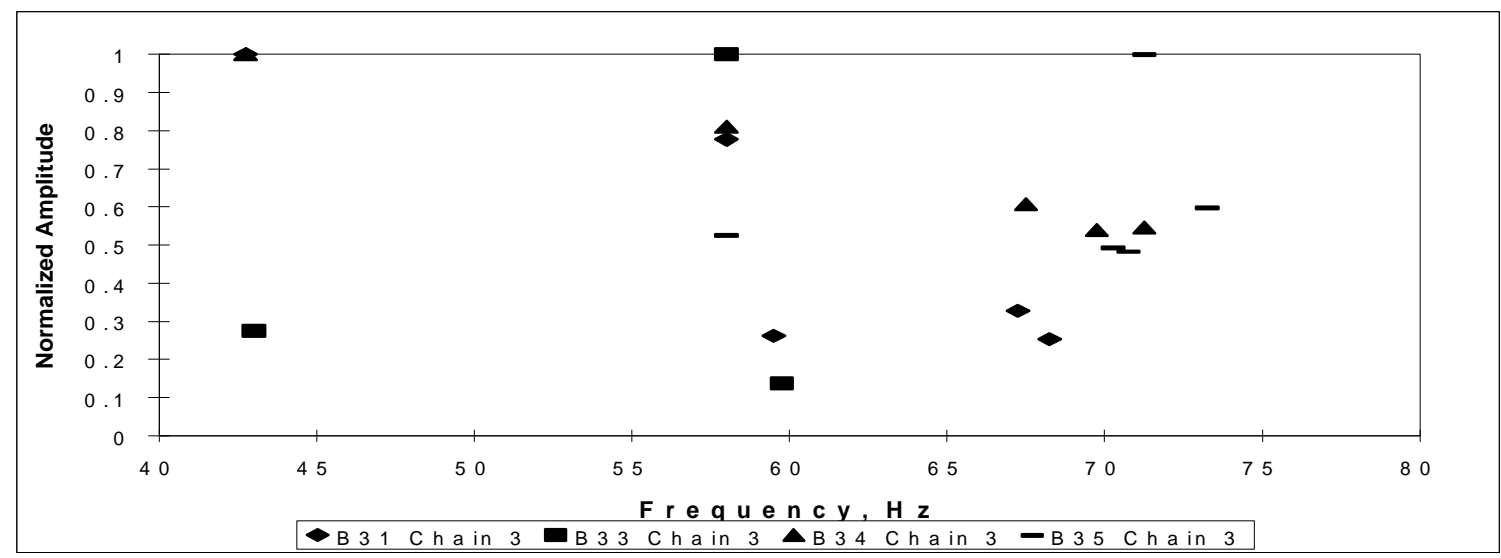

Figure 4.26: Comparison of Batch 3 with Chain 3 


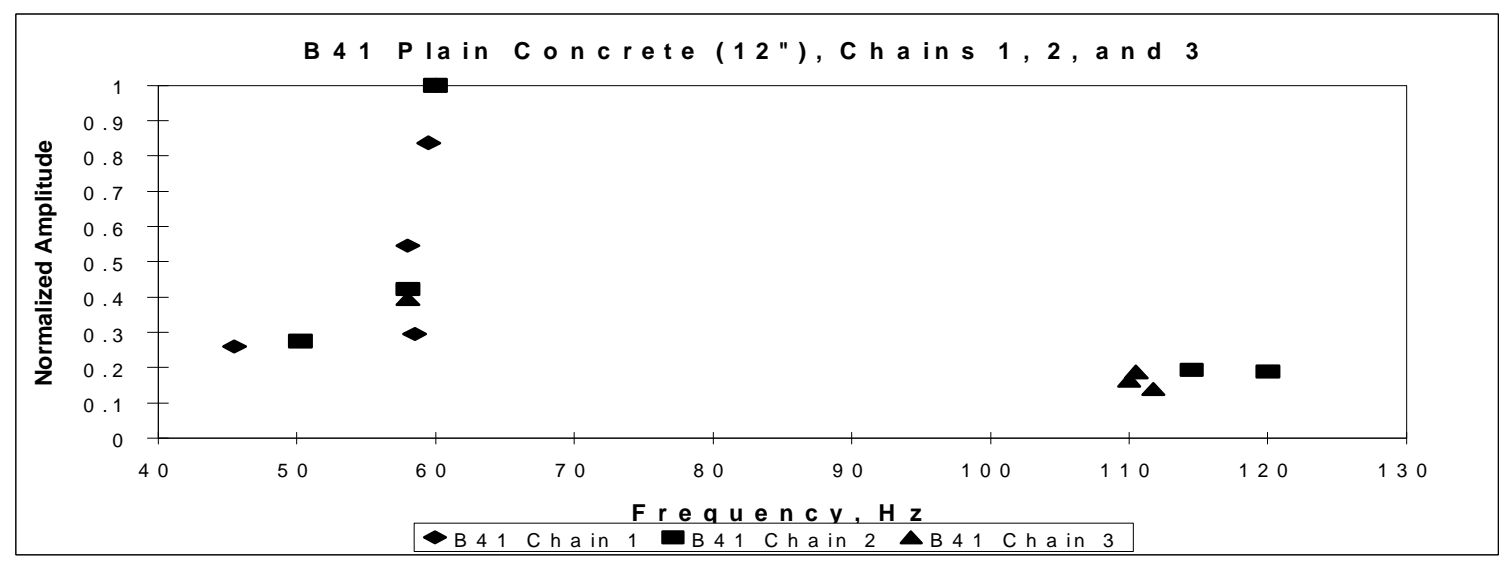

Figure 4.27: Specimen B41 with Chains 1, 2, and 3

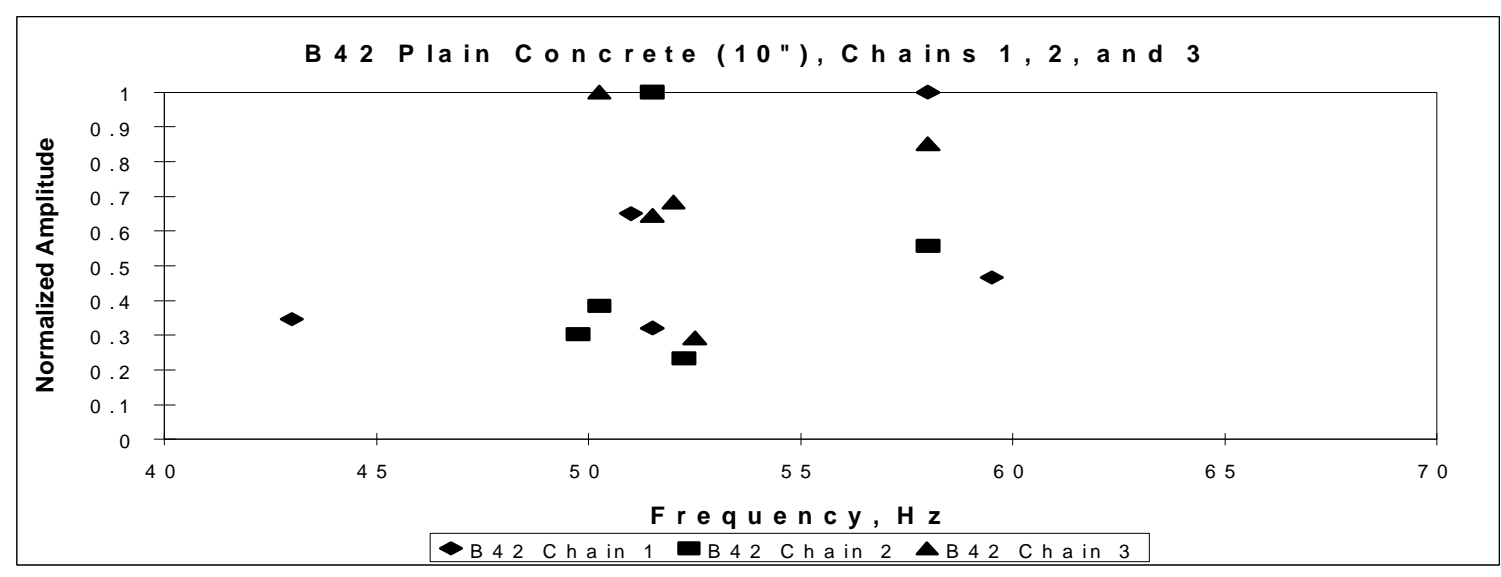

Figure 4.28: Specimen B42 with Chains 1, 2, and 3

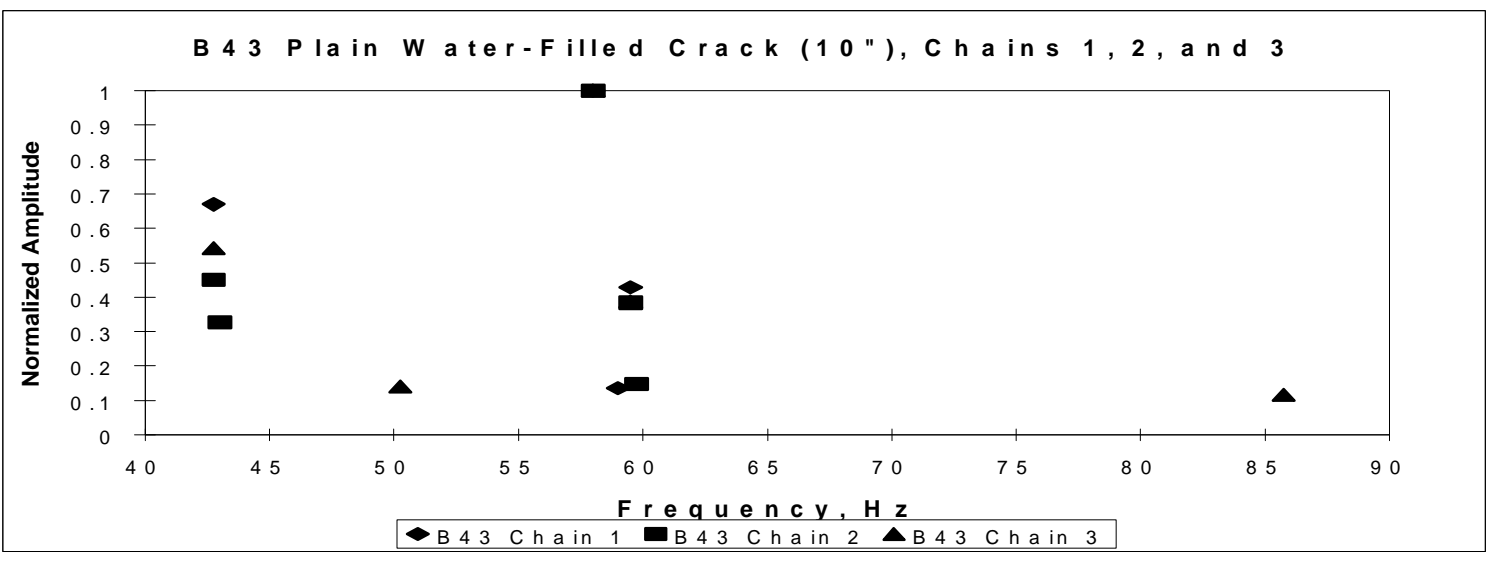

Figure 4.29: Specimen B43 with Chains 1, 2, and 3 


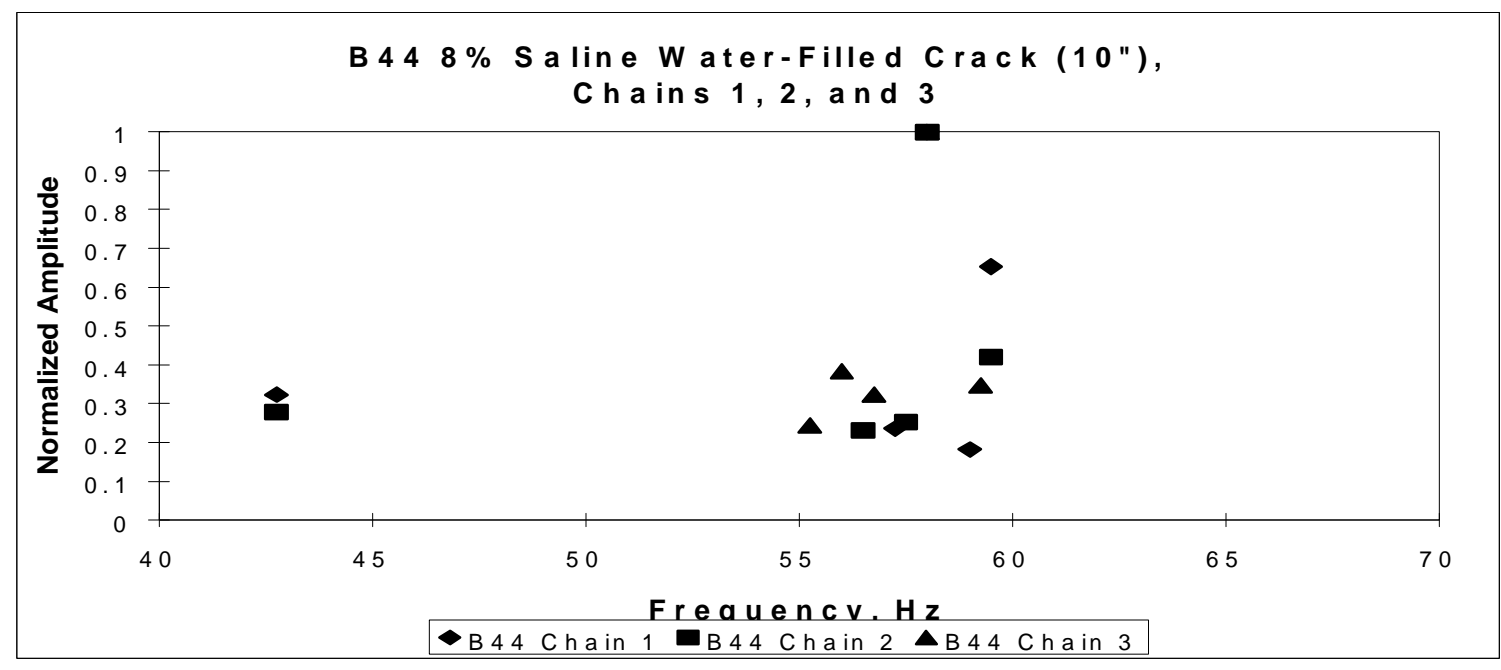

Figure 4.30: Specimen B44 with Chains 1, 2, and 3

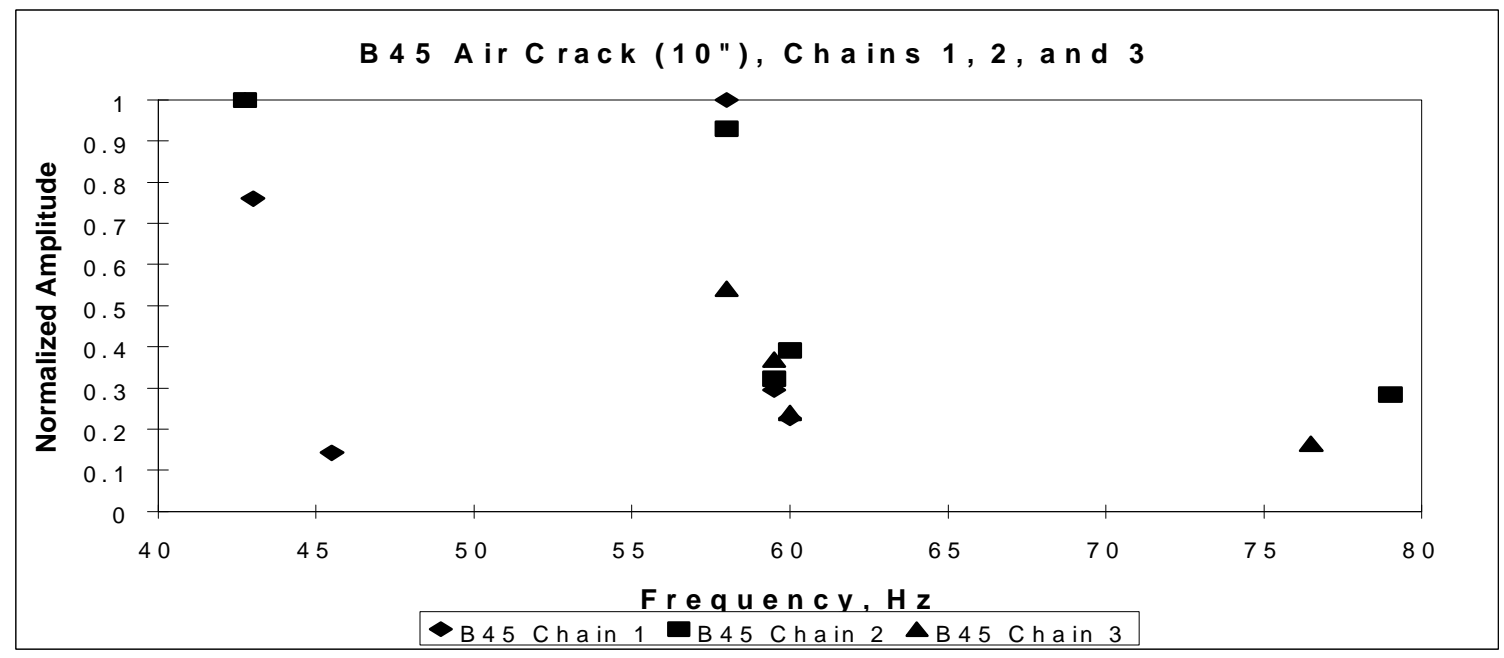

Figure 4.31: Specimen B45 with Chains 1, 2, and 3 


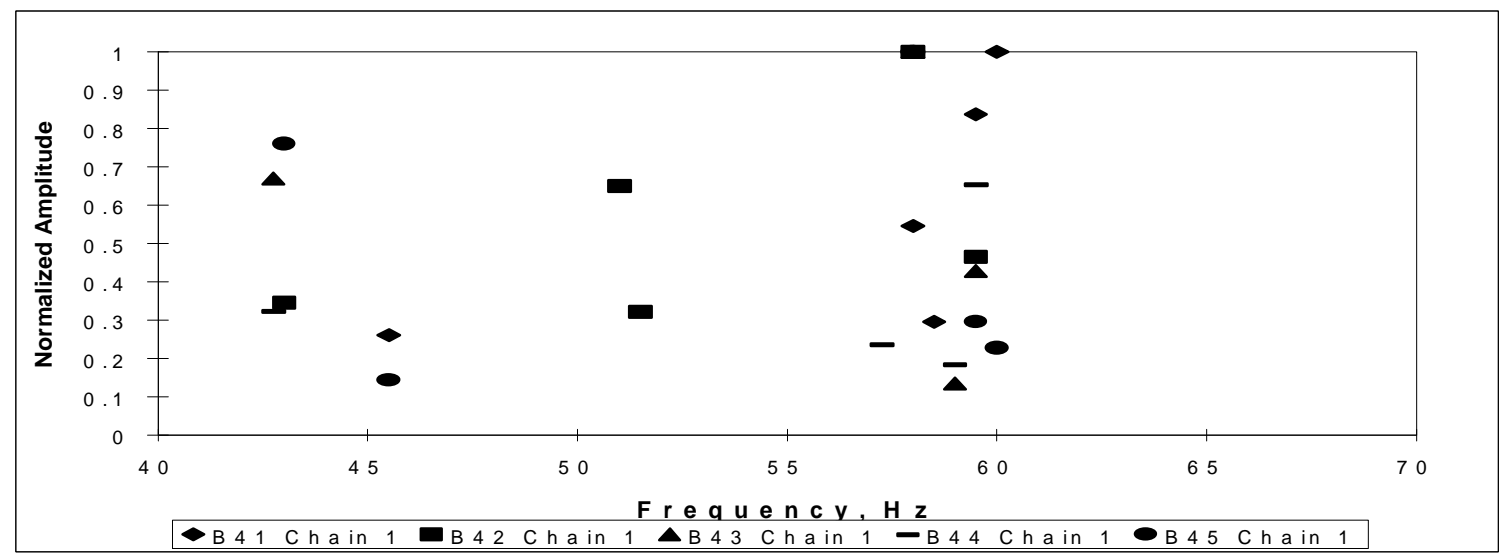

Figure 4.32: Comparison of Batch 4 with Chain 1

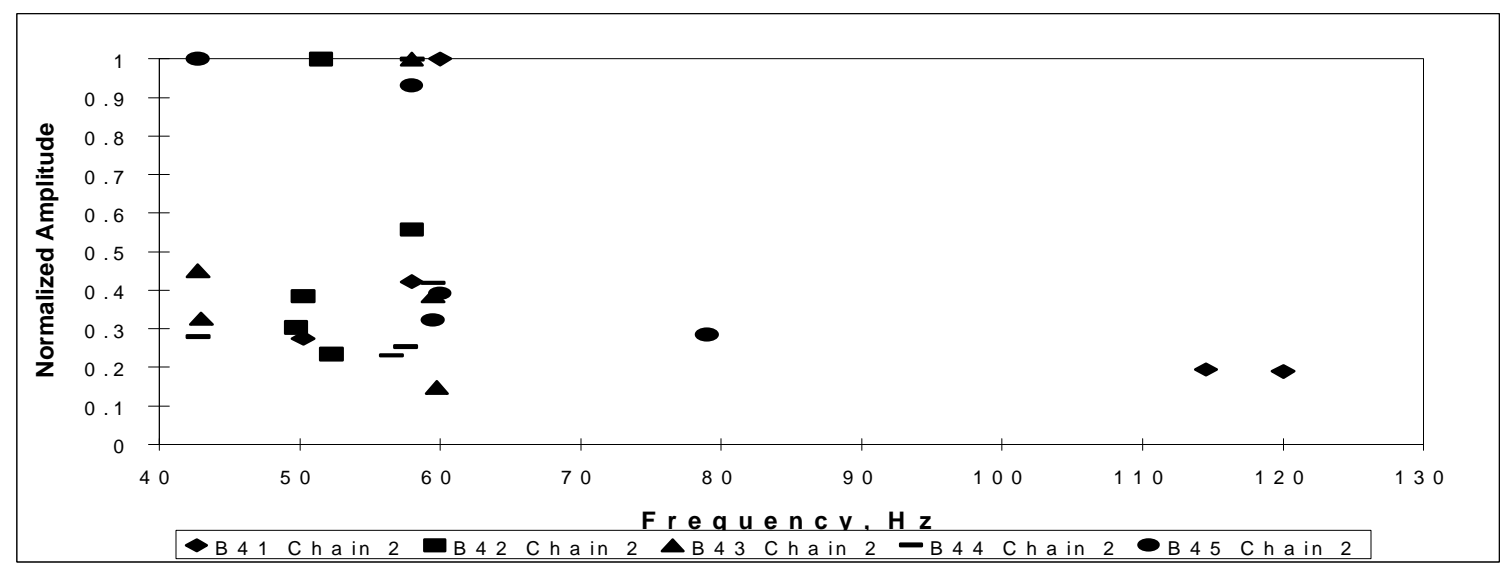

Figure 4.33: Comparison of Batch 4 with Chain 2

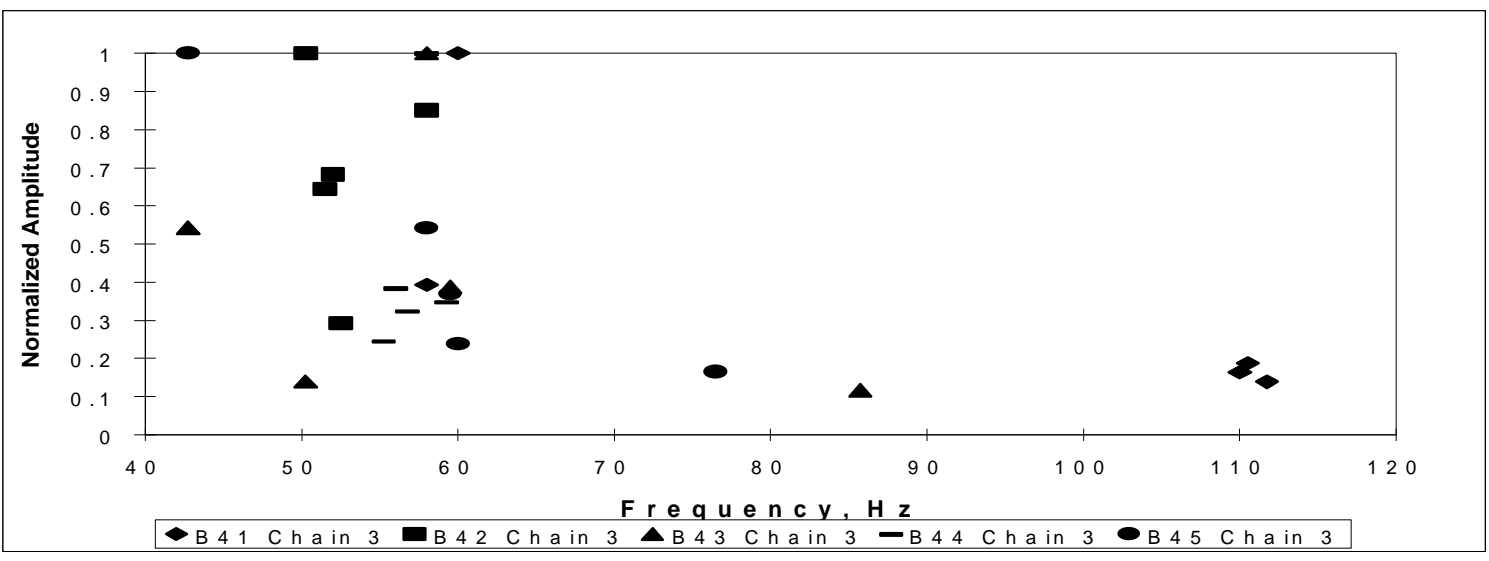

Figure 4.34: Comparison of Batch 4 with Chain 3 


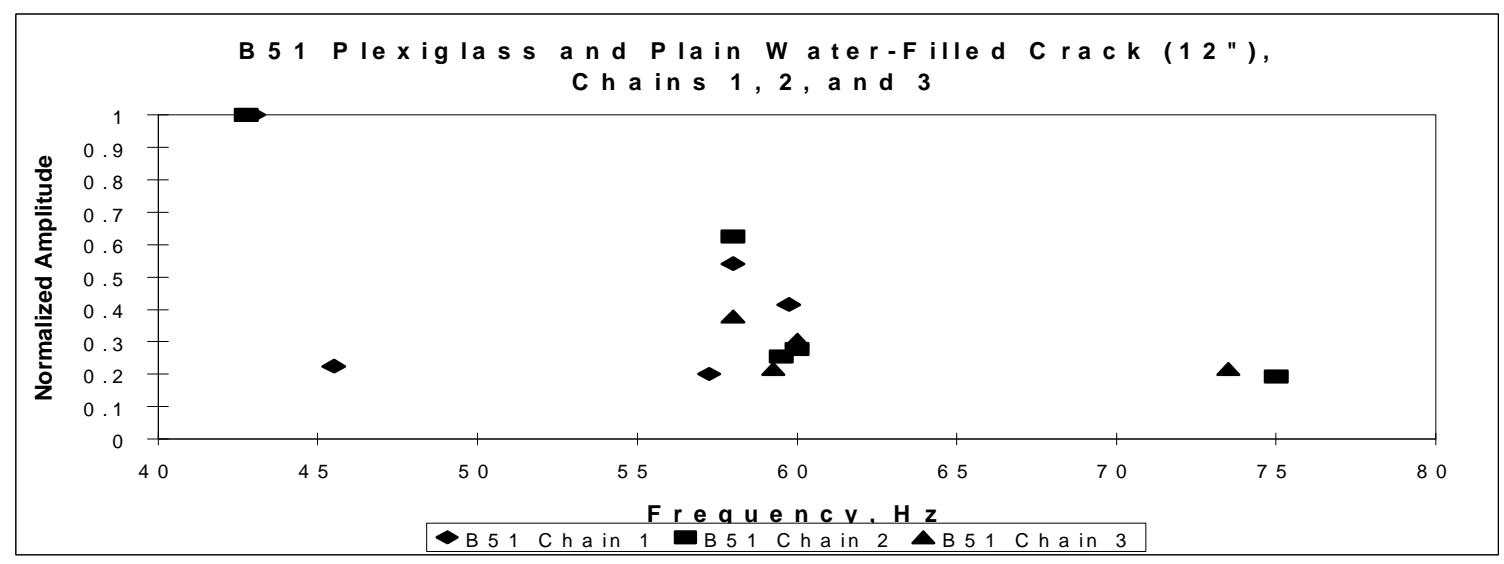

Figure 4.35: Specimen B51 with Chains 1, 2, and 3

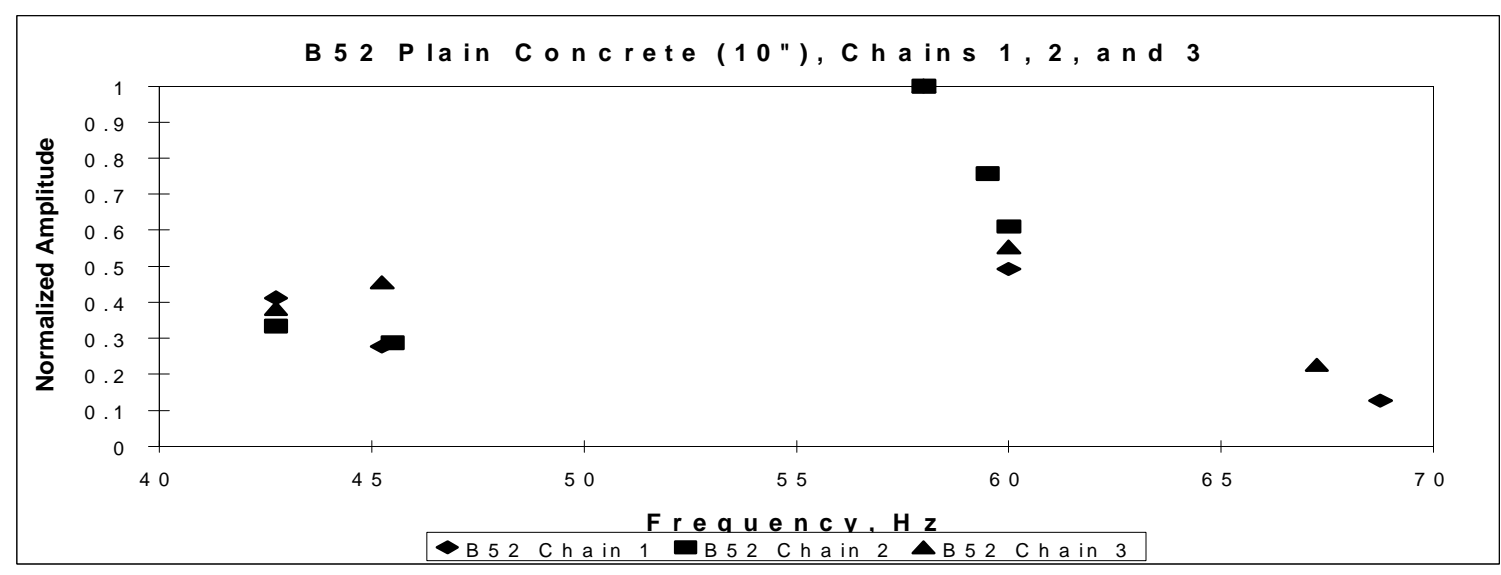

Figure 4.36: Specimen B52 with Chains 1, 2, and 3

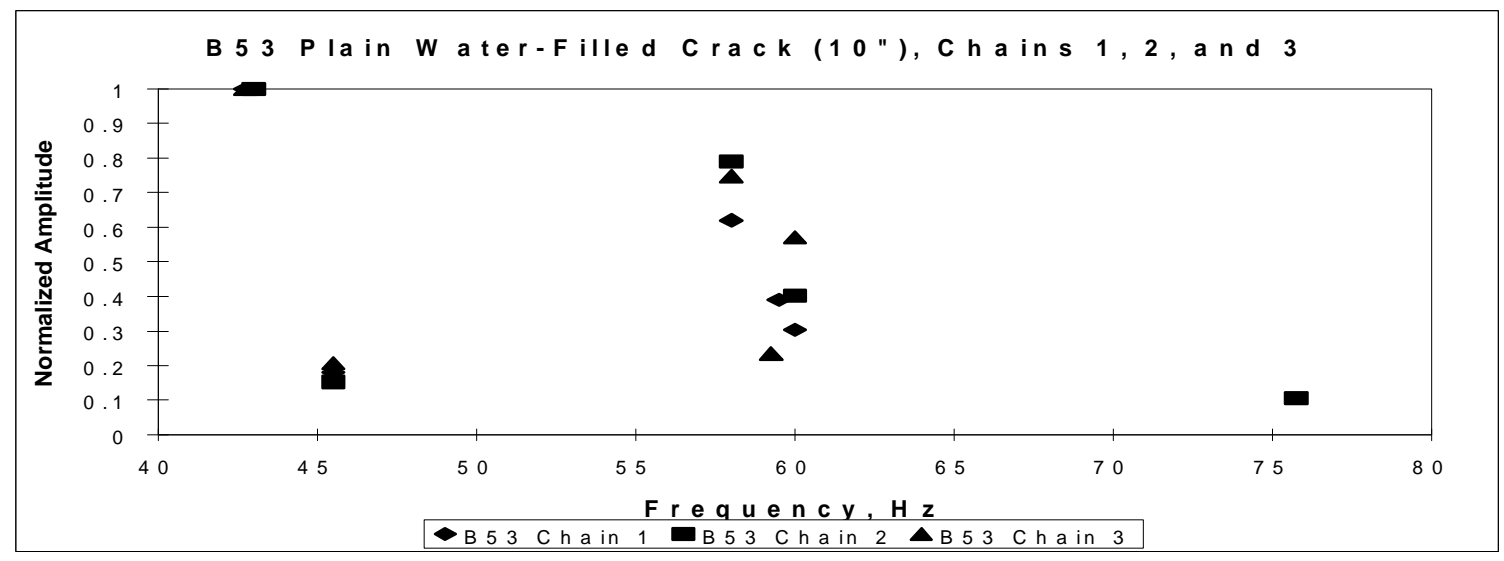

Figure 4.37: Specimen B53 with Chains 1, 2, and 3 


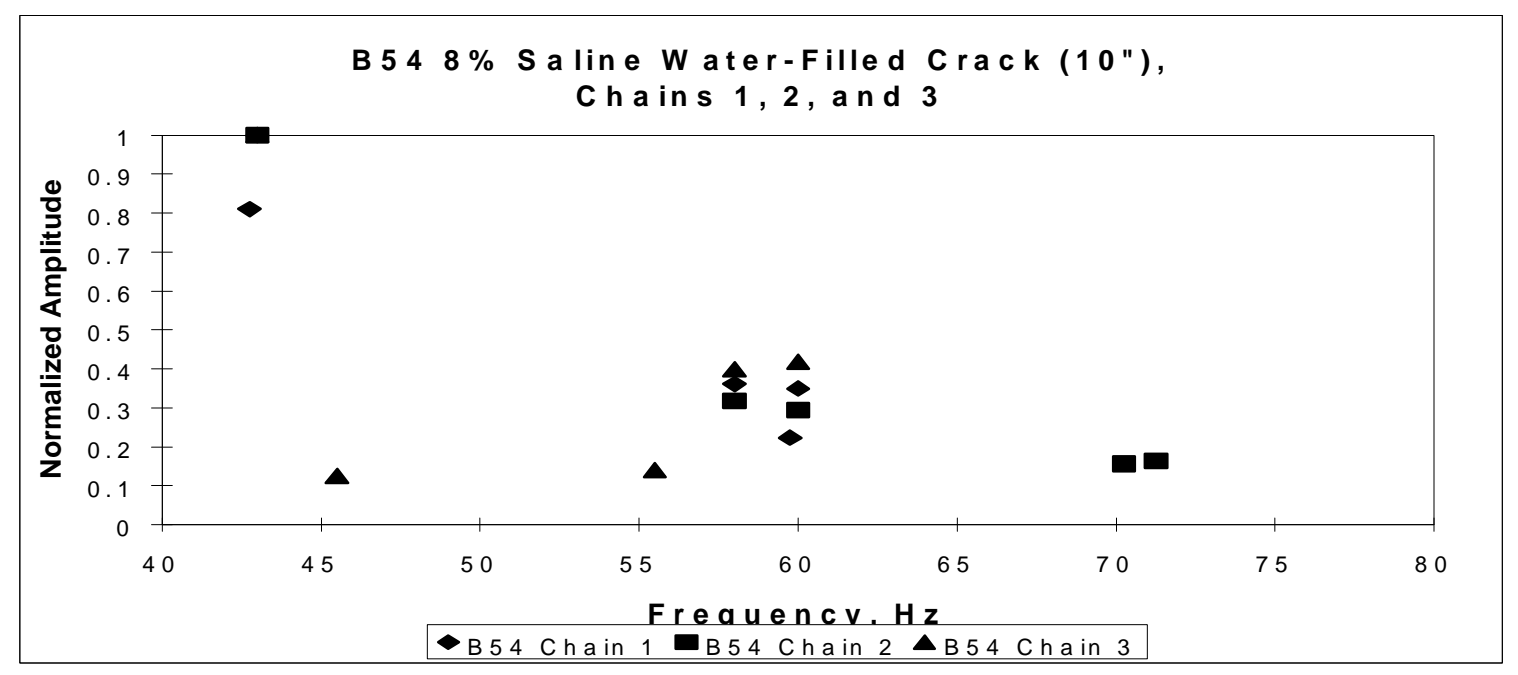

Figure 4.38: Specimen B54 with Chains 1, 2, and 3

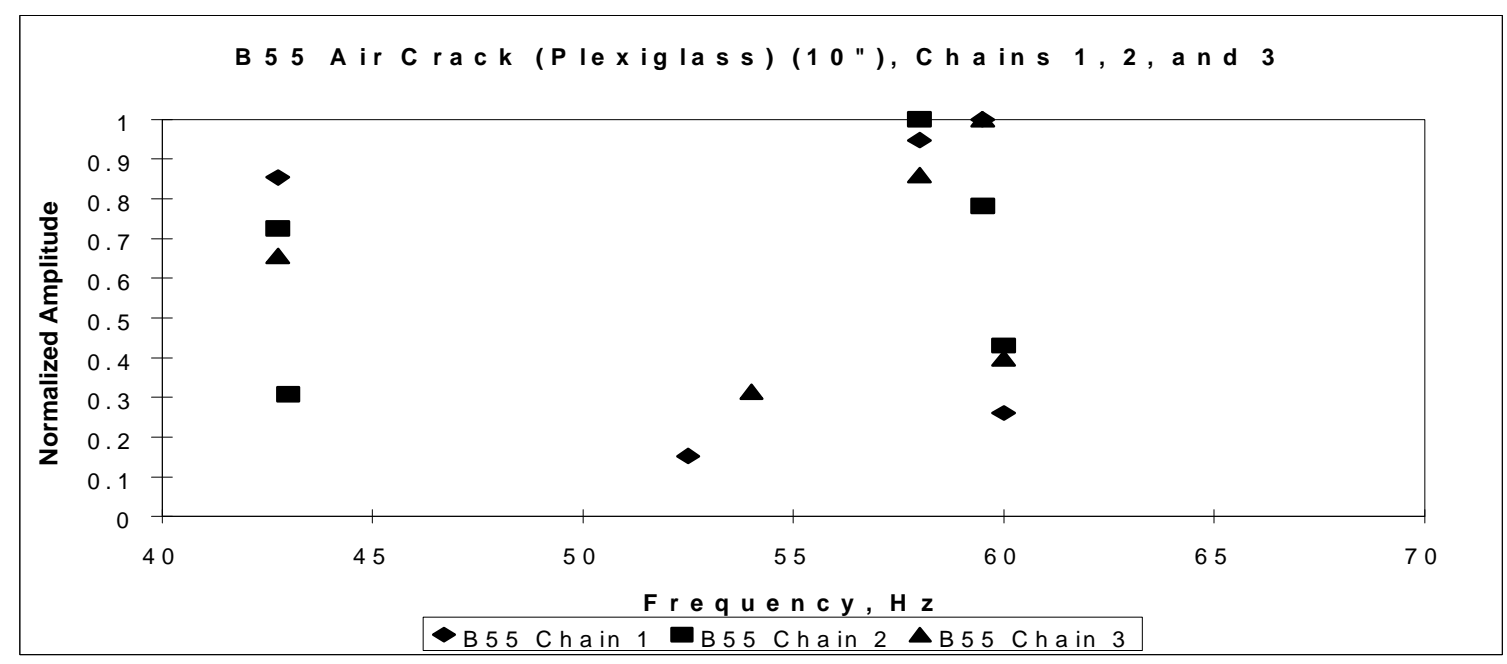

Figure 4.39: Specimen B55 with Chains 1, 2, and 3 


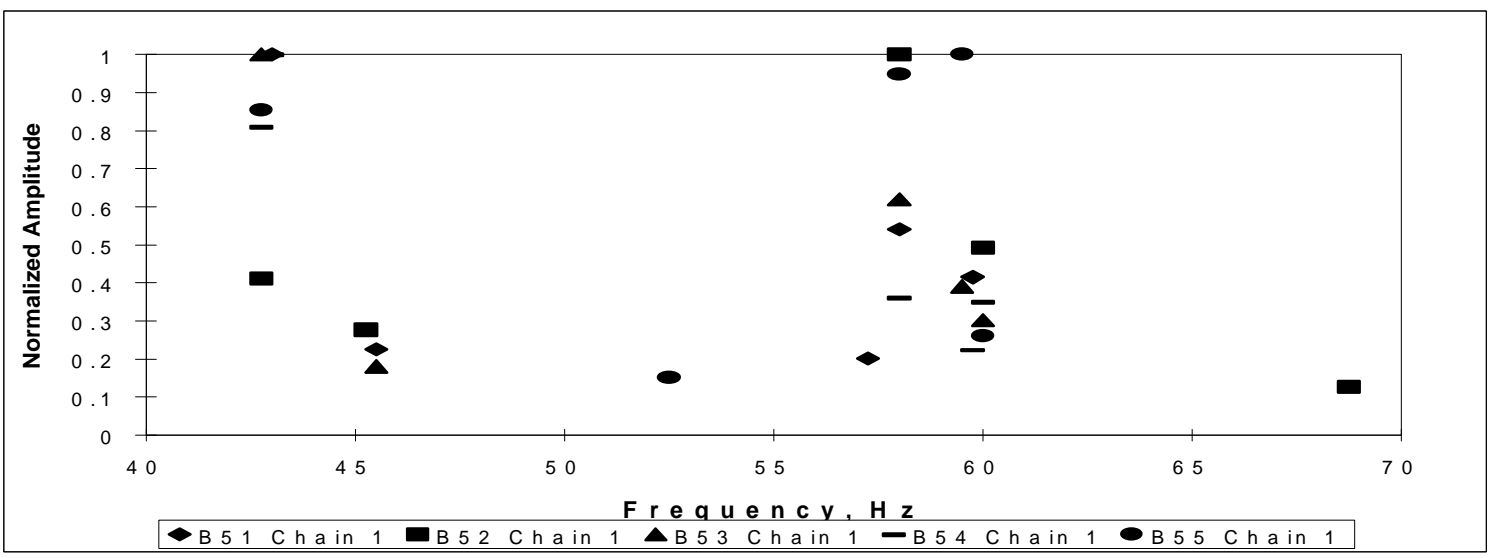

Figure 4.40: Comparison of Batch 5 with Chain 1

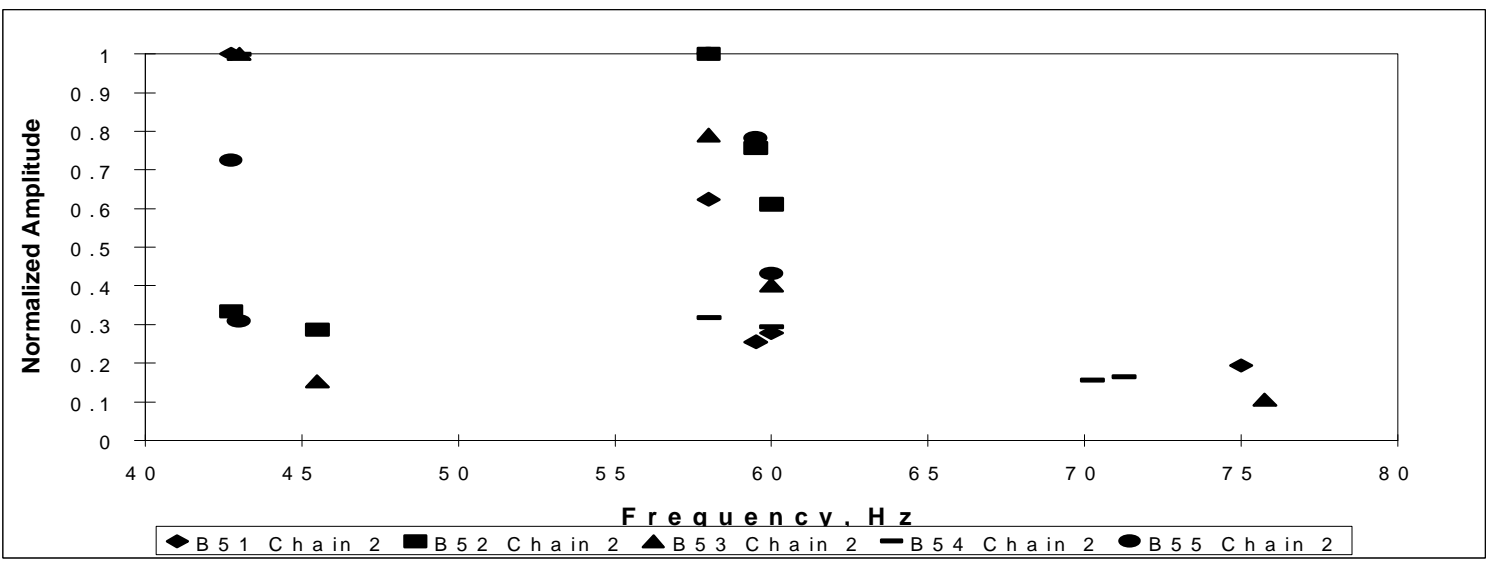

Figure 4.41: Comparison of Batch 5 with Chain 2

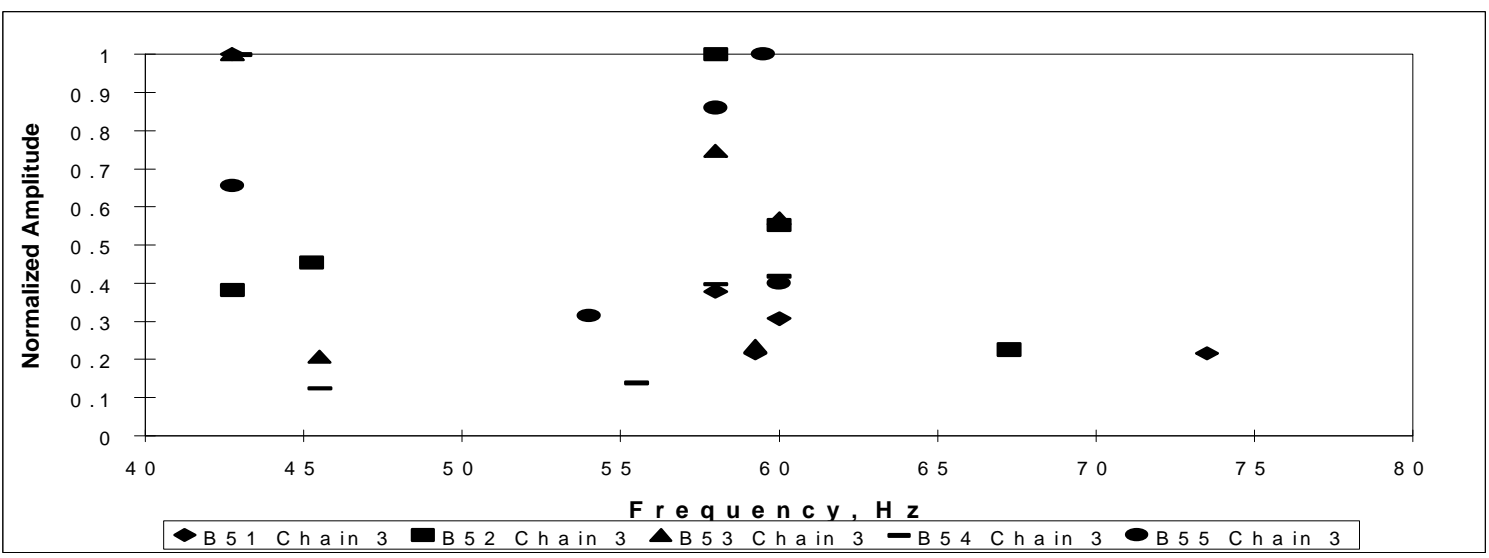

Figure 4.42: Comparison of Batch 5 with Chain 3 


\section{CHAPTER 5}

\section{GPR SYSTEM AND BRIDGE INFORMATION}

\subsection{Introduction}

This chapter discusses basic information concerning the inspection of three actual bridge decks using the GPR system owned by the WVDOT. The equipment used in the radar testing will be reviewed, along with the location, size, surroundings, and other pertinent information about the three bridges.

\subsection{GPR System}

The GPR system purchased from Penetradar Corporation performs two major tasks: bridge deck inspection and pavement evaluation. Under bridge deck inspection, this system offers delamination and deterioration inspection on asphalt covered and exposed concrete decks. High speed surveys can be conducted to determine the general deck condition and estimate the quantity of concrete that is deteriorated on the deck. These high speed radar inspections usually require little or no traffic control and can be performed at highway speeds. In addition to high speed inspections, this system also offers detailed deck inspection, which is performed at lower speeds, providing additional information, such as bridge maps, $100 \%$ deck coverage by the radar, and deterioration percentages calculated on a pass by pass and overall basis (Penetradar, 1995).

The high speed pavement evaluation performed by the GPR system provides information on pavement layer thickness over several hundred lane miles of highway per 
day. There are three specific formats for the presentation of thickness data. Numerical listings of pavement thicknesses are calculated and presented longitudinally in increments determined by the particular project specifications. The pavement cross section can be shown graphically with multicolored, three-dimensional pavement thickness profile maps. The radar inspections also detect air voids beneath rigid pavement and can detect areas of high subsurface moisture accumulation (Penetradar, 1995).

\subsection{GPR Equipment}

As was previously mentioned and shown in Chapter 2, the radar equipment was located entirely inside of a van, with the exception of the antenna, which was mounted on the rear of the vehicle. The equipment was given the acronym IRIS, which stands for Integrated Radar Inspection System. The IRIS includes up to three Penetradar Model

PS-24 Radar Antennas, Master Control Console (MCC), ACPRO Data Acquisition and Processing System, and Computer Interface/Display Control Unit (CDU).

\subsubsection{Radar Antenna}

This particular radar project used only one antenna for scanning the bridge decks. The antenna transmits short pulses of electromagnetic energy of extremely short duration, on the order of nanoseconds, with a central frequency of $1 \mathrm{GHz}$ (Bhandarkar, 1993). The antenna was suspended approximately $143 / 4$ inches above the surface of the deck, enabling it to cover an area of approximately $0.093 \mathrm{~m}^{2}\left(1 \mathrm{ft}^{2}\right)$. 


\subsubsection{Master Control Console}

The MCC acts as the central power control and primary interface between antennas, ACPRO computer, and display devices. The MCC controls radar waveform digitization (A/D) and reconstruction (D/A). Another handy component of the MCC is a speed and distance indicator.

\subsubsection{ACPRO Data Acquisition and Processing System}

This data acquisition and processing system consists of a $33 \mathrm{MHz}$, IBM compatible computer with a high resolution super VGA display, high speed data acquisition subsystem, distance measuring instrument (DMI), and monitor oscilloscope. This piece of equipment digitizes and stores data on disk as radar data are taken, therefore eliminating the need for any other storage devices, such as tape recorders.

\subsubsection{Computer Interface/Display Control Unit}

The CDU controls radar data conversion and selects the input data source: either from the antennas or other auxiliary sources. Another function of the CDU is to select the display source, such as direct radar signals, tape recorded radar signals, or pre-digitized radar data.

\subsection{Functions of GPR Software}

There are three main functions associated with GPR software that was utilized for this project: radar data acquisition (RDA), radar data processing (RDP), and post- 
processing. As the name implies, the RDA deals with the collection of the radar data from the bridge deck or pavement. The RDA was performed by the WVDOH. The RDP converts the data acquired from the RDA into a workable form for the post-processing phase. Calibration files are used and color intensity plots are generated in the RDP phase. All of the results, outside of the color intensity plots, are displayed in the post-processing phase. Such results include bridge maps and thickness tables, among others. The RDP and post-processing was performed at West Virginia University.

\subsubsection{Radar Data Acquisition}

There are many items which should be noted when performing the RDA which is crucial for the later RDP and post-processing phases. The first important detail is the weather and deck conditions. There are functions in the post-processing section that deal with whether the deck is wet or dry. Not knowing the deck conditions can lead to drastic differences between the generated bridge maps and the true nature of the concrete deck. The bridge number, the road it is on, and other pertinent information is important in order to keep track of the many bridges that are inspected. Perhaps the most important item is to make a quick sketch of the deck, including the passes along with pass numbers, direction of travel, and distance between passes. The skew angle or distance, if one exists, should also be included in the sketch, along with the distance from the edge of the deck to the nearest pass. The bridge inspector should also note the pass of maximum skew, and the process interval, which is the amount of traces transmitted from the antenna per foot of bridge deck scanned. If these items are not included, then it will be very difficult to 
generate precise results and the testing will become moot. A checklist containing these items is included in Appendix A.

\subsubsection{Radar Data Processing}

After the radar data has been acquired from the deck, the RDP phase is ready to be performed. The data from the RDA can be saved onto a disk and transferred into a personal computer that contains the RDP software. The version of the RDP software employed in this project is performed outside of the windows environment, at the DOS

prompt. The first task to accomplish in the RDP phase is to transfer the files obtained in the RDA into a workable file for post-processing with a .DAT extension. Each pass that is made by the radar van has a file that is associated with it.

It is in the RDP section where the very important calibration files are utilized. The calibration files include the flat metal plate (FMP) file and the free space calibration (FSP) file. The FMP file is used as a scaling factor for the waveforms obtained from the deck. The FMP file is obtained by scanning a metal plate, making sure that the antenna and the metal plate have the identical distance between them, as did the same antenna and the tested concrete deck. The metal plate allows for no transmission through the plate, therefore the entire signal is reflected back to the antenna. There is a section of the RDP that can bypass the FMP file if the distance between the deck surface and the antenna is known. It asks for the average peak-to-peak voltage of the surface echo reflection peak from the FMP waveform. That average peak-to-peak voltage can be obtained by using the following equation (Halabe et al., 1996):

$$
y=2.15 e^{-0.0203 x}
$$




$$
\begin{aligned}
& \text { where, } \quad \mathrm{x}=\text { two way distance of metal plate from antenna in inches } \\
& \mathrm{y}=\text { metal plate reflection at distance } \mathrm{x} \text {. }
\end{aligned}
$$

The FSP file is used to eradicate the noise associated with the reflections from internal antenna sources. This characteristic initial portion is contained in all waveforms and must be removed to observe the true signal. The FSP file is obtained by pointing the antenna towards the sky so that no pulse returns to the antenna. The RDP software takes the FSP file and subtracts the unwanted antenna noise from the waveform.

Once the calibration files have been input into the RDP software, a waterfall plot is generated onto the screen. The waterfall plot displays radar waveforms selected throughout the data file and provides the overall pattern of radar signatures formed by the data for each pass. The trace numbers are shown along the $\mathrm{Y}$-axis, while the $\mathrm{X}$-axis provides the time information in nanoseconds. The location of major echoes reflected from the different interfaces of the bridge deck are selected using the waterfall plot. The software requires the user to indicate these locations for enhancing the signal processing algorithms (Penetradar, 1995).

The user can also view the color intensity plots in the RDP phase. Color intensity plots are a quick reference to locate areas with major delaminations. These plots are basically a colorful profile view of the bridge deck. The X-axis corresponds to the length of deck traveled by the antenna and the Y-axis corresponds to the time of pulse travel, 
which can be easily converted to distance. The colors within the body of the plot are associated with the voltage at which the waveforms return to the antenna.

The step-by-step procedure of the RDP process can be seen in Appendix B.

\subsubsection{Post-processing}

The post-processing phase takes the information obtained from the RDP phase and generates valuable results. The first task to complete in the this third phase is to define the bridge. It is at this point where many of the previously discussed checklist items of Appendix A are employed, such as bridge name, skew angle/distance, pass distance, process interval, and pass of maximum skew.

Once the bridge has been defined, parameters that the user wants to be checked are set. Such parameters include joint detection, major echo locations, thickness measurement (concrete cover and/or asphalt cover), and delamination locations. For each category selected an illustrative graph is displayed onto the monitor.

Perhaps the best representation of whether a deck is satisfactory or substandard is by studying the bridge map. The bridge map is a plan view of the bridge deck with dark regions designating delaminated or deteriorated concrete. The user must choose one of four delamination identifiers: attenuation of the radar signal in concrete; asphalt/concrete (AC) echo characteristics; change detector parameters; and bottom echo characteristics. For each pass of radar data, the post-processing software computes a detection threshold depending on the type of identifier chosen. Any data that exceeds the threshold level is considered as deterioration on the bridge map. It is at this point where the checklist items consisting of weather and deck conditions play an important role in the deck analysis. 


\subsubsection{Attenuation}

Attenuation is the reduction or weakening of intensity of the radar signal due to a number of reasons including the presence of moisture and chloride within the body of the deck. Sound concrete does not contain much moisture or chloride, while substandard concrete does contain these rust producing agents. This method is an indirect measure of concrete deterioration and is effective when applied to process radar signals associated with wet bridge decks suspected of high chloride content.

\subsubsection{AC Echo Characteristics}

The presence of delaminations are in some ways associated with the increase in reflectivity at the AC interface. The user must be careful when incorporating this indicator because the presence of moisture in the concrete or at the AC interface may also produce the increase in reflectivity (Penetradar, 1995).

\subsubsection{Change Detector}

A bridge deck that is in good condition typically does not have a varying radar waveform signature. However, a deck that is in poor condition may contain many variations between adjacent waveforms. This direct method of measuring concrete deterioration and laminar cracks quantifies these variations. The change detector is effective when utilized with dry decks that were scanned during favorable weather conditions. 


\subsubsection{Bottom Echo Characteristic}

Another effective tool in locating delaminated or deteriorated concrete is the reflectivity of the deck bottom echo. The bottom echo characteristic is another indirect method of locating delaminations for radar signals showing high-loss conditions (Penetradar, 1995).

The step-by-step procedure of the post-processing phase for a typical bridge deck can be seen in Appendix C.

\subsection{Pertinent Bridge Information}

All three bridges that were scanned with the GPR system were located within the vicinity of Charleston, West Virginia, in Kanawha County, on Interstate 79.

\section{$\underline{5.5 .1 \text { Bridge } 1}$}

The first bridge that was tested with radar was bridge \#2666, located northbound on Interstate 79 at milepost 1.03. The thickness of the reinforced concrete bridge deck is 215.9mm (8.5”) with an additional 25.4mm (1") latex modified concrete wearing surface. There is a $76.2 \mathrm{~mm}$ (3") clearance between the riding surface and the top layer of steel reinforcement in addition to a $25.4 \mathrm{~mm}$ (1") clearance from the bottom of the deck to the bottom layer of rebar. This bridge was constructed in 1978, making it 20 years old at this time. Photographs of this bridge can be seen in Figure 5.1. 


\section{$\underline{5.5 .2}$ Bridge 2}

The second bridge that will be discussed in this report is known as the Knollwood Bridge. The number associated with the Knollwood Bridge is \#2667 and it is located northbound on Interstate 79 at milepost 0.76 . The total thickness of this deck is $228.6 \mathrm{~mm}$ (9"), which also includes a $25.4 \mathrm{~mm}$ (1") latex modified concrete overlay. The age of

Bridge 2 is similar to Bridge 1. Photographs of the Knollwood Bridge can be seen in Figure 5.2.

\section{$\underline{5.5 .3 \text { Bridge } 3}$}

The last bridge that will be discussed is also the Knollwood Bridge, but it is located in the southbound direction of Interstate 79 at milepost 0.76. Both Knollwood Bridges are not connected to one another, therefore they are two separate structures. The details of both bridges are exactly the same. A photograph of Bridge 3 can be seen in Figure 5.3. 


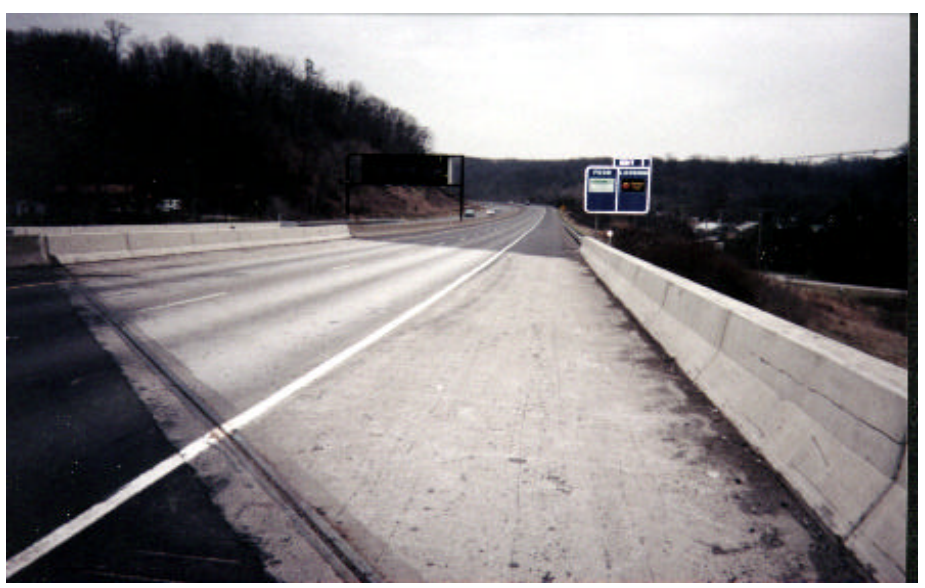

Figure 5.1: Photograph of Bridge \#2666, I-79 North

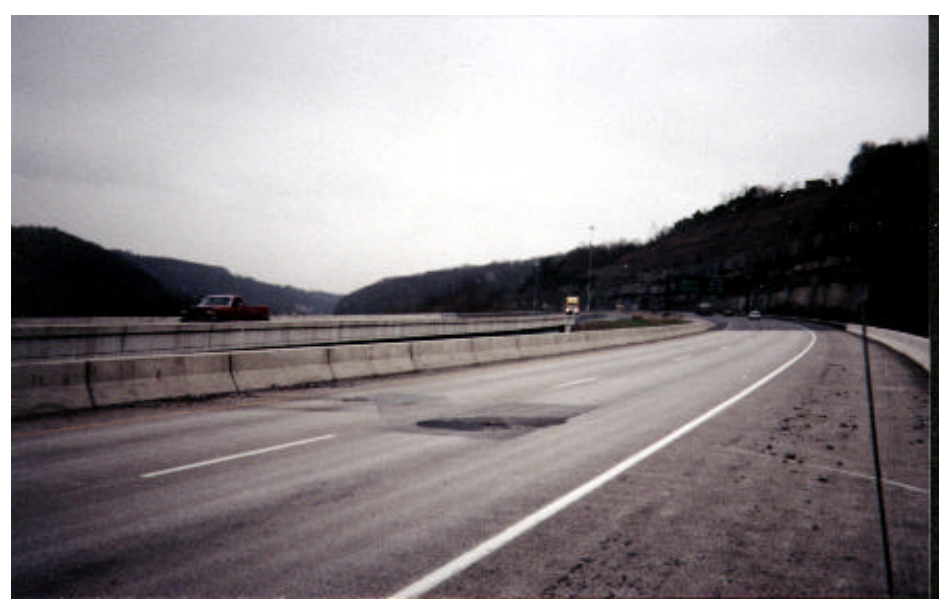

Figure 5.3: Photograph of Bridge \#2667, I-79 North

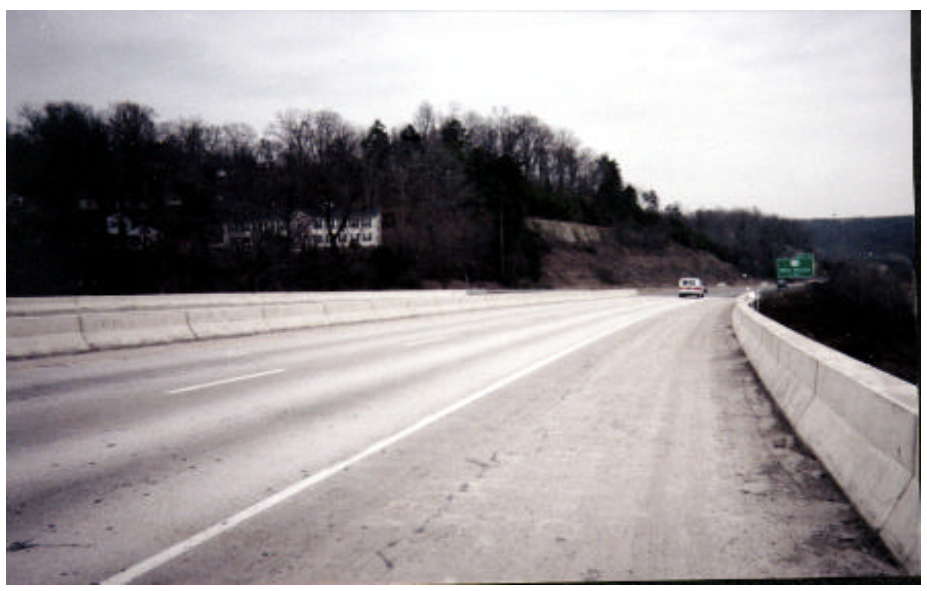

Figure 5.3: Photograph of Bridge \#2667, I-79 South 


\section{CHAPTER 6}

\section{RESULTS OF GPR TESTING}

\subsection{Introduction}

In this chapter, the color intensity plots will play an important role in directly determining the thickness of each deck interface. Also, the postprocessing thickness calculations will be compared to the results found directly from the color intensity plots. In addition, bridge deterioration maps for each bridge will be displayed.

\subsection{Results}

The way in which the thicknesses of the interfaces within the body of the deck are directly determined is by utilizing equations 2.6 and 2.7. Equation 2.6 deals with calculating the velocity of an electromagnetic wave passing through a media. The variables of equation 2.6 are the velocity of an electromagnetic wave in a vacuum $(0.3 \mathrm{~m} / \mathrm{ns})$ and the relative dielectric constant of concrete (8.22 is used in the software). Equation 2.7 is utilized to find the thickness of the interface due to the velocity computed from equation 2.6 and the two-way travel time of the wave within the interface. Since both variables in equation 2.6 are known, the velocity of the radar wave traveling through a concrete bridge deck can now be determined.

$$
\mathrm{v}=\frac{c}{\sqrt{\varepsilon_{r}}}=\frac{0.3 m}{n s} * \frac{1000 \mathrm{~mm}}{1 \mathrm{~m}} * \frac{1}{\sqrt{8.22}}=104.6 \mathrm{~mm} / \mathrm{ns}
$$


Upon inspection of the color intensity plots that are located at the end of this chapter, it is seen that the surface echo reflection is located at 1.0 nanoseconds for each pass made on each bridge. Therefore, 1.0 nanoseconds must be subtracted from each time that is associated for all other interfaces in order to obtain an accurate thickness calculation. Another important note to mention at this point is that the relative dielectric constant of the $25.4 \mathrm{~mm}$ (1") latex modified concrete overlay is unknown and assumed to be equal to the relative dielectric constant of concrete. This assumption may cause minute erroneous results.

\subsubsection{Bridge 1:}

The first bridge that will be analyzed is bridge \#2666 on Interstate 79 North. Representative color intensity plots of Bridge 1 are located in Figures 6.1 through 6.5. Upon inspection of those plots, the time locations for each interface is easily discernible. Table 6.1 shows the relative times for each interface with respect to the surface echo location, along with the calculated and actual depth values.

\begin{tabular}{|c|c|c|c|c|}
\hline Interface & $\begin{array}{c}\text { Relative Time } \\
(\mathbf{n s})\end{array}$ & $\begin{array}{c}\text { Calculated } \\
\text { Depth }(\mathbf{m m})\end{array}$ & $\begin{array}{c}\text { Actual Depth } \\
(\mathbf{m m})\end{array}$ & \% error \\
\hline Air/Surface & 0 & 0 & 0 & --- \\
\hline Overlay/Concrete & 0.711 & 37.1 & 25.4 & 46.0 \\
\hline 1st Layer Rebar & 1.733 & 90.7 & 76.2 & 19.0 \\
\hline 2nd Layer Rebar & 4.000 & 209.3 & 215.9 & -3.1 \\
\hline Deck Bottom & 4.867 & 254.8 & 241.3 & 5.6 \\
\hline
\end{tabular}

Table 6.1: Calculated vs. Actual Interface Depths for Bridge \#2666-Assumed Dielectric Constant of Overlay Same as Concrete (From Color Intensity Plots) 
As seen from Table 6.1, the calculated interface depths are somewhat erroneous. However, if the depths were measured with the overlay/concrete interface as the datum, the percent error would decrease moderately (see Table 6.2).

\begin{tabular}{|c|c|c|c|c|}
\hline Interface & $\begin{array}{c}\text { Relative Time } \\
(\mathbf{n s})\end{array}$ & $\begin{array}{c}\text { Calculated } \\
\text { Depth }(\mathbf{m m})\end{array}$ & $\begin{array}{c}\text { Actual Depth } \\
(\mathbf{m m})\end{array}$ & \% error \\
\hline Overlay/Concrete & 0 & 0 & 0 & --- \\
\hline 1st Layer Rebar & 1.022 & 53.6 & 50.8 & 5.5 \\
\hline 2nd Layer Rebar & 3.289 & 172.2 & 190.5 & -9.6 \\
\hline Deck Bottom & 4.156 & 217.4 & 215.9 & 0.7 \\
\hline
\end{tabular}

Table 6.2: Calculated vs. Actual Depths Measured from Overlay/Concrete Interface for Bridge \#2666 (From Color Intensity Plots)

Table 6.2 shows that the calculated depths are closer to the true value when measured from the overlay/concrete interface. Therefore, the assumption that the relative dielectric constant of the overlay and that of concrete are equal does influence the outcome of the thickness calculation.

The postprocessing software also provides a graph of the major echo locations with a time vs. deck length plot. There are only four interfaces that can be shown at a time on this graph because of the limitation of only being able to choose three echo locations, other than the surface echo, on the waterfall plot of the processing phase. Therefore, if it is known that there are more than four interfaces, the user will have to process the information twice.

In order to determine the depth at which the deck interfaces exist according to the 
major echo locations graph, equations 2.6 and 2.7 must be utilized again. The time vs. deck length graph for Bridge 1 can be seen in Figure 6.16, and the depths to the deck interfaces measured from the surface and the overlay/concrete interfaces can be seen in Tables 6.3 and 6.4, respectively. The user must remember which interfaces are being analyzed when looking at the major echo locations graph because the software automatically names the interfaces. For instance, in Figure 6.2 the second interface from the bottom is labeled as the asphalt/concrete interface, when in reality it is the interface between the latex modified concrete overlay and the concrete deck.

\begin{tabular}{|c|c|c|c|c|}
\hline Interface & $\begin{array}{c}\text { Relative Time } \\
(\mathbf{n s})\end{array}$ & $\begin{array}{c}\text { Calculated } \\
\text { Depth } \mathbf{( m m})\end{array}$ & $\begin{array}{c}\text { Actual Depth } \\
(\mathbf{m m})\end{array}$ & \% error \\
\hline Air/Surface & 0 & 0 & 0 & --- \\
\hline Overlay/Concrete & 1.50 & 78.5 & 25.4 & 209.0 \\
\hline 1st Layer Rebar & 2.75 & 144.0 & 76.2 & 89.0 \\
\hline 2nd Layer Rebar & 5.00 & 261.6 & 215.9 & 21.2 \\
\hline Deck Bottom & 5.50 & 287.8 & 241.3 & 19.3 \\
\hline
\end{tabular}

Table 6.3: Calculated vs. Actual Interface Depths for Bridge \#2666-Assumed Dielectric Constant of Overlay Same as Concrete (From Postprocessing)

\begin{tabular}{|c|c|c|c|c|}
\hline Interface & $\begin{array}{c}\text { Relative Time } \\
(\mathbf{n s})\end{array}$ & $\begin{array}{c}\text { Calculated } \\
\text { Depth }(\mathbf{m m})\end{array}$ & $\begin{array}{c}\text { Actual Depth } \\
(\mathbf{m m})\end{array}$ & \% error \\
\hline Overlay/Concrete & 0 & 0 & 0 & --- \\
\hline 1st Layer Rebar & 1.25 & 65.5 & 50.8 & 28.9 \\
\hline 2nd Layer Rebar & 3.50 & 183.1 & 190.5 & -3.9 \\
\hline Deck Bottom & 4.00 & 209.3 & 215.9 & -3.1 \\
\hline
\end{tabular}

Table 6.4: Calculated vs. Actual Interface Depths Measured from Overlay/Concrete Interface for Bridge \#2666 (From Postprocessing) 
It is quite apparent from Table 6.3 that the calculated interface depths from the postprocessing software is very inaccurate when measured from the deck surface. However, when the interface depths are determined with respect to the overlay/concrete interface, the results are much better as evidenced by Table 6.4. An important note to mention at this point is the relative times that were taken from Figure 6.16 are estimations because of the time fluctuations for each radar wave.

The postprocessing software also provides a bridge deterioration map which is a plan view of the bridge deck with darkened squares representing defective areas. The bridge deterioration map for Bridge 1 is located in Figure 6.17. From that figure and from statistical information provided by the software, the percent of deck deterioration per radar pass and for the whole deck is given. That information for Bridge 1 is located in Table 6.5. The deterioration information from that table is based on the postprocessing parameter of change detector, type 1 , with a threshold coefficient of 0.70 . Using different parameters may change the outcome of the analysis greatly.

\begin{tabular}{|c|c|c|c|c|c|c|}
\hline & Pass 1 & Pass 2 & Pass 3 & Pass 4 & Pass 5 & Total Deck \\
\hline \% Deter. & 7.18 & 8.28 & 10.53 & 5.39 & 7.10 & 7.70 \\
\hline
\end{tabular}

Table 6.5: Percentage of Deck Deteriorated for Bridge \#2666

\subsubsection{Bridge 2:}

The second bridge that will be analyzed in detail using the GPR equipment and software is the Knollwood Bridge on northbound Interstate 79. Representative color intensity plots of this bridge can be seen in Figures 6.6 through 6.11. Upon inspection of 
those figures, the locations of the major echoes can easily be determined. In a similar fashion as what was done with Bridge 1, the depths to the major interfaces can be calculated using equations 2.6 and 2.7. The results of these calculations, along with the relative two-way travel times of the radar waves are given in Table 6.6. The same calculations using the overlay/concrete interface as the datum is given in Table 6.7.

\begin{tabular}{|c|c|c|c|c|}
\hline Interface & $\begin{array}{c}\text { Relative Time } \\
(\mathbf{n s})\end{array}$ & $\begin{array}{c}\text { Calculated } \\
\text { Depth }(\mathbf{m m})\end{array}$ & $\begin{array}{c}\text { Actual Depth } \\
(\mathbf{m m})\end{array}$ & \% error \\
\hline Air/Surface & 0 & 0 & 0 & --- \\
\hline Overlay/Concrete & 0.667 & 34.8 & 25.4 & 37.0 \\
\hline 1st Layer Rebar & 1.733 & 90.7 & 76.2 & 19.0 \\
\hline 2nd Layer Rebar & 4.022 & 210.6 & 203.2 & 3.6 \\
\hline Deck Bottom & 4.844 & 253.5 & 228.6 & 10.9 \\
\hline
\end{tabular}

Table 6.6: Calculated vs. Actual Interface Depths Measured for Knollwood Bridge, I-79 North-Assumed Dielectric Constant of Overlay Same as Concrete (From Color Intensity Plots)

\begin{tabular}{|c|c|c|c|c|}
\hline Interface & $\begin{array}{c}\text { Relative Time } \\
(\mathbf{n s})\end{array}$ & $\begin{array}{c}\text { Calculated } \\
\text { Depth }(\mathbf{m m})\end{array}$ & $\begin{array}{c}\text { Actual Depth } \\
(\mathbf{m m})\end{array}$ & \% error \\
\hline Overlay/Concrete & 0 & 0 & 0 & --- \\
\hline 1st Layer Rebar & 1.067 & 55.9 & 50.8 & 10.0 \\
\hline 2nd Layer Rebar & 3.356 & 175.5 & 177.8 & -1.3 \\
\hline Deck Bottom & 4.178 & 218.7 & 203.2 & 7.6 \\
\hline
\end{tabular}

Table 6.7: Calculated vs. Actual Interface Depths Measured from Overlay/Concrete Interface for Knollwood Bridge, I-79 North (From Color Intensity Plots) 
Again, from inspection of the previous two tables it is apparent that the results are less erroneous when the depth measurements are taken with respect to the overlay/concrete interface because of the unknown relative dielectric constant of the overlay.

The time vs. deck length plot from the postprocessing software associated with Bridge 2 is located in Figure 6.18. After applying equations 2.6 and 2.7 to the estimated times taken from Figure 6.18, the depths to the different interfaces can be determined and are given in Tables 6.8 and 6.9 .

\begin{tabular}{|c|c|c|c|c|}
\hline Interface & $\begin{array}{c}\text { Relative Time } \\
(\mathbf{n s})\end{array}$ & $\begin{array}{c}\text { Calculated } \\
\text { Depth }(\mathbf{m m})\end{array}$ & $\begin{array}{c}\text { Actual Depth } \\
(\mathbf{m m})\end{array}$ & \% error \\
\hline Air/Surface & 0 & 0 & 0 & --- \\
\hline Overlay/Concrete & 1.50 & 78.5 & 25.4 & 209.0 \\
\hline 1st Layer Rebar & 2.60 & 136.1 & 76.2 & 78.6 \\
\hline 2nd Layer Rebar & 5.00 & 261.6 & 203.2 & 28.7 \\
\hline Deck Bottom & 5.50 & 287.8 & 228.6 & 25.9 \\
\hline
\end{tabular}

Table 6.8: Calculated vs. Actual Interface Depths for Knollwood Bridge, I-79 NorthAssumed Dielectric Constant of Overlay Same as Concrete (From Postprocessing)

\begin{tabular}{|c|c|c|c|c|}
\hline Interface & $\begin{array}{c}\text { Relative Time } \\
(\mathbf{n s})\end{array}$ & $\begin{array}{c}\text { Calculated } \\
\text { Depth }(\mathbf{m m})\end{array}$ & $\begin{array}{c}\text { Actual Depth } \\
(\mathbf{m m})\end{array}$ & \% error \\
\hline Overlay/Concrete & 0 & 0 & 0 & --- \\
\hline 1st Layer Rebar & 1.10 & 57.7 & 50.8 & 13.6 \\
\hline 2nd Layer Rebar & 3.50 & 183.1 & 177.8 & 3.0 \\
\hline Deck Bottom & 4.00 & 209.3 & 203.2 & 3.0 \\
\hline
\end{tabular}

Table 6.9: Calculated vs. Actual Depths Measured from Overlay/Concrete Interface for Knollwood Bridge, I-79 North (From Postprocessing) 
The bridge deterioration map for the northbound Knollwood Bridge which is generated by the postprocessing program is given in Figure 6.19. From this figure and the statistical information kept within the text files, the percentage of deterioration per pass and for the total deck is provided and shown in Table 6.10. The parameters used in the postprocessing of Bridge 2 was the same as what was used in Bridge 1: Change detector, type 1 , with a threshold coefficient of 0.70 . The user may wish to increase or decrease the threshold coefficient as he/she deems necessary.

\begin{tabular}{|c|c|c|c|c|c|c|}
\hline & Pass 1 & Pass 2 & Pass 3 & Pass 4 & Pass 5 & Total Deck \\
\hline \% Deter. & 5.04 & 2.72 & 2.39 & 7.62 & 7.62 & 5.20 \\
\hline
\end{tabular}

Table 6.10: Percentage of Deck Deteriorated for Knollwood Bridge, I-79 North

\subsubsection{Bridge 3:}

The third bridge that will be analyzed in detail using the GPR equipment and software is the Knollwood Bridge on southbound Interstate 79. Representative color intensity plots of this bridge, with echo locations marked, can be seen in Figures 6.12 through 6.15. In a similar fashion as what was done with the previous two bridges, the depths to the major interfaces can be calculated using equations 2.6 and 2.7. The results of these calculations, along with the two-way travel times of the radar waves with respect to the two established datums, are given in Tables 6.11 and 6.12. 


\begin{tabular}{|c|c|c|c|c|}
\hline Interface & $\begin{array}{c}\text { Relative Time } \\
(\mathbf{n s})\end{array}$ & $\begin{array}{c}\text { Calculated } \\
\text { Depth }(\mathbf{m m})\end{array}$ & $\begin{array}{c}\text { Actual Depth } \\
(\mathbf{m m})\end{array}$ & \% error \\
\hline Air/Surface & 0 & 0 & 0 & --- \\
\hline Overlay/Concrete & 0.667 & 34.8 & 25.4 & 37.0 \\
\hline 1st Layer Rebar & 1.733 & 90.7 & 76.2 & 19.0 \\
\hline 2nd Layer Rebar & 4.000 & 209.3 & 203.2 & 3.0 \\
\hline Deck Bottom & 4.822 & 252.2 & 228.6 & 10.3 \\
\hline
\end{tabular}

Table 6.11: Calculated vs. Actual Interface Depths for Knollwood Bridge, I-79

South-Assumed Dielectric Constant of Overlay Same as Concrete (From Color

Intensity Plots)

\begin{tabular}{|c|c|c|c|c|}
\hline Interface & $\begin{array}{c}\text { Relative Time } \\
(\mathbf{n s})\end{array}$ & $\begin{array}{c}\text { Calculated } \\
\text { Depth }(\mathbf{m m})\end{array}$ & $\begin{array}{c}\text { Actual Depth } \\
(\mathbf{m m})\end{array}$ & \% error \\
\hline Overlay/Concrete & 0 & 0 & 0 & --- \\
\hline 1st Layer Rebar & 1.066 & 55.9 & 50.8 & 10.0 \\
\hline 2nd Layer Rebar & 3.333 & 174.5 & 177.8 & -1.9 \\
\hline Deck Bottom & 4.155 & 217.4 & 203.2 & 7.0 \\
\hline
\end{tabular}

Table 6.12: Calculated vs. Actual Depths Measured from Overlay/Concrete Interface for Knollwood Bridge, I-79 South (From Color Intensity Plots)

From inspection of the previous two tables it is proven again that the results are less erroneous when the depth measurements are taken with respect to the overlay/concrete interface because of the unknown relative dielectric constant of the overlay.

The time vs. deck length plot from the postprocessing software associated with Bridge 3 is located in Figure 6.20. After applying equations 2.6 and 2.7 to the estimated 
times taken from Figure 6.20, the depths to the different interfaces can be determined and are given in Tables 6.13 and 6.14 .

\begin{tabular}{|c|c|c|c|c|}
\hline Interface & $\begin{array}{c}\text { Relative Time } \\
(\mathbf{n s})\end{array}$ & $\begin{array}{c}\text { Calculated } \\
\text { Depth }(\mathbf{m m})\end{array}$ & $\begin{array}{c}\text { Actual Depth } \\
(\mathbf{m m})\end{array}$ & \% error \\
\hline Air/Surface & 0 & 0 & 0 & --- \\
\hline Overlay/Concrete & 1.45 & 75.9 & 25.4 & 198.8 \\
\hline 1st Layer Rebar & 2.15 & 112.5 & 76.2 & 47.6 \\
\hline 2nd Layer Rebar & 5.00 & 261.6 & 203.2 & 28.7 \\
\hline Deck Bottom & 5.50 & 287.8 & 228.6 & 25.9 \\
\hline
\end{tabular}

Table 6.13: Calculated vs. Actual Interface Depths for Knollwood Bridge, I-79 South-Assumed Dielectric Constant of Overlay Same as Concrete (From Postprocessing)

\begin{tabular}{|c|c|c|c|c|}
\hline Interface & $\begin{array}{c}\text { Relative Time } \\
(\mathbf{n s})\end{array}$ & $\begin{array}{c}\text { Calculated } \\
\text { Depth }(\mathbf{m m})\end{array}$ & $\begin{array}{c}\text { Actual Depth } \\
(\mathbf{m m})\end{array}$ & \% error \\
\hline Overlay/Concrete & 0 & 0 & 0 & --- \\
\hline 1st Layer Rebar & 0.70 & 36.6 & 50.8 & -28.0 \\
\hline 2nd Layer Rebar & 3.55 & 185.7 & 177.8 & 4.4 \\
\hline Deck Bottom & 4.05 & 211.8 & 203.2 & 4.2 \\
\hline
\end{tabular}

Table 6.14:Calculated vs. Actual Interface Depths Measured from Overlay/Concrete Interface for Knollwood Bridge, I-79 South (From Postprocessing)

The bridge deterioration map generated by the postprocessing software for the southbound Knollwood Bridge is given in Figure 6.21. From this figure and the statistical information provided by the software, the percentage of deterioration per pass and for the total deck is provided and shown in Table 6.15. The parameters used in the 
postprocessing of Bridge 3 was the same as what was used in the previous two bridges: Change detector, type 1 , with a threshold coefficient of 0.70 . Again, the user may wish to increase or decrease the threshold coefficient as he/she deems necessary.

\begin{tabular}{|c|c|c|c|c|c|}
\hline & Pass 1 & Pass 2 & Pass 3 & Pass 4 & Total Deck \\
\hline \% Deter. & 7.49 & 4.09 & 4.71 & 1.70 & 4.50 \\
\hline
\end{tabular}

Table 6.15: Percentage of Deck Deteriorated for Knollwood Bridge, I-79 South

Also provided for Bridge 3 is a delamination survey generated from a chain drag test which occurred in 1993. This survey can be seen in Figure 6.22. Since the chain drag testing occurred five years prior to the radar scanning, some of the information from Figure 6.22 may not be accurate at the present time. Also, the exact location of the radar scanning passes are not known because the checklist of Appendix A had not been developed as of the time of scanning. However, at this point this delamination survey is the only item that can be used as a direct comparison to the postprocessing bridge deterioration map. In Figure 6.22, the approximate locations of the passes made by the radar van were to the right of the dotted line. Even though the exact location of the passes are not known, one can see that the information from the two NDT methods do not match very well. According to the postprocessing program, it is seen in Figure 6.21 that there is sporadic deterioration throughout the length of the deck where the radar van made passes. From Figure 6.22 it is seen that there is deterioration at approximately the 18.3, 21.3, 27.4, 64.0, 76.2, and 79.2 meter $(60,70,90,210,250$, and 260 foot) markers. Again, the chain drag analysis for Bridge 3 was conducted approximately five years ago 
and some of the information associated with it may be incorrect today. However, due to the extreme differences between Figures 6.21 and 6.22, there seems to be problems with the postprocessing software. As a matter of fact, a representative of the company which produced the software stated that the 1995 version of the program is not their most updated release and may have some bugs. New deck analysis software has since been developed by Penetradar Corporation which may not carry the same problems.

\subsection{Summary of GPR Testing}

The results of the GPR scanning show that color intensity plots are useful tools in determining thickness profiles of highway bridge decks. The maximum error encountered when using the color intensity plots was $10 \%$. The postprocessing software is not as reliable as the direct method of using the color intensity plots, as indicated by the $29 \%$ maximum error associated with its use. In addition, engineers must practice caution when performing radar inspections on bridge decks with material that has unknown relative dielectric constants.

The results of the deterioration investigation showed that the postprocessing software used in this project needs some revision. In fact, new software has hence been produced, as mentioned previously. The reason for the uncertainty lies in the fact that the deterioration maps vary considerably from minute adjustments of the postprocessing parameters. Therefore, engineers conducting deck inspections must exercise caution when utilizing the 1995 version of this particular software. 


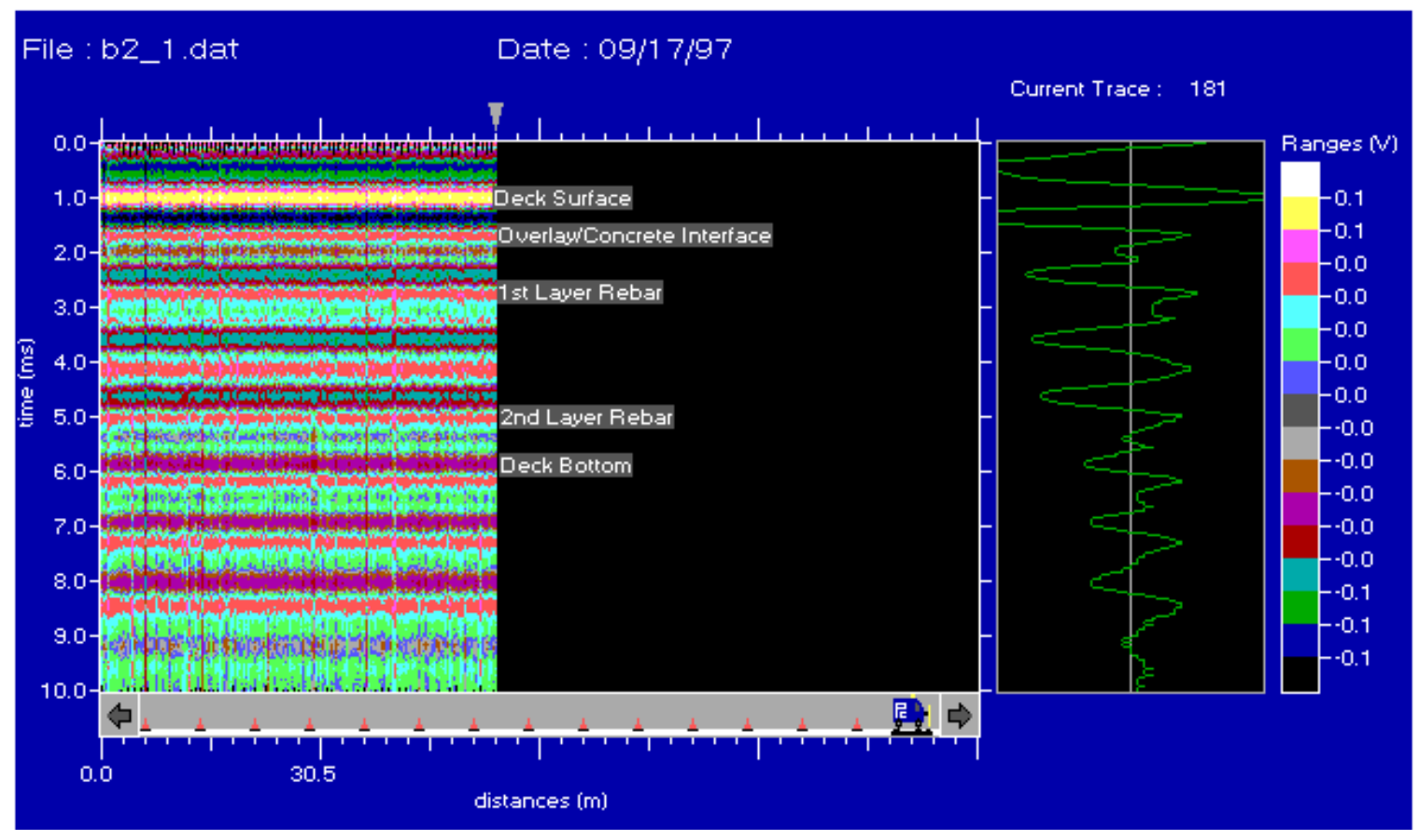

Figure 6.1: Color Intensity Plot of Bridge 1, Pass 1

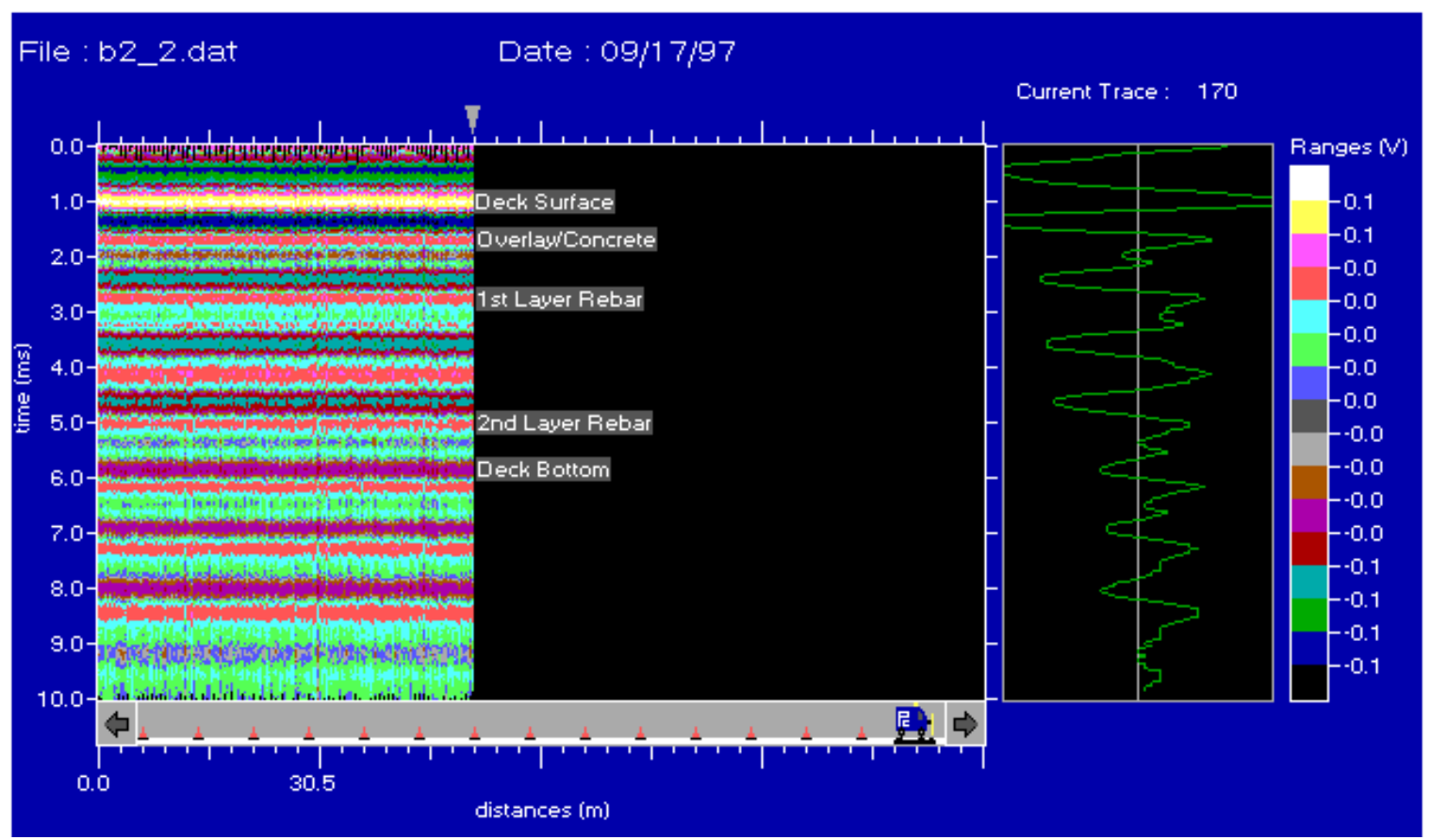

Figure 6.2: Color Intensity Plot of Bridge 1, Pass 2 


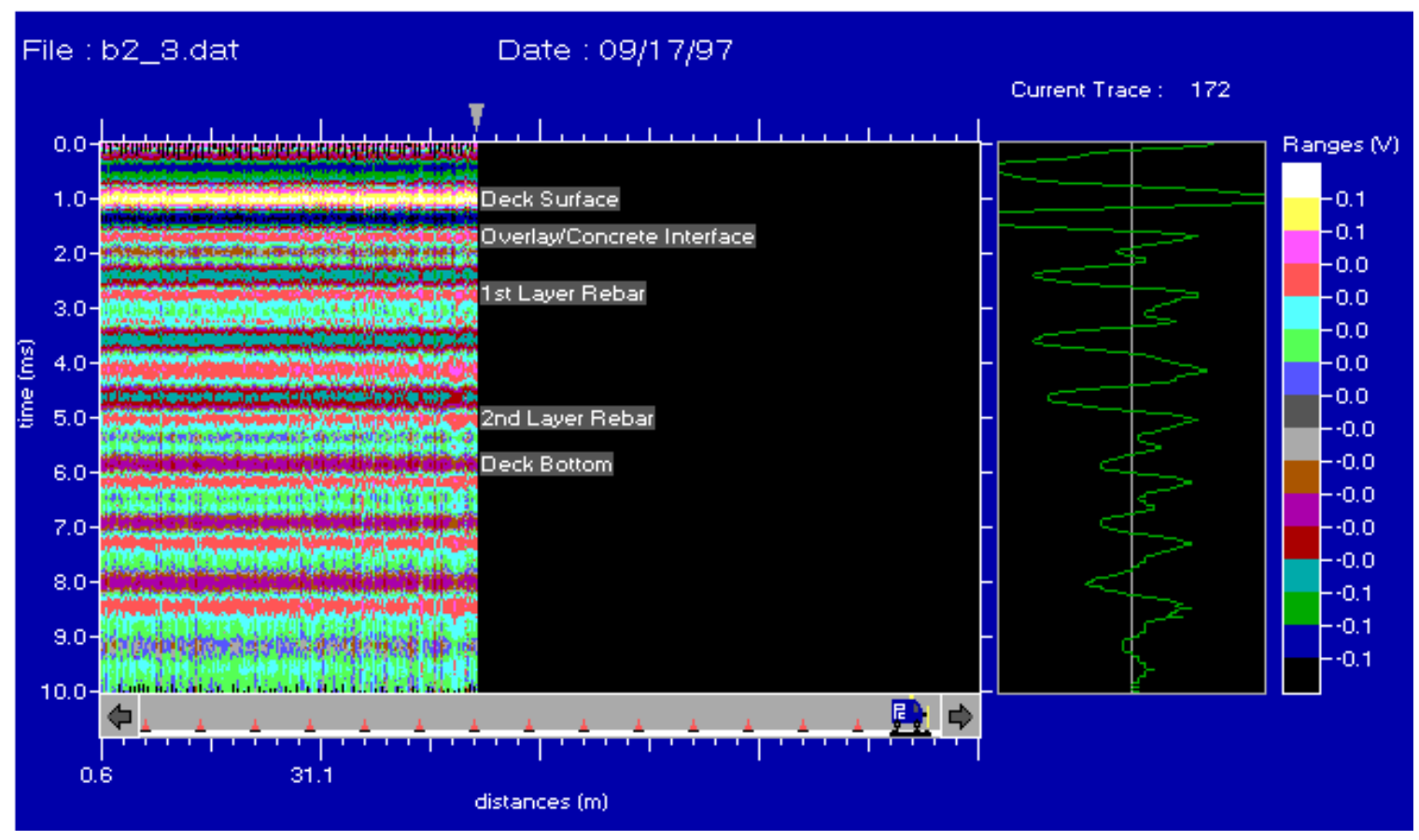

Figure 6.3: Color Intensity Plot of Bridge 1, Pass 3

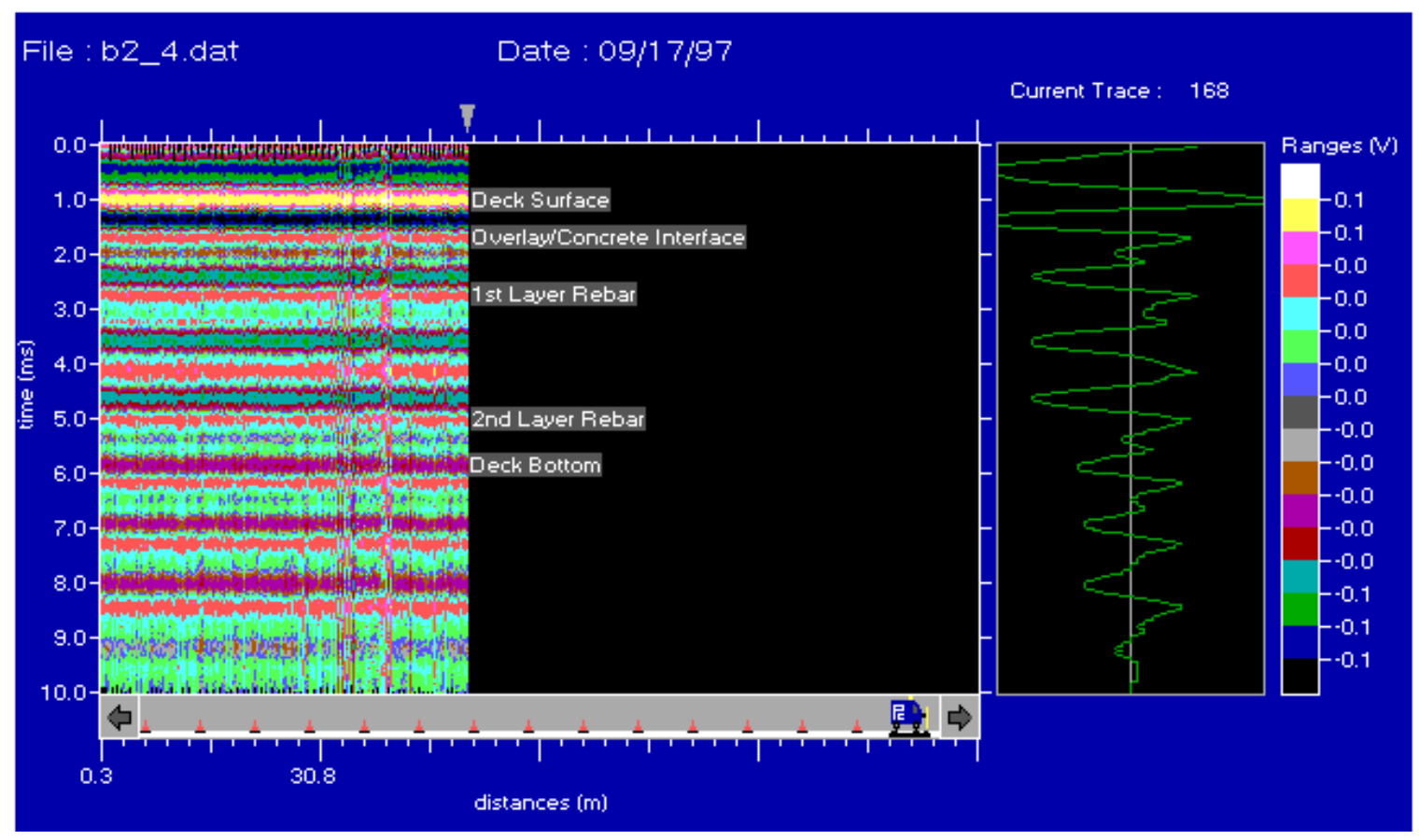

Figure 6.4: Color Intensity Plot of Bridge 1, Pass 4 


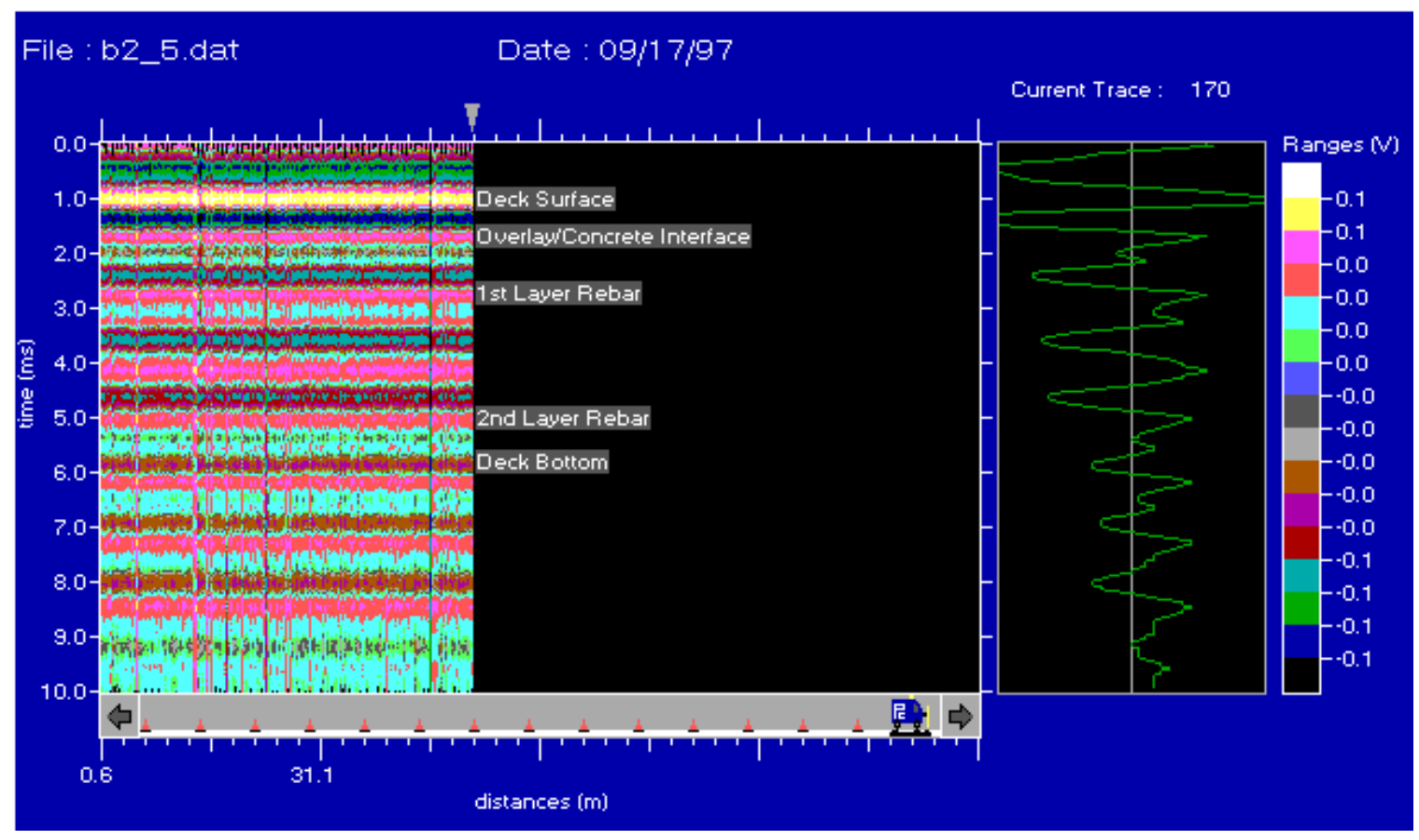

Figure 6.5: Color Intensity Plot of Bridge 1, Pass 5

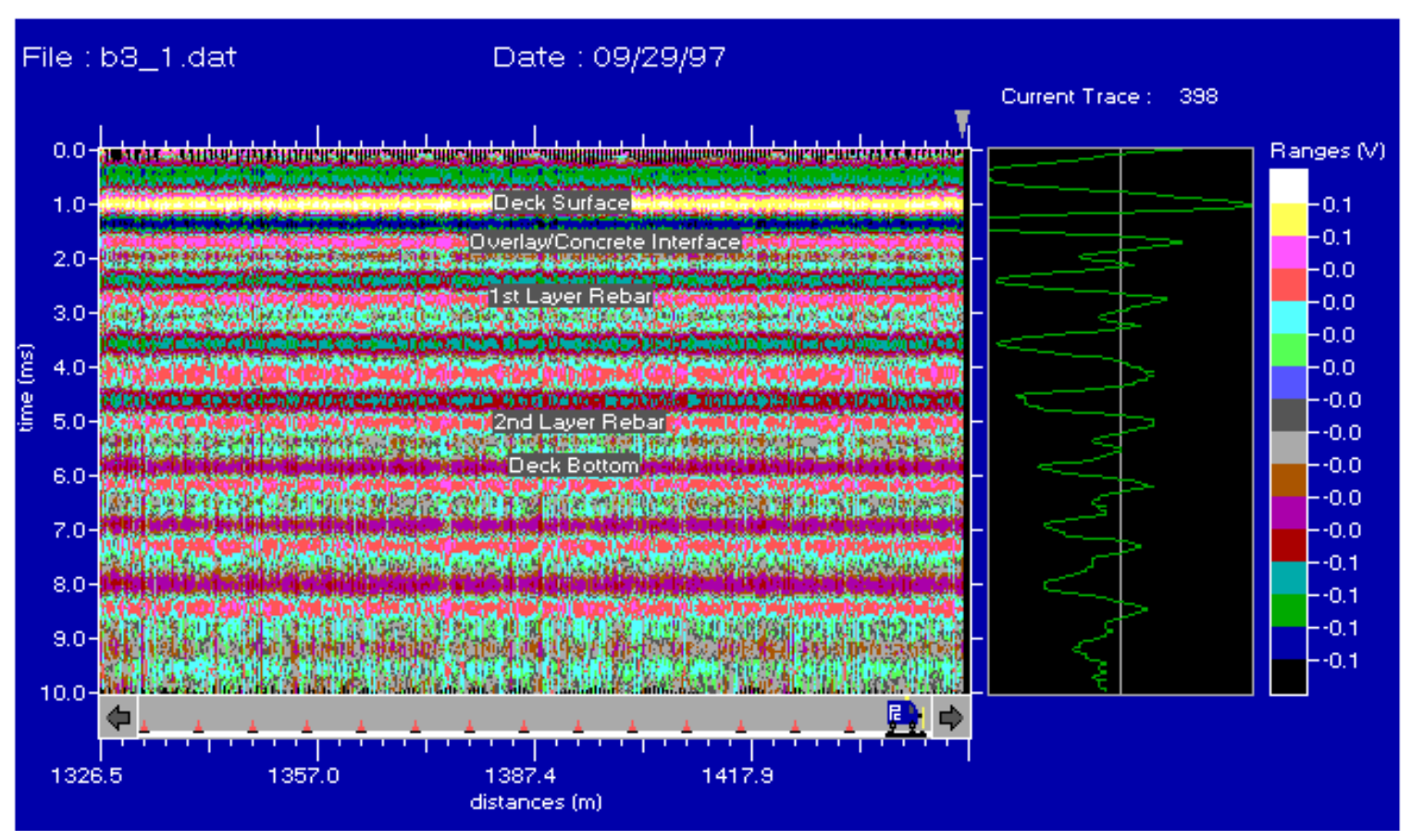

Figure 6.6: Color Intensity Plot of Bridge 2, Pass 1 


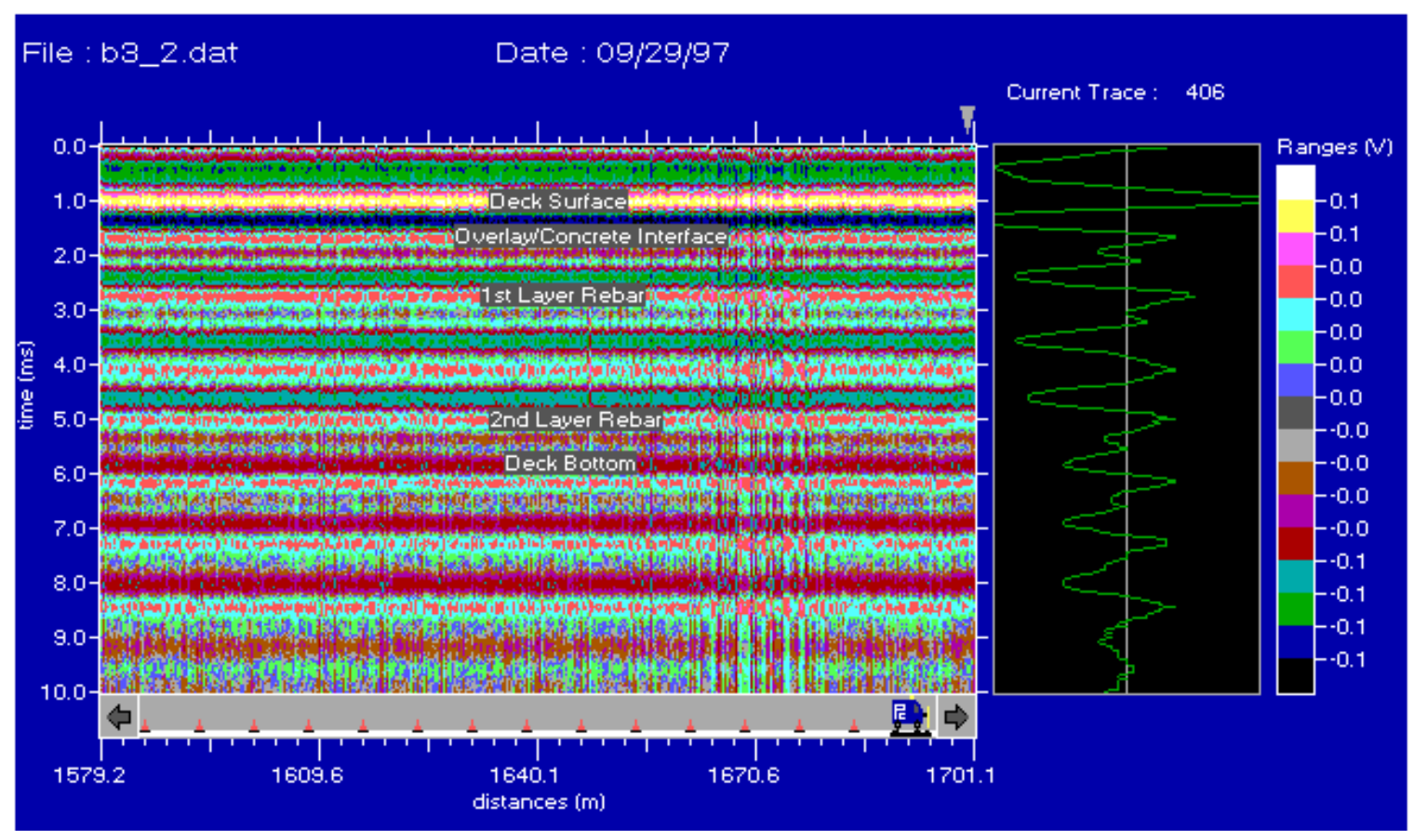

Figure 6.7: Color Intensity Plot of Bridge 2, Pass 2

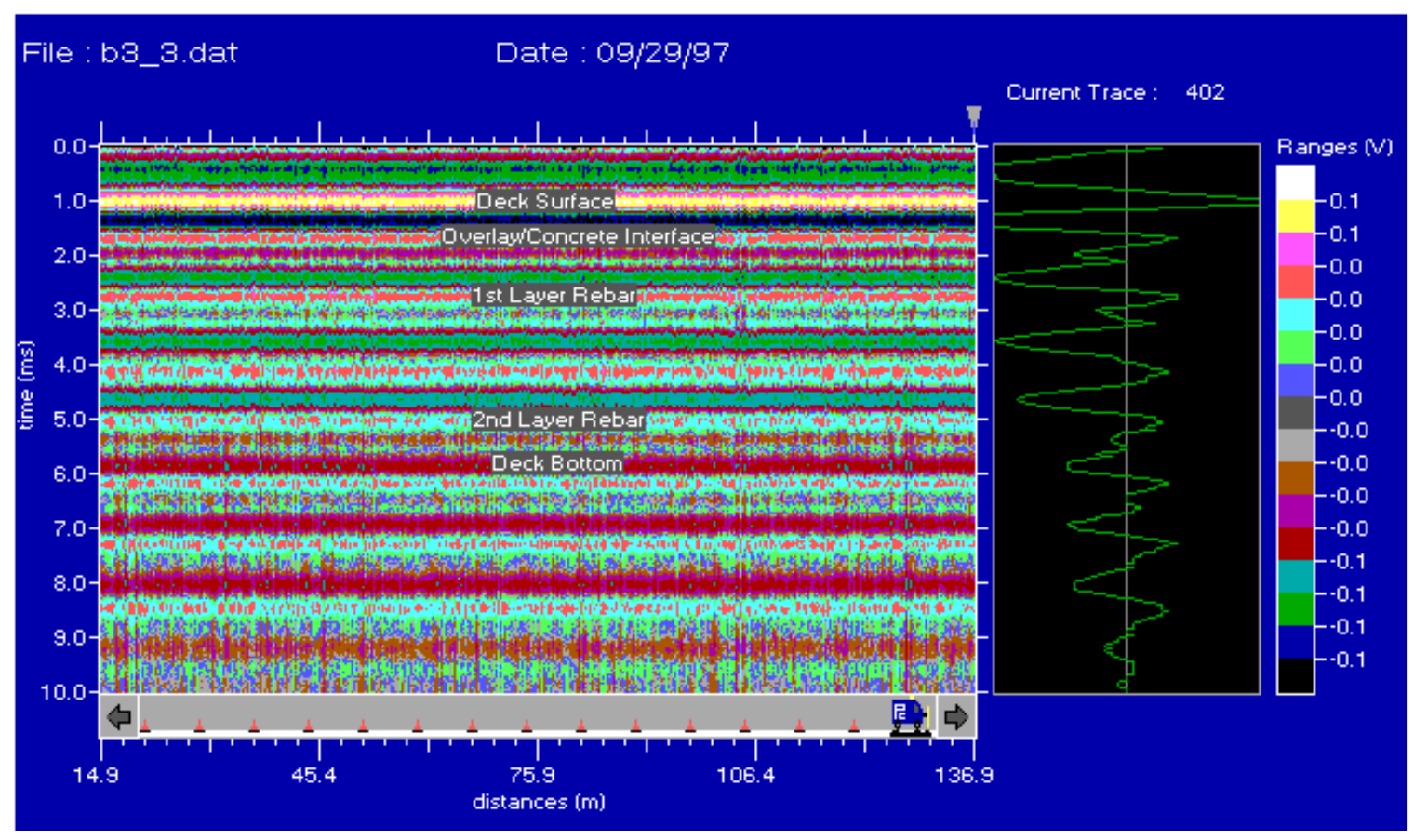

Figure 6.8: Color Intensity Plot of Bridge 2, Pass 3 


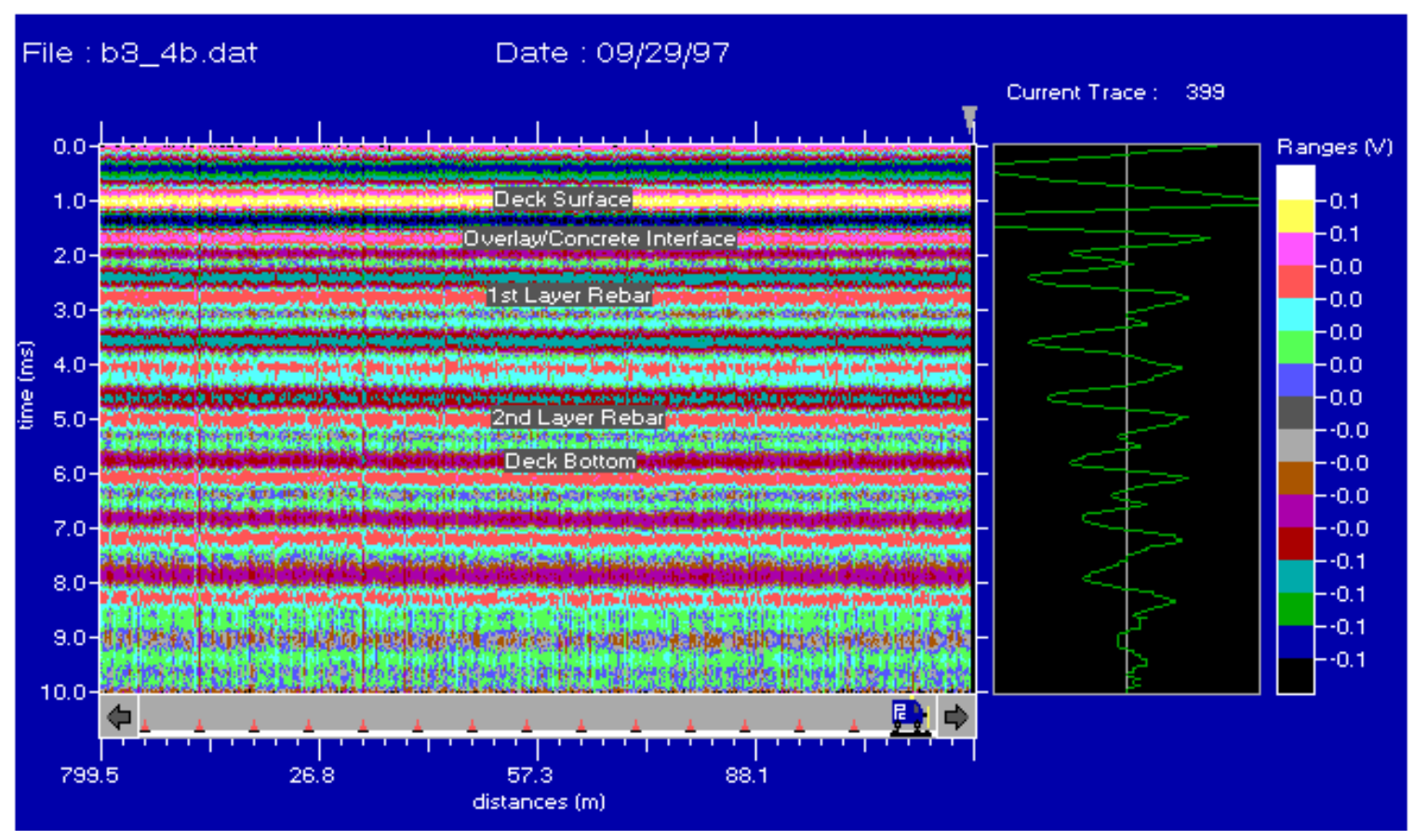

Figure 6.9: Color Intensity Plot of Bridge 2, Pass 4

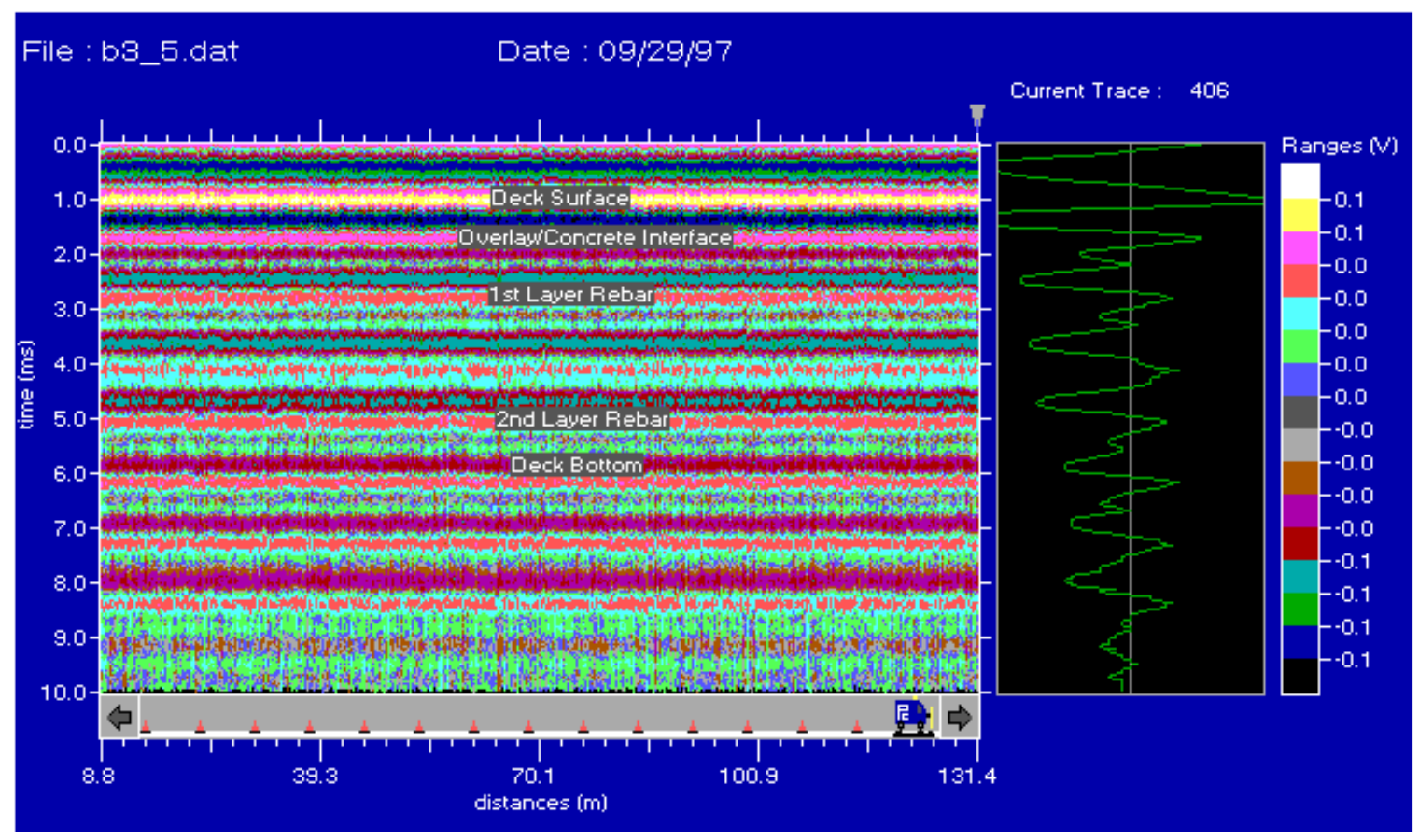

Figure 6.10: Color Intensity Plot of Bridge 2, Pass 5 


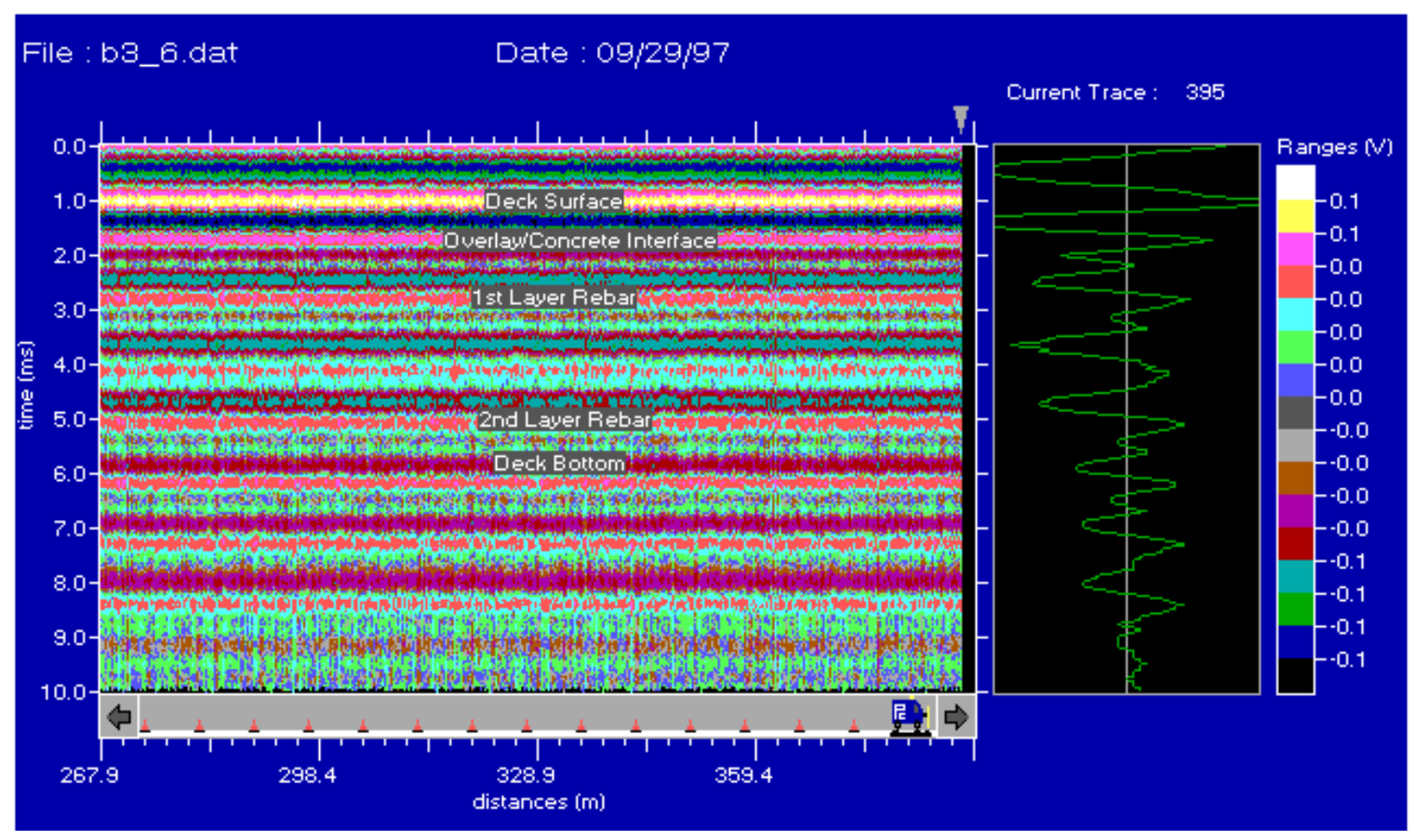

Figure 6.11: Color Intensity Plot of Bridge 2, Pass 6

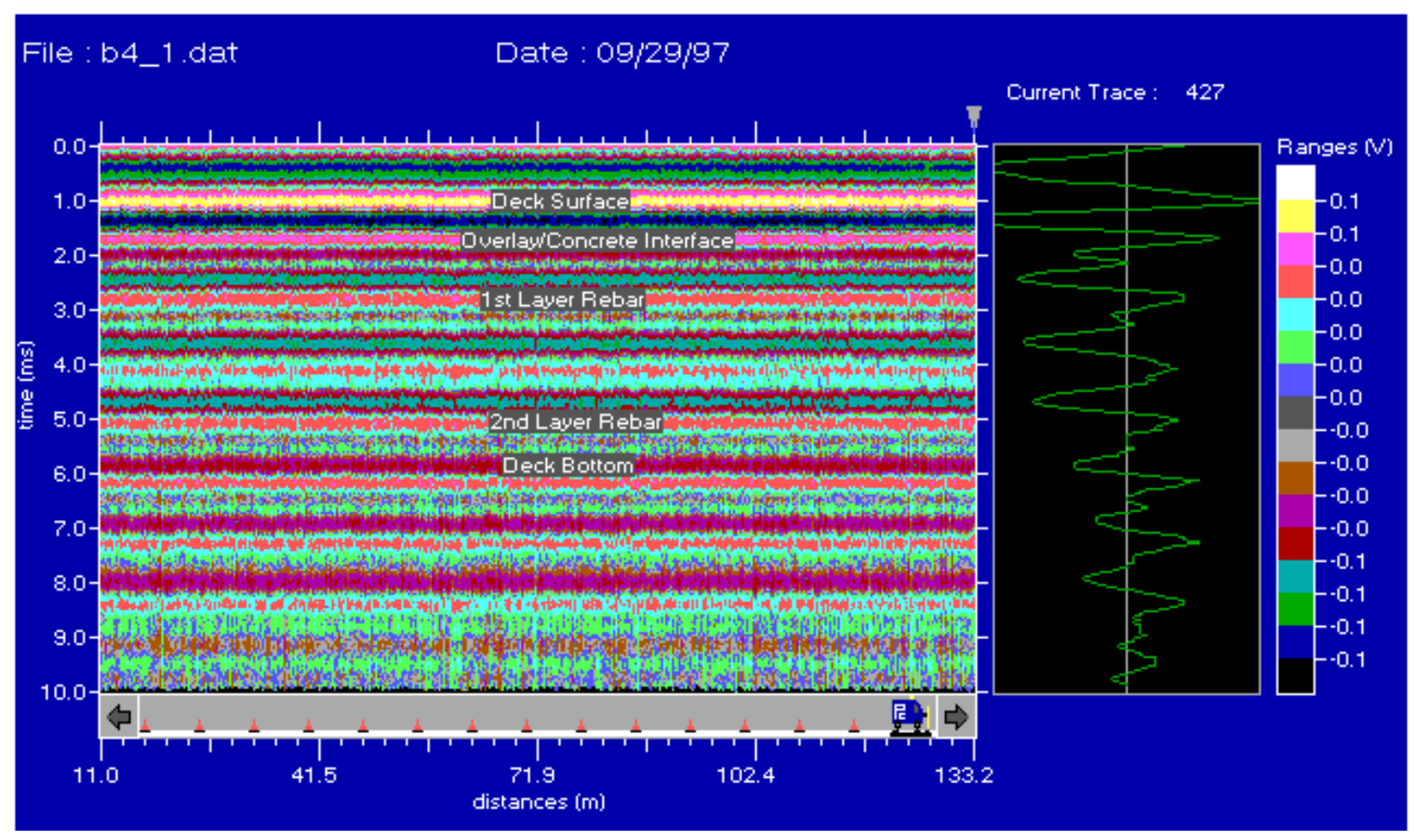

Figure 6.12: Color Intensity Plot of Bridge 3, Pass 1 


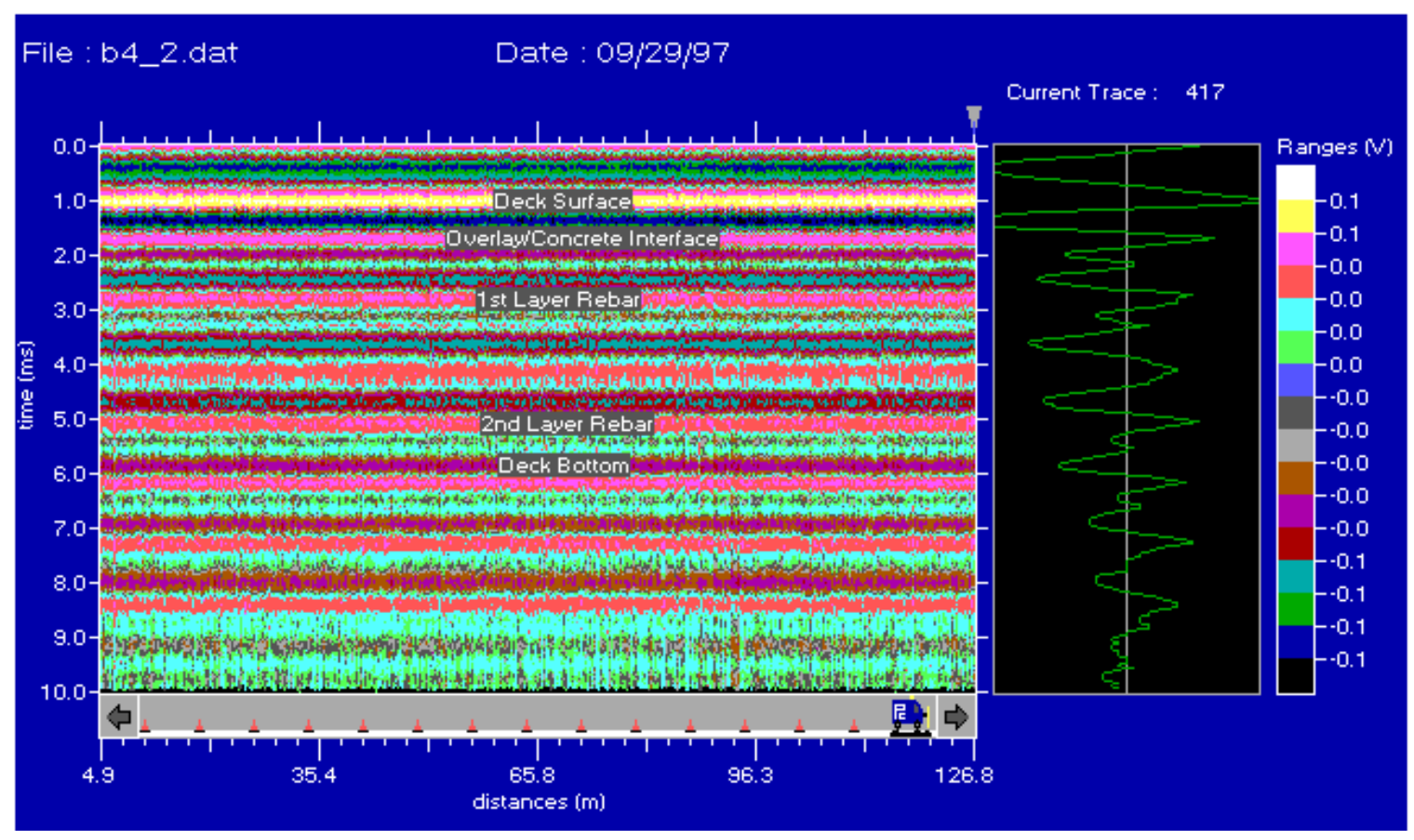

Figure 6.13: Color Intensity Plot of Bridge 3, Pass 2

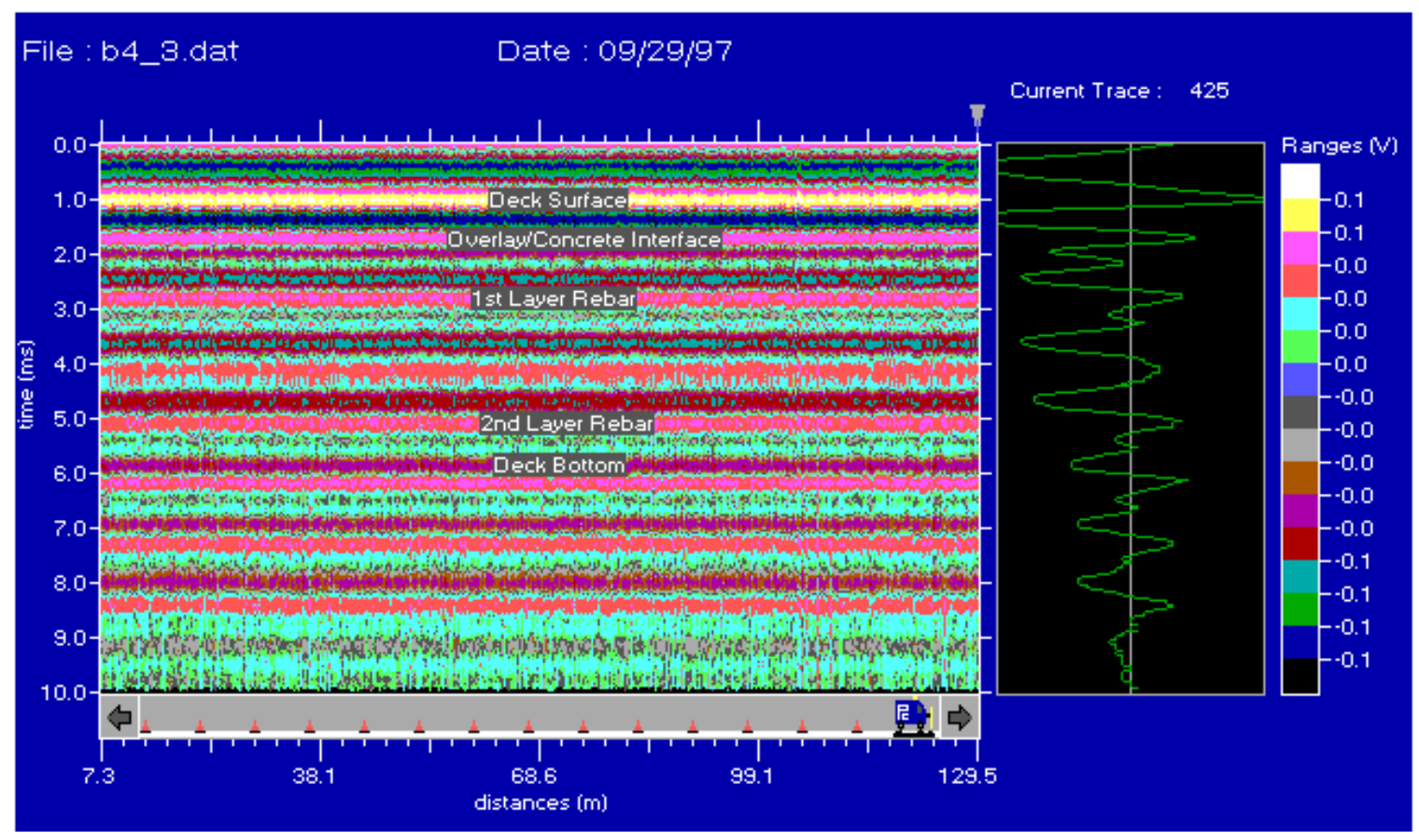

Figure 6.14: Color Intensity Plot of Bridge 3, Pass 3 


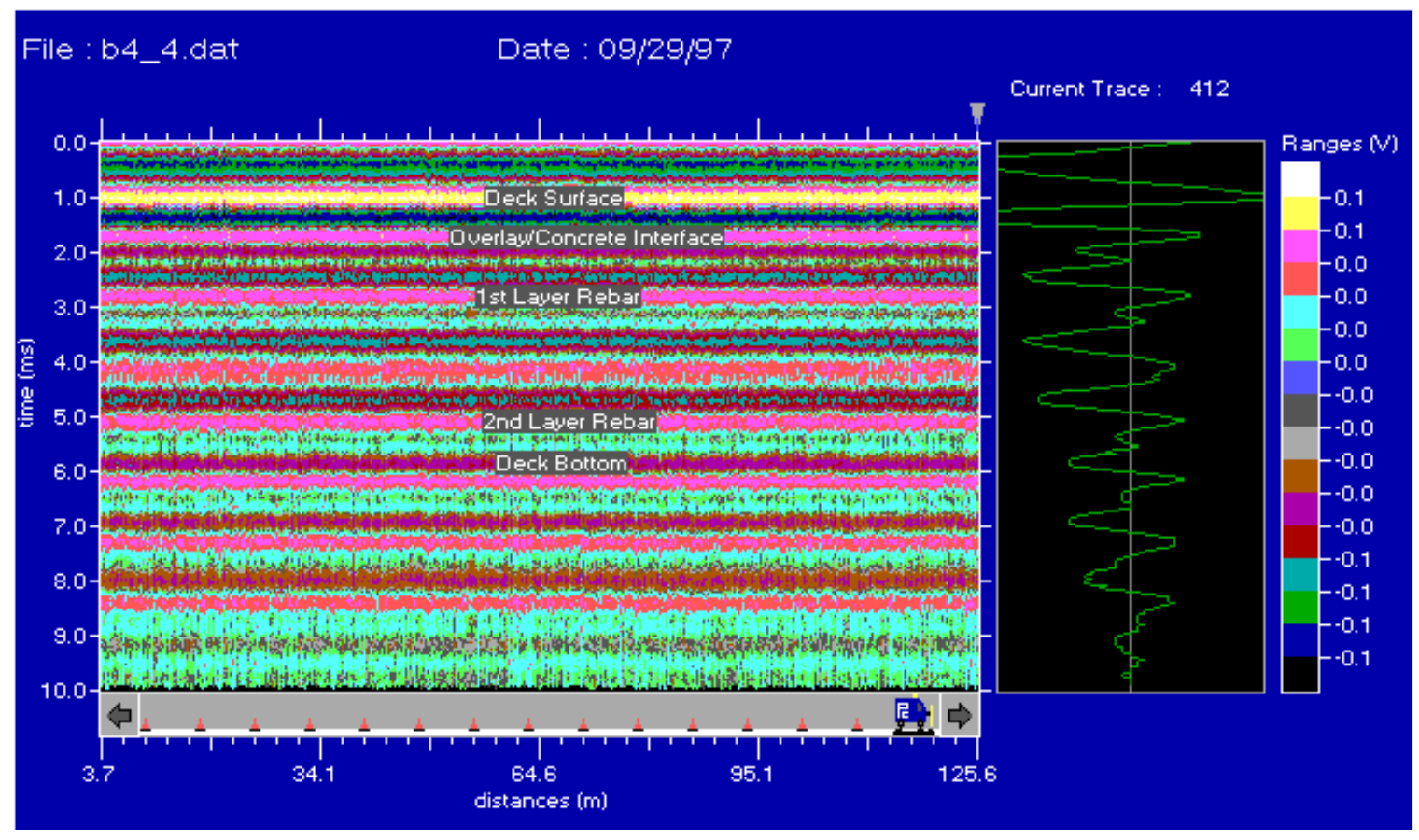

Figure 6.15: Color Intensity Plot of Bridge 3, Pass 4 


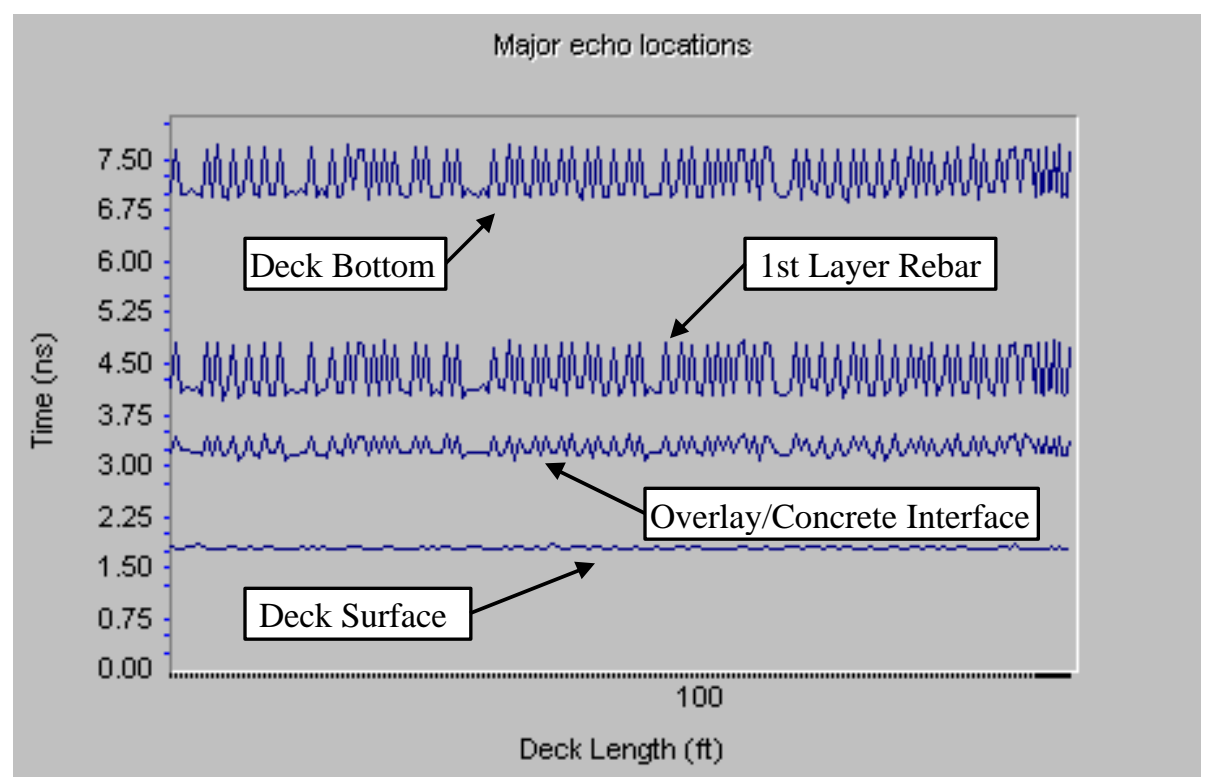

Figure 6.16: Time vs. Deck Length for Bridge 1 

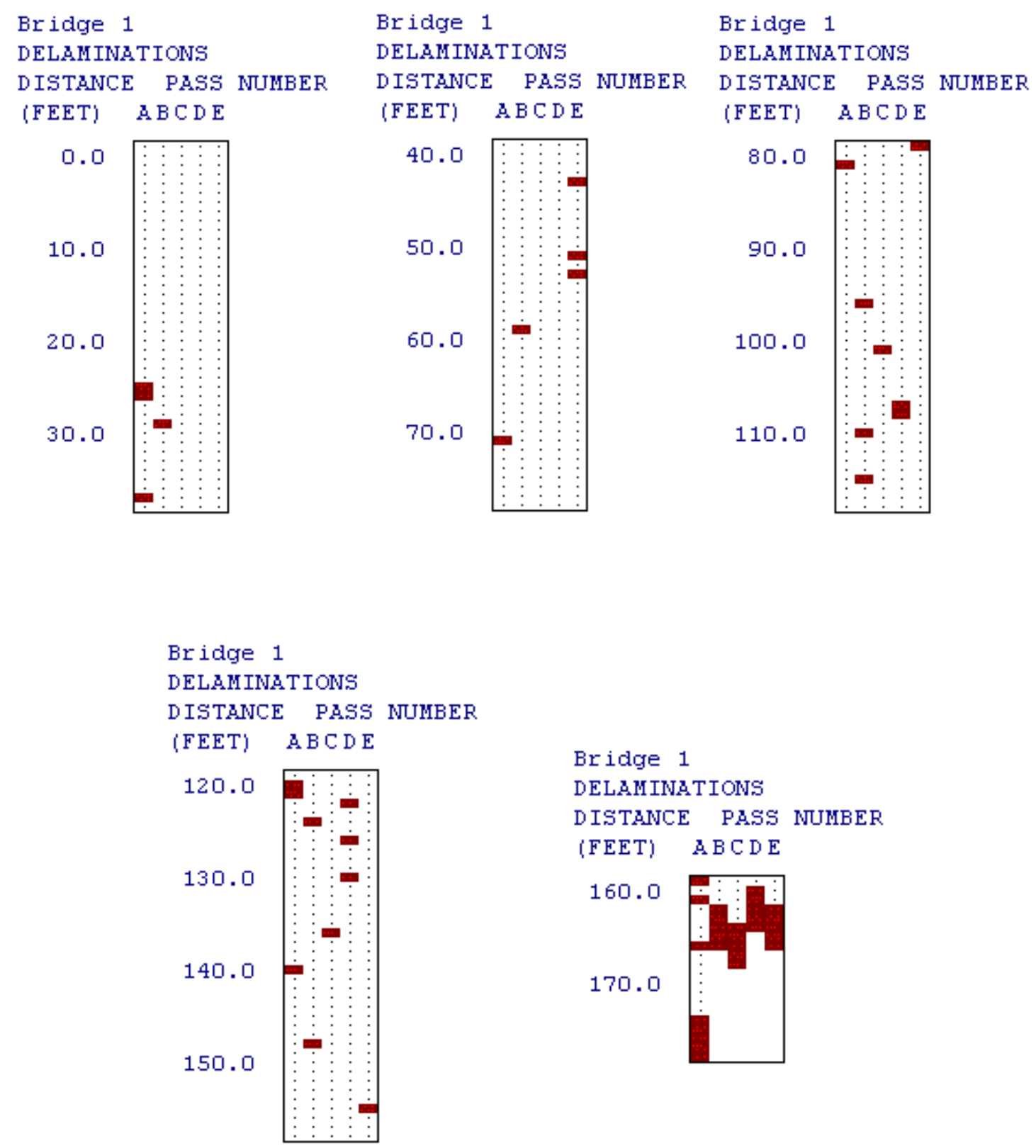

Figure 6.17: Bridge 1 Deterioration Map 


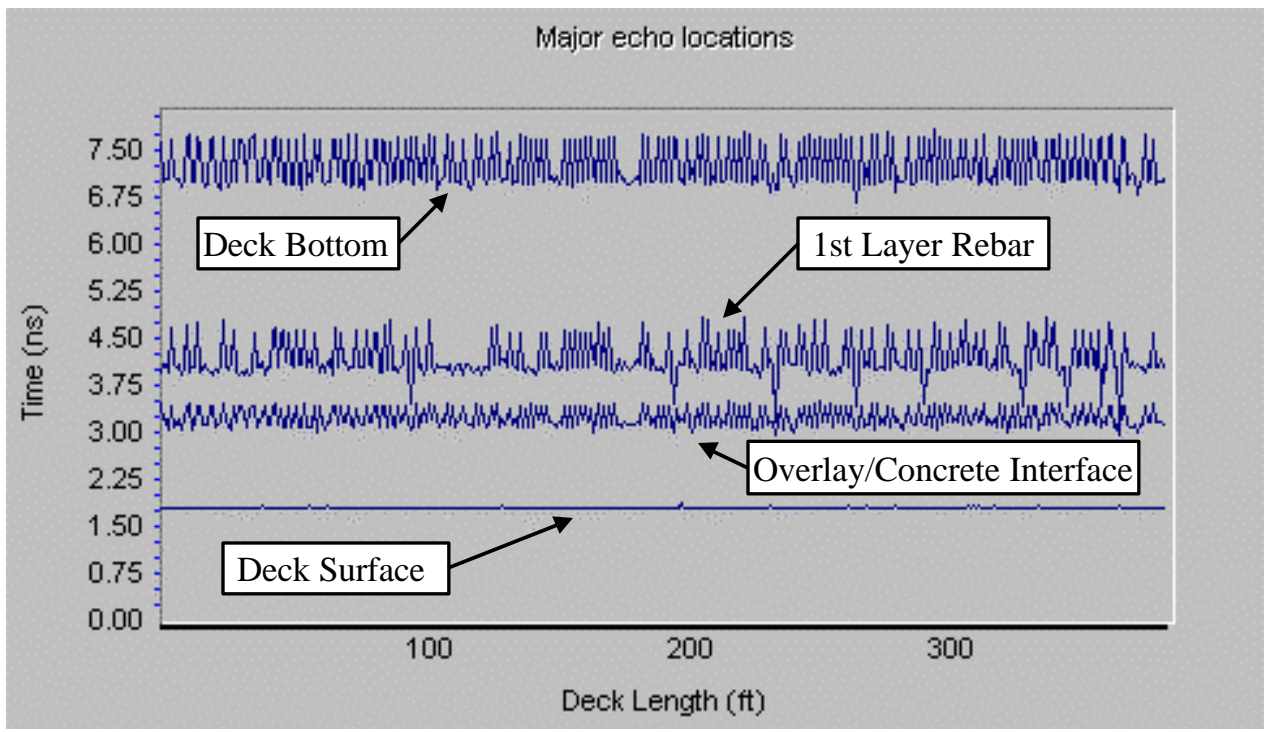

Figure 6.18: Time vs. Deck Length for Bridge 2 


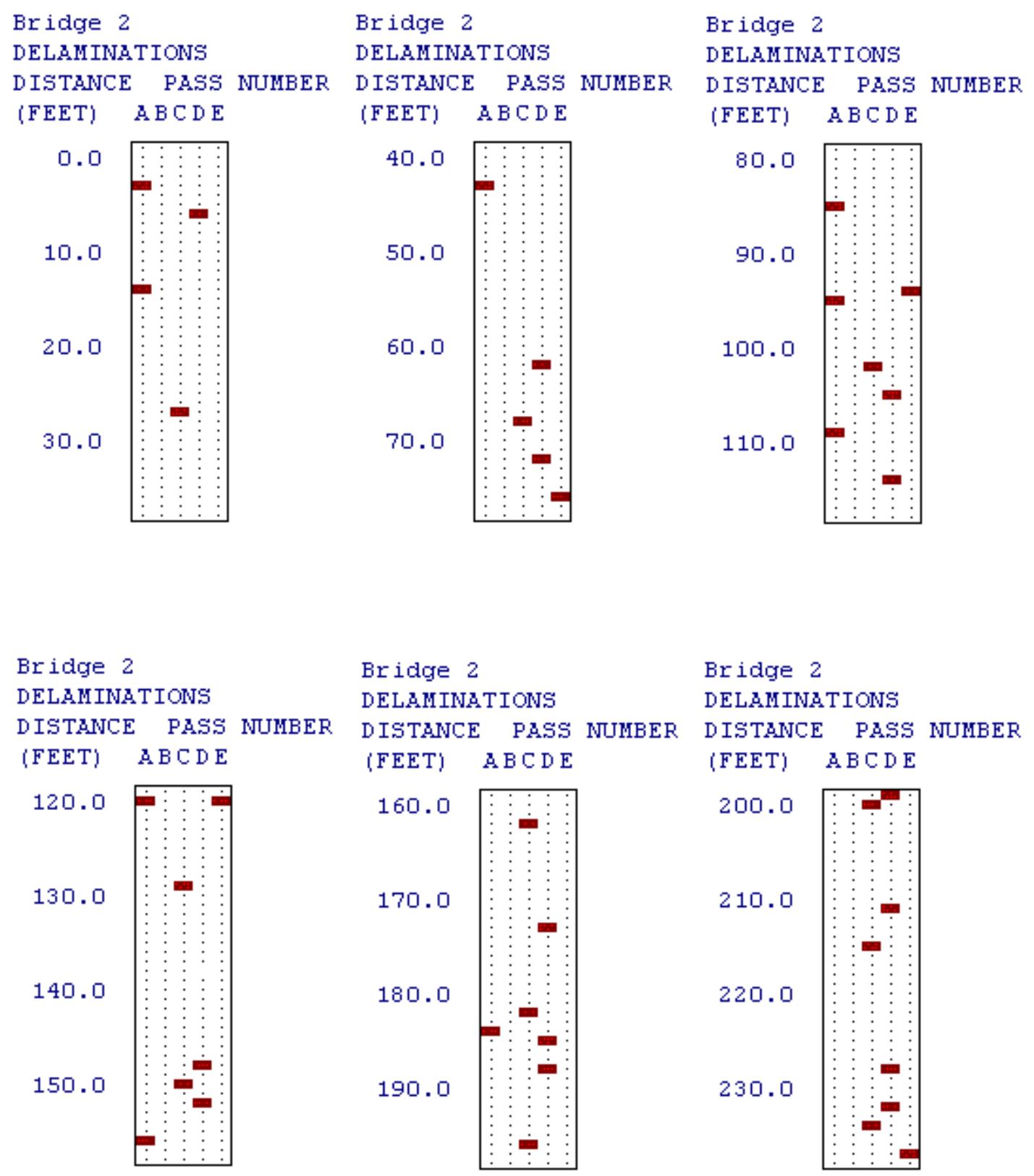

Figure 6.19a: Bridge 2 Deterioration Map 


\begin{tabular}{|c|c|c|c|c|c|c|c|c|}
\hline $\begin{array}{l}\text { Bridge } 2 \\
\text { DELAMINA }\end{array}$ & TTONS & & Bridge 2 & thones & & Bridge 2 & & \\
\hline $\begin{array}{l}\text { DELAMINA } \\
\text { D ISTANCE }\end{array}$ & TIONS & NUMBER & $\begin{array}{l}\text { DELAMINA } \\
\text { DISTANCE }\end{array}$ & TIONS & NIMRER & $\begin{array}{l}\text { DELAMINA } \\
\text { DISTANCE }\end{array}$ & PAST & NUMBER \\
\hline (FEET) & $\triangle B C D E$ & & (FEET) & $\triangle B C D E$ & & (FEET) & $\mathrm{ABCDE}$ & \\
\hline 240.0 & & & 280.0 & & & 320.0 & & \\
\hline 250.0 & & & 290.0 & & & 330.0 & & \\
\hline 260.0 & & & 300.0 & $\dot{\varphi}$ & & 340.0 & 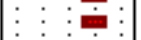 & \\
\hline 270.0 & & & 310.0 & & & 350.0 & & \\
\hline
\end{tabular}

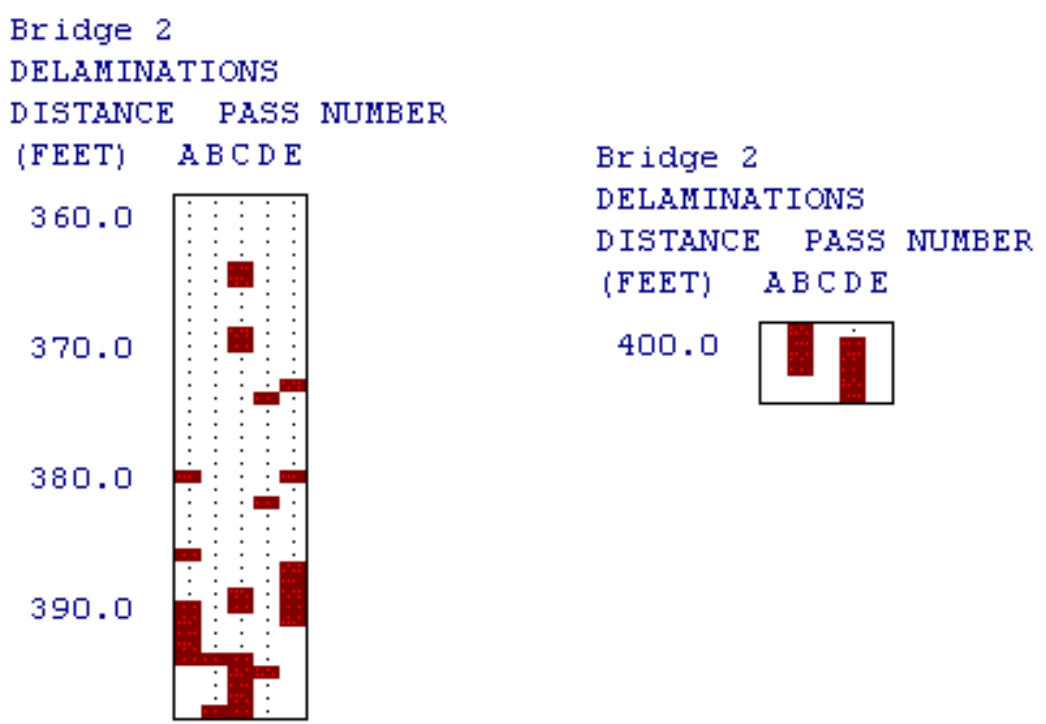

Figure 6.19b: Bridge 2 Deterioration Map, Continued 


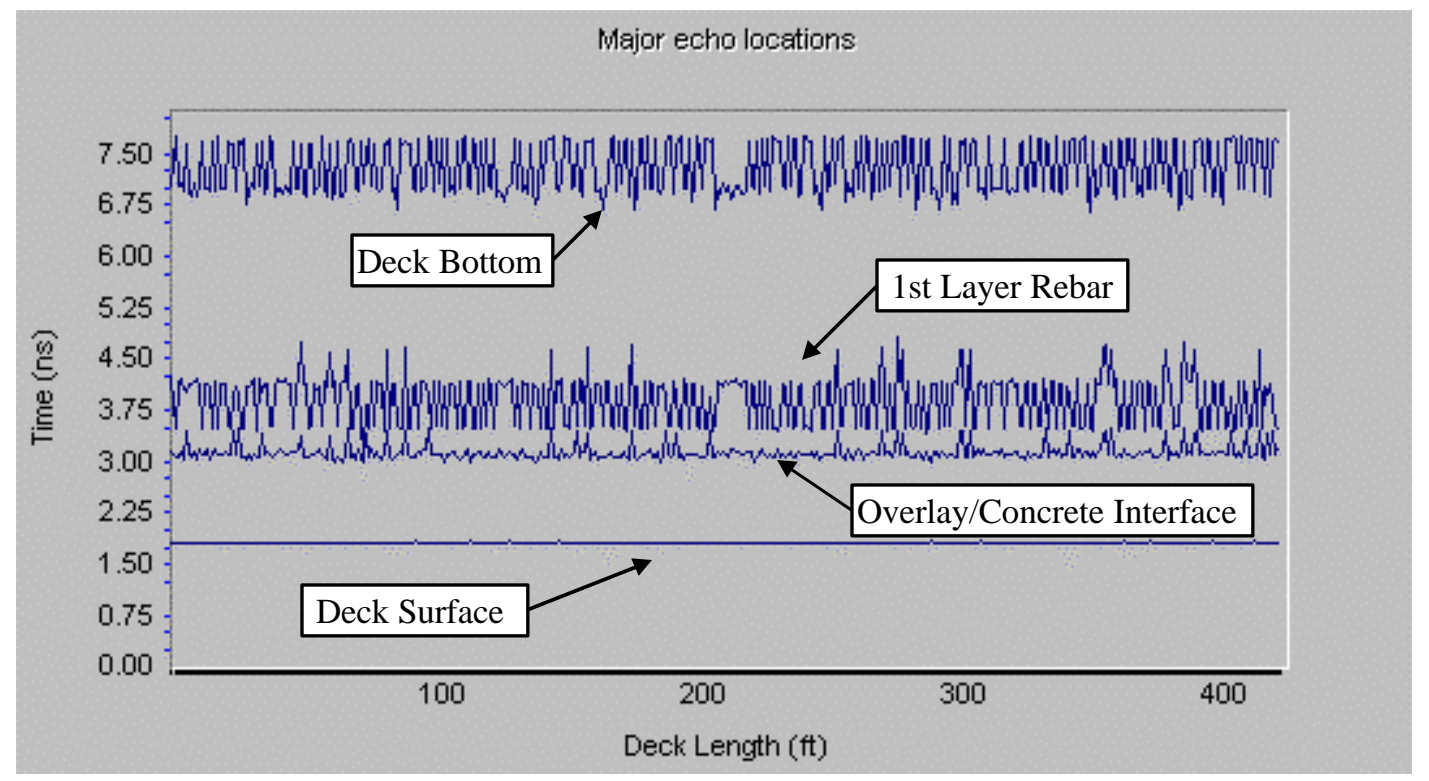

Figure 6.20: Time vs. Deck Length for Bridge 3 


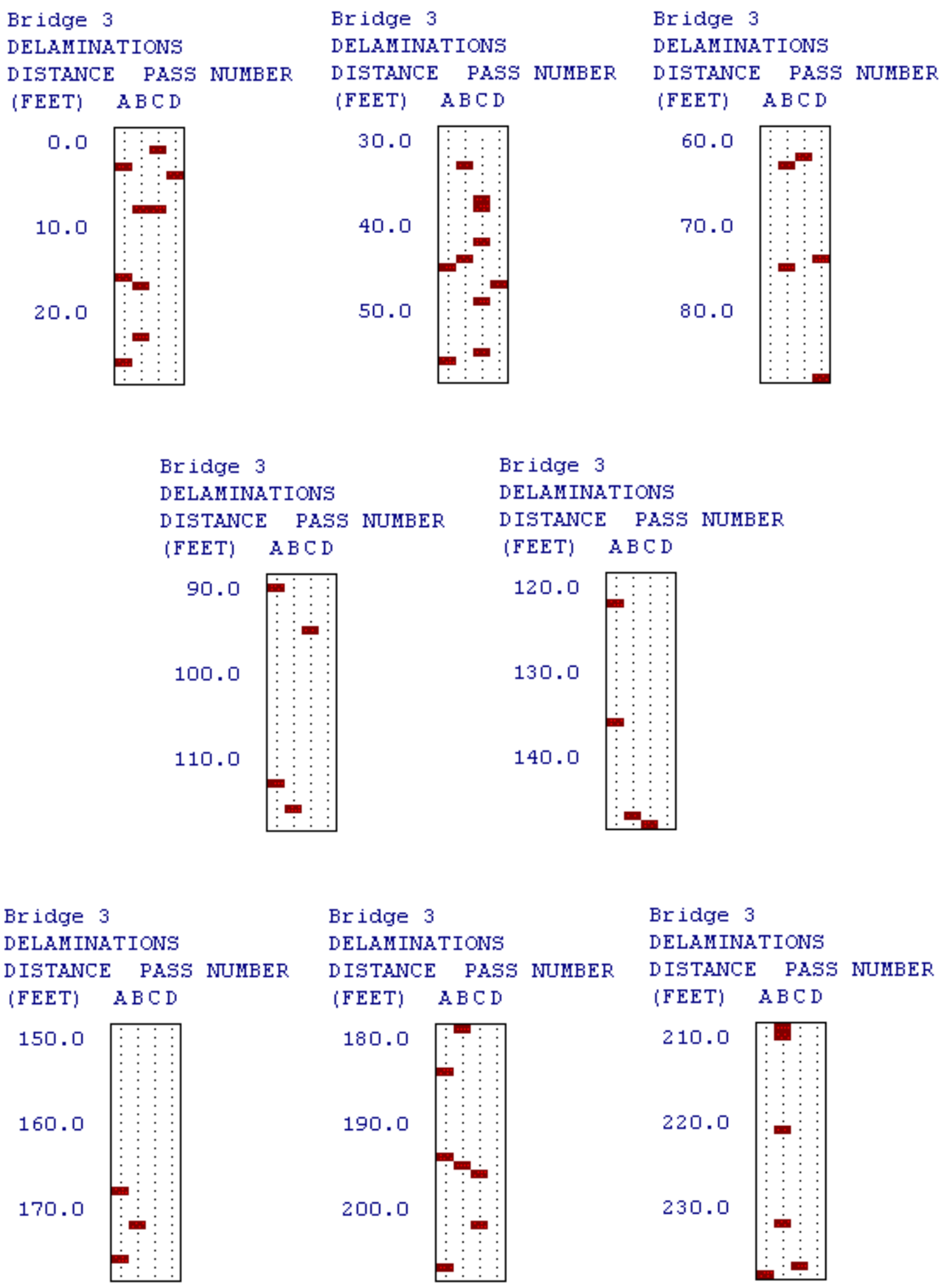

Figure 6.21a: Bridge 3 Deterioration Map 

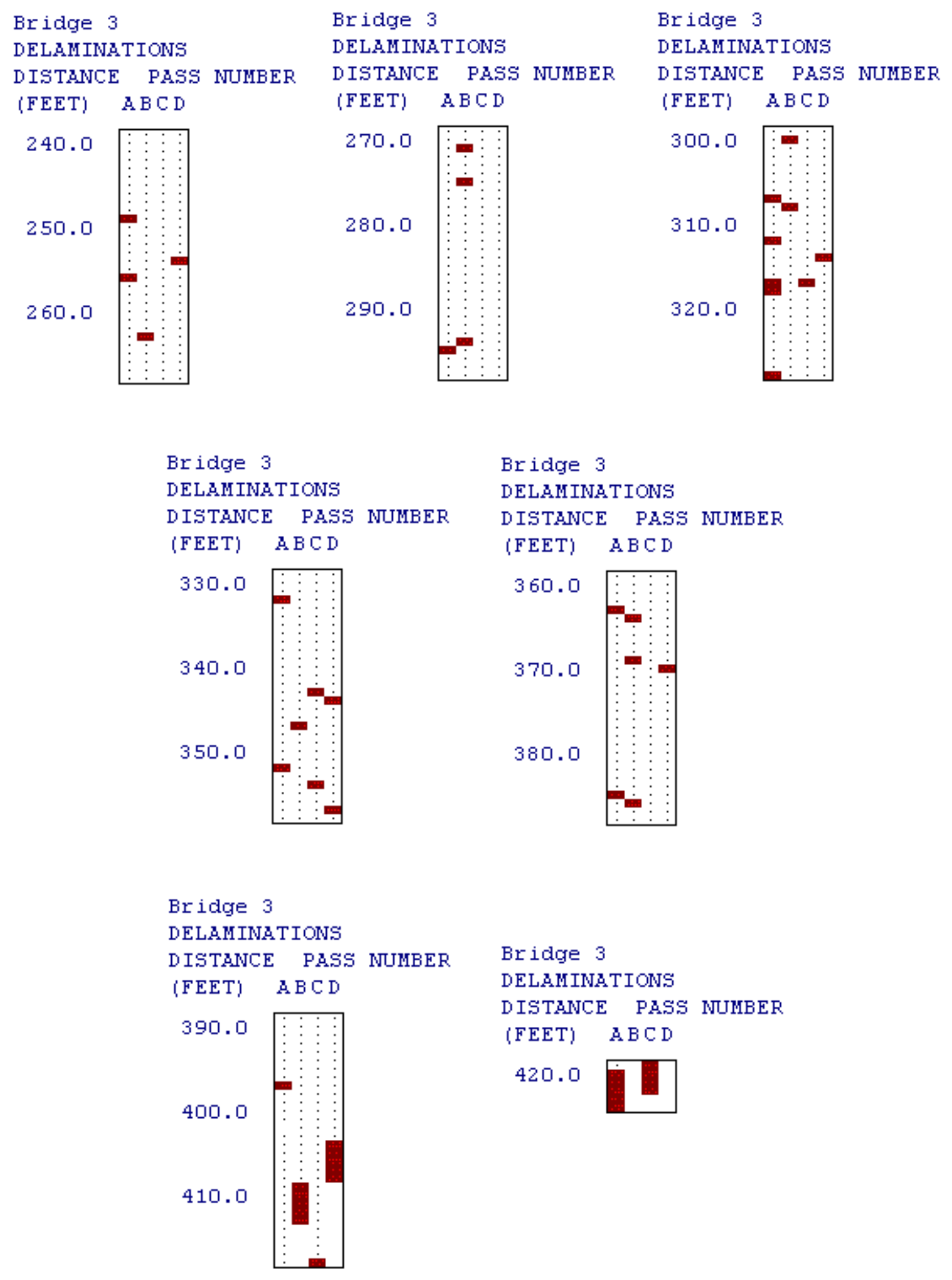

Figure 6.21b: Bridge 3 Deterioration Map, Continued 

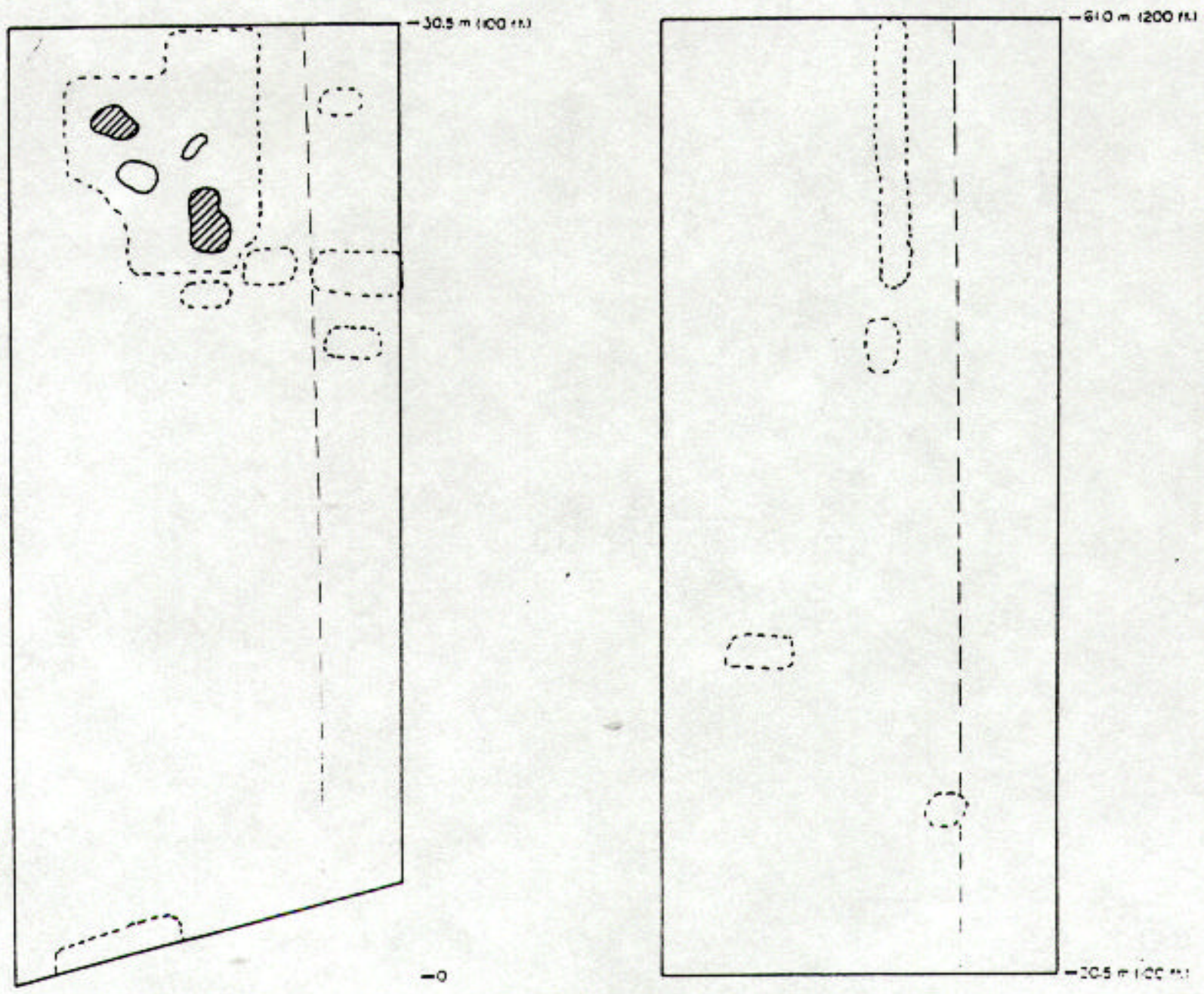

Figure 6.22a: Knollwood Bridge, I-79 South Delamination Survey from 1993 Chain Drag Testing (WVDOT) 

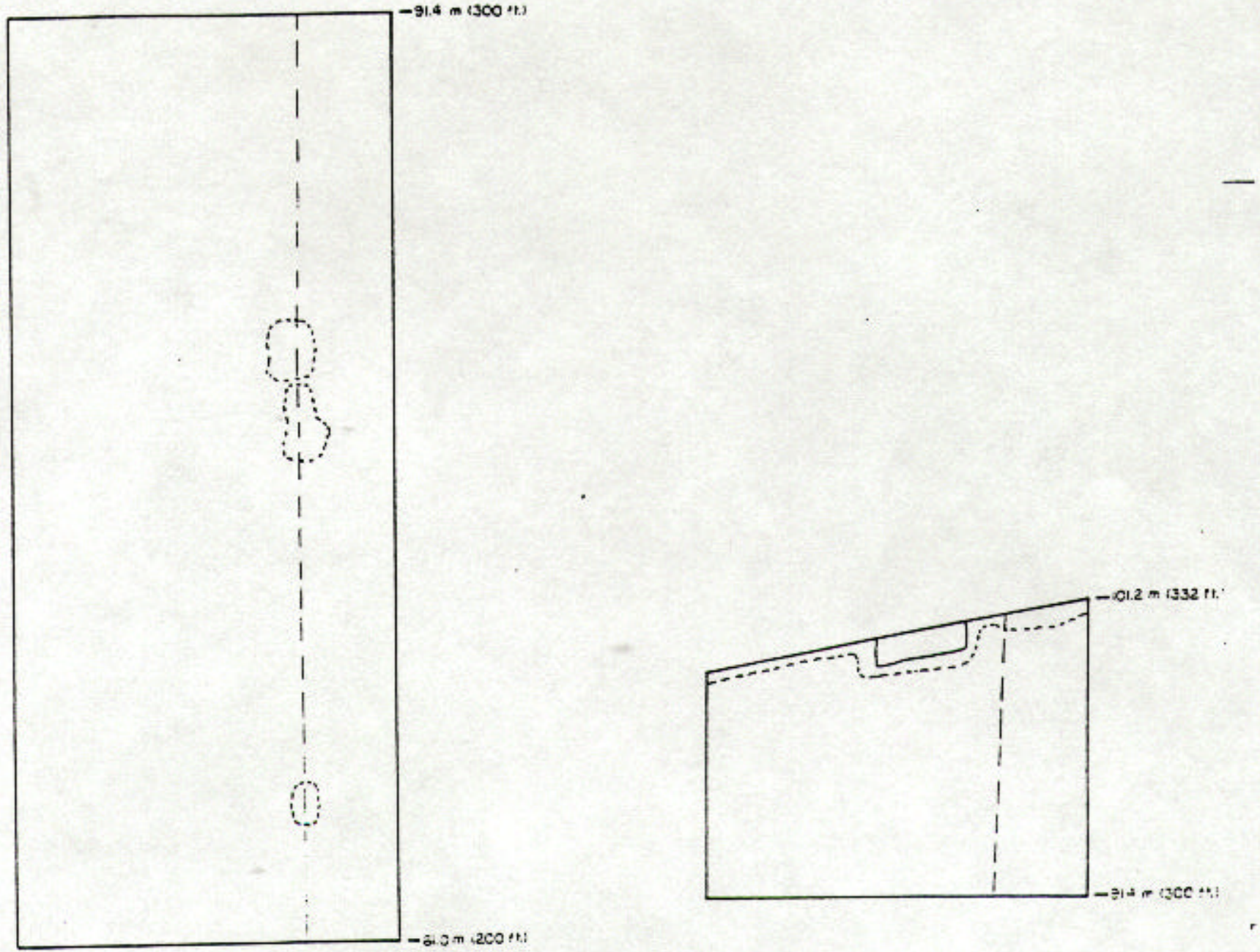

Figure 6.22b: Knollwood Bridge, I-79 South Delamination Survey from 1993 Chain Drag Testing, Continued (WVDOT) 


\section{CHAPTER 7}

\section{DISCUSSION}

\subsection{Introduction}

The purpose of this chapter is to provide a discussion on some of the situations encountered throughout the project that influenced the outcome of the results.

\subsection{Discussion of Laboratory Chain Drag Testing}

The first item to mention in this section is the fact that concrete is very nonhomogeneous. The composition and layout of the aggregates will not be exactly the same from specimen to specimen. Therefore, two specimens with the same characteristics may not yield the same acoustic results. An example of this type of discrepancy was with specimens B42 and B52. Both blocks were composed of plain concrete, ten inches in thickness. However, the frequencies for B42 ranged between $50-55 \mathrm{~Hz}$, while the frequencies for B52 ranged from 60-70 Hz.

Another situation encountered during the laboratory testing dealt with the repetition of the signals. As mentioned in section 3.4, five different signals for each chain on each block was collected for consistency purposes. Those five signals were then transformed into the frequency domain using a power spectral density (PSD). The peak amplitude for each PSD graph was then inspected. Ideally, each of the five PSD graphs would have the same peak amplitude. That way all five signals could be averaged together for a better signal representation and all amplitudes could be normalized by the same peak, giving the normalized peak amplitude a value of one. However, in many instances only 
three or four peak amplitudes matched, giving a slightly less reliable representation of the signal characteristics for the individual chain and specimen.

It is difficult to determine whether the difference between some of the five signals collected for each specimen and chain was from the true impact or from human error. The differences most likely can be attributed to human error because the force at which the chain was dragged against the concrete was not exactly the same for every test conducted. The same phenomena could be encountered in the field, as well as in the lab, for any personnel conducting a chain drag test. Bridge inspectors should be aware of the differences in acoustic signals due to human errors so that potential problematic situations can be avoided.

Another item that should be mentioned in this section is the embedded water cracks inside some of the specimens may have evaporated over time. The specimens were cast and cured approximately five years ago, and the water cracks may actually resemble air cracks at the present time.

The last topic to be discussed under the laboratory testing is about the amplification of the signal obtained from dragging the chains on the specimens. Without the use of an amplifier, the signal was too weak to trigger the oscilloscope. The audio amplifier that was used in the experiment has a variable gain value. The volume setting on the amplifier, which adjusted the strength of the incoming signal, was always set to the medium position, thus ensuring consistency throughout the testing.

\subsection{Discussion of In-Situ GPR Scanning}

At the onset of this research it was the intention to have delamination surveys from 
both chain dragging and GPR scanning for comparison on at least one of the actual bridge decks in the field. That goal was strived for very diligently by both the WVDOH and the researchers at West Virginia University. The difficulty in obtaining both surveys lies in the traffic control. Traffic control takes much money and advanced planning to conduct, therefore it would be ideal to perform both the chain dragging and the GPR scanning together, making the most efficient usage of the traffic control. On two different occasions both NDT methods were employed together when traffic control was obtained for a particular bridge; however, unfortunately problems arose with the GPR data each time and no comparisons could be performed. Eventually, the time for project completion had neared and it was decided to make do with the information that was collected on three bridges that had no recent chain drag reports associated with them. Although no delamination comparisons were made, interface thickness comparisons were conducted and GPR delamination bridge maps were generated.

One of the two bridges that had corrupted radar data was the Greenbrier Bridge located near Charleston, West Virginia. A photograph of the Greenbrier Bridge can be seen in Figure 7.1. There are two main reasons why the collected data was unusable. The first reason was because the waveforms contained too much noise. On the waveform display of the color intensity plot for the Greenbrier Bridge shown in Figure 7.2, it is noticed that there is a shift in the wave from the zero line. A good waveform is relatively symmetric about the zero line. The second reason why the data was unusable, and perhaps the most important reason, was the fact that all waveforms were almost exactly the same. See Figure 7.3 for the waterfall plot of one pass of the Greenbrier Bridge which clearly displays that all waveforms were the same. A common waterfall plot, which 
contains different waveforms, can be seen in Figure 7.4. The probable cause of the uniformity among waveforms was most likely because of an internal problem with the radar equipment.

A significant difficulty encountered in the analysis of the radar data was in the inspection of the radar waves. The interpretation of the radar signals obtained from the bridge deck is a complex task to perform for three major reasons: multiple reflections, overlapping, and distortion. As mentioned previously, radar waves are reflected and transmitted at different interfaces within the body of the bridge deck. Sometimes the signal will reflect back and forth multiple times within interfaces. It may be difficult to analyze a radar signal because these multiple reflections do not look very different from the other reflections. Overlapping occurs when two interfaces exist in very close proximity of one another. When the two waves overlap, the peaks that represent the locations of the interfaces may shift, causing the results to become erroneous. Radar signals experience distortion when a normal wave changes shape. Distortion often occurs at or about steel rebars. The distorted signal does not look similar to a normal signal, thus making it difficult for an engineer to pinpoint the location of an interface.

Another situation encountered occurred during the postprocessing of the radar data and dealt with choosing the correct parameter to generate the bridge maps. As mentioned previously, there are four different parameters to choose from for postprocessing: attenuation, asphalt/concrete $(\mathrm{A} / \mathrm{C})$ echo characteristics, change detector, and bottom echo characteristics. Attenuation is used generally for older decks that are expected to contain considerable deterioration due to high chloride contents causing corrosion. A/C echo characteristics would be the parameter of choice during wet 
conditions. Change detector is ideal when the deck is dry and expected to be in relatively good condition. The parameter entitled bottom echo characteristics should be used in similar situations as when attenuation is used, but especially when the deck bottom echo is predominantly present. The analysis performed in this project used change detector because the decks seemed to be in sound condition, from inspection of the color intensity and waterfall plots.

Choosing the correct threshold value is also very important for the postprocessing phase. The threshold value can range anywhere between 0 and 1.0 in the program. A good threshold value lies above common signals, but below abnormal signals. In the analysis of the bridge decks in this project, the threshold value was kept at 0.7 .

A concern about the postprocessing software is that the bridge maps vary considerably between parameters used, which will lower the confidence of the inspecting engineer in determining the locations of deterioration.

In addition, the unknown relative dielectric constant of the latex modified concrete overlay can be determined from back calculations of equations 2.6 and 2.7, since the thickness of the overlay is known. After performing such calculations for each of the three bridges with the times taken with respect to the color intensity plots, the relative dielectric constant for the overlay ranged from 15 to 18 . 


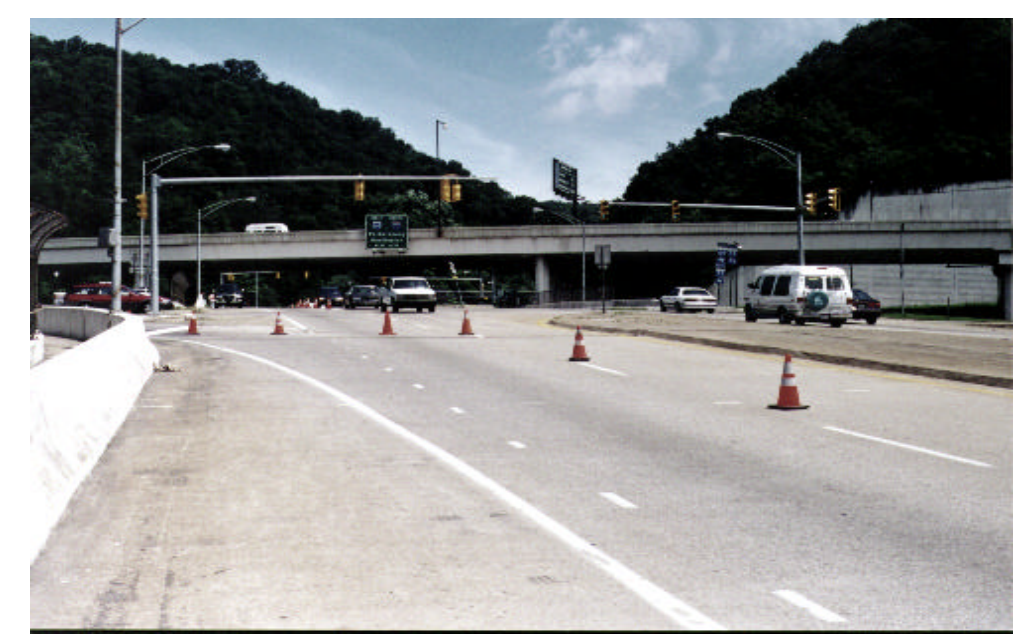

Figure 7.1: Photograph of Greenbrier Bridge

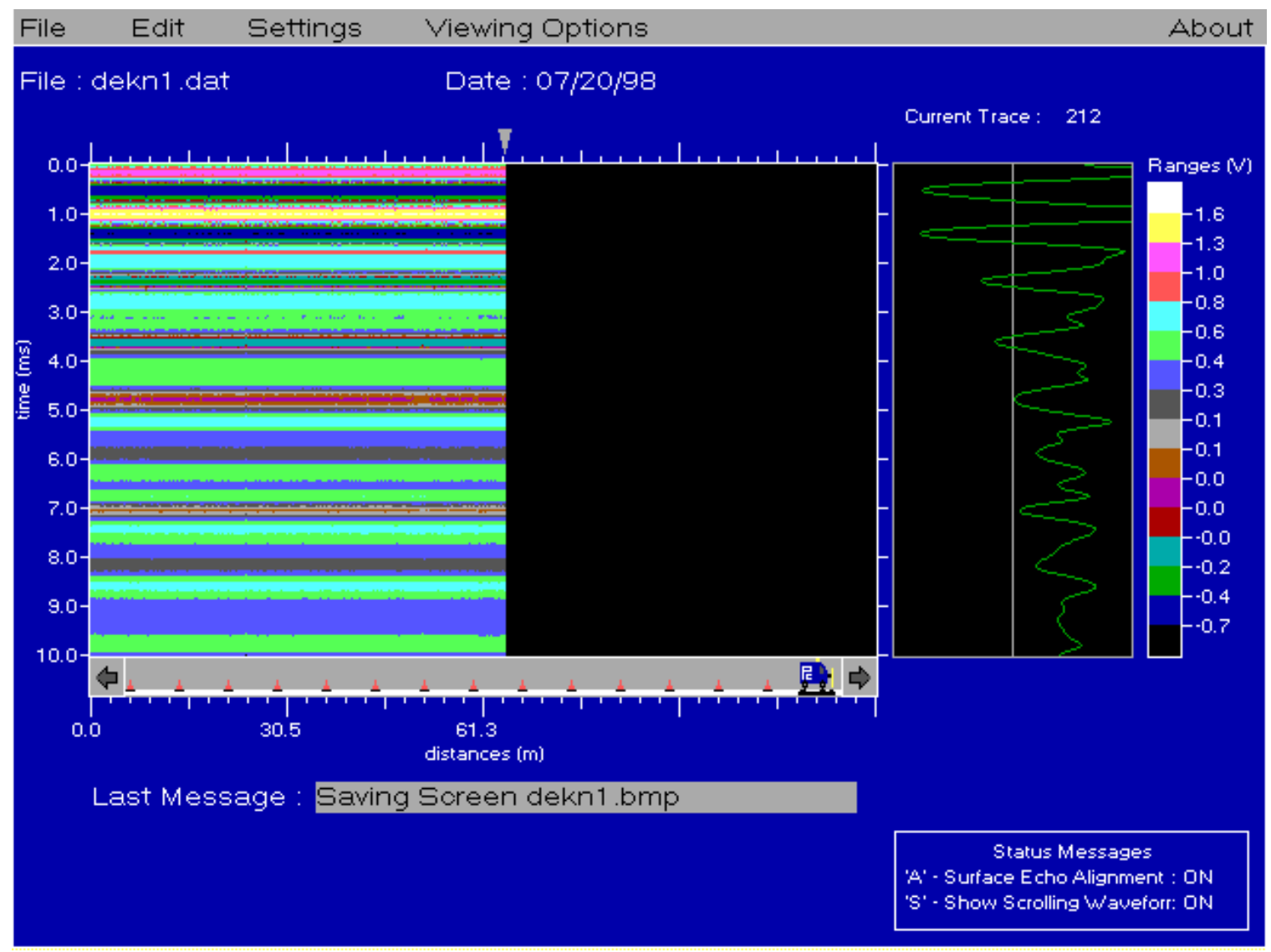

Figure 7.2: Color Intensity Plot of Greenbrier Bridge 


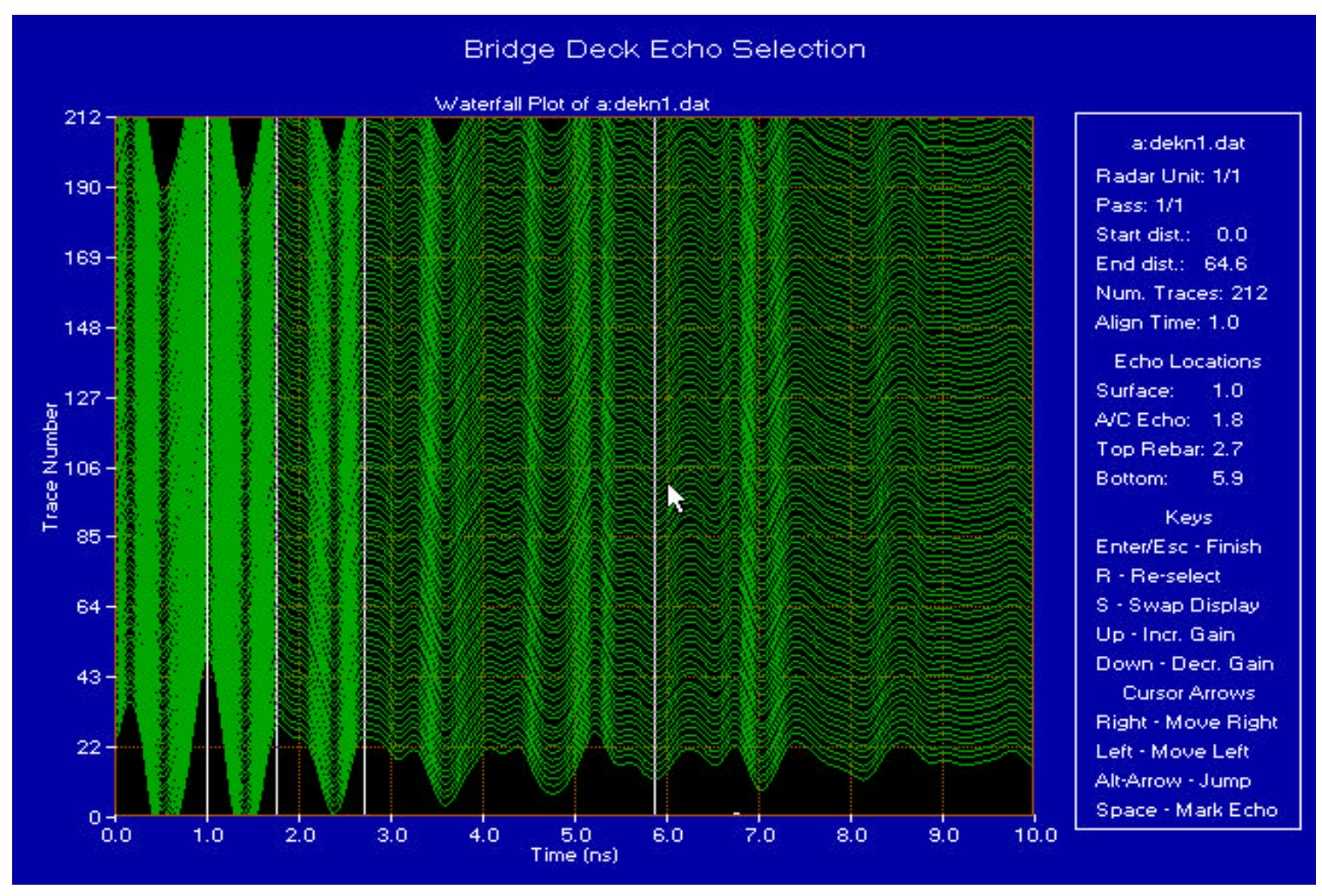

Figure 7.3: Waterfall Plot of Greenbrier Bridge

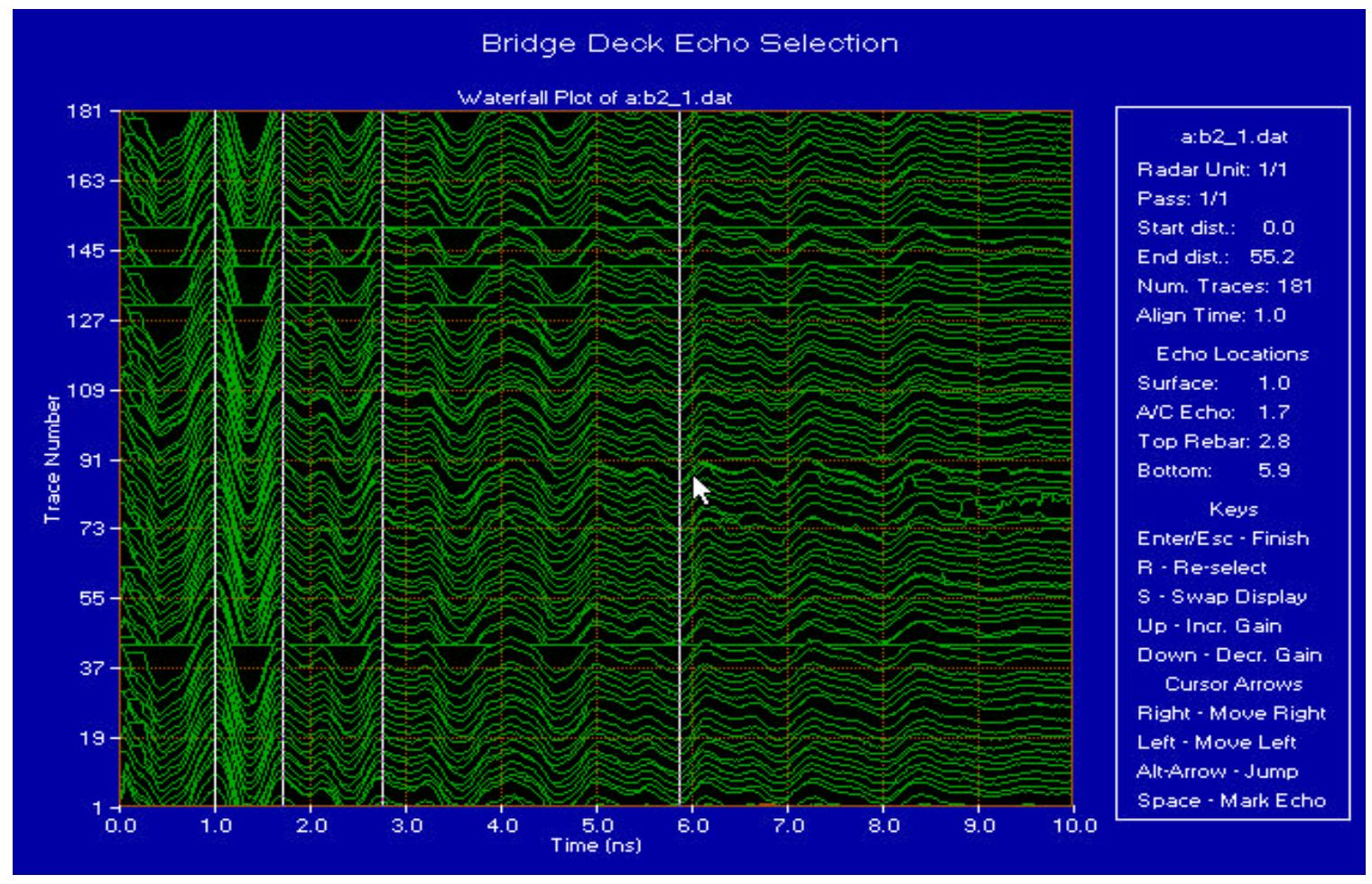

Figure 7.4: Waterfall Plot of Normal Bridge 


\section{CHAPTER 8}

\section{CONCLUSIONS AND RECOMMENDATIONS}

\subsection{Introduction}

There are two objectives of this chapter. The first objective is to provide the conclusions of this research project on the basis of the background information, the literature review, the laboratory chain drag testing, and the in-situ radar scanning of the three highway bridge decks. The second objective is to provide recommendations for future research.

\subsection{Conclusions}

From the background information provided in Chapter 2, the following can be concluded:

- Major factors contributing to the structural deficiency of a bridge include designs according to loads and specifications that are no longer applicable today, and the reduction of the live-load carrying capacity of bridges due to aging and deterioration.

- There are different bridge rating systems, such as the sufficiency rating, which aids in the decision making process of the engineer in determining whether a bridge should be rehabilitated extensively or sparsely, or replaced altogether. 
From the literature review conducted on the usage of GPR and the impact-echo method for nondestructively analyzing structures, the following can be concluded:

- $\quad$ Experiments using GPR on controlled laboratory specimens yield results that are quite promising, but more in-situ experiments need to be conducted for better reliability.

- $\quad$ The impact-echo method also yields accurate results; however, this method is not practical for usage on bridge decks because of the long duration of testing and the influence of outside factors, such as impact loadings from vehicles.

The study of the frequencies acquired from dragging three chains of different sizes on twenty-three model bridge deck specimens with controlled laboratory conditions led to the following conclusions:

- The presence of noise in the signals is unavoidable because of the electrical equipment used in the testing. However, since the frequencies associated with the noise are known $(40-45 \mathrm{~Hz}$ and $55-60 \mathrm{~Hz})$, their values can be disregarded during analysis.

- $\quad$ The frequencies associated with specimens that had embedded air cracks were found within the frequency range of $50-55 \mathrm{~Hz}$ and $60-80 \mathrm{~Hz}$, depending on the size and shape of the simulated crack.

- $\quad$ The frequencies associated with specimens that had embedded steel rebars were found within the frequency range of $70-80 \mathrm{~Hz}$. 
- Discrepancies between specimens of similar characteristics found in different batches can be attributed to the fact that concrete is a nonhomogeneous material. Specimens in different batches were not cast and cured at the same time, therefore they may not all be exactly the same.

- The size of the chain used in the testing definitely influences the outcome of the experiment. There were very many instances when the heavier Chains 2 and 3 uncovered frequencies that the lighter Chain 1 could not produce, as evidenced by the scatter plots of Chapter 4 .

The study of the three highway bridge decks that were scanned by the WVDOH with the equipment purchased from Penetradar Corporation led to the following conclusions:

- $\quad$ The use of color intensity plots provides a direct approach for determining the thickness profile of concrete bridge decks.

- Depth measurements taken with respect to the overlay/concrete interface are more accurate than depth measurements taken with respect to the deck surface. This is due to the unknown relative dielectric constant of the 25.4mm (1") latex modified concrete overlay.

- When using the color intensity plots to determine the interface depths from the overlay/concrete interface, the results are quite reliable. The maximum margin of error under these circumstances was $17.8 \mathrm{~mm}(0.7$ ').

- Depth measurements from the postprocessing software are less accurate than depth measurements found from the color intensity plots. This may 
be due to the fact that the postprocessing software that was used has been updated and may have some bugs.

- $\quad$ Bridge delamination maps generated from the postprocessing software vary greatly according to the parameter and threshold value chosen, and do not match well with chain drag delamination surveys.

- Maximum errors associated with using color intensity plots to directly determine thickness profiles measured from the overlay/concrete interface were $-9.6 \%, 10.0 \%$, and $10.0 \%$ for Bridges 1,2 , and 3 , respectively.

- Maximum errors associated with using the postprocessing software to determine thickness profiles measured from the overlay/concrete interface were $29.0 \%, 13.5 \%$, and $-28.0 \%$ for Bridges 1,2 , and 3 , respectively.

\subsection{Recommendations}

Future research regarding the laboratory chain drag testing should concentrate on determining ways to minimize the unwanted noise signals from electrical systems and from other outside sources. In addition, an increase in the frequency band from $0-1000 \mathrm{~Hz}$ to 0-3000 Hz should be invoked to allow more specimen characteristics to become evident. Perhaps equipment could be designed, after better understanding of the true acoustic signals, to be used in the field. If absolute trends can be found for the frequencies associated with rubbing a chain against concrete, then not only would the engineer be able to locate defective areas, but also profiles of the bridge deck may be more accurately determined. 
Future research for GPR scanning of bridge decks is recommended to include:

- The use of color intensity plots to directly determine depth measurements on bridge decks in the field rather than using the first version of the postprocessing software from Penetradar Corporation.

- The purchase and study of an updated version of the postprocessing software to see if results become more accurate.

- $\quad$ Comparison of bridge deterioration maps from both chain drag testing and GPR testing on the same bridge in the field. 


\section{REFERENCES}

1. ASTM D4580-86, "Standard Practice for Measuring Delaminations in Concrete Bridge Decks by Sounding," ASTM Committee D-4, 1986.

2. Beckwith, T.G., Marangoni, R.D., and Lienhard V, J.H., Mechanical Measurements, Addison-Wesley Publishing Company, Reading, Mass., 1993.

3. Bhandarkar, V.A., Detection of Subsurface Anomalies in Concrete Bridge Decks Using Ground Penetrating Radar, M.S. Thesis, West Virginia University, Morgantown, WV, 1993.

4. Brinckerhoff, P., Bridge Inspection and Rehabilitation: A Practical Guide, John Wiley \& Sons, Inc., New York, NY, 1993.

5. Bungey, J.H., and Millard, S.G., "Detecting Sub-Surface Features in Concrete by Impulse Radar," Nondestructive Testing and Evaluation, Vol. 12, pp. 33-51, 1995.

6. Bungey, J.H., Millard, S.G., and Shaw, M.R., "The Influence of Reinforcing Steel on Radar Surveys of Concrete Structures," Construction and Building Materials, Vol. 8, 1994.

7. Cengal, Y.A., and Boles, M.A., Thermodynamics: An Engineering Approach, McGraw-Hill, Inc., New York, NY, 1994.

8. Chen, H.L., Halabe, U.B., Bhandarkar, V., and Sami, Z., "Radar Signal Processing and Analysis for In-Situ Evaluation of Reinforced Concrete Bridge Decks," Final Report \#CFC-93-167, Constructed Facilities Center, Dept. of Civil and Environmental Engineering, West Virginia University, Morgantown, WV, August, 1994a.

9. Chen, H.L., Halabe, U.B., Sami, Z., and Bhandarkar, V., "Impulse Radar Reflection Waveforms of Simulated Reinforced Concrete Bridge Decks," Materials Evaluation, Vol. 52, March 1994b, pp. 1382-1388.

10. Chung, T., Carter, C.R., Masliwec, T., and Manning, D.G., "Impulse Radar Evaluation of Concrete, Asphalt, and Waterproofing Membrane," IEEE Transactions of Aerospace and Electonic Systems, Vol. 30, April 1994, pp. 404415.

11. Clough, R.W., Penzien, J., Dynamics of Structures, McGraw-Hill, Inc., New York, NY, 1998.

12. FHWA, "Recording and Coding Guide for the Structure Inventory and Appraisal of the Nation's Bridges," Bridge Division, December 1995. 
13. GangaRao, H.V.S., "CE 461: Bridge Engineering," Class Lecture, Dept. of Civil and Environmental Engineering, West Virginia University, Morgantown, WV, Spring 1998.

14. Halabe, U.B., Sotoodehnia, A., and Maser, K.R., "Modeling the Electromagnetic Waves in Concrete," ACI Materials Journal, Vol. 90, No.6, November/December, 1993.

15. Halabe, U.B., Chen, H.L., Allu, M., and Pei, L., "Radar Signal Processing and Analysis for In-Situ Evaluation of Reinforced Concrete Bridge Decks and Pavements," Final Report \#CFC-96-234, Constructed Facilities Center, Dept. of Civil and Environmental Engineering, West Virginia University, Morgantown, WV, December 1996.

16. Lin, J., and Sansalone, M., "A Procedure for Determining P-Wave Speed in Concrete for Use in Impact-Echo Testing Using a Rayleigh Wave Speed Measurement Technique," Innovations in Nondestructive Testing of Concrete, ACI Committee 228, 1997.

17. Millard, S.G., Bungey, J.H., Shaw, M.R., Thomas, C., and Austin, B.A., "Interpretation of Radar Test Results," Innovations in Nondestructive Testing of Concrete, ACI Committee 228, 1997.

18. Molyneaux, T.C.K., Millard, S.G., Bungey, J.H., and Zhou, J.Q., "Radar Assessment of Structural Concrete Using Neural Networks," NDT \& E International, Vol. 28, 1995, pp. 281-288.

19. Penetradar Corporation, Penetradar IRIS Operating Software: Operation Manual, Niagara Falls, NY, December 1995.

20. Penetradar Corporation, "Penetradar Radar Systems," Company Brochure, 1995.

21. Padaratz, I.J., and Forde, M.C., "A Theoretical Evaluation of Impulse Radar Wave Propagation Through Concrete," Nondestructive Testing Evaluation, Vol. 12, 1995, pp. 9-32.

22. Pitt, J.B., "Use of Impulse Radar as a Method for the Non-Destructive Testing of Concrete Slabs," Building Research and Information, Vol. 20, 1992, pp. 152-156.

23. Pla-Rucki, G.F., and Eberhard, M.O., "Imaging of Reinforced Concrete: State-ofthe-Art Review," Journal of Infrastructure Systems, June 1995, pp. 134-141.

24. Poston, R., and Sansalone, M., "Detecting Cracks in the Beams and Columns of a Post-Tensioned Parking Garage Using the Impact-Echo Method," Innovations in Nondestructive Testing of Concrete, ACI Committee 228, 1997. 
25. Reel, R., Tharmabala, T., Wood, D., Chung, T., and Carter, C.R., "New Impulse Radar Strategies for Bridge Deck Assessment," Innovations in Nondestructive Testing of Concrete, ACI Committee 228, 1997.

26. Rhim, H.C., Buyukozturk, O., and Blejar, D.J., "Remote Radar Imaging of Concrete Slabs With and Without a Rebar," Materials Evaluation, February 1995, pp. 295-299.

27. Roddis, W.M.K., Concrete Bridge Deck Assessment Using Thermography and

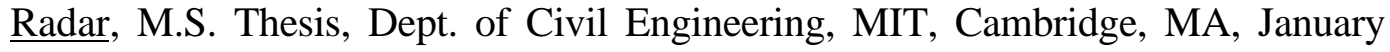
1987.

28. Saarenketo, T., and Soderqvist, M.K., "Ground Penetrating Radar Applications for Bridge Deck Evaluations in Finland," Insight, Vol. 36, July 1994, pp. 496-501.

29. Sansalone, M., Lin, J., and Streett, W.B., "A Procedure for Determining Concrete Pavement Thickness Using P-Wave Speed Measurements and the Impact-Echo Method," Innovations in Nondestructive Testing of Concrete, ACI Committee $228,1997$.

30. Shaw, P., and Xu, A., "Pulse-Echo Methods in Inspection of Concrete Structures," Insight, Vol. 39, March 1997, pp. 180-185.

31. SlatonBarker, A.B., and Wallace, J.W., "Nondestructive Testing of Bridge Decks Using Dual Frequency Radar," Innovations in Nondestructive Testing of Concrete, ACI Committee 228, 1997.

32. Taly, N., Design of Modern Highway Bridges, McGraw-Hill, Inc., New York, NY, 1998.

33. WVDOT, Bridge Deck Delamination Survey, Project: IR-0773-243-E, I-79 South over Knollwood Road, Kanawha County, District One, October 8, 1993.

34. Ziomek, L.J., Fundamentals of Acoustic Field Theory and Space-Time Signal Processing, CRC Press, Ann Arbor, MI, 1995. 


\section{APPENDIX A \\ SAMPLE CHECKLIST FOR RADAR DATA ACQUISITION}

1. What are the weather conditions?

2. What are the deck conditions? (Hot, dry, cold, wet, etc...)

3. What is the bridge number and what road is it on? (e.g. Bridge \#2667, I-79 North)

4. What are any other descriptions? (What it overpasses, etc...)

5. Get either skew angle or skew distance (see accompanying figure).

6. Draw passes along with pass numbers and direction of travel (include north arrow).

7. Make sure at least one pass is referenced to the deck (for instance, pass 1 is 10 feet from deck edge.

8. Write down pass distance (distance between passes).

9. Write down process interval (for example, 1 trace/pulse every 1 foot).

10. Write down pass of maximum skew. 


\section{APPENDIX B \\ STEP-BY-STEP PROCEDURE FOR RADAR DATA PROCESSING}

This section is included to provide the step-by-step procedure of the radar data processing (RDP) function of the Penetradar software used in this project. It should be noted that this version of the software is not the updated version. All of the RDP that will be covered in this section is performed in the DOS environment, not the Windows environment.

\section{Step 1:}

It may be wise to copy the radar data files from the 3.5 " floppy disk onto the hard drive of the computer.

\section{Step 2:}

Under the IRIS subdirectory type FILEUTIL. The user will notice four different options on the menu screen (Figure B-1).

\section{Step 3:}

Choose F1 to convert the radar data files into an acceptable form for the software to use. The next screen will ask for the original data file (Figure B-2). Once that has been entered, press TAB to move to the second line. On the second line, enter the new name with a .DAT extension. The user may wish to keep the same name as the original name, 
but must add the .DAT extension. The user must convert all data files that will be utilized, including the calibration files.

\section{Step 4:}

On the main menu screen under the FILEUTIL routine, enter F3 to change the DMI constant. Figure B-3 shows the screen that will be displayed after pressing the F3 key. The user is warned that changing the DMI constant will change the data file. Enter the data file on the first line, with .DAT extension, and press TAB to move to the second line. The second line asks for the DMI constant. On this line the user should enter the value corresponding to the number of centimeters traveled by the antenna per pulse transmitted. For instance, if it is known that a pulse was generated at one foot intervals, the user should enter 30.48 . This is because there are 30.48 centimeters in one foot. This action should be performed for each pass made by the antenna.

\section{$\underline{\text { Step 5: }}$}

On the FILEUTIL main menu screen press escape to exit. Then, under the IRIS subdirectory, enter GOBRIDGE to process the bridge deck data files. The user will notice four options on the screen (Figure B-4).

\section{Step 6:}

Under the GOBRIDGE main menu screen, press F2 for Radar Data Processing. Then press F2 again for Bridge Processing. The user will notice a screen with four options. 
Press F1 for Processing Settings. The following screen will display to the user six different settings to input (Figure B-5). "System Calibration" should be set to "yes" so that the Free Space (FSP) Calibration files can be used. "Filtering" and "Debug Mode" is up to the discretion of the user, but is recommended to be set to "yes." The values to input under "Measurements" and "Surface Echo Reference Location" is up to the preference of the user. "Measurements" asks for either Metric or English units to be used in the processing, and "Surface Echo Reference Location" is for choosing the location of the surface echo. Press ENTER to return to the GOBRIDGE main menu screen.

\section{Step 7:}

The F2 button will send the user to the Advanced Settings screen. However, most of the time the Advanced Settings are kept at the default values.

\section{Step 8:}

Press F3 to begin the actual processing of the bridge deck data files. The software then takes the user to a screen that asks for the bridge name and the number of data files to be processed (Figure B-6). The bridge name is up to the preference of the user. The maximum number of data files that can be processed at a given time is six.

\section{Step 9:}

Enter up to six data files, making certain to include the subdirectories if obtaining the files from the hard drive. 


\section{$\underline{\text { Step 10: }}$}

The program now asks the user to input the Flat Metal Plate (FMP) file name (Figure B7). It is important to enter the correct file name that corresponds to the FMP file obtained at the same antenna height as was used on the deck. If no FMP file is available, the user may bypass inputting the FMP file by pressing ENTER and inputting the average peak-topeak voltage of the surface echo reflection (Figure B-8).

\section{Step 11:}

If the FMP file is used in Step 10, the next step is to enter the channel and gain for the chosen FMP file. The default values are usually used in this step.

\section{$\underline{\text { Step 12: }}$}

The next step is to enter the FSP calibration file (Figure B-9). Enter the FSP file that corresponds to the same antenna used on the bridge deck that is currently being processed.

\section{Step 13:}

The next step is to enter the channel for the FSP file. Again, the default value is usually used.

\section{Step 14:}

After all of the prementioned steps have been completed, a Waterfall Plot for selecting 
echo locations from all of the total waveforms is displayed (Figure B-10). The user is asked to select three major echo locations. The three echoes will be labeled: A/C Echo, Top Rebar Echo, and Bottom Echo. The selected echoes do not necessarily have to match their description; however, the user must understand that the selected echoes will keep their descriptions in the postprocessing phase. The user can also select the three echoes for an individual waveform by pressing S, which stands for Scope Display (Figure B-11). Pressing S again will return the Waterfall Plot screen. A list of keyboard inputs is located on the right-hand side of the Waterfall Plot screen.

\section{Step 15:}

Once the three major echo locations have been selected for all of the radar passes made on the bridge deck (up to six at a time), the program processes the information. The screen shows the status of the bridge deck processing (Figure B-12). It is good practice to copy the new files that are generated into a different directory, so that they are not overwritten when the program runs again. Every time when the Bridge Processing main menu screen is displayed, the program will warn the user to take appropriate actions so that the files are not overwritten. A list of the generated files are as follows:

CHKINPUT.BDG: A log file to record all users input.

POST0[xx].BDG: These are data files that hold all processed results, where $[\mathrm{xx}]$ stands for the respective pass number in numerical sequence. 
Note: The previous two files are generated regardless of selecting to use the Debug Mode from the Processing Settings. The following files are generated only if Debug Mode is set to "yes."

CHKHDER.BDG: Records header information of all input data files.

CHKDATA.BDG: This file records the distance, time, and event tag of the data acquired in the field.

AVEFMP.BDG: This file contains the average FMP radar signal computed from the raw radar data.

AVEFSP.BDG: $\quad$ Same as AVEFMP.BDG, except that it is for the FSP calibration file.

PREFMP.BDG: This file contains the processed FMP radar signal.

RAWSDATA.BDG: This file contains the raw radar data from the bridge deck.

PREDATA.BDG: This file contains the processed radar waveforms from the bridge deck.

Also, if the user wants to view the color intensity plot for a particular radar pass, enter RDA_C at the IRIS subdirectory. Go to FILE, then open the file from the appropriate directory. This plot can be printed by saving it with a .BMP extension and opening it in paintbrush from the Windows environment. 


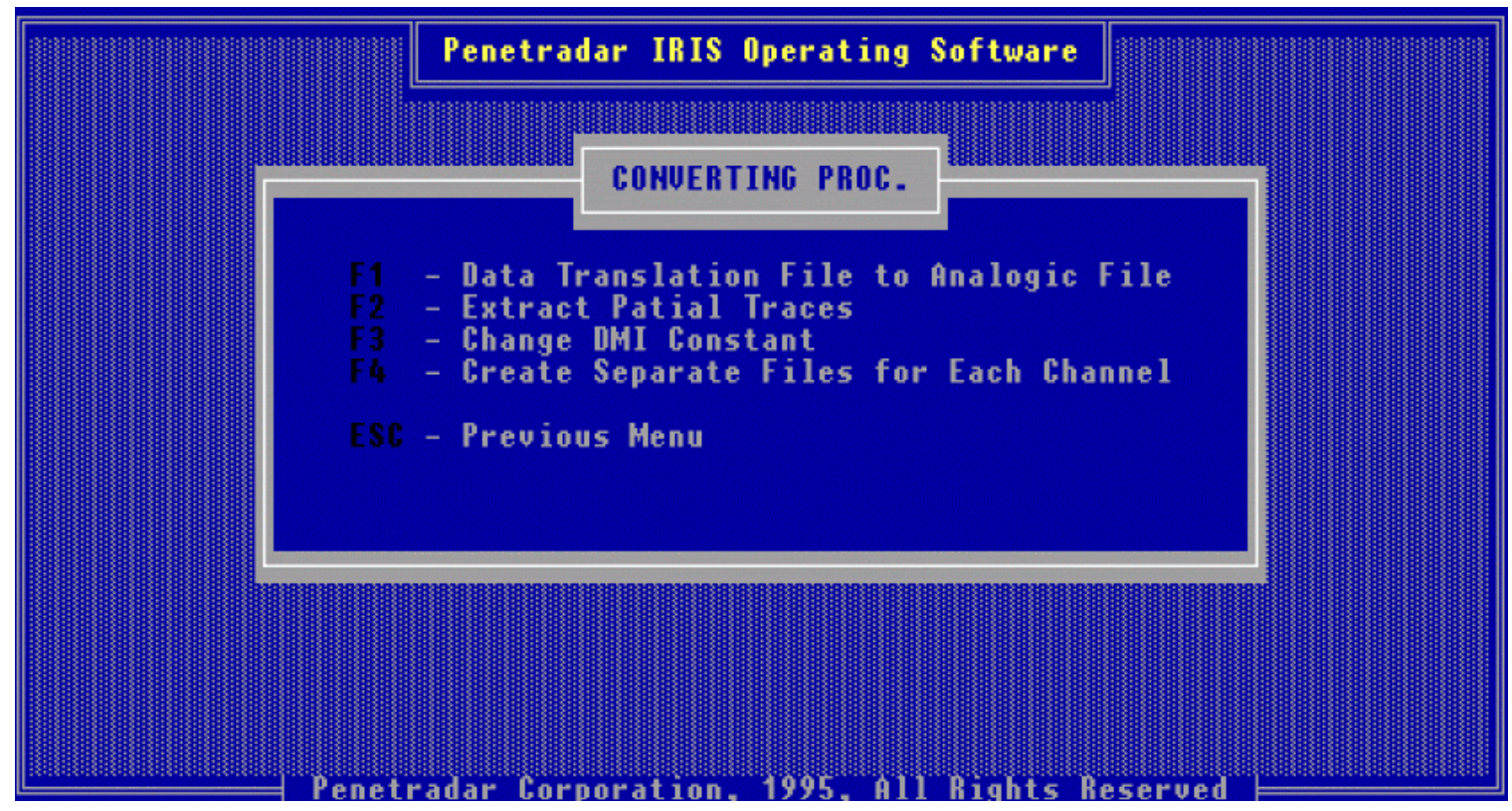

Figure B-1: FILEUTIL Main Menu Screen

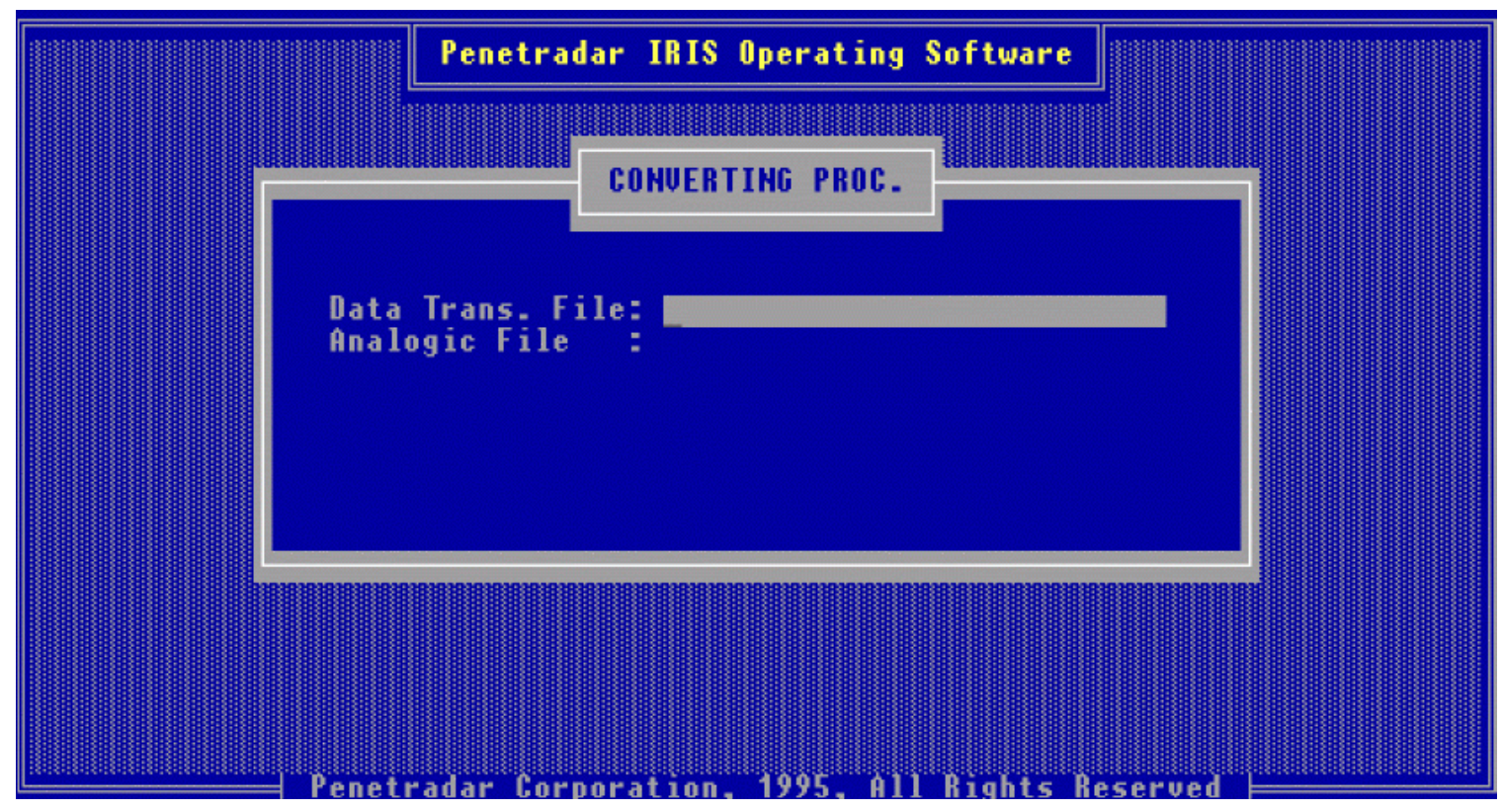

Figure B-2: Radar Data File Conversion Menu Screen 


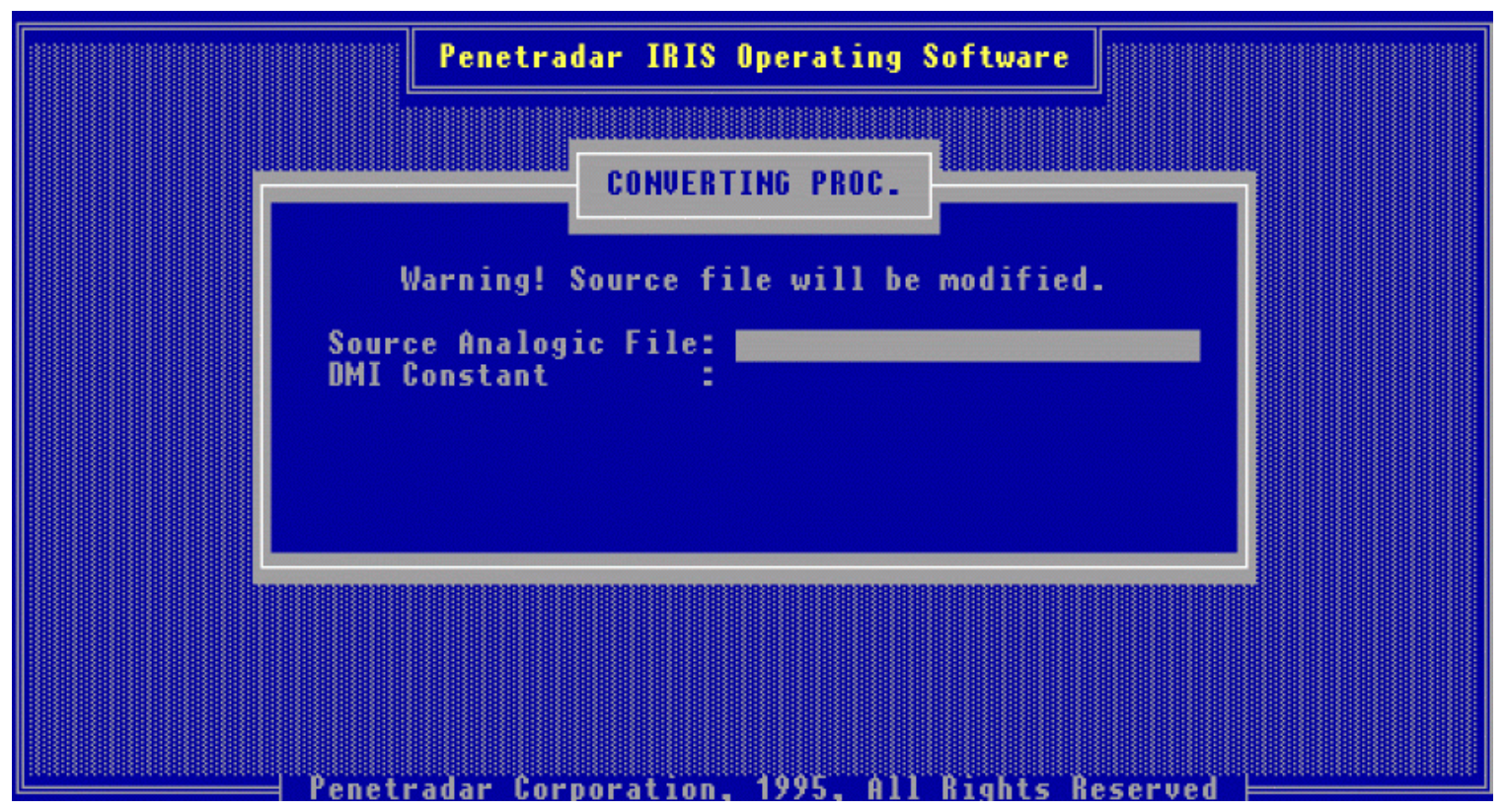

Figure B-3: Changing DMI Constant Menu Screen

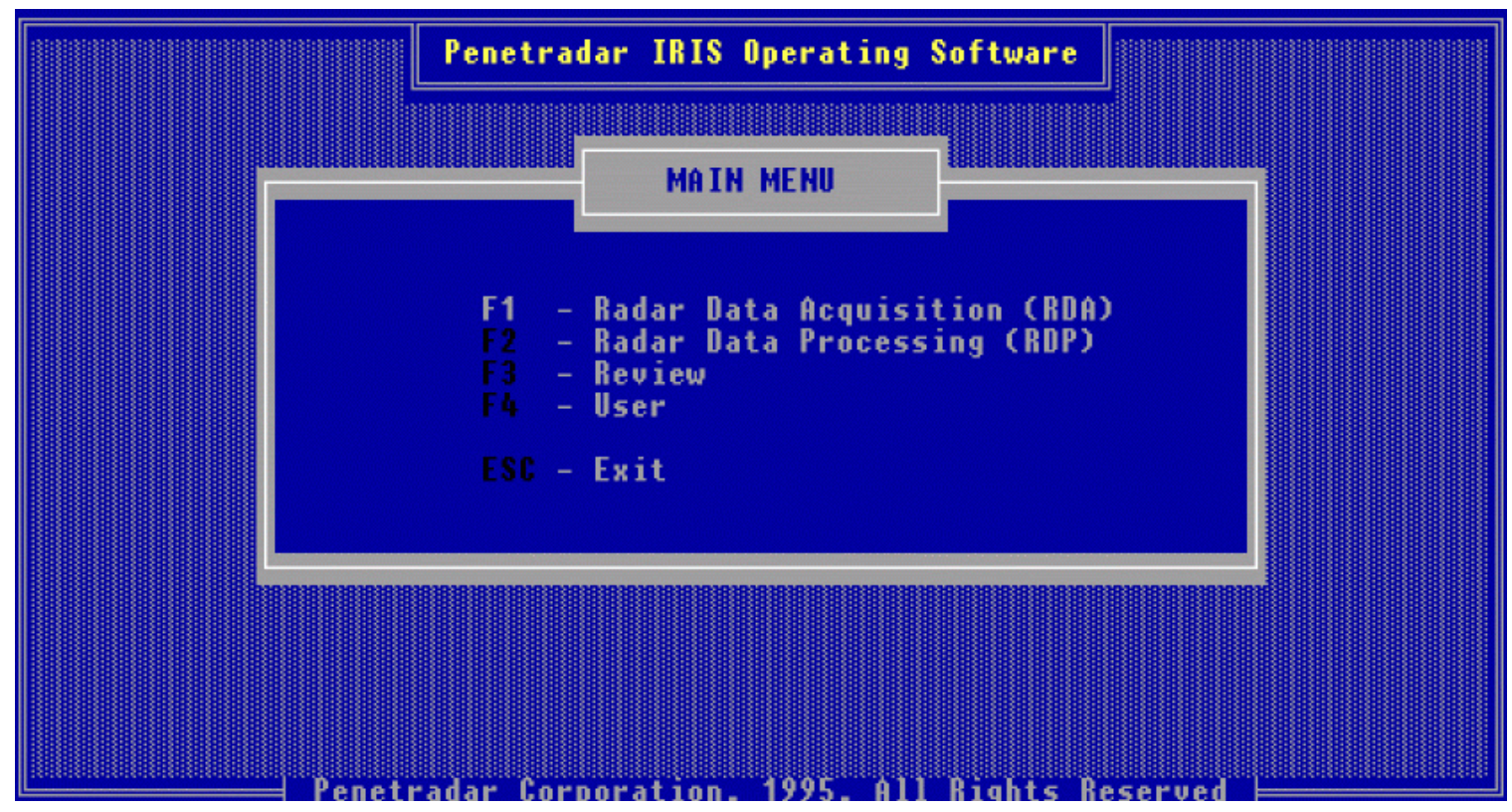

Figure B-4: Bridge Processing Main Menu Screen 


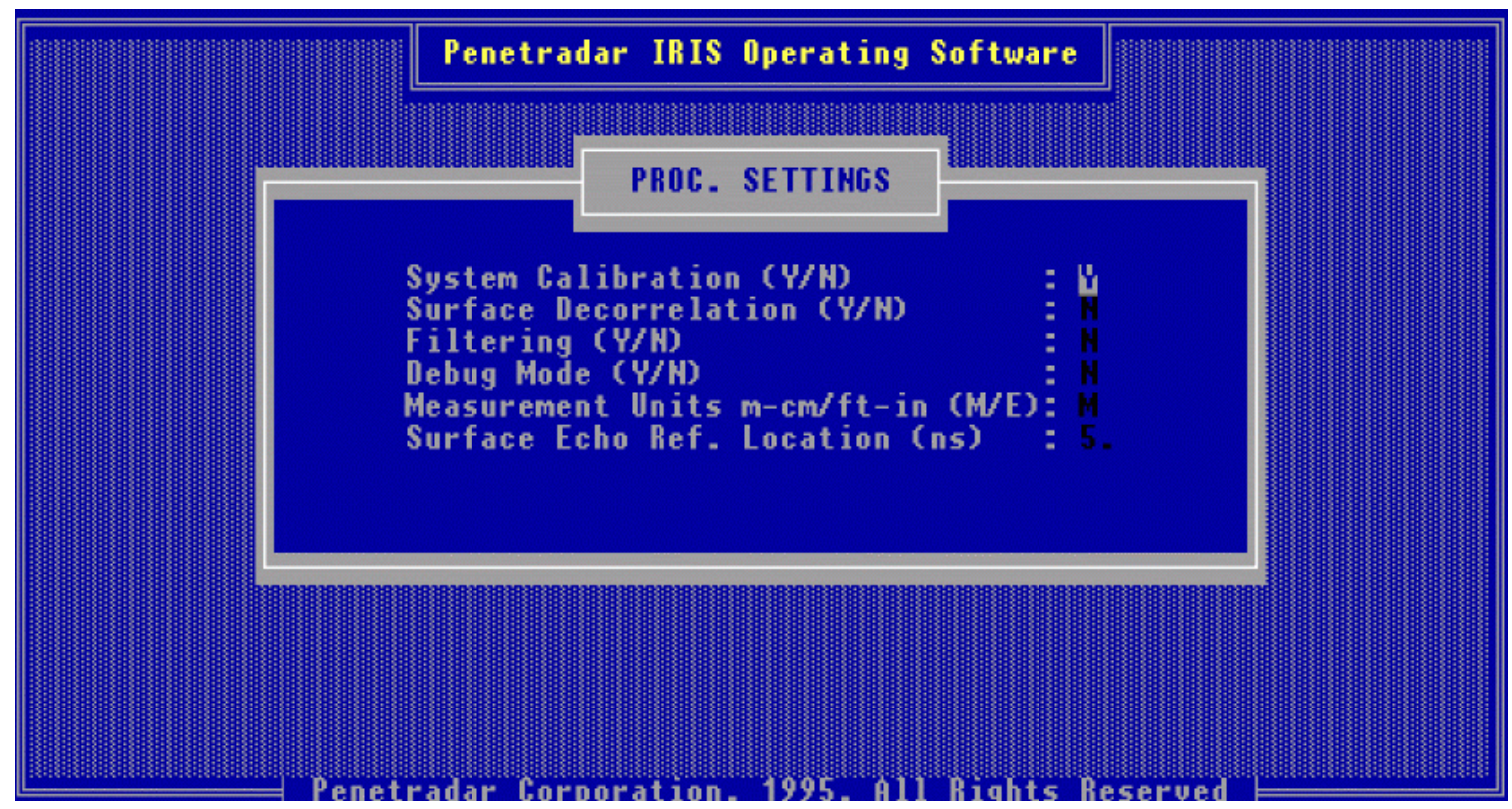

Figure B-5: Processing Settings Menu Screen

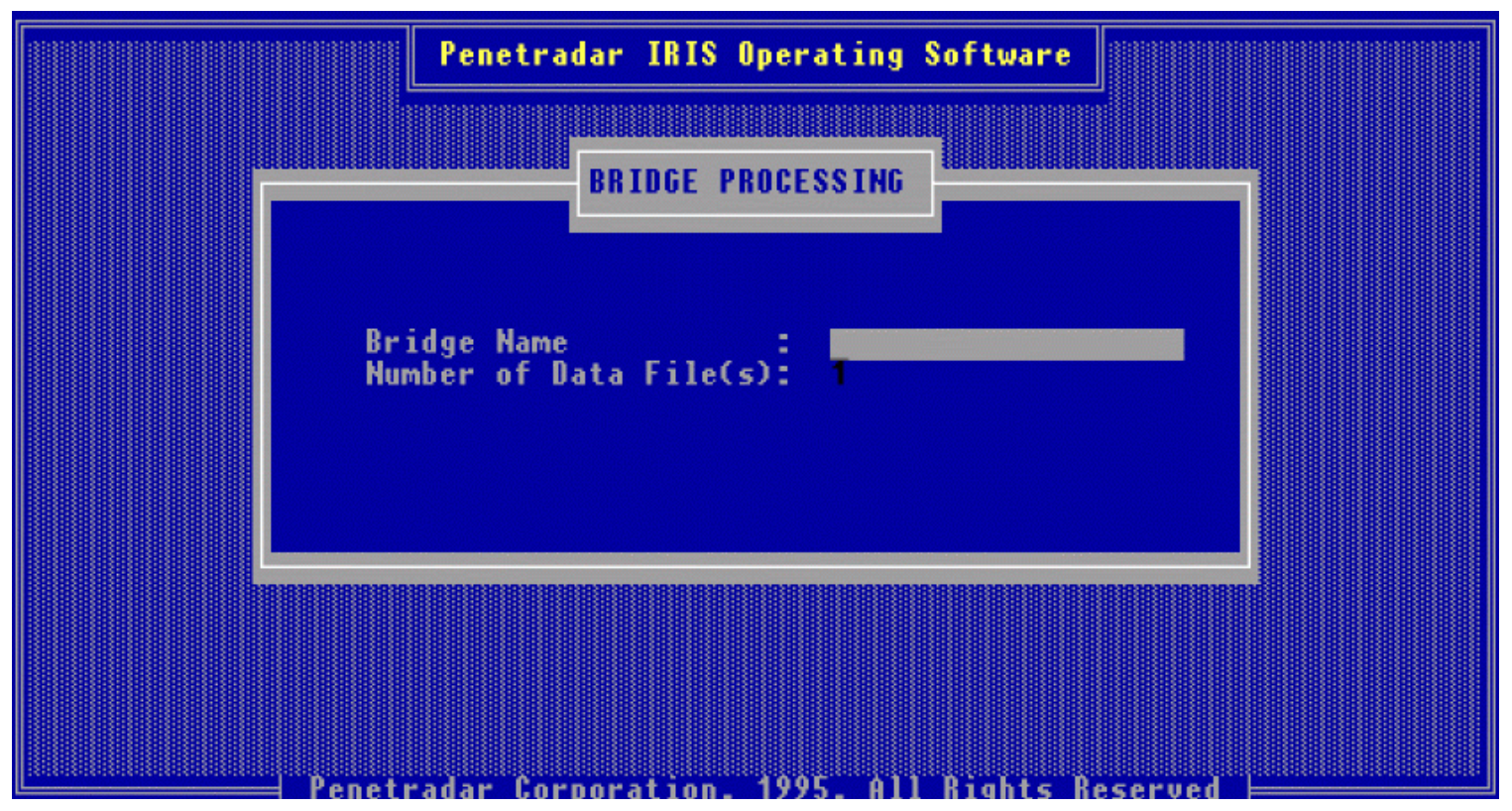

Figure B-6: Number of Data Files Menu Screen 


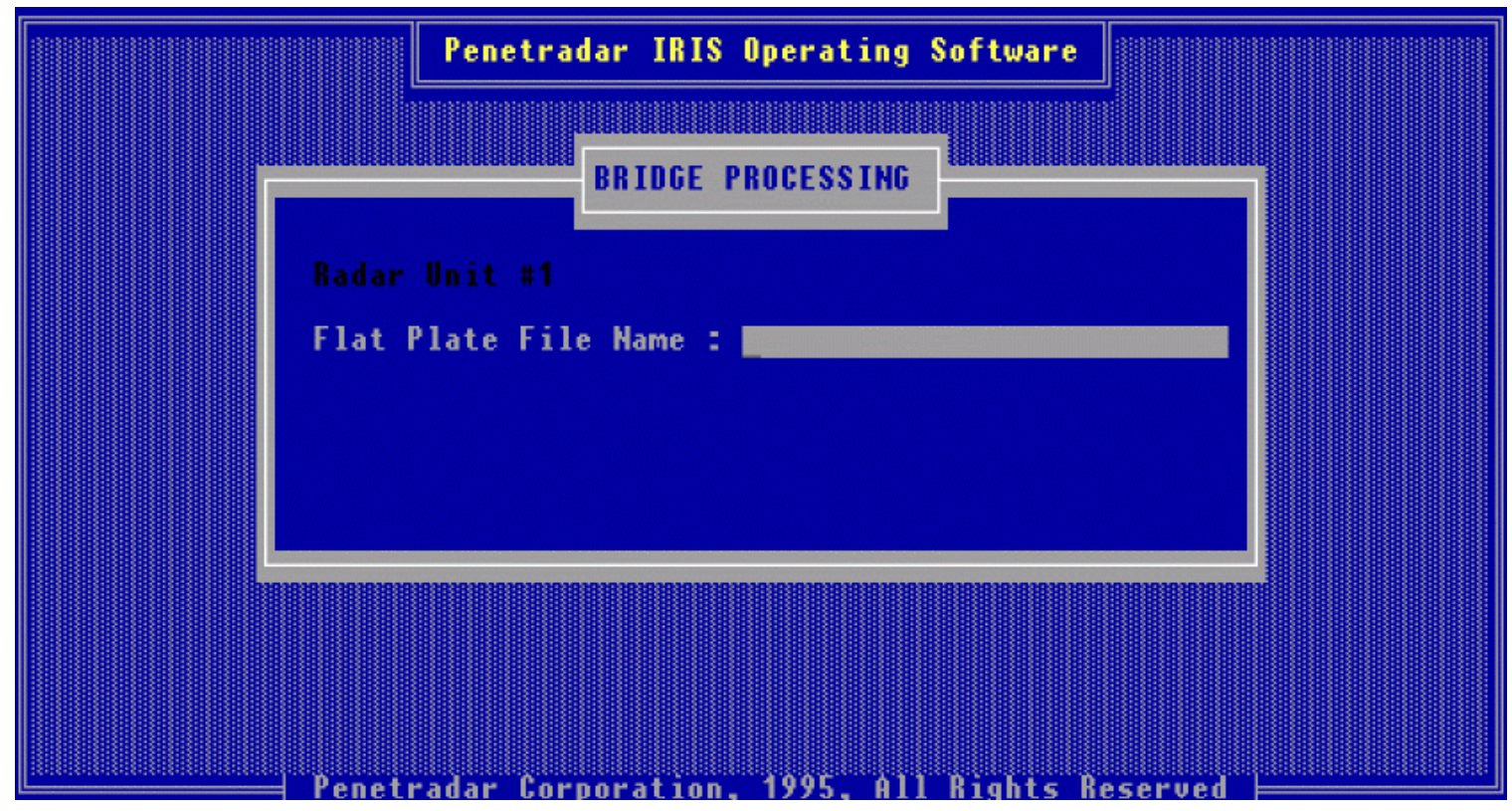

Figure B-7: Flat Metal Plate Filename Menu Screen

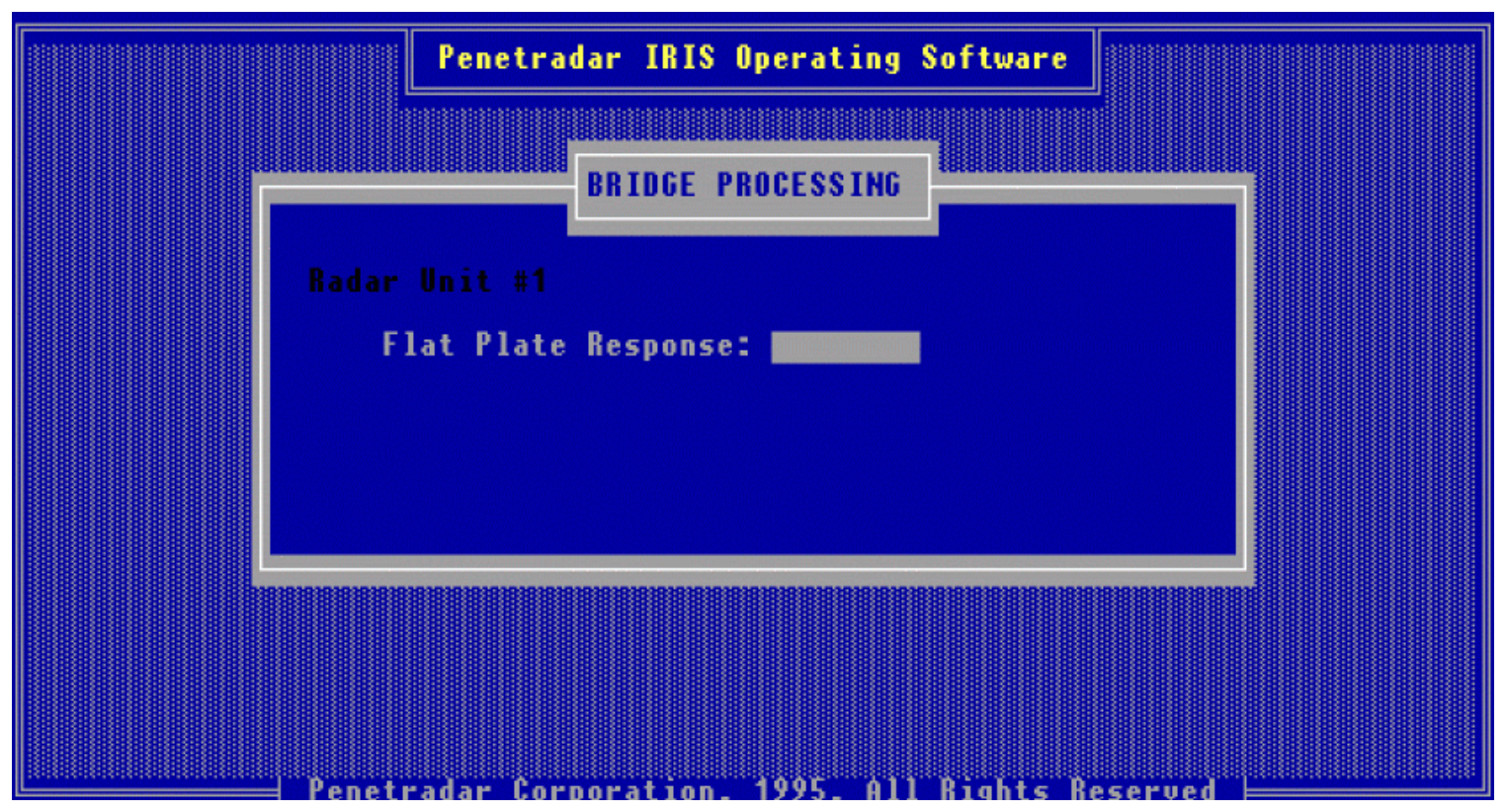

Figure B-8: Flat Plate Response Menu Screen 


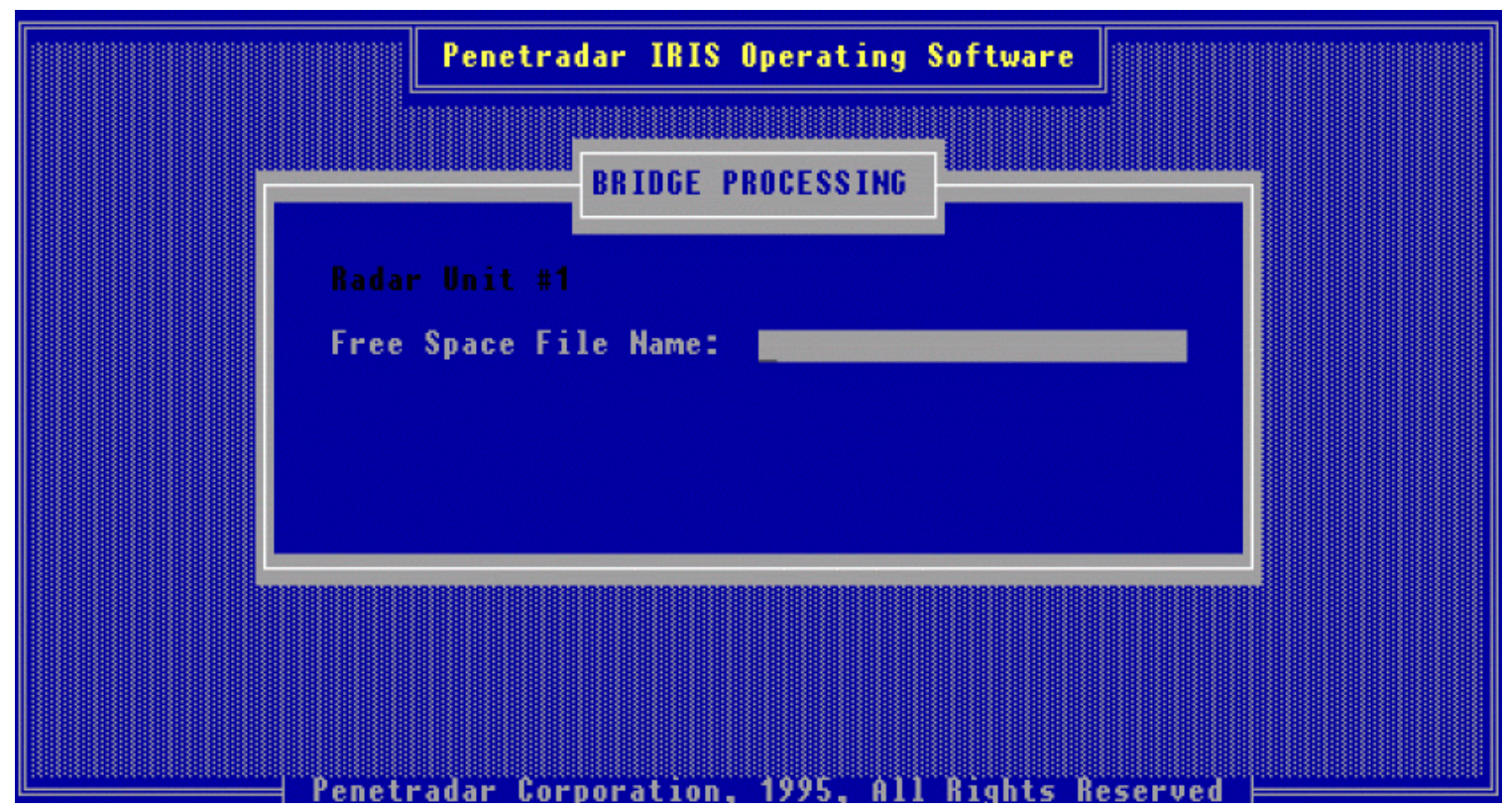

Figure B-9: Free Space Calibration Filename Menu Screen

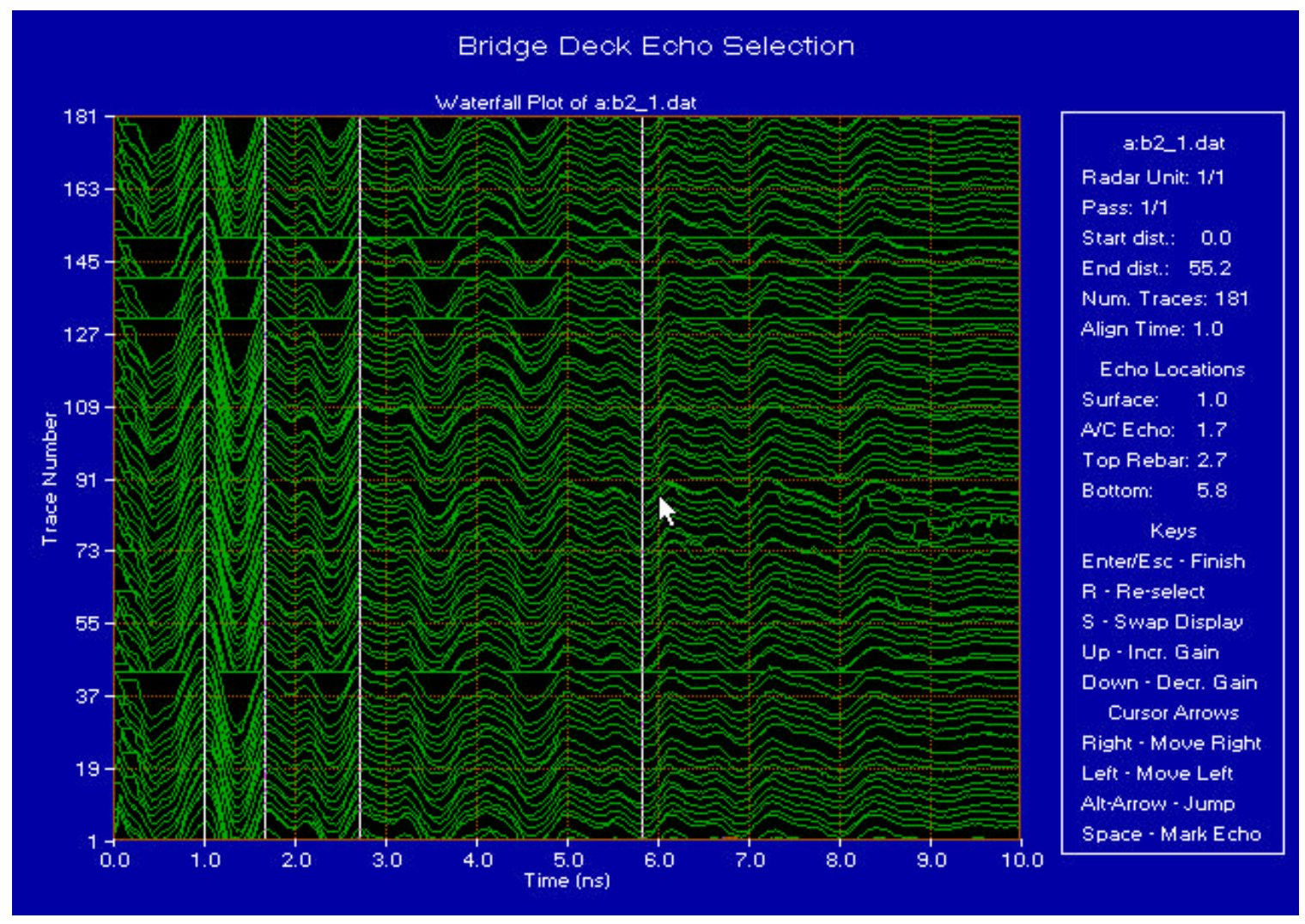

Figure B-10: Waterfall Plot for Choosing Echo Locations 


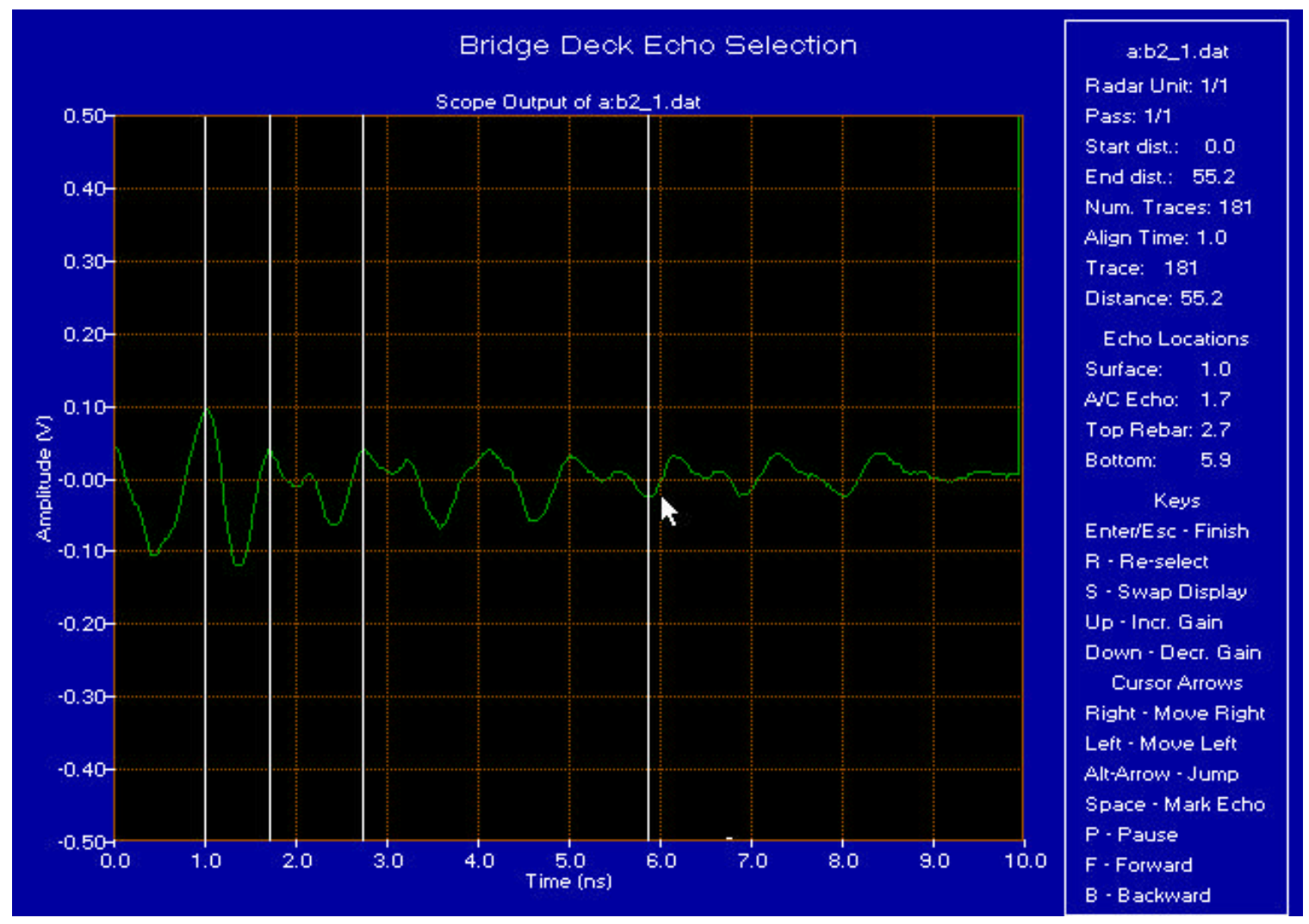

Figure B-11: Scope Display Screen for Choosing Echo Locations

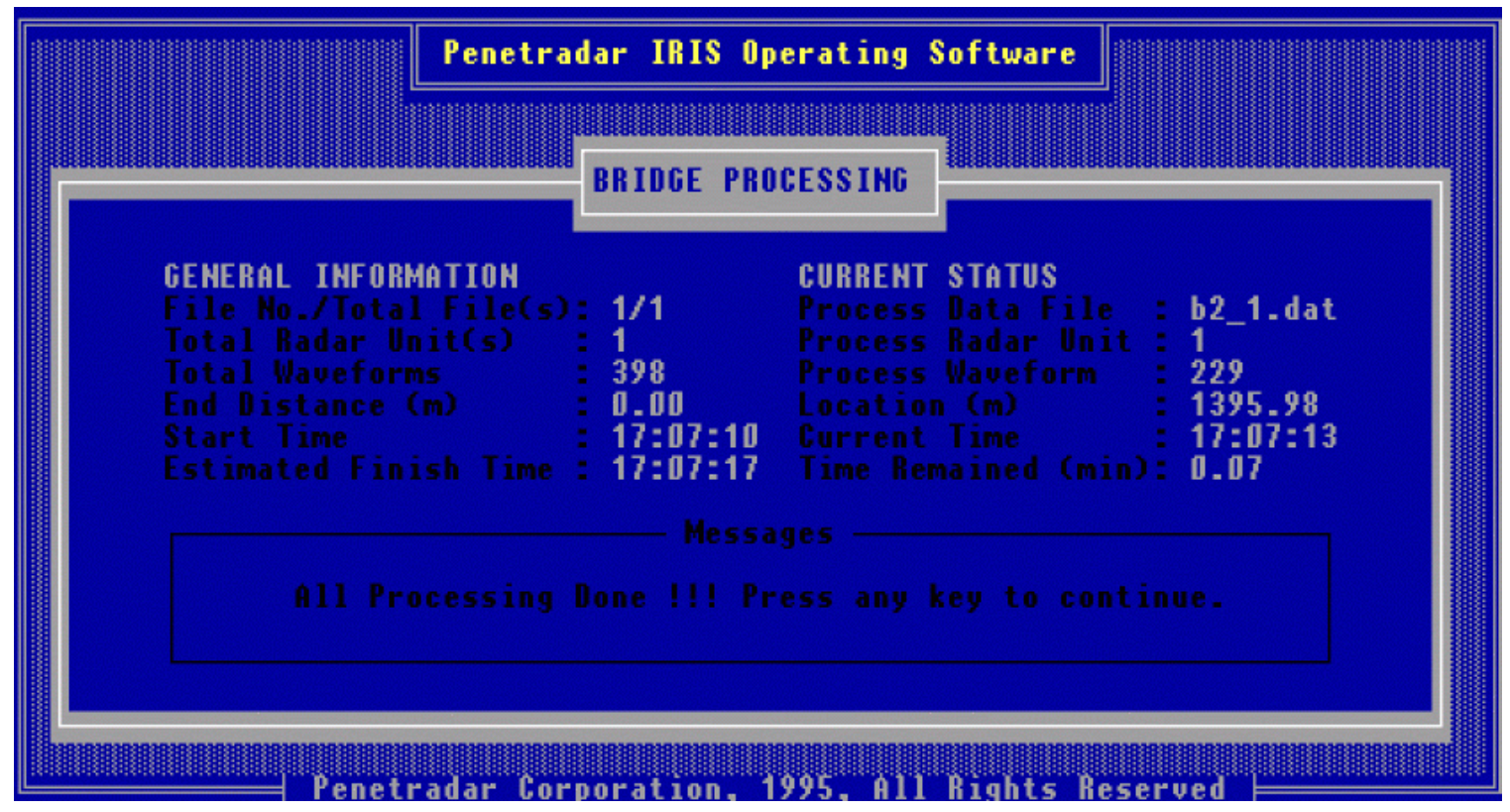

Figure B-12: Bridge Processing Output Screen 


\section{APPENDIX C \\ STEP-BY-STEP PROCEDURE FOR RADAR POSTPROCESSING}

This section is included to provide the user with the step-by-step procedure for operating the Penetradar postprocessing software used in this project. It should be noted that this version of the software is not the updated version. The postprocessing discussed in this section is performed in the Windows environment.

\section{$\underline{\text { Step 1: }}$}

Either double-click on the postprocessing icon or on the POSTP.EXE file located within the file manager to initiate the postprocessing phase.

\section{Step 2:}

Use the mouse pointer to choose the DEFINE menu and then BRIDGE DEFINITION. The next screen will ask the user to input some of the information from the checklist of Appendix A (Figure C-1). The BRIDGE DEFINITION dialog box also asks for the pass files to be processed. Click on INSERT to choose the pass files to include. A new screen appears and the user must locate the pass files and add them to the working list (Figure C2). Then press the OK button. The previous BRIDGE DEFINITION dialog box is displayed again. Then press OK again. The user should notice a bridge map on the screen at this point. 


\section{Step 3:}

The next step is to click on the CHECK menu and choose what is desired to be checked by the software (Figure C-3). The user may select more than one item by highlighting all wanted items and then marking ALL SELECTED TESTS. By marking ALL TESTS, all checks will be made.

\section{Step 4:}

After the checks have been selected, different graphs are displayed on the screen. These graphs are quite useful in understanding the characteristics of the bridge deck.

\section{Step 5:}

Once satisfied with the previous graphs, click on the POSTPROCESSING menu (Figure C-5). The software then waits for the user to select a postprocessing parameter, such as Attenuation, A/C Characteristics, Change Detector, or Bottom Echo Characteristics. See section 5.4.3 for a detailed discussion of when to choose each criterion. Type 1 and Type 2 use the same principles to evaluate the conditions of the bridge deck; however, Type 2 is more rigorous than Type 1 .

\section{Step 6:}

After the parameter has been selected under the POSTPROCESSING menu, the screen displays another graph (Figure C-6). Any value that exceeds the threshold value is characterized as deterioration. The threshold value can be changed under the DEFINE menu by clicking on THRESHOLD COEFFICIENT (Figure C-4). After clicking OK, the 
bridge map is displayed again, but with darkened areas representing deteriorated areas on the bridge deck.

\section{Step 7:}

The user may now click on the VIEW menu and choose any one of a number of items to obtain more specific information about the deck and about the files used in the postprocessing. The BRIDGE DATA SHEET selection informs the user of the percent of the whole deck that is delaminated. The PASS DATA SHEET performs the same task, but for each individual pass. There are two different bar charts that provide delamination information. The VIEW menu also gives the user the option to recheck or re-postprocess the data files. The last item under the VIEW menu allows the user to see different text files. The INPUT text file displays all information that was given in the RDP phase. The SUMMARY text file gives more delamination information. The deck THICKNESS TABLE may also be viewed in this section.

Refer to the Penetradar IRIS Operating Software: Operation Manual for more indepth explanations for the topics within the postprocessing phase. 


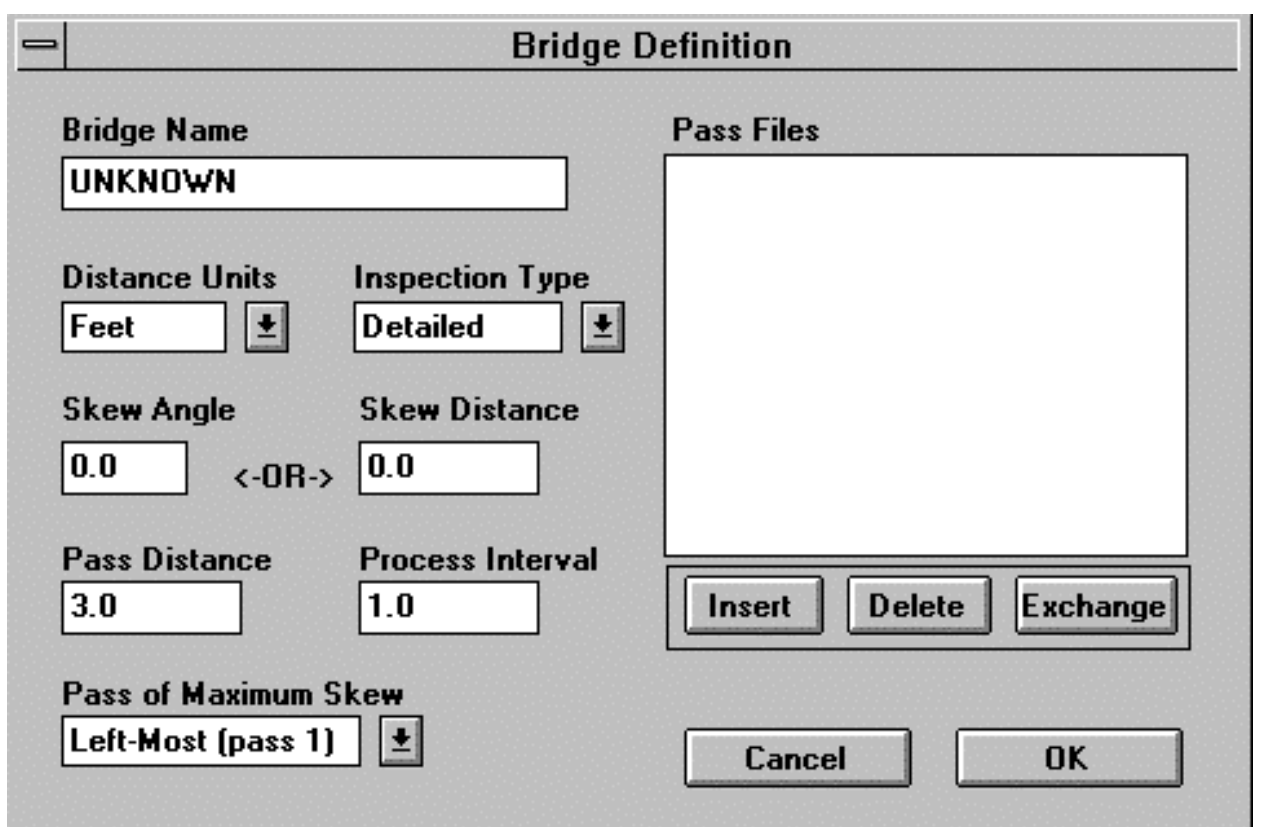

Figure C-1: Bridge Definition Dialog Box

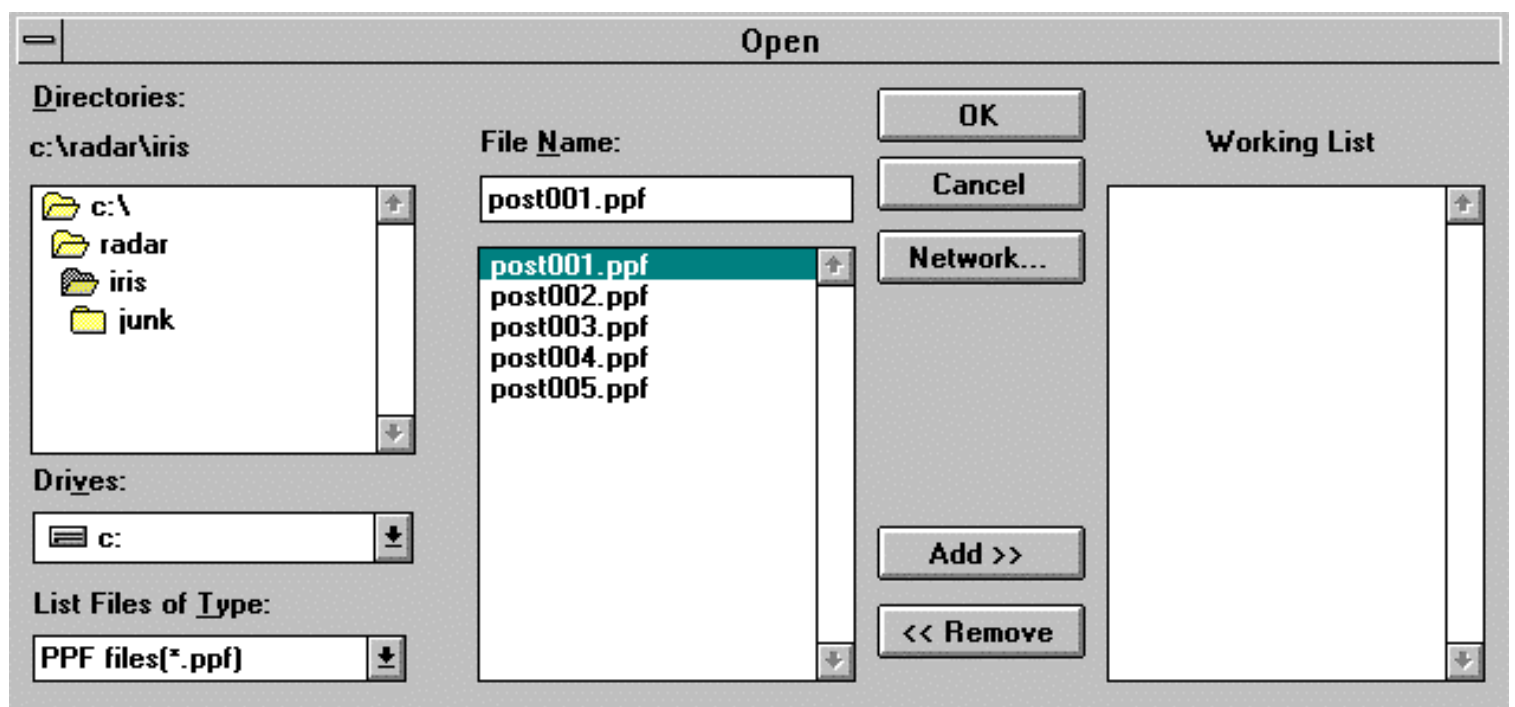

Figure C-2: File Select Dialog Box 


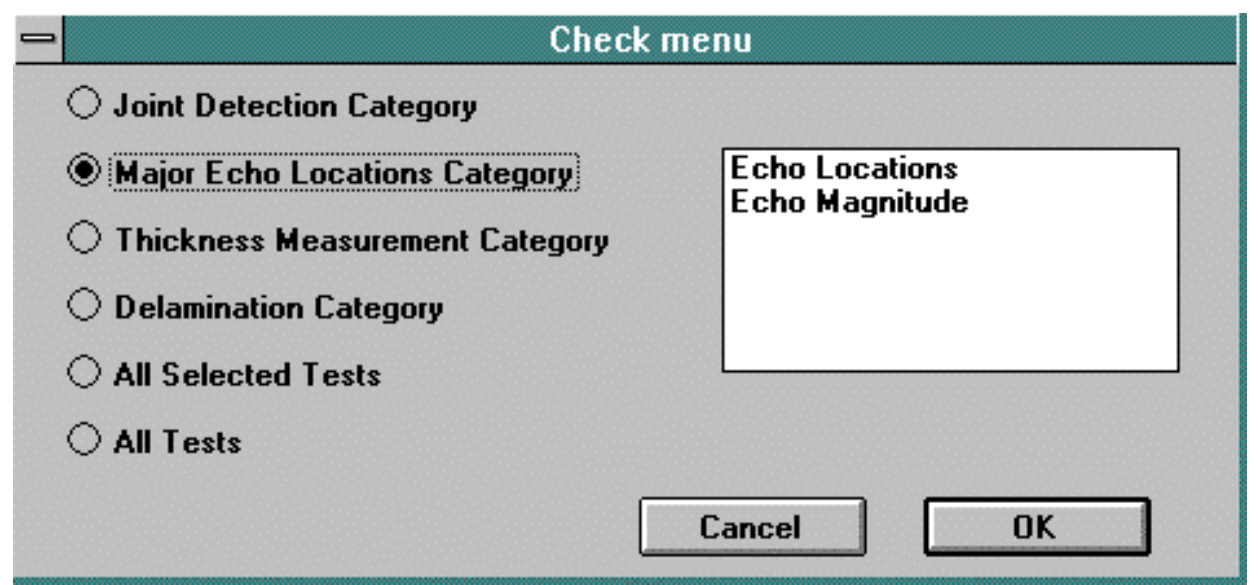

Figure C-3: Check Selection Dialog Box

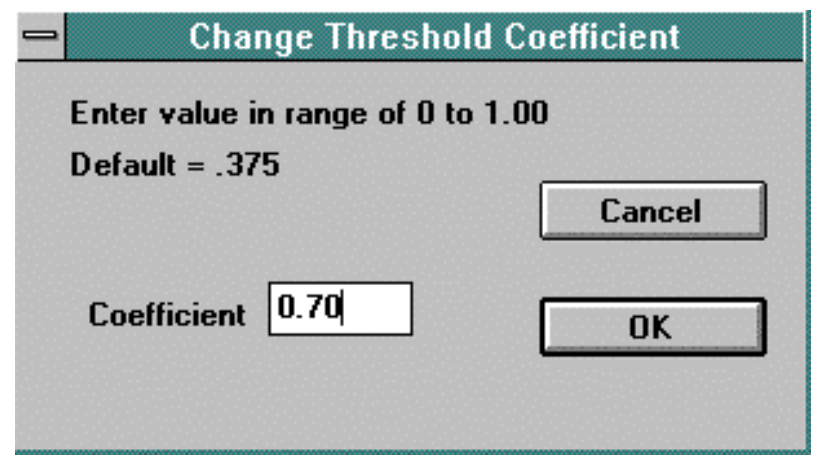

Figure C-4: User Defined Threshold Coefficient Dialog Box 


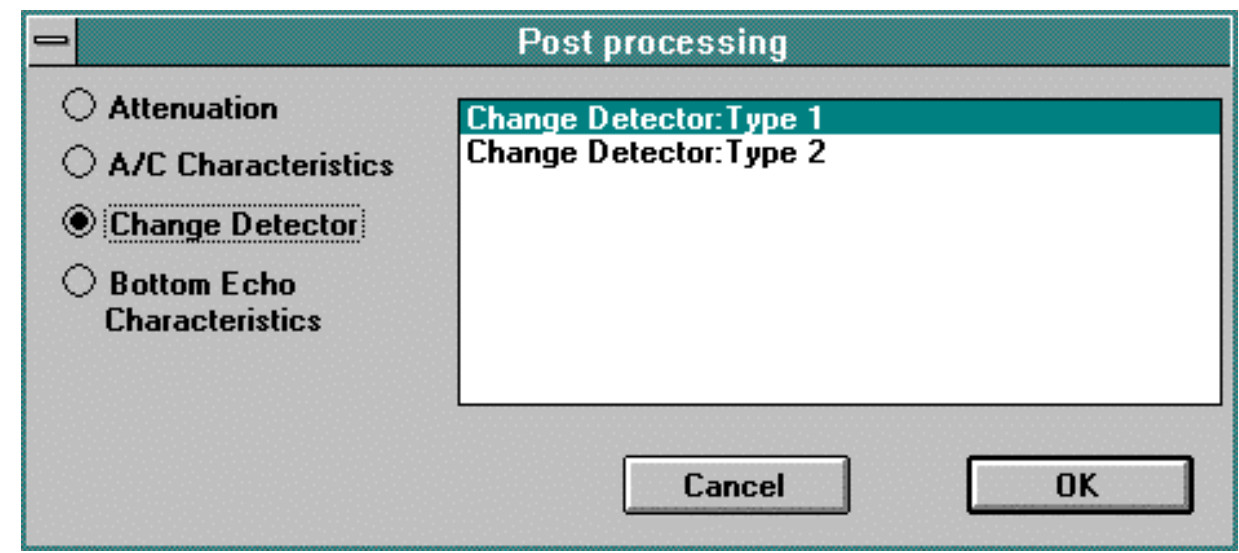

Figure C-5: Postprocessing Selection Dialog Box

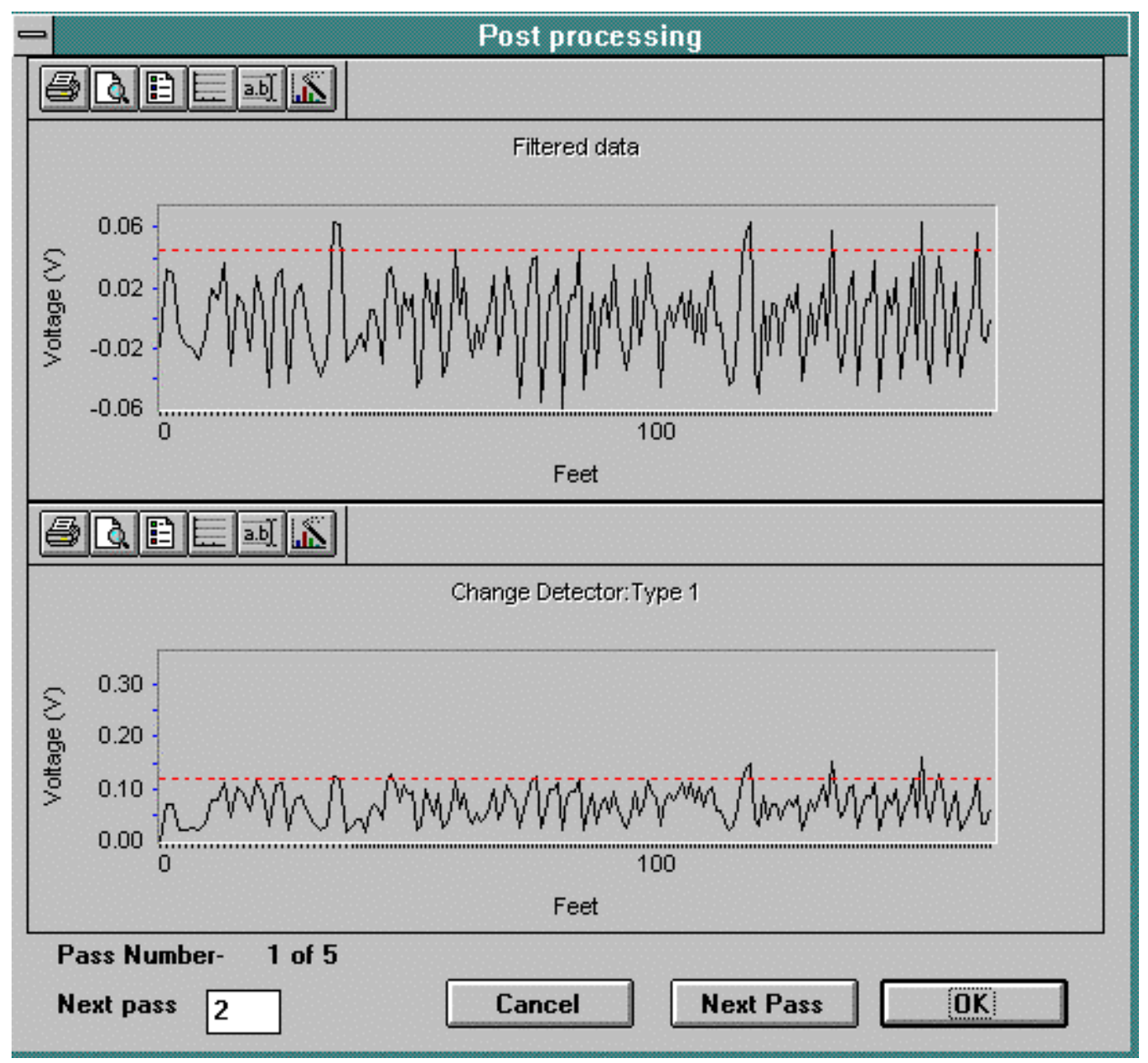

Figure C-6: Graphs Displaying Postprocessed Data and Filtering 


\title{
NONDESTRUCTIVE TESTING OF CONCRETE BRIDGE DECKS USING GROUND PENETRATING RADAR AND THE CHAIN DRAG METHOD
}

By

\author{
Jerry J. Scheff
}

\author{
A Thesis \\ Submitted to the Advisory and Examining Committee \\ College of Engineering and Mineral Resources \\ West Virginia University \\ In Partial Fulfillment of the Requirements \\ for the Degree of \\ Master of Science \\ in \\ Civil Engineering
}

\section{APPROVAL OF EXAMINING COMMITTEE}

Udaya B. Halabe, Ph.D.

Hota V.S. GangaRao, Ph.D.

Date

Roger H.L. Chen, Ph.D. , Chairman 